\title{
FIELD AND GREENHOUSE STUDIES OF PHYTOREMEDIATION WITH \\ CALIFORNIA NATIVE PLANTS FOR SOIL CONTAMINATED WITH \\ PETROLEUM HYDROCARBONS, PAHS, PCBS, CHLORINATED \\ DIOXINS/FURANS, AND HEAVY METALS
}

\author{
A Thesis \\ presented to \\ the Faculty of California Polytechnic State University, \\ San Luis Obispo \\ In Partial Fulfillment \\ of the Requirements for the Degree \\ Master of Science in Civil and Environmental Engineering
}

By

Matthew Robert Poltorak

December 2014 
(C) 2014

Matthew Robert Poltorak

ALL RIGHTS RESERVED 


\section{COMMITTEE MEMBERSHIP}

TITLE:

Field and Greenhouse Studies of Phytoremediation with California Native Plants for Soil Contaminated with Petroleum Hydrocarbons, PAHs, PCBs, Chlorinated Dioxins/Furans, and Heavy Metals

AUTHOR:

Matthew Robert Poltorak

DATE SUBMITTED:

December 2014

COMMITTEE CHAIR: $\quad$ Yarrow Nelson, $\mathrm{PhD}$, Professor, Department of Civil and Environmental Engineering, California Polytechnic State University, San Luis Obispo

COMMITTEE MEMBER: Nirupam Pal, PhD, Professor, Department of Civil and Environmental Engineering, California Polytechnic State University, San Luis Obispo

COMMITTEE MEMBER: Christopher Kitts, PhD, Professor and Department Chair, Department of Biological Sciences, California Polytechnic State University, San Luis Obispo 


\begin{abstract}
Field and Greenhouse Studies of Phytoremediation with California Native Plants for Soil Contaminated with Petroleum Hydrocarbons, PAHs, PCBs, Chlorinated Dioxins/Furans, and Heavy Metals

Matthew Robert Poltorak
\end{abstract}

Native and naturalized California plant species were screened for their phytoremediation potential for the cleanup of soil contaminated with petroleum hydrocarbons (PHCs), poly-aromatic hydrocarbons (PAHs), polychlorinated biphenyls (PCBs), chlorinated dioxins/furans, and heavy metals. This screening was followed by controlled greenhouse experiments to further evaluate the phytoremediation potential of the best candidates. Field specimens and soils used for this study were collected from the former Energy Technology Engineering Center (ETEC) at the Santa Susana Field Laboratory in Southern California that was operated by the Department of Energy (DOE). Soils at this site contain all of the contaminants of interest (COIs). Nine plant species were screened in the field: Purple Needlegrass (Nassella pulchra), Blue Elderberry (Sambucus nigra), Laurel Sumac (Malosma laurina), Mule Fat (Baccharis salicifolia), Palmer's Goldenbush (Ericameria palmeri), Summer Mustard (Hirschfeldia incana), Narrowleaf Milkweed (Asclepias fascicularis), Coyote Brush (Baccharis pilularis), and Thickleaf Yerba Santa (Eriodictyon crassifolium). In the field three samples of each species growing in contaminated soil and one of each species growing in uncontaminated soil were selected for harvesting and analysis. The roots, above ground plant tissue, and soil around the roots were sampled separately and analyzed for the COIs: PHCs, PAHs, PCBs, 
chlorinated dioxins/furans, and metals (which include mercury, silver, cadmium, and lead). All of the plants in the field appeared to generate compounds which result in higher measured PHC concentrations than those measured in the associated soil. The highest concentrations of PAHs in the roots were observed for Blue Elderberry (1740 ug/ $/ \mathrm{kg})$, Purple Needlegrass (703 ug/kg), and Yerba Santa (200 ug/kg). No uptake of PCBs was observed in the roots or foliage of any species. The highest concentrations of total chlorinated dioxins/furans in the roots were observed for Purple Needlegrass (2237 ng/kg), Blue Elderberry (1026 ng/kg), Palmer’s Goldenbush (432 ng/kg), and Yerba Santa $(421 \mathrm{ng} / \mathrm{kg})$. The highest concentrations of total chlorinated dioxins/furans in the foliage were observed for Yerba Santa (901 ng/kg), Palmer's Goldenbush (757 ng/kg), and Purple Needlegrass $(694 \mathrm{ng} / \mathrm{kg})$. No uptake of mercury was observed in the roots or foliage of any species. The highest concentration of silver in the roots was observed for Laurel Sumac (7.34 mg/kg). Summer Mustard (SM) was the only species that showed uptake of silver into the foliage $(0.405 \mathrm{mg} / \mathrm{kg})$. The highest concentrations of cadmium in the roots and foliage were observed for Mule Fat $(1.84 \mathrm{mg} / \mathrm{kg}$ and $3.64 \mathrm{mg} / \mathrm{kg})$ and Coyote Brush $(1.52 \mathrm{mg} / \mathrm{kg}$ and $2.12 \mathrm{mg} / \mathrm{kg})$ and the greatest concentration of lead in the roots and foliage was observed for Purple Needlegrass $(8.92 \mathrm{mg} / \mathrm{kg}$ and $1.17 \mathrm{mg} / \mathrm{kg}$ ).

Plants with a wide variety of observed contaminant uptake in the field were selected for a second phase of research in which three of the most promising species were grown in greenhouse microcosms to quantify the removal of contaminants from the soil. The three species selected based on preliminary results from the field study were Coyote Brush, Mule Fat, and Purple Needlegrass. Microcosms consisted of $2.17 \mathrm{~kg}$ of soil in 4-L glass 
jars with glass marbles for an underdrain. Plants were watered with deionized water and no leachate was collected. Five replicates of each microcosm type were created and incubated for 211 days with soil sampling at 85 and 211 days. Soil, plant roots/above ground tissue, and volatilization from the plants were analyzed for COIs to determine the mechanisms of phytoremediation. One set of microcosms was used to test the effect of addition of achelating agent (ethylenediaminetetraacetic acid) and another set was used to test the effect of fertilizer addition on phytoremediation potential. Three control treatments were tested: sterilized (gamma irradiation) soil planted with Purple Needlegrass, unplanted soil, and sterilized unplanted soil. None of the plant species demonstrated volatilization of COIs under these conditions. Volatilization of mercury was not tested for. The average PCB concentration (measured as Aroclor 1260) reductions in soils with Purple Needlegrass and chelated Coyote Brush were 49.4\% and $51.4 \%$ respectively $(\mathrm{p}<0.05)$. However, the sterilized unplanted control also had a decrease of Aroclor 1260 concentrations in the soil of $36.6 \%(p<0.05)$. None of the species phytoextracted PCBs, so the mechanism of PCB remediation appears to be phytostimulation of the rhizosphere. Purple Needlegrass showed the greatest uptake of dioxins/furans into the foliage but did not appear to reduce the dioxin/furan concentrations in the soil. Coyote Brush, fertilized Coyote Brush, and Mule Fat also showed uptake of dioxins/furans into the roots and foliage. Only the Coyote Brush and fertilized Coyote Brush significantly $(\mathrm{p}=0.036, \mathrm{p}=0.022)$ reduced the total dioxin/furan concentration in the soil (17.8\% and 19.8\% respectively). Coyote Brush may have stimulated microbes in the rhizosphere to better degrade the dioxins/furans. None of the plants were identified as hyper-accumulators of metals, and none of the soil metal 
concentrations significantly decreased in any of the microcosms. All of the metals (except mercury) were taken into the roots of plants to some degree, with Purple Needlegrass showing the most promise for metal extraction as it showed some of the highest concentrations of metals in roots and was the only species that contained mercury and silver in the foliage.

This study suggests that there is some potential for phytoremediation of PCBs and chlorinated dioxins/furans. The results for petroleum hydrocarbons were inconclusive. Metal uptake was not substantial enough to lower metal concentrations in the soils. Thus phytoremediation of COIs at the site is limited and more aggressive forms of remediation may be required to reduce the concentrations of COIs quickly. 


\section{ACKNOWLEDGMENTS}

I would like to thank the Department of Energy for providing me with this opportunity to work on such a complex and challenging project and providing the funding to assist the project.

Thanks to CDM Smith for providing project management and collaboration. I want to specifically thank Pam Hartman for her tireless work during the sampling events and Keegan Roberts for his detailed and diligent management of this project. You were both a pleasure to work with and I hope we will cross paths again.

Thanks to the Natural Resources Management and Environmental Sciences department for lending the greenhouse for these experiments.

Thanks to Michael Curto, Peter Waldburger, and Jessica Sheetz for your invaluable plant wisdom and for all the many hours you watched and cared for the precious greenhouse plants.

Thanks to Alli Koivunen and Devon Dowd for researching during the summer and participating in the Research Experience for Undergraduates (REU) program.

Thanks to Mackenzie Billings for her hard work on the bioremediation project and her collaboration to make both of our projects even better.

Thanks to Reese Wilson for being an awesome friend and for your help with the final sampling event; it was intense but we did it!

Thanks to my committee members Dr. Nirupam Pal and Dr. Chris Kitts for providing insight and support during this project.

Thanks to Dr. Yarrow Nelson, the best thesis advisor in the entire world. Your dedication, enthusiasm, humor, and dark chocolate honey mints inspired me to work harder than ever and enjoy my work more than ever. I appreciate your relaxed, calm demeanor and your genuine respect of me as a person and as a student. I feel very blessed to have you as my advisor, and you are a big part of my decision to pursue a Master of Science degree at Cal Poly. Thank you!

Thanks so much to my dad and mom Robert and Valerie Poltorak. You both raised me to work hard, persevere, and find joy in all parts of life. I love you guys and I wouldn't be here without you. I hope I made you proud!

Very special thanks to my girlfriend Katherine Sanine who showed me endless support and love and believed in me. She has been there smiling, laughing, and crying with me through the good and bad times. I love you so much.

Finally, I would like to thank my God for giving me the talent and ability to complete this thesis, and the opportunity to attend Cal Poly. "I can do all things through Christ who strengthens me." Philippians 4:13 


\section{TABLE OF CONTENTS}

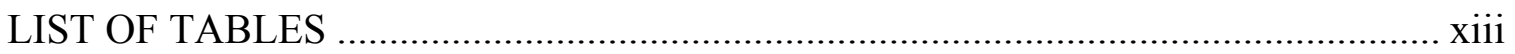

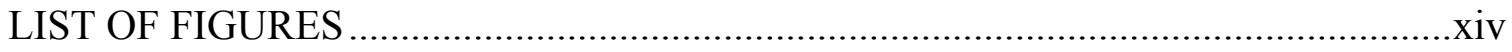

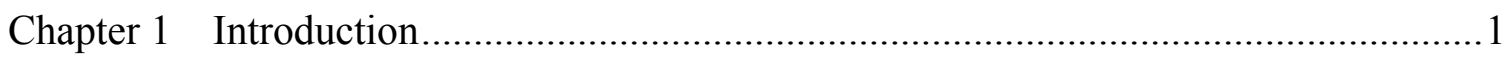

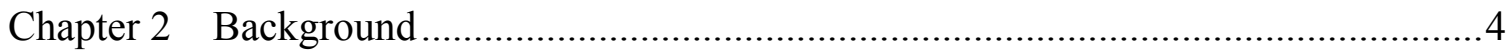

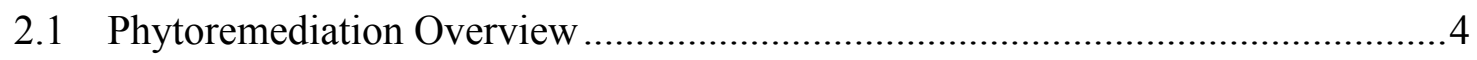

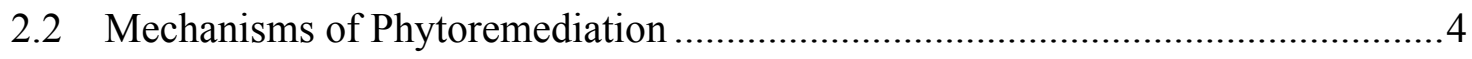

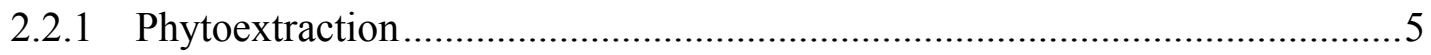

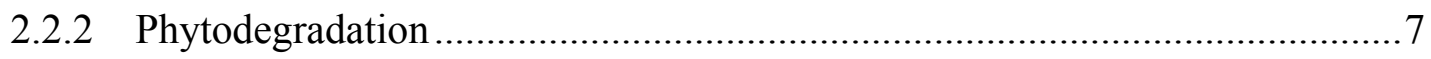

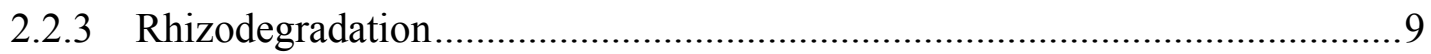

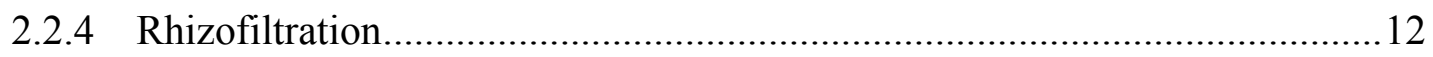

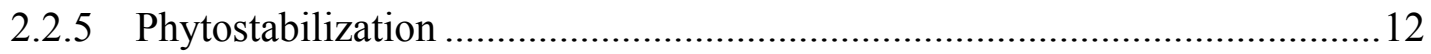

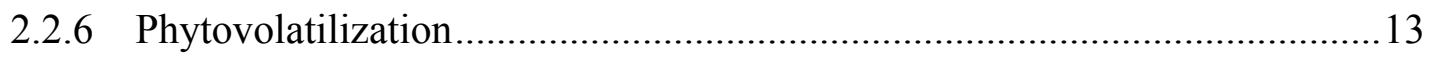

2.3 SSFL Site History and Characterization..........................................................17

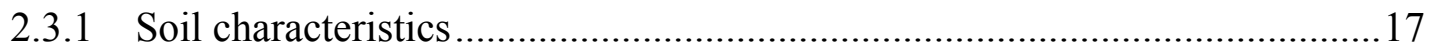

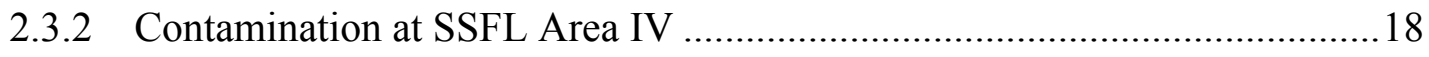

2.3.2.1 Petroleum Hydrocarbons ……………..................................................

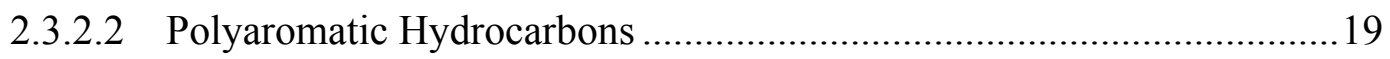

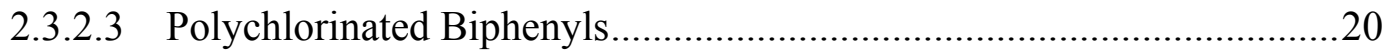

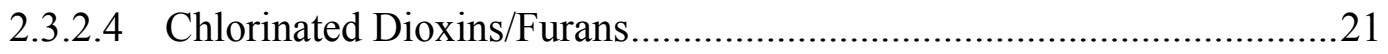

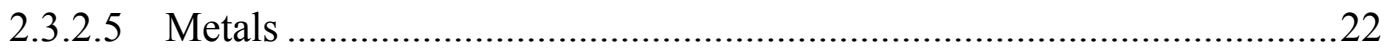

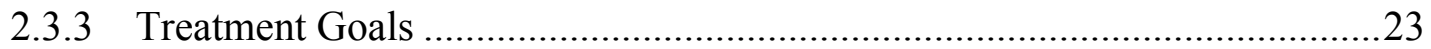


2.3.4 Vegetation.

2.4 Phytoremediation Research on Plant Candidates .........................................26

2.4.1 Plant Characteristics Ideal for Phytoremediation ...................................27

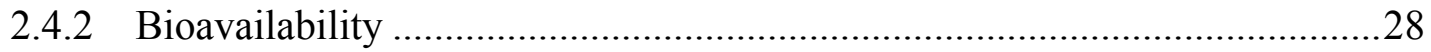

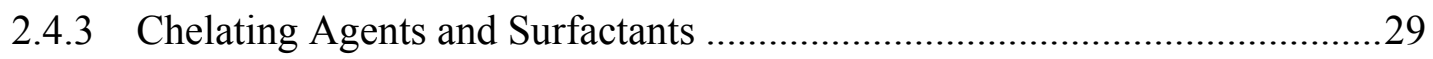

2.4.4 Expected Effectiveness of Phytoremediation for COIs at SSFL ...................31

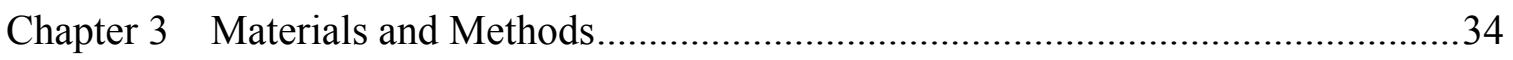

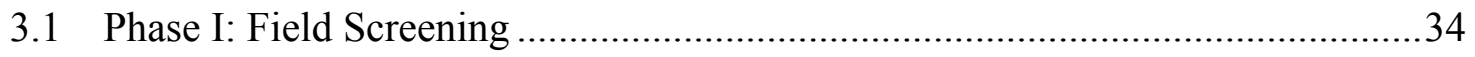

3.1.1 Plant Selection and Tagging for Phase I field sampling..............................34

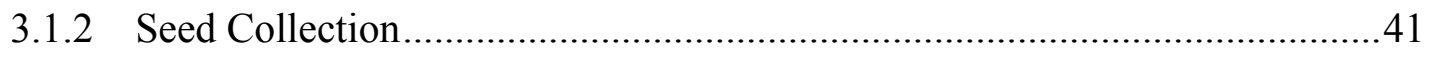

3.1.3 Plant Tissue and Root-Zone Soil Sampling........................................... 41

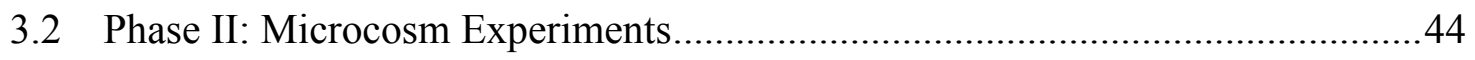

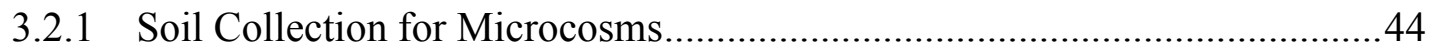

3.2.2 Microcosm Soil Homogenization .........................................................45

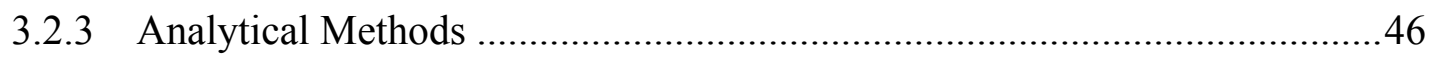

3.2.4 Decontamination of Sampling Equipment ............................................46

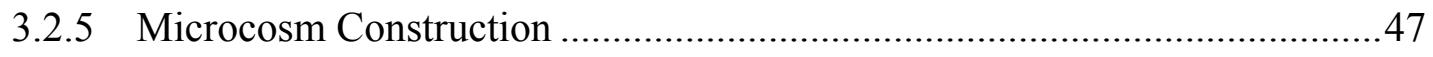

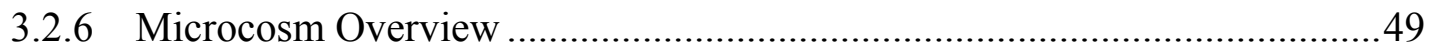

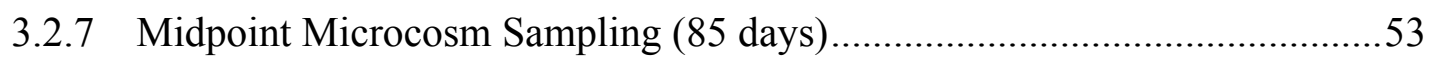

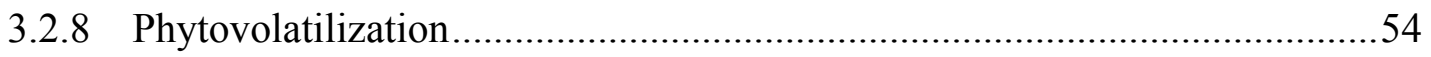

3.2.9 Final Microcosm Sampling (211 days) ...............................................57

3.2.10 Terminal Restriction Fragment (TRF) Analysis....................................60

3.2.11 Statistical Methods for Microcosm Analysis ........................................61 


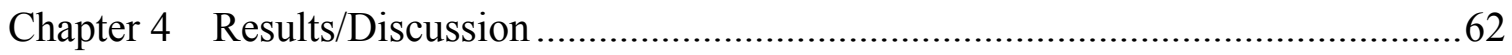

4.1 Phase I: Field Screening Results ………………….......................................62

4.1.1 Petroleum Hydrocarbon Phytoextraction in the Field ...................................62

4.1.2 Polyaromatic Hydrocarbon Phytoextraction in the Field ................................68

4.1.3 Polychlorinated Biphenyl Phytoextraction in the Field..................................75

4.1.4 Chlorinated Dioxins/Furans Phytoextraction in the Field .............................75

4.1.5 Mercury Phytoextraction in the Field .......................................................... 81

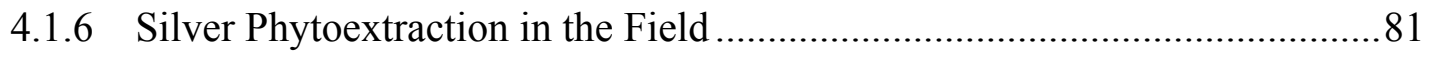

4.1.7 Cadmium Phytoextraction in the Field ........................................................... 86

4.1.8 Lead Phytoextraction in the Field............................................................91

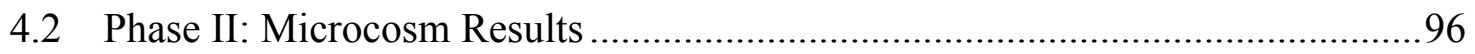

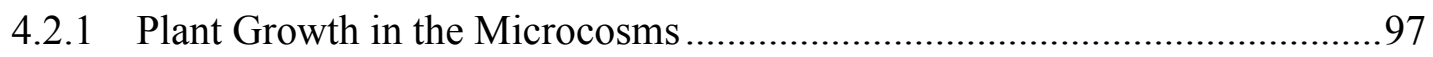

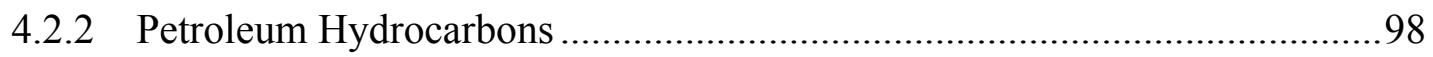

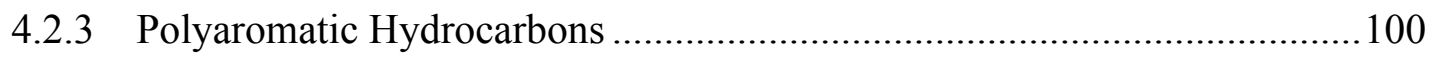

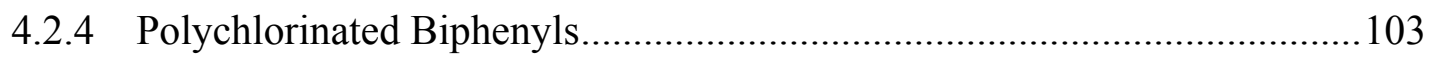

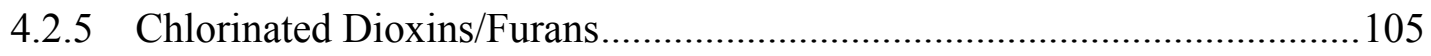

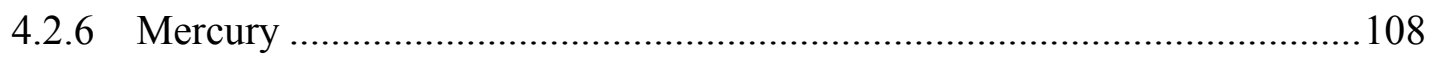

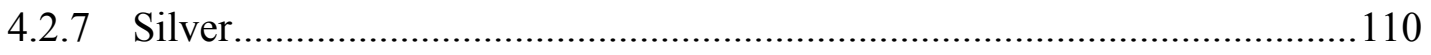

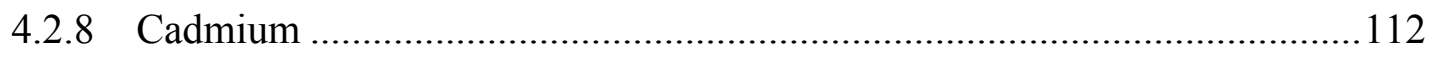

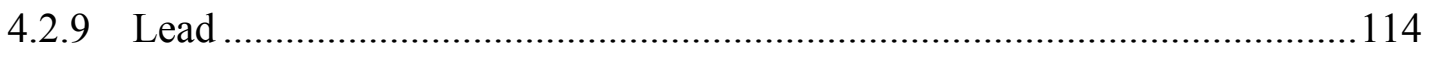

4.2.10 Phytovolatilization...........................................................................116

4.2.11 Soil Microbial Characterization Using Terminal Restriction Fragment

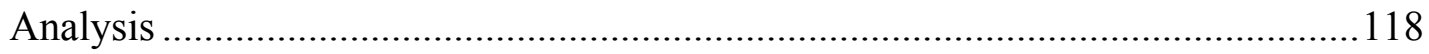




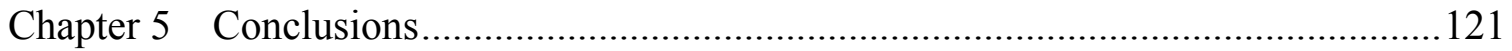

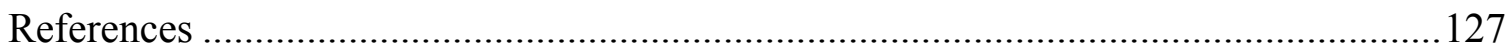

APPENDICES

A. Graphs of Soil Microcosm Concentrations after 0, 85, and 211 Days .................152

B. Statistical Analysis on Microcosm Experiment Results ....................................163 


\section{LIST OF TABLES}

Table 2.1. Phytovolatilization experimental methods from current literature..................15

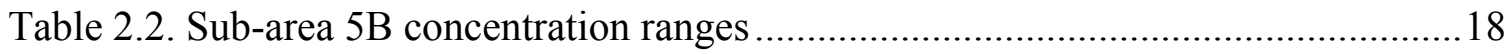

Table 2.3. Known phytoremediators and SSFL site alternatives .................................25

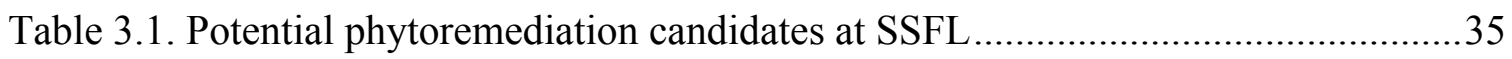

Table 3.2. Required sample mass for analytical methods .........................................43

Table 3.3. EPA methods used to analyze soil and plant samples...................................44

Table 3.4. Overview of the microcosm laboratory experiment ....................................50

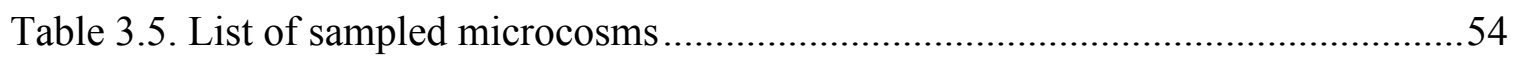

Table 3.6. Average flow rates for microcosm phytovolatilization sampling ...................56

Table 3.7. Replicate combinations for new composite sample IDs .............................60

Table 4.1. Summary of microcosm sampling events ..............................................97

Table 5.1. The greatest contaminant concentrations observed in plant tissue from the

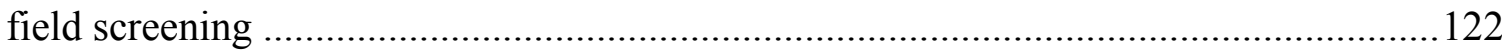




\section{LIST OF FIGURES}

Figure 2.1. The six mechanisms of phytoremediation ...............................................

Figure 2.2. Generic PCB molecular structure ........................................................ 21

Figure 2.3. Generic chlorinated dioxins and furans ................................................22

Figure 3.1. Suitable and unsuitable sampling points for plant control sampling in

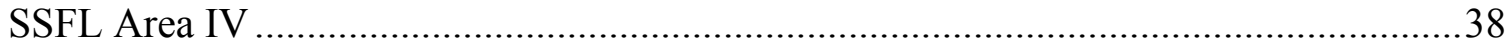

Figure 3.2. Location of tagged plants in Area IV on August 13, 2013 ...........................40

Figure 3.3. Collection of bulk soil for microcosm experiment ..................................45

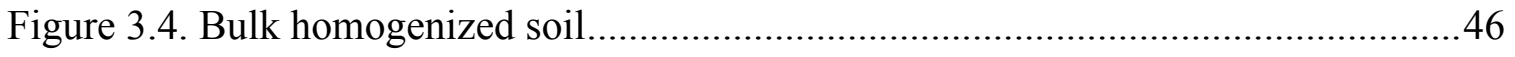

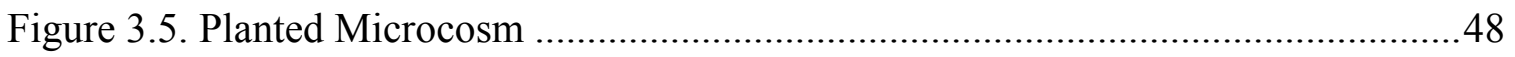

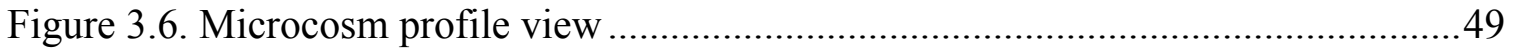

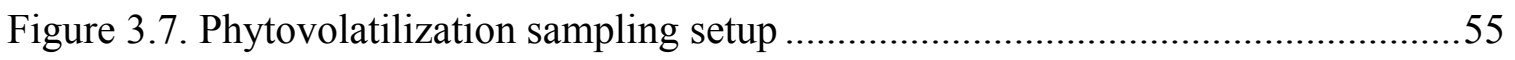

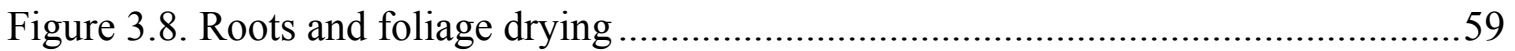

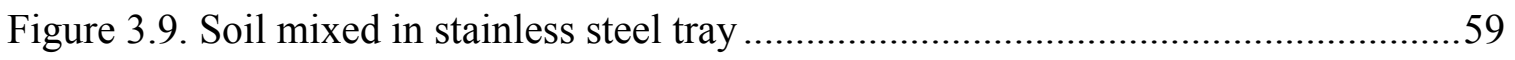

Figure 4.1. Total EFH concentrations for Palmer's Goldenbush ..................................63

Figure 4.2. Total EFH concentrations for Blue Elderberry ........................................64

Figure 4.3. Total EFH concentrations for Laurel Sumac ..........................................64

Figure 4.4. Total EFH concentrations for Mule Fat ................................................65

Figure 4.5. Total EFH concentrations for Summer Mustard .....................................65

Figure 4.6. Total EFH concentrations for Narrowleaf Milkweed .................................66

Figure 4.7. Total EFH concentrations for Coyote Brush...........................................66

Figure 4.8. Total EFH concentrations for Yerba Santa ............................................67

Figure 4.9. Total EFH concentrations for Purple Needlegrass .....................................67 
Figure 4.10. Total PAH concentrations for Blue Elderberry....................................... 70

Figure 4.11. Total PAH concentrations for Yerba Santa............................................ 70

Figure 4.12. Total PAH concentrations for Purple Needlegrass ...................................71

Figure 4.13. Total PAH concentrations for Mule Fat................................................ 71

Figure 4.14. Total PAH concentrations for Laurel Sumac ........................................... 72

Figure 4.15. Total PAH concentrations for Palmer's Goldenbush ................................72

Figure 4.16. Total PAH concentrations for Summer Mustard ......................................73

Figure 4.17. Total PAH concentrations for Narrowleaf Milkweed ................................73

Figure 4.18. Total PAH concentrations for Coyote Brush .......................................... 74

Figure 4.19. Total dioxin/furan concentrations for Purple Needlegrass ........................76

Figure 4.20. Total dioxin/furan concentrations for Blue Elderberry ............................76

Figure 4.21. Total dioxin/furan concentrations for Yerba Santa .................................77

Figure 4.22. Total dioxin/furan concentrations for Palmer's Goldenbush.......................77

Figure 4.23. Total dioxin/furan concentrations for Laurel Sumac ...............................78

Figure 4.24. Total dioxin/furan concentrations for Mule Fat .................................... 78

Figure 4.25. Total dioxin/furan concentrations for Summer Mustard............................79

Figure 4.26. Total dioxin/furan concentrations for Narrowleaf Milkweed .....................79

Figure 4.27. Total dioxin/furan concentrations for Coyote Brush ................................80

Figure 4.28. Silver concentrations for Laurel Sumac ................................................ 81

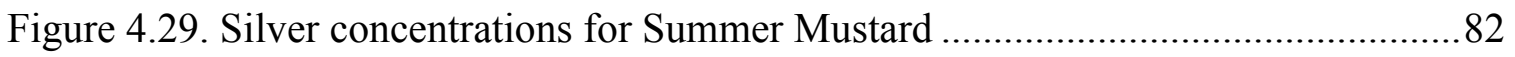

Figure 4.30. Silver concentrations for Blue Elderberry …..................................... 82

Figure 4.31. Silver concentrations for Mule Fat.................................................. 83

Figure 4.32. Silver concentrations for Palmer's Goldenbush ....................................83 
Figure 4.33. Silver concentrations for Narrowleaf Milkweed.....................................84

Figure 4.34. Silver concentrations for Coyote Brush ............................................... 84

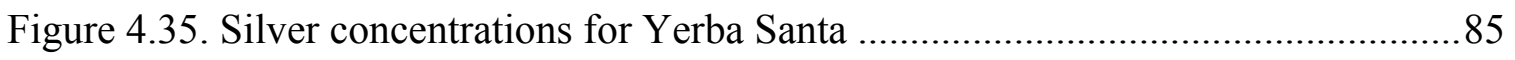

Figure 4.36. Silver concentrations for Purple Needlegrass .........................................85

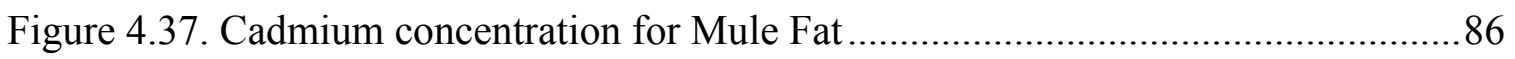

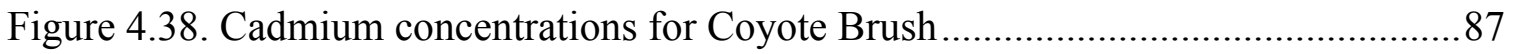

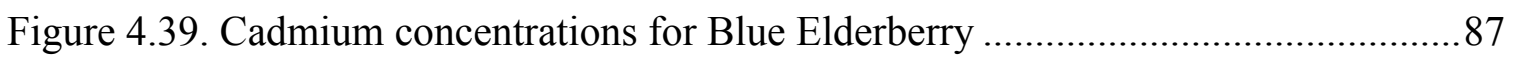

Figure 4.40. Cadmium concentrations for Palmer's Goldenbush .................................8

Figure 4.41. Cadmium concentrations for Laurel Sumac............................................ 88

Figure 4.42. Cadmium concentrations for Summer Mustard ......................................8 89

Figure 4.43. Cadmium concentrations for Narrowleaf Milkweed ................................89

Figure 4.44. Cadmium concentrations for Yerba Santa ...........................................90

Figure 4.45. Cadmium concentrations for Purple Needlegrass ..................................90

Figure 4.46. Lead concentrations for Purple Needlegrass ..........................................91

Figure 4.47. Lead concentrations for Blue Elderberry ….........................................92

Figure 4.48. Lead concentrations for Laurel Sumac .............................................99

Figure 4.49. Lead concentrations for Mule Fat ....................................................93

Figure 4.50. Lead concentrations for Palmer's Goldenbush.......................................93

Figure 4.51. Lead concentrations for Summer Mustard ............................................94

Figure 4.52. Lead concentrations for Narrowleaf Milkweed ......................................94

Figure 4.53. Lead concentrations for Coyote Brush...............................................95

Figure 4.54. Lead concentrations for Yerba Santa ................................................95

Figure 4.55. Normal, chelated, and fertilized Coyote Brush plants ..............................98 
Figure 4.56. Total EFH concentrations in microcosm soil after 0, 85, and 211 days .....100

Figure 4.57. Total PAH concentrations in microcosm soil after 0,85 , and 211 days.....101

Figure 4.58. Total PAH concentrations in soil, roots, and foliage across treatments .....102

Figure 4.59. Aroclor 1260 concentrations in microcosm soil after 0, 85, and 211

days

Figure 4.60. Total dioxin/furan concentrations in microcosm soil after 0,85 , and 211

days

Figure 4.61. Total dioxin/furan concentrations in soil, roots, and foliage across

treatments 108

Figure 4.62. Mercury concentrations in microcosm soil after 0, 85, and 211 days 109

Figure 4.63. Mercury concentrations in soil, roots, and foliage across treatments 110

Figure 4.64. Silver concentrations in microcosm soil after 0,85 , and 211 days 111

Figure 4.65. Silver concentrations in soil, roots, and foliage across treatments .111

Figure 4.66. Cadmium concentrations in microcosm soil after 0,85 , and 211 days ......113

Figure 4.67. Cadmium concentrations in soil, roots, and foliage across treatments

Figure 4.68. Lead concentrations in microcosm soil after 0, 85, and 211 days .115

Figure 4.69. Lead concentrations in soil, roots, and foliage across treatments

Figure 4.70. Gas chromatography peaks from volatilization sampling....

Figure 4.71. Microbial population groupings (MDS) as determined by TRF analysis of Purple Needlegrass (PC), sterilized Purple Needlegrass (SP), unplanted (U), and sterilized unplanted (SU) treatments

xvii 
Figure 4.72. Microbial population groupings (MDS) as determined by TRF analysis of Purple Needlegrass (PC), sterilized Purple Needlegrass (SP), and unplanted (U) treatments

Figure 4.73. Dendogram for Purple Needlegrass (PC), sterilized Purple Needlegrass (SP), unplanted (U), and sterilized unplanted (SU) treatments showing groupings of microbial communities by treatment. .120 


\section{Chapter 1 Introduction}

Phytoremediation is defined as the use of green plants to contain or remove pollutants from the environment, or render them harmless (Cunningham and Berti 1993; Salt, Smith, and Raskin 1998; Pilon-Smits 2005). Phytoremediation provides an in-situ alternative to more aggressive and intrusive forms of conventional remediation (EPA 1999). When compared to excavation and other physical/chemical remediation methods, phytoremediation is less expensive and provides additional benefits: (1) contaminant containment (2) possible extraction of metals with market value, and (3) durable land management that can gradually improve soil quality (Vangronsveld et al. 2009; Aken, Correa, and Schnoor 2010). The absence of energy-consuming equipment and limited maintenance, little or no negative environmental impacts, and public acceptance as a "green technology" are several other advantages of phytoremediation (Gerhardt et al. 2009).

Most phytoremediation research has focused on a single contaminant (Blaylock et al. 1997; Campanella, Bock, and Schröder 2002; Cook and Hesterberg 2013; Cordale Johnson, John Thomlinson 2009; D’Orazio, Ghanem, and Senesi 2013; Duckart, Waldron, and Donner 1992; Ficko, Rutter, and Zeeb 2010; Newman et al. 1997; Wei et al. 2009), but field sites often contain multiple contaminants, and phytoremediation with a variety of plant species could better contribute to ecological restoration of a site. Such ecological restoration would best be accomplished using species of plants indigenous to the site. The purpose of this thesis research was therefore to investigate the potential for phytoremediation by a variety of California native plant species which could be useful at 
numerous contaminated sites in California. A field site with a wide variety of contaminants was used for this study so that many contaminants could be investigated simultaneously. The field site used for this research was the Santa Susana Field Laboratory (SSFL) located in southern California. SSFL was established in 1947 by North American Aviation for testing liquid-propulsion rocket engines. SSFL was divided into four different areas, and the Department of Energy (DOE) performed research in a section of Area IV named the Energy Technology Engineering Center (ETEC). During the ETEC's operation, the soil was polluted with petroleum hydrocarbons, poly-aromatic hydrocarbons (PAHs), polychlorinated biphenyls (PCBs), chlorinated dioxins/furans, and heavy metals which together are referred to as the contaminants of interest (COIs). After the closure of ETEC, the DOE was made responsible for the cleanup of soil in Area IV. The DOE commissioned this study of phytoremediation as one of five soil treatability studies that were designed to support the evaluation of methods for reducing the volume of contaminated soils that may need to be removed from Area IV by traditional excavation, hauling, and disposal methods (Sandia National Laboratories 2012). The objective of this master's thesis was to determine what plant species are presently growing in Area IV soils that may be contributing to phytoremediation, what are the phytoremediation mechanisms for contaminant uptake/degradation, and what nutrients/additives can be added to stimulate/increase phytoremediation rates (Sandia National Laboratories 2012).

In Phase I of this study, native and naturalized plants growing in the contaminated areas at SSFL were harvested and analyzed to assess their phytoremediation potential. Uptake 
of COIs was considered an indicator of phytoremediation potential, so uptake of COIs by plants currently growing in the contaminated soil was used to screen for the best candidates for further study. In Phase II of the study, three of the most promising species were grown in greenhouse microcosms to quantify the removal of contaminants from the soil. Several different microcosm treatments and controls were used to elucidate the effectiveness of phytoremediation. A chelating agent ethylenediaminetetraacetic acid (EDTA) was added to one set of microcosms and fertilizer was added to another set to test their effect(s) on the remediation process. There were three control microcosm sets: unplanted, sterilized planted, and unplanted sterilized. The COI concentration in the soil was measured at 0,85 , and 211 days after planting. Both the roots and foliage from the plants were tested for COIs at the end of the 6-month experiment. Emissions from the microcosms were sampled with sorbent tubes and measured to identify any COI volatilization from the plants. 


\section{Chapter 2 Background}

\subsection{Phytoremediation Overview}

Phytoremediation has applications in many sites where there are chlorinated solvents, fuel spills, ammunition wastes, landfill leachates, and agricultural runoff (Schnoor et al. 1995). Phytoremediation is typically used to remediate areas where soil contamination is shallow and accessible by the plant roots. Plants can often survive higher pollutant concentrations than many microorganisms that are used for bioremediation (Schnoor et al. 1995). Phytoremediation can be used to remediate many different contaminants because of the different phytoremediation mechanisms that are used in the

phytoremediation process. These mechanisms coupled with the unique characteristics of individual plant species can be a formidable remediation option for contaminated media. The following sub-sections give detailed descriptions of each phytoremediation mechanism and the pollutants that are most affected by it.

\subsection{Mechanisms of Phytoremediation}

Water, slurry, and soil matrices can be remediated through the use of various plant mechanisms listed by Salt, Smith, and Raskin (1998):

- Phytoextraction: the use of pollutant-accumulating plants to remove metals or organics from soil by concentrating them in the harvestable parts

- Phytodegradation: the use of plants and associated microorganisms to degrade organic pollutants;

- Rhizodgradation: the use of associated microorganisms to degrade organic pollutants in the root-soil zone; 
- Rhizofiltration: the use of plant roots to absorb and adsorb pollutants, mainly metals, from water and aqueous waste streams;

- Phytostabilization: the use of plants to reduce the bioavailability of pollutants in the environment;

- Phytovolatilization: the use of plants to volatilize pollutants

All of the mechanisms of phytoremediation are depicted in Figure 2.1.

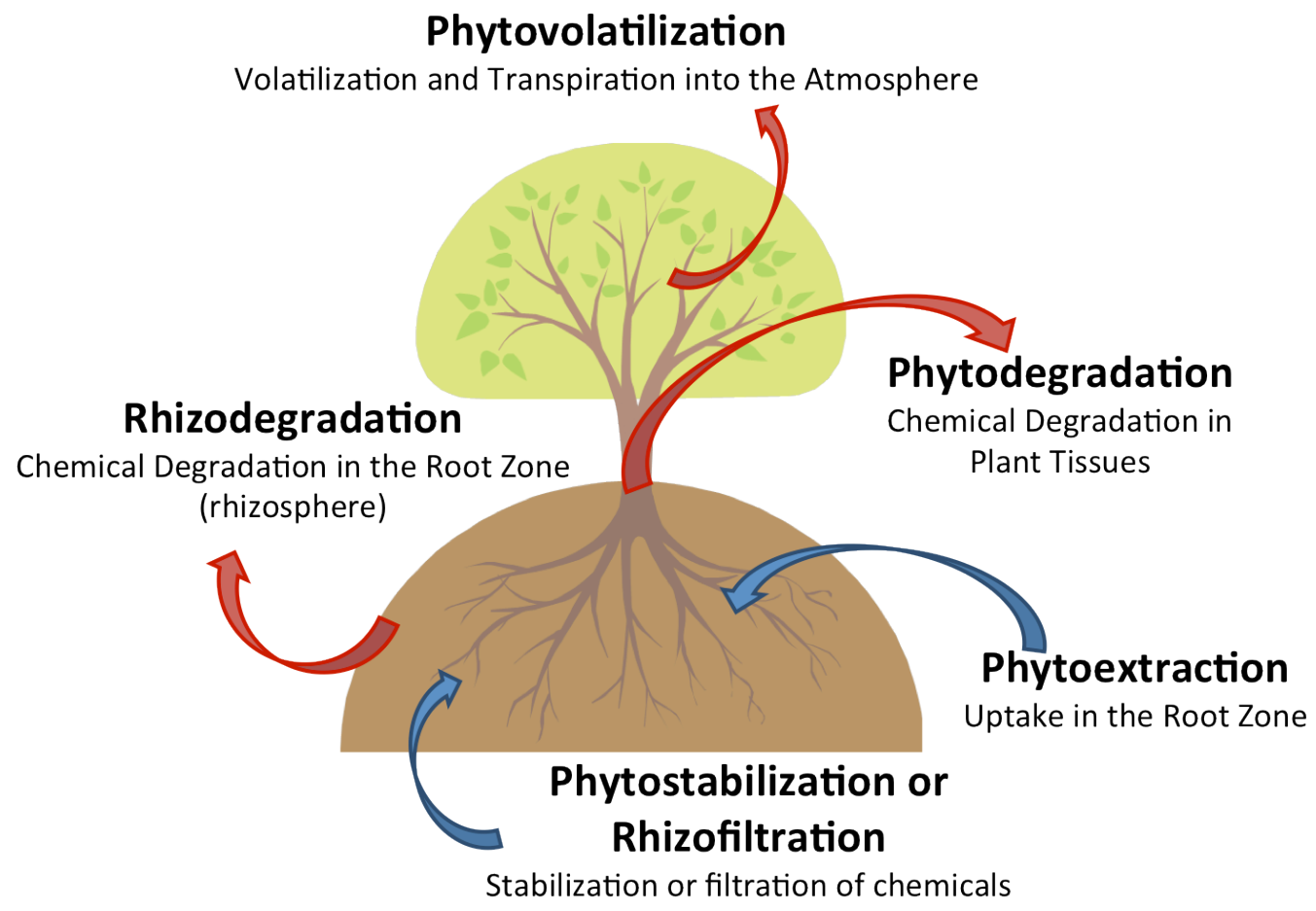

Figure 2.1. The six mechanisms of phytoremediation

\subsubsection{Phytoextraction}

Phytoextraction is the mechanism that extracts contaminants from the surroundings and transports them in the roots, stem, or foliage part of the plant (Greenwood, Rutter, and Zeeb 2011). Both organic and inorganic contaminants can be extracted by plants 
(Newman et al. 1997; Slater, Gouin, and Leigh 2011; Huelster, Mueller, and Marschner 1994; Jianwei W. Huang et al. 1997; McGrath and Zhao 2003), however, this mechanism is particularly suited for the remediation of heavy metals from the environment since only organics with a $\log \mathrm{K}_{\mathrm{ow}}$ (octanol-water partitioning coefficient) between 0.5-3.0 are typically able to be extracted from soil/water (Schnoor et al. 1995). There are several possible defense mechanisms that plants may use to tolerate heavy metals and the primary mechanism is chelation using binding proteins such as metallothioneins or phytochelatins (Mejáre and Bülow 2001). These proteins can bind to metals and form a complex, thereby increasing the bioavailability of the contaminant which can then be more readily taken up into the plant. Thus the effectiveness of phytoextraction can be largely based on the bioavailability of the contaminants in the soil. Lowering $\mathrm{pH}$, using soil microorganisms that stimulate metal uptake, and adding chelating agents to soil can often greatly increase the bioavailability of metals (Jianwei W. Huang et al. 1997; Salt, Smith, and Raskin 1998). Plants can be genetically engineered to express genes that will increase heavy metal tolerance or facilitate greater metal uptake than would normally occur. For example the merA gene encodes mercuric reductase which can reduce mercuric ions $\left(\mathrm{Hg}^{2+}\right)$ into the less toxic elemental mercury $\left(\mathrm{Hg}^{0}\right)$ which can be taken up into the plant and potentially volatilized into the atmosphere (Rugh et al. 1998; Wang et al. 2012).

If a plant accumulates metals in the foliage or stems, those sections can be harvested and the metals disposed of safely. The plant can then grow back, accumulate more metals, and be harvested until the surroundings have been remediated (McGrath and Zhao 2003). 
This process is particularly beneficial with certain plants that have been identified as metal hyperaccumulators. Although the exact criteria used to identify metal hyperaccumulators is under discussion (Ent et al. 2013), in general, metal hyperaccumulators are plants capable of storing metals in their tissue at concentrations that are much higher than the surrounding environment (Baker and Brooks 1989; Memon and Schröder 2009). With such high concentrations, it can be beneficial to extract and reuse the metals collected in the plant. Metal price, plant biomass, and the maximum metal concentration achievable in plant tissue are important factors in making metal extraction economically feasible (Brooks et al. 1998).

While metals may be the primary focus of phytoextraction, many different organic compounds can also be extracted. Alfalfa and other plant species have been shown by several studies to extract PCBs from soil or water (Zeeb et al. 2006; Ficko, Rutter, and Zeeb 2010; Xu et al. 2010; Ying Teng et al. 2010; Liu and Schnoor 2008; Greenwood, Rutter, and Zeeb 2011). Chlorinated dioxins can also be extracted from the environment using plants (Campanella and Paul 2000; Huelster, Mueller, and Marschner 1994).

\subsubsection{Phytodegradation}

Phytodegradation is the uptake and degradation of contaminants within plants, or the degradation of contaminants in soil or water using enzymes exuded by plants (J. H. Lee 2013; Pilon-Smits 2005; Gerhardt et al. 2009). Organic compounds which are introduced into the plant are metabolized in a similar process as contaminants in an animal liver; this is known as the "green-liver" concept (Shang, Newman, and Gordon 2003). Two 
sequential processes are used to phytodegrade contaminants. The first is chemical transformation by enzyme-catalyzed reactions which often results in a less toxic product; the second is compartmentation of the transformed contaminant into the vacuoles or apoplast of the plant (Coleman, Blake-Kalff, and Davies 1997). The enzymes inside the plant matrix can degrade organic contaminants into inorganic compounds like $\mathrm{CO}_{2}$ or water, or degrade them partially into stable intermediates after they enter the plant (PilonSmits 2005). The presence of enzymes such as dehalogenase, nitroreductase, and peroxidase, catalyze the transformation of organics inside plant tissue (Schnoor et al. 1995; Salt, Smith, and Raskin 1998). Plants are capable of metabolizing a wide variety of persistent organic pollutants (POPs) like pesticides and PCBs (Aken, Correa, and Schnoor 2010). Phytodegradation has also been used on ammunition wastes such as trinitrotoluene (TNT) and the chlorinated organic compound trichloroethylene (TCE) (Schnoor et al. 1995). Since the organic compounds must first be phytoextracted by the plant, moderately hydrophobic contaminants with a $\log \mathrm{K}_{\mathrm{ow}}$ between $0.5-3.0$ are well suited for phytodegradation (Schnoor et al. 1995). As a general trend, highly hydrophilic compounds $\left(\log \mathrm{K}_{\mathrm{ow}}<0.5\right)$ have difficulty passing through the plant membranes, whereas highly hydrophobic compounds ( $\left.\log \mathrm{K}_{\mathrm{ow}}>3.0\right)$ bind tightly to the roots and are not translocated well within the plant (Briggs, Bromilow, and Evans 1982; Aken, Correa, and Schnoor 2010). This can limit the effectiveness of phytoremediation of some hydrocarbons because hydrocarbon compounds have $\log \mathrm{K}_{\mathrm{ow}}$ values that range from 0.37 to 6.57 (Heath et al., 1993). However, contaminants that are highly hydrophobic/hydrophilic are not necessarily excluded from phytodegradation consideration. Zucchini exudates have been shown to bind to dioxins creating a complex 
that decreases the $\log \mathrm{K}_{\mathrm{ow}}$ and improves the uptake of dioxin into the plant (Campanella, Bock, and Schröder 2002). Also, if the contaminants are transformed inside the plant, they could become more amenable to translocation and subsequent degradation. Examples of moderately hydrophobic contaminants are MTBE (methyl-tert-butyl ether) with a $\log \mathrm{K}_{\mathrm{ow}}$ of 1.2 , BTEX (benzene, toluene, ethylbenzene, and xylene) with a $\log \mathrm{K}_{\mathrm{ow}}$ of 2.13, 2.69, 3.15, and 3.12-3.2 respectively (EPA 1995), chlorinated solvents, and short-chain aliphatic hydrocarbons (Newman and Reynolds 2004; Schnoor et al. 1995; J. H. Lee 2013). As stated previously, studies have shown the uptake of PCB's (Zeeb et al. 2006; Ficko, Rutter, and Zeeb 2010) and dioxins (Huelster, Mueller, and Marschner 1994) into plant tissue. But PCB metabolism in plants is slow and dioxins have not yet been shown to degrade within the plant (Campanella, Bock, and Schröder 2002).

\subsubsection{Rhizodegradation}

The rhizodegradation mechanism can also be termed "rhizoremediation," "phytostimulation," or "rhizostimulation." The rhizosphere is the zone of the root-soil interface where there is increased microbial activity and biomass due to the effect of the plant roots. This mechanism uses the symbiotic relationship between plants and bacteria/fungi in the rhizosphere to enhance biodegradation of organic contaminants by stimulating the microbial community (Anderson, Guthrie, and Walton 1993). Several types of bacteria and fungi are capable of partially or completely degrading contaminants in the soil through the use of enzymes like dehalogenase or peroxidase (Gerhardt et al. 2009). Mycorrhizae fungi can grow in symbiotic association with plants and help degrade organics that are recalcitrant to bacteria alone (Schnoor et al. 1995). Plant root exudates 
can enhance the degradation of pollutants by stimulating the survival and action of these microbes present in the rhizosphere (Kuiper et al. 2004; Salt, Smith, and Raskin 1998). Certain bacteria such as Pseudomonas putida and Azospirillum spp. are even capable of coaxing nutrient release from plants using biochemical signals (Anderson, Guthrie, and Walton 1993).

Rhizoremediation can be used to degrade a wide variety of contaminants like BTEX, PAHs, and petroleum hydrocarbons using trees and grasses to stimulate the remediation (Cook and Hesterberg 2013). An 80-day greenhouse experiment showed the remediation of phenanthrene- and pyrene-contaminated soil using several plant species to stimulate the rhizosphere (S.-H. Lee et al. 2008). Similarly, increased bacterial and fungal counts were observed when pyrene soil concentrations were reduced in the laboratory using Medicago sativa, Brassica napus, and Lolium perenne plant species (D’Orazio, Ghanem, and Senesi 2013). Grasses are known to stimulate the rhizosphere and much of the phytoremediation research for removal of organic compounds such as petroleum hydrocarbons (PHCs) focuses on Poaceae grass species (Hall, Soole, and Bentham 2011).

Persistent organic pollutants (POPs) such as PCBs and dioxins can also be remediated by enhancing the rhizosphere. Campanella et al. (2002) list four ways plants aid in degrading chlorinated compounds: (1) Root exudates contain compounds readily available for bacterial metabolism, (2) Plants increase the rhizosphere oxygen content, (3) Plants produce pollutant analogs, and (4) Root exudates contain general growth-promoting 
factors. One study demonstrated PCB degradation enhancement using two grass species (Phalaris arundinacea and Panicum virgatum) to stimulate the rhizosphere and increase enzyme activity (Chekol, Vough, and Chaney 2004). Several studies have suggested that rhizoremediation was the primary mechanism of PCB degradation; stimulated enzyme activity and increased microbial population in the root zone supported this hypothesis $(\mathrm{Li}$ et al. 2013; Chekol, Vough, and Chaney 2004; Xu et al. 2010; Ying Teng et al. 2010). A study done on dioxin remediation by melon (Cucumis melo) and zucchini (Cucurbita pepo L. var. Diament) showed that certain compounds released by these plants bind to the contaminant and increase the hydrophilic nature and increase the bioavailability of dioxins (Campanella and Paul 2000). The increased bioavailability enables bacteria or fungi to better access the contaminants and degrade them more efficiently.

Sometimes the bacterial degradation of a contaminant will be halted if another compound is competing for degradation. For example, Burkholderia xenovorans LB400 can use PCBs as a carbon source, however, PAH compounds can act as a competing carbon source since bacteria in the Burkholderia genus are known to degrade PAHs (Seo, Keum, and $\mathrm{Li}$ 2009). The interaction between contaminants is important and studies are underway to identify other molecules that may interfere and compete with PCBs for bacterial degradation (Secher et al. 2013).

Although the research is promising, there are two primary challenges of applying rhizoremediation in the field that are listed by Gerhardt et al. (2009): (1) Plants in the field experience additional stresses that are not present in laboratory conditions, (2) 
Current methods of assessing rhizoremediation may not be sufficient to determine whether contaminant concentrations are decreasing or not. There are many differences between the field and the laboratory, for example, plants in the field will experience nutrient deficiencies and harsh weather that do not occur under laboratory conditions.

Often the distribution of contaminants in soil is uneven and includes areas of extremely high concentrations or "hot spots" which differs from the generally well-mixed laboratory soil.

\subsubsection{Rhizofiltration}

Rhizofiltration is used to remediate aqueous waste streams by absorbing/adsorbing contaminants to plant roots thus preventing contaminants from traveling horizontally downstream or leaching into the ground (Dushenkov et al. 1995; Raskin, Smith, and Salt 1997). Since aqueous waste streams are not an aspect of concern for this project, rhizofiltration will not be discussed in detail.

\subsubsection{Phytostabilization}

Phytostabilization stabilizes or immobilizes contaminants in the soil using plants, which in turn reduces the bioavailability of pollutants in the environment (J. H. Lee 2013). This process sequesters the contaminants in the soil near the root zone, but does not degrade or absorb the contaminant into the plant tissue (Morikawa and Erkin 2003). Phytostabilization is a less-researched area of phytoremediation (Raskin, Smith, and Salt 1997), and since the ultimate objective of this project was to remove the contamination from SSFL Area IV, phytostabilization will not be discussed in detail. 


\subsubsection{Phytovolatilization}

Phytovolatilization is a mechanism used to release contaminants from the plant into a gaseous form (Salt, Smith, and Raskin 1998; Pilon-Smits 2005). Phytovolatilization can occur after an absorbed pollutant is translocated to the foliage of the plant and volatilized. After observing the garlicky odor of certain plants, Lewis, Johnson, and Delwiche (1966) discovered that selenium compounds were being volatilized by both accumulator and non-accumulator species. Other studies have since confirmed those results and shown that certain plants can convert inorganic selenium into volatile forms such as dimethylselenide (Duckart, Waldron, and Donner 1992; Terry et al. 2000). Orchard et al. (2000) developed a novel laboratory system to show that TCE was being extracted and volatilized by plants grown in a hydroponic solution. Further studies have shown volatilization of TCE and other volatilize organic contaminants (VOCs) such as MTBE (Yu and Gu 2006; Newman et al. 1997).

Another promising area of phytovolatilization is the transformation of mercuric ions $\left(\mathrm{Hg}^{2+}\right)$ into the less toxic elemental mercury $\left(\mathrm{Hg}^{0}\right)$ which can be volatilized by specific plants. However, natural plants have not demonstrated enough $\mathrm{Hg}$ volatilization to be useful without some genetic modification (Heaton et al. 1998). The main barriers to $\mathrm{Hg}$ uptake are lack of $\mathrm{Hg}$ bioavailability and poor translocation of $\mathrm{Hg}$ from the roots to the aerial portion of the plant (Heaton et al. 1998). But certain plants, such as willows or tobacco, can be genetically altered to express the mer $A$ gene which enables a greater resistance to mercury contamination and a greater rate of $\mathrm{Hg}^{0}$ volatilization (Rugh et al. 1996; Rugh et al. 1998). MerB is another gene that encodes a mercury-processing 
enzyme called organomercurial lyase. This enzyme catalyzes the breaking of carbonmercury bonds in methyl-mercury $\left(\mathrm{MeHg}\right.$ ) and produces $\mathrm{Hg}^{2+}$ which is then used by the mercuric reductase enzyme and volatilized (Heaton et al. 1998).

Chelating chemicals such as EDTA or sodium thiosulfate have been shown to increase the bioavailability of mercury in the soil with limited effect on the physical or chemical soil properties (Wang et al. 2012). The increased bioavailability of mercury may allow phytoextraction from the soil and increase the amount of phytovolatilization if the plant is capable. Phytovolatilization does not require harvesting for the contaminant elimination process and therefore has potential to be a powerful remediation tool (Pilon-Smits 2005). However, since the contaminants are released to the atmosphere, careful analysis must be done to ensure that phytovolatilization does not create an air pollution problem.

An extensive list (from current available research) of the different plant species and methods used to investigate contaminant phytovolatilization is shown in Table 2.1. 
Table 2.1. Phytovolatilization experimental methods from current literature

\begin{tabular}{|c|c|c|c|c|c|c|c|c|}
\hline Contaminants & Type of Plant & $\begin{array}{l}\text { Contaminated } \\
\text { Media }\end{array}$ & $\begin{array}{l}\text { Spiked or } \\
\text { Unspiked }\end{array}$ & Chamber Type & Flow Rate & Duration & $\begin{array}{l}\text { Type of } \\
\text { Sorbent/Media }\end{array}$ & Source \\
\hline $\begin{array}{l}\mathrm{DCB}, \mathrm{TCB}^{\mathrm{a}} \\
\text { (Chlorinated } \\
\text { Hydrocarbon) } \\
\end{array}$ & $\begin{array}{l}\text { Phragmites } \\
\text { australis (wetland } \\
\text { grass) }\end{array}$ & $\begin{array}{l}\text { Hydroponic } \mathrm{C} 14-\mathrm{OC} \\
\text { solution }\end{array}$ & Spiked & $\begin{array}{l}\text { Glass bell sealed at the } \\
\text { base with a paraffin film } \\
\text { to cover opening of } \\
\text { flask }\end{array}$ & $\mathrm{NL}^{\mathrm{b}}$ & $\begin{array}{l}30 \text { minutes twice a } \\
\text { day; tested } \\
\text { scintillating liquid } \\
\text { each day; did this for } \\
28 \text { days }\end{array}$ & Scintillation Liquid & $\begin{array}{l}\text { (San Miguel, } \\
\text { Ravanel, and } \\
\text { Raveton 2013) }\end{array}$ \\
\hline $\mathrm{Hg}(\mathrm{II})$ (Metal) & $\begin{array}{l}\text { Arabidopsis } \\
\text { thaliana (small, } \\
\text { flowering, winter } \\
\text { annual) }\end{array}$ & $\begin{array}{l}1.5 \mathrm{ml} \text { of } 25 \mathrm{uM} \\
\mathrm{HgCl} 2 \text { solution }\end{array}$ & Spiked & $\begin{array}{l}\text { Closed-tube incubation } \\
\text { assay (plants placed in a } \\
\text { test-tube containing Hg } \\
\text { solution; bubble air } \\
\text { down through the top of } \\
\text { flask and air passes } \\
\text { through side arm into } \\
\text { analyzer) }\end{array}$ & $\begin{array}{l}3 \mathrm{~cm}^{\wedge} 3 / \mathrm{sec}= \\
180 \mathrm{ml} / \mathrm{min}\end{array}$ & $\begin{array}{l}\text { Sampled each minute } \\
\text { over the course of } 10 \\
\text { minutes }\end{array}$ & $\begin{array}{l}\text { Gold foil; Jerome } \\
431 \text { Mercury Vapor } \\
\text { Analyzer }\end{array}$ & (Heaton et al. 1998) \\
\hline $\begin{array}{l}\text { Naphthalene } \\
\text { (PAH) }\end{array}$ & $\begin{array}{l}\text { Unsaturated zone } \\
\text { soil with poplar } \\
\text { trees } \\
\text { (wetland/riparian } \\
\text { trees) }\end{array}$ & $\begin{array}{l}\text { DNAPL } 3.7 \mathrm{~m} \text { below } \\
\text { ground surface; } \\
\text { [Naphthalene] }=10-500 \\
\text { ug/L }\end{array}$ & Unspiked & $\begin{array}{l}\text { Stainless steel tray w/ } \\
\text { open bottom flux } \\
\text { chamber: }(24 \times 29 \times 4.4 \\
\mathrm{cm}) \text {. Air passes through } \\
570 \mathrm{~g} \text { drying column } \\
\text { anhydrous CaSO4, } \\
\text { enters chamber through } \\
10.3 \mathrm{~cm} \text { holes in Teflon } \\
\text { manifold, passes } \\
\text { through chamber and } \\
\text { over soil, exits through } \\
\text { two } 0.6 \mathrm{~cm} \text { holes into } \\
\text { resin tubes }\end{array}$ & $\begin{array}{l}2 \mathrm{~L} / \mathrm{min} \text { by } \mathrm{SKC} \text {, } \\
\text { Inc. PCXR } 8 \\
\text { personal sampling } \\
\text { pump }\end{array}$ & $\begin{array}{l}\text { Ran pump for } 5 \text { min. } \\
\text { to create steady state, } \\
\text { then ran for } 3 \text { days }\end{array}$ & $\begin{array}{l}\text { Two XAD-2sorbent } \\
\text { tubes (SKC, Inc.) }\end{array}$ & (Marr et al. 2006) \\
\hline TCE (VOC) & $\begin{array}{l}\text { Baldcypress Tree } \\
\text { (deciduous conifer } \\
\text { tree that grows in } \\
\text { saturated soil) }\end{array}$ & $\begin{array}{l}\text { gravel/sand substrate } \\
\text { with water level above } \\
\text { surface; added 200- } \\
300 \mathrm{uL} \text { pure TCE }\end{array}$ & Spiked & $\begin{array}{l}\text { Glass-carboy } \\
\text { mesocosm; closed-cell } \\
\text { neoprene and silicone } \\
\text { glue sealed off neck; } \\
\text { sealed an airtight clear } \\
\text { polycarbonate (Lexan) } \\
\text { chamber (80L) and a } \\
\text { sensor head mounted on } \\
\text { top of the chamber; } 2 \\
12 \mathrm{~V} \text { fans mixed } \\
\text { chamber headspace; } \\
\text { chilled water circulated } \\
\text { at bottom to maintain } \\
\text { ambient temp. }\end{array}$ & No pump & $\begin{array}{l}\text { Air sampled every } 10 \\
\text { min. for a } 30 \text { min. } \\
\text { time series; measured } \\
\text { twice during day and } \\
\text { twice during night; } \\
\text { TCE water conc. also } \\
\text { tested weekly } \\
\text { (summer) to } \\
\text { biweekly (winter) }\end{array}$ & $\begin{array}{l}\text { Roots washed in tap } \\
\text { water, sealed in } \\
\text { serum vials, heated } \\
\text { overnight, and } \\
\text { analyzed for TCE by } \\
\text { GC; sample of } \\
\text { chamber air into a } \\
100 \text { microliter } \\
\text { syringe then } \\
\text { immediately injected } \\
\text { into the GC }\end{array}$ & $\begin{array}{l}\text { (Nietch, Morris, and } \\
\text { Vroblesky 1999) }\end{array}$ \\
\hline
\end{tabular}




\begin{tabular}{|c|c|c|c|c|c|c|c|c|}
\hline Se (Metal) & $\begin{array}{l}\text { Cattail, baltic rush, } \\
\text { smooth cordgrass, } \\
\text { saltgrass, tule, } \\
\text { widgeon grass } \\
\text { (wetland plants) } \\
\end{array}$ & $\begin{array}{l}\text { Madmade water flow- } \\
\text { through wetland cells: } \\
15 \mathrm{mx} 77 \mathrm{~m} \text { and } 30-60 \\
\mathrm{~cm} \text { deep; Selenate } \\
\text { (Se04^2-) added to the } \\
\text { water flow }\end{array}$ & Spiked & $\begin{array}{l}6.6 \mathrm{~mm} \text { thick Plexiglas } \\
\text { with dimensions of } 0.71 \\
\mathrm{~m} \text { long, } 0.71 \mathrm{~m} \text { wide, } \\
\text { and } 0.76 \mathrm{~m} \text { high }\end{array}$ & $\begin{array}{l}\text { vacuum pump: } \\
0.85 \mathrm{~m}^{\wedge} 3 / \mathrm{hr}= \\
14,166 \mathrm{~mL} / \mathrm{min}\end{array}$ & $\begin{array}{l}24 \mathrm{hr} \text { sampling } \\
\text { duration; rates } \\
\text { monitored for } 2 \text { years }\end{array}$ & charcoal filters & (Lin and Terry 2003) \\
\hline Se (Metal) & $\begin{array}{l}\text { Rabbitfoot grass } \\
\text { seeds }\end{array}$ & $\begin{array}{l}510 \mathrm{mg} \mathrm{Se} \text { added to } \\
\text { soil; } 170 \mathrm{mg} \text { of } \mathrm{Se} \text { as } \\
\text { selenate }(\mathrm{Na} 2 \mathrm{SeO} 4), \\
\text { selenite }(\mathrm{Na} 2 \mathrm{SeO} 3), \\
\text { and SeMet } \\
(\mathrm{C} 5 \mathrm{H} 11 \mathrm{NO} 2 \mathrm{Se})\end{array}$ & Spiked & $\begin{array}{l}6.6 \mathrm{~mm} \text { thick Plexiglas } \\
\text { with dimensions of } 0.71 \\
\mathrm{~m} \text { long, } 0.71 \mathrm{~m} \text { wide, } \\
\text { and } 0.76 \mathrm{~m} \text { high }\end{array}$ & NL & 38 days & charcoal filters & (Lin and Terry 2003) \\
\hline TCE (VOC) & $\begin{array}{l}\text { Carrots, spinach, } \\
\text { tomatoes }\end{array}$ & $\begin{array}{l}140 \mathrm{ug} / \mathrm{L} ; 560 \mathrm{ug} / \mathrm{L} \\
\text { soil }\end{array}$ & & $\begin{array}{l}\text { Vegetables grown in } \\
\text { ceramic pots that were } \\
\text { enclosed in a modified } \\
\text { aquarium; the air was } \\
\text { continuously pulled } \\
\text { through the chambers }\end{array}$ & NL & 3.5-15 weeks & $\begin{array}{l}\text { Liquid ethylene } \\
\text { glycol monomethyl } \\
\text { ether traps }\end{array}$ & (Orchard et al. 2000) \\
\hline TCE (VOC) & Poplar & $50 \mathrm{mg} / \mathrm{L}$ soil & & $\begin{array}{l}\text { Root and foliage were } \\
\text { separated by teflon tape, } \\
\text { a teflon-lined septum, } \\
\text { and acrylic bathroom } \\
\text { caulk; Semistatic system } \\
\text { of two flasks w/ vacuum } \\
\text { attached to foliage } \\
\text { chamber }\end{array}$ & $\begin{array}{l}0.8-1.1 \mathrm{~L} / \mathrm{min} \text { flow } \\
\text { rate }\end{array}$ & 1 week & $\begin{array}{l}\text { Liquid ethylene } \\
\text { glycol monomethyl } \\
\text { ether traps }\end{array}$ & (Orchard et al. 2000) \\
\hline As (Metal) & Pteris vittata (fern) & $\begin{array}{l}6540 \mathrm{mg} \text { As } / \mathrm{kg} \text { dry } \\
\text { weight soil; fronds } \\
\text { accumulated } 3830- \\
11020 \mathrm{mg} / \mathrm{kg} \mathrm{DW}\end{array}$ & Unspiked & $\begin{array}{l}\text { A stem on the fern was } \\
\text { guided into a } 20 \mathrm{~L} \text { low- } \\
\text { density polyethylene } \\
\text { bottle and sealed at the } \\
\text { opening with sealant } \\
\text { and tape; the water } \\
\text { vapor was sampled }\end{array}$ & NL & 2-7 days & none & $\begin{array}{l}\text { (Sakakibara et al. } \\
2010 \text { ) }\end{array}$ \\
\hline
\end{tabular}

${ }^{\mathrm{a}} \mathrm{DCB}=$ Dichlorobenzene, $\mathrm{TCB}=$ Trichlorobenzene

${ }^{\mathrm{b}} \mathrm{NL}=$ Not Listed 


\subsection{SSFL Site History and Characterization}

The Santa Susana Field Laboratory (SSFL) was established in 1947 by North American Aviation as a location for testing liquid-propulsion rocket engines. Testing was done initially for the Department of Defense and later for the National Aeronautic Space Administration (NASA). Area IV of SSFL was used for energy and liquid metals research from the mid-1950s until approximately 2000. A 90-acre portion of Area IV was leased to the Department of Energy (DOE) for nuclear energy and other research (Department of Energy 2003). This 90-acre portion of Area IV was termed the Energy Technology Engineering Center (ETEC) and also served as DOE's Liquid Metals Center of Excellence. Ten small nuclear reactors were tested during ETEC operations and a variety of chemicals were used during the operation of research in Area IV. These chemicals included PCBs used in electrical components and hydraulic fluids, fuels that ran auxiliary generators and heated water for steam, metals such as silver for photograph development, and mercury for cooling the nuclear reactors. Onsite waste burning and a wildfire in 2005 produced dioxins/furans, and releases of PCBs, metals, fuels, and lubricants contaminated the soil within Area IV. In addition, solvents from transformers, storage tanks, drums, and leach fields also contributed to contamination.

\subsubsection{Soil characteristics}

The soil in Area IV varies depending on the subarea. The subareas that contain most of the contamination are primarily a type of loam, either Saugus sandy loam with 5 to 30 percent slopes, or Zamora loam with 2 to 15 percent slopes (HydroGeoLogic Inc. 2012). The soil is aerobic with June, 2014 measured $\mathrm{O}_{2}$ concentrations ranging from $13 \%$ to 
$20 \%$. The soil temperature in March, one foot below the ground surface ranged from 61$86^{\circ} \mathrm{F}$.

\subsubsection{Contamination at SSFL Area IV}

The contaminants of interest (COIs) at SSLF Area IV fall into five general categories, petroleum hydrocarbons (measured as extractable fuel hydrocarbons $[\mathrm{EFH}]$ and quantitated for a range of alkanes C8-C11, C12-C14, C15-C20, C21-C30 and C30-C40), polyaromatic hydrocarbons (PAHs), polychlorinated biphenyls (PCBs), chlorinated dioxins/furans, and heavy metals. Other categories of contaminants are present at the site, but are not the focus of the phytoremediation soil treatability study. Each type of contaminant has unique properties and challenges associated with it. The contamination concentrations in Area IV are extremely varied due to concentrated spills, building demolition, the wildfire, and other site disturbances. Table 2.2 shows the wide range of concentrations present in Sub-Area 5B.

Table 2.2. Sub-area 5B concentration ranges

\begin{tabular}{|l|l|}
\hline Contaminant & Range in Sub-Area 5B \\
\hline TPH EFH $(\mathrm{C} 15-\mathrm{C} 20)^{\mathrm{a}}$ & $0.41-22 \mathrm{ppm}$ \\
\hline PAHs & $0.34-53000 \mathrm{ppb}$ \\
\hline PCBs & $0.34-18000 \mathrm{ppb}$ \\
\hline Dioxins/Furans & $0.00516-130000 \mathrm{ppt}$ \\
\hline Mercury & $0.0028-23.6 \mathrm{ppm}^{\mathrm{b}}$ \\
\hline
\end{tabular}

${ }^{\mathrm{a}}$ TPH Extractable Fuel Hydrocarbons (EFH) equivalent carbon chain length of 15 to 20 carbon atoms (C15-C20)

${ }^{\mathrm{b}}$ Parts per million (ppm), parts per billion (ppb), and parts per trillion (ppt)

These values come from an expansive dataset developed to characterize the contamination in Area IV. This dataset contains the analytical results from hundreds of 
soil samples and details the contaminants present in the soil, the measured concentrations of the COIs, the exact GPS coordinates of each soil sample, and much more.

\subsubsection{Petroleum Hydrocarbons}

Petroleum hydrocarbons (PHCs) is a term that describes a class of chemicals that originate from crude oil and is a mixture of hundreds of compounds that are primarily formed from carbon and hydrogen. Santa Susana Area IV was contaminated with PHCs through onsite use and disposal of petroleum based fuels (Department of Energy 2003). PHCs can cause nerve disorders, affect the blood and immune system, affect reproduction, and can cause cancer (ATSDR 2014).

\subsubsection{Polyaromatic Hydrocarbons}

Polyaromatic hydrocarbons (PAHs) are a subset of PHCs that are of particular concern due to their stability and persistence in the environment. They are composed of two or more benzene rings fused together, hence the "poly-aromatic" part of the name. Most PAHs have a high affinity for soil (not water) as indicated by high octanol-water partitioning coefficients $\left(\mathrm{K}_{\mathrm{ow}}\right)$. For example pyrene, a four ringed $\mathrm{PAH}$, has a $\log \mathrm{K}_{\mathrm{ow}}$ of 4.88 compared to a $\log \mathrm{K}_{\mathrm{ow}}$ of 2.18 for benzene. PAH contamination was introduced to Area IV through open burning of wastes, burning of rocket and vehicle fuels, and incomplete combustion of vegetation during the 2005 wildfire (Boeing 2005). Many PAHs are reasonably expected to be carcinogenic and suspected to cause birth defects (ATSDR 2014). 


\subsubsection{Polychlorinated Biphenyls}

PCBs are man-made chlorinated organic compounds. The structure of PCBs consists of two benzene rings attached by a single bond with a varied amount of chlorines attached to carbons in the benzene ring. Each PCB with a different arrangement and number of chlorines is referred to as a congener (Figure 2.2). Since PCBs are often known by their industrial trade names, the most common being Aroclor (US EPA 2013b). PCBs are known as persistent organic pollutants (POPs) because of their high thermal and chemical stability due to their highly chlorinated aromatic structure Campanella et al. (2002). A high $\log \mathrm{K}_{\mathrm{ow}}(4.46-8.18)$ causes PCBs to accumulate in soils and sediments. In general, the more highly chlorinated the congener, the less water-soluble and volatile it is (Campanella, Bock, and Schröder 2002). Highly chlorinated PCBs are also harder to degrade. PCB congeners with 5 or more chlorine atoms must undergo anaerobic reductive dechlorination to 3 or less chlorine atoms before they can be aerobically degraded (Aken, Correa, and Schnoor 2010). PCBs were used as coolants in transformers and electrical equipment in Area IV because of their insulating properties. Chronic exposure to PCBs can have serious neurological and immunological effects on children and they have been determined to be probably carcinogenic to humans by the EPA and International Agency for Research on Cancer (ATSDR 2014). 


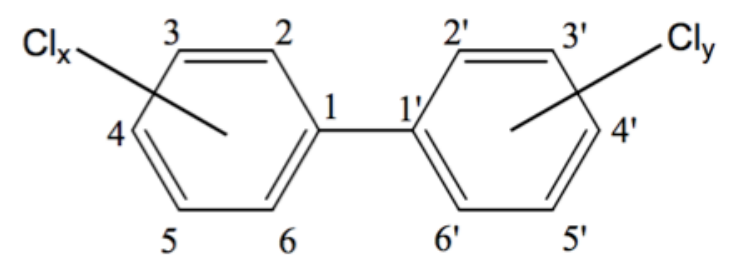

Figure 2.2. Generic PCB molecular structure

\subsubsection{Chlorinated Dioxins/Furans}

The term "dioxin" is often used to refer to polychlorinated dibenzo-p-dioxins (PCDDs), which have similar physical and chemical properties as PCBs. The dioxin molecule is a central part of PCDDs which are the compounds of primary concern. Compounds that contain furan such as polychlorinated dibenzofurans (PCDFs) are very closely related to PCDDs and are often grouped together in discussion because of their similar structure and chemical properties (US EPA 2011). In this thesis the term "dioxins/furans" refers to both PCDDs and PCDFs. PCDD/Fs consist of a dioxin or furan center that links two benzene rings together that have 8 or less chlorine atoms bonded to the carbon atoms of the benzene rings (Figure 2.3). PCDD/Fs are even more hydrophobic than PCBs having $\log \mathrm{K}_{\mathrm{ow}}$ values from 7-10 which cause them to bind tightly to soil (Campanella, Bock, and Schröder 2002). Like PCBs, the compounds with different number and positioning of chlorines are referred to as congeners. They also follow the same trend that the more highly chlorinated the congener, the less water-soluble and volatile it is (Campanella, Bock, and Schröder 2002). They differ from PCBs in that they are formed through both natural and industrial combustion processes (Lemieux, Lutes, and Santoianni 2004; ATSDR 2014). The most toxic congener is 2,3,7,8-tetrachlorodibenzo-p-dioxin (TCDD) 
and all other dioxin toxicity is evaluated relative to this congener (ATSDR 2014). In several animal studies exposure to TCDD has been shown to cause liver and immune system damage and the World Health Organization (WHO) has determined that 2,3,7,8TDD is a human carcinogen (ATSDR 2014).

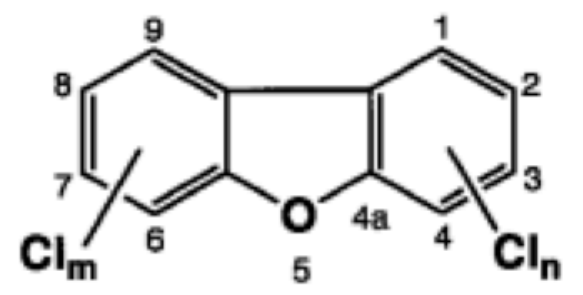

Polychlorinated dibenzofurans (PCDF)

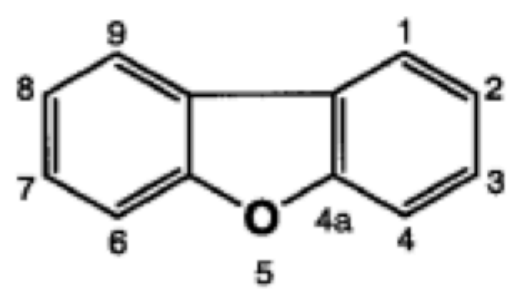

Dibenzofuran (DF)

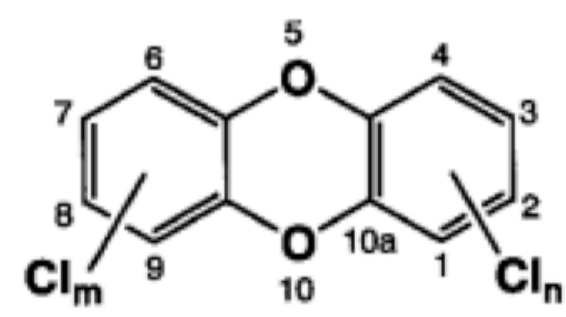

Polychlorinated dibenzo-p-dioxins (PCDDs)

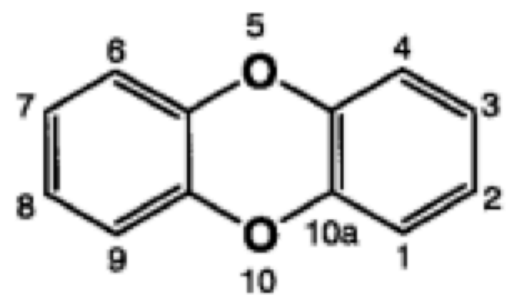

Dibenzo-p-dioxin (DD)

Figure 2.3. Generic chlorinated dioxins and furans

\subsubsection{Metals}

Metals are elements which are non-biodegradable and tend to accumulate in the environment and living organisms. Metals exist in either an elemental or oxidized state. For example, $\mathrm{Hg}$ can exist in the elemental form $\left(\mathrm{Hg}^{0}\right)$, the oxidized form $\left(\mathrm{Hg}^{+}\right)$, and the oxidized form $\left(\mathrm{Hg}^{2+}\right)$. Thus metals can be transported through the environment by dissolving into water or forming inorganic/organic compounds. Most metals do not 
volatilize readily, but mercury is the one exception and is often released into the atmosphere when mercury-containing coal is burned (US EPA 2013a). Some of the metals that have contaminated Area IV are silver, cadmium, copper, mercury, lead, zinc, nickel, and chromium. Mercury is known to disrupt the nervous system, damage the brain, kidneys and lungs, and cause changes in vision and loss of memory in humans (ATSDR 2014). Other metals have similar toxic effects on humans. Metals are also extremely toxic to microorganisms in the environment and can also cause mutations, sickness, and death to plants at high concentrations (Giller, Witter, and Mcgrath 1998; Patra et al. 2004).

\subsubsection{Treatment Goals}

The Department of Toxic Substance Control created Look-Up Tables that provide the standards for acceptable levels of contamination for the SSFL site. These tables separate major classes of chemicals (PCBs, PAHs, TPH, etc.) and give values for a multitude of compounds within those classes. The DTSC established background threshold values (BTVs) by analyzing the background and sampling data from the Chatsworth and Santa Susana geological formations and used these values to calculate the Look-Up values by adjusting for an analytical measurement uncertainty of 5\%. The method reporting limit (MRL) was used to calculate the Look-Up values when a BTV was not known for a certain chemical. The MRL is the minimum level that an analytical instrument can report and provide a reliable (accurate and precise) result (Raphael 2013). To ensure all the Look-Up values meet the goals of protecting human health and the environment, DTSC examined the list of MRL-based Look-Up Table values compared against both the 
ecological and suburban residential human-health risk-based screening levels. No MRLs exceed either the ecological or suburban residential human-health risk-based screening levels for the COIs.

\subsubsection{Vegetation}

The vegetation in SSFL Area IV is made up of a mixture of native, naturalized, and invasive plant species. Recent site disturbances have changed many parts of the vegetation cover. Much of Area IV was burned in the 2005 wildfire, and in 2010 the EPA cut back most of the vegetation in order to conduct radiological surveys of the entire area (HydroGeoLogic 2010). One benefit of phytoremediation could be the re-vegetation of Area IV with native or naturalized plants. With re-vegetation in mind, invasive species were not considered to be viable phytoremediation candidates. The Sandia report (2012) listed a collection of plants species known to remediate the COIs in other studies and a list of plant species thought to be analogous to them that might be growing in Area IV. A shortened version of that list is reproduced in Table 2.3. 
Table 2.3. Known phytoremediators and SSFL site alternatives

\begin{tabular}{|c|c|c|}
\hline $\begin{array}{l}\text { Contaminant } \\
\text { Group }\end{array}$ & $\begin{array}{l}\text { Plants shown to Demonstrate } \\
\text { Remediation Potential }\end{array}$ & Suggested On-Site Alternative \\
\hline \multirow{4}{*}{ TPHs } & Clover/Alfalfa (Trifolium sp.) & $\begin{array}{l}\text { Small-headed Clover, Creek Clover, } \\
\text { White-Tipped Clover, Tomcat } \\
\text { Clover, White Clover }\end{array}$ \\
\hline & Fescue (Festuca sp.) & $\begin{array}{l}\text { Red Fescue, Small Fescue, Rat-Tail } \\
\text { Fescue }\end{array}$ \\
\hline & Ryegrass (Lolium multiflorum) & Giant Ryegrass, Beardless Wildrye \\
\hline & Bermuda Grass (Cynodon dactylon) & $\begin{array}{l}\text { Bermuda Grass (naturalized in wet } \\
\text { areas) }\end{array}$ \\
\hline \multirow{4}{*}{ PAHs } & Clover/Alfalfa (Trifolium sp.) & $\begin{array}{l}\text { Small-headed Clover, Creek Clover, } \\
\text { White-Tipped Clover, Tomcat } \\
\text { Clover, White Clover }\end{array}$ \\
\hline & Fescue (Festuca sp.) & $\begin{array}{l}\text { Red Fescue, Small Fescue, Rat-Tail } \\
\text { Fescue }\end{array}$ \\
\hline & Ryegrass (Lolium multiflorum) & Giant Ryegrass, Beardless Wildrye \\
\hline & Bermuda Grass (Cynodon dactylon) & $\begin{array}{l}\text { Bermuda Grass (naturalized in wet } \\
\text { areas) }\end{array}$ \\
\hline \multirow{6}{*}{ PCBs } & Pumpkin/Zucchini (C. pepo) & $\begin{array}{l}\text { Buffalo Gourd (native), } \\
\text { Pumpkin/Zucchini Gourd } \\
\text { (naturalized), Gourd }\end{array}$ \\
\hline & Clover/Alfalfa (Trifolium sp.) & $\begin{array}{l}\text { Small-headed Clover, Creek Clover, } \\
\text { White-Tipped Clover, Tomcat } \\
\text { Clover, White Clover }\end{array}$ \\
\hline & Fescue (Festuca sp.) & $\begin{array}{l}\text { Red Fescue, Small Fescue, Rat-Tail } \\
\text { Fescue }\end{array}$ \\
\hline & Ryegrass (Lolium multiflorum) & Giant Ryegrass, Beardless Wildrye \\
\hline & Willows (Salix spp.) & Red Willow, Arroyo Willow \\
\hline & Bermuda Grass (Cynodon dactylon) & $\begin{array}{l}\text { Bermuda Grass (naturalized in wet } \\
\text { areas) }\end{array}$ \\
\hline Dioxins & Poplar (Populus sp.) & Black Cottonwood \\
\hline
\end{tabular}




\begin{tabular}{|c|l|l|}
\hline \multirow{4}{*}{ Metals } & Indian Mustard (Brassica juncea) & $\begin{array}{l}\text { Black Mustard, Mediterranean } \\
\text { Mustard }\end{array}$ \\
\cline { 2 - 3 } & Sunflower (Helianthus annuus) & $\begin{array}{l}\text { Canyon Sunflower, Common } \\
\text { Sunflower, California Sunflower, } \\
\text { Slender Sunflower, Bush Sunflower }\end{array}$ \\
& & Little Barley \\
\cline { 2 - 3 } & Barley (Hordeum vulgare) & \\
\hline
\end{tabular}

\subsection{Phytoremediation Research on Plant Candidates}

Several of the plants considered in this study have been involved in previous phytoremediation studies. Canadian Horseweed (Conyza canadensis) was identified as a $\mathrm{Cd}$ accumulator in laboratory growth experiments using $\mathrm{Cd}$-spiked soil as well as in field experiments at a Cd-contaminated site (Wei et al. 2009). Another study showed that Slender Wild Oat (Avena barbata) enhanced the biodegradation rates of phenanthrene in the rhizosphere and also increased the number of bacterial phenanthrene degraders in the soil (Miya and Firestone 2000). A subsequent study by the same authors showed an increase in phenanthrene degradation for soil amended with Slender Wild Oat root exudates and debris (Miya and Firestone 2001). Soft Chess (Bromus hordeaceus) was reported to accumulate a fair amount of $\mathrm{Ni}(1467 \mathrm{mg} / \mathrm{kg}$ in the aerial parts) in a screening study of plants growing in an old mining area of Braganca, Portugal (Freitas, Prasad, and Pratas 2004). Another screening study of 32 different plant species showed that Summer Mustard (Hirschfeldia incana) had the best characteristics to phytoextract $\mathrm{Cu}$ from the soil (Poschenrieder et al. 2001). The Summer Mustard exhibited high Cu tolerance and high root to shoot transfer of $\mathrm{Cu}$ within the plant. In a 40-day pot experiment, Summer Mustard extracted large amounts of $\mathrm{Zn}$ and $\mathrm{Pb}$ from soil taken from a site historically contaminated by industrial activity (Gisbert et al. 2006). Summer Mustard also showed a 
high uptake of As from the alluvial flats of the Turia River in Valencia, Spain (Gisbert et al. 2008). Wild Oat (Avena fatua) accumulated more $\mathrm{Pb}$ than several other plant species and accumulated $\mathrm{Pb}$ mostly in the roots (Wu, Chen, and Tang 2005). Purple Needlegrass (Nassella pulchra) was used in combination with other native grasses (Bromus carinatus, Elymus glaucus, Festuca ruba, Hordeum californicum, Leymus triticoides) to reduce concentrations of petroleum hydrocarbons by $30 \%$ in two years (Siciliano et al. 2003). The Sierra Streams Institute also found that Purple Needlegrass accumulated five times as much lead as other non-accumulating species at two abandoned mine sites in Nevada City (Institute 2013). A study done with Mule Fat (Baccharis salicifolia) showed that copper is sequestered into the roots of the plant but not into the leaves (Cordale Johnson, John Thomlinson 2009).

\subsubsection{Plant Characteristics Ideal for Phytoremediation}

A wide variety of plant species have been identified as phytoremediators. From large trees to small grasses, many different plants exhibit certain characteristics that make them candidates for phytoremediation. The following are the primary phytoremediation characteristics (Anderson, Guthrie, and Walton 1993; Salt, Smith, and Raskin 1998; Pilon-Smits 2005; Memon and Schröder 2009; Ali, Khan, and Sajad 2013; Cook and Hesterberg 2013):

1. Rapid growth

2. Tolerance to toxic contaminants

3. High accumulation of contaminants in the roots

4. Efficient translocation of contaminants from roots to above ground plant tissue 
5. Ability to produce large amounts of biomass

6. Dense/expansive root system

7. High production of degrading enzymes

8. Tolerance to environmental conditions

9. Resistance to pathogens and pests

10. Repulsive to herbivores

11. Easy to cultivate and harvest

The first seven characteristics listed are important for handling the contaminant itself, whereas the last four characteristics are important for the practical implementation of phytoremediation at a contaminated site. The accumulation potential of plants can be evaluated using the bioconcentration factor $(\mathrm{BF})$ - the ratio of contaminant concentrations in the plant to that in the soil, and the translocation factor (TF) - the ratio of contaminant concentrations in the shoots to that in the roots (Marchiol et al. 2013; Baker and Brooks 1989). The BF indicates the plant's ability to extract contaminants from the soil and the TF indicates the plant's ability to transport the contaminants from the roots to the shoots of the plant.

\subsubsection{Bioavailability}

The Bioavailability of contaminants can limit the effectiveness of phytoremediation. Bioavailability is a measure of how accessible contaminants are to biological organisms. Plants and microorganisms must be able to access/contact the pollutant in order to start the biodegradation process. Metals, such as $\mathrm{Pb}$, often form complexes with organic matter or precipitate with carbon, phosphorous, and hydroxide which limit $\mathrm{Pb}$ 's 
availability for plant uptake (Blaylock et al. 1997). $\mathrm{Hg}$ at mining sites can also be largely unavailable because it is in the form of $\mathrm{HgS}$ (Wang et al. 2012). PCBs and other organic compounds with high octanol-water partitioning coefficients are often bound tightly to soil which prevents them from entering the soil-water phase where contaminant degrading microorganisms may reside (Providenti, Lee, and Trevors 1993; Shen et al. 2009).

Increased contaminant bioavailability allows plants and microorganisms to be more effective at remediation. Different factors can increase the bioavailability of compounds in soil. Surfactants, or chelating agents, can increase the bioavailability of organics or metals by forming a water-soluble compound or complex that can be absorbed into plant tissue or accessed by bacteria (Blaylock et al. 1997; Shen et al. 2009). Plants themselves can release compounds that increase contaminant water solubility and improve phytoextraction (Campanella, Bock, and Schröder 2002). Other factors such as pH and temperature can also increase or decrease bioavailability depending on the type of contaminant (Blaylock et al. 1997; Wang et al. 2012).

\subsubsection{Chelating Agents and Surfactants}

Chelating agents are chemical compounds that form two or more distinct bonds to a metal ion forming a complex which can make the metal more mobile (Flora and Pachauri 2010). Ethylenediaminetetraacetic acid (EDTA) is a widely used synthetic chelating agent that has been shown to increase the uptake of metals into plants (Salt, Smith, and Raskin 1998). The Indian mustard plant (Brassica juncea) is well known for its ability to 
hyperaccumulate $\mathrm{Pb}$ from soils amended with EDTA. Not only does EDTA increase the uptake of $\mathrm{Pb}$ into $B$. juncea, but it also increases the translocation of $\mathrm{Pb}$ from the roots into the shoots of the plant (Blaylock et al., 1997; Jianwei W. Huang et al., 1997). Ethylenebis[oxyethylenetrinitrilo]tetraacetic acid (EGTA) and (2-Hydroxyethyl) ethylenediaminetriacetic acid (HEDTA) have also been shown to increase the bioavailability of $\mathrm{Cd}$ and $\mathrm{Pb}$ for enhanced accumulation in B. juncea and Zea mays plants respectively (J. W. Huang and Cunningham 1996; Blaylock et al. 1997). The effectiveness of these chelating agents varies depending on the contaminant, soil characteristics, and the plant species.

For phytoremedation purposes, surfactants are chemicals that can decrease the sorption of contaminants to soils and increase the bioavailability of the contaminant. Cyclodextrins, which are non-toxic, biodegradable surfactants used in the food industry, have been shown to enhance the availability of PCBs in soil to improve uptake into plants (Fava, Di Gioia, and Marchetti 1998; Shen et al. 2009). Biosurfactants, such as glycolipids or rhamnolipids, can be used to increase the solubility of organic contaminants and are an appealing alternative to synthetic surfactants because of lower toxicity and enhanced biodegradation (Providenti, Lee, and Trevors 1993).

Harvesting plants to remove contaminants becomes more efficient and economically feasible when using chelating agents and surfactants to increase the rate of phytoextraction and improve translocation within plants. However, care must be taken 
when enhancing the bioavailability of contaminants using chelates/surfactants because the contaminants will also be transported by groundwater or rain more easily.

\subsubsection{Expected Effectiveness of Phytoremediation for COIs at SSFL}

PHCs: Based on published data, phytoremediation of PHCs could be effective. One study showed over $50 \%$ degradation of approximately $7000 \mathrm{ppm}$ of TPH in one year (Phillips et al. 2009). Another study showed over $63 \%$ degradation of $5000 \mathrm{ppm}$ of TPH in only 127 days (Peng et al., 2009). Slower rates have been reported by Banks et al. (2003), with $50 \%$ reduction of $3000 \mathrm{ppm}$ of TPH observed in 870 days. Based on these studies, the time to remediate $5000 \mathrm{ppm}$ of TPH down to the SSFL background level of $5.7 \mathrm{ppm}$ could take between 1.3 and 23 years (assuming first order kinetics).

PAHs: Studies have shown remediation of PAHs through rhizosphere stimulation and even some phytoextraction into the tissue of several different plant species, although phytoextraction was limited (Gao and Zhu 2004; Hall, Soole, and Bentham 2011). For instance, a study by Gao and Zhu (2004) showed that phytoextraction alone contributed to only $0.01 \%$ (phenanthrene) and $0.24 \%$ (pyrene) of the total PAH reduction by plants. The rates of removal vary depending on the specific $\mathrm{PAH}$, the plant species, and concentration of contaminant. The phytoremediation rates for PAHs can be very rapid as shown in one study that removed $67.5 \%$ of pyrene from soil in 28 days (Liste and Alexander 2000). Based on the published studies, phytoremediation of PAHs could reduce soil PAH concentrations at SSFL from $50 \mathrm{ppm}$ (typical value at SSFL) to 0.00447 ppm (background level) on a time scale of 1.5 to 2.7 years. This estimate is based on first order rate constants for various PAHs calculated in a study by Robinson et al. (2003). 
However, slower degradation rates $(9.1 \%$ reduction in a year) have been observed with weathered soil that could indicate a longer remediation time of around 98 years at SSFL based on first order kinetics (Parrish et al., 2004). Clearly phytoremediation rates of PAHs are site specific, and studies would need to be conducted specifically with SSFL soils to provide a narrower estimate of phytoremediation rates at the site.

$\underline{P C B s}$ : Both phytoextraction and rhizoremediation have been shown to be operative mechanisms of remediation of PCBs in soil (Aken et al., 2010). Alfalfa and other plant species have been shown by several studies to extract PCBs from soil (Ficko et al., 2010; Greenwood et al., 2011; Liu \& Schnoor, 2008; Xu et al., 2010; Teng et al., 2010; Zeeb et al., 2006). However, PCB degradation within the plant does not appear to be the primary mechanism of phytoremediation. Several studies have suggested that rhizoremediation was the primary mechanism of PCB degradation at specific field sites, and in these studies stimulated enzyme activity and increased microbial populations in the root zone supported this hypothesis (Chekol et al., 2004; Y. Li et al., 2013; Xu et al., 2010; and Teng et al., 2010). Field and lab studies reported varying phytoremediation rates for PCBs, with rates ranging from $8.1 \%$ removal in 180 days to $77 \%$ removal in 122 days. The type of PCB congener, the plant species, and the PCB concentration impact the rates of removal. Given the observed rates of removal cited in the literature, phytoremediation for PCBs at a soil concentration of 10 ppm could be effective on a time scale of 2 to 50 years assuming first order kinetics and a final concentration of $0.017 \mathrm{ppm}$ (look-up table). Chlorinated Dioxins/Furans: Chlorinated Dioxins are similar to PCBs in their chemical structure and properties but limited research has been done on dioxin phytoremediation. Studies done with zucchini (Cucurbita pepo) have shown that this species can efficiently 
phytoextract dioxins from soil (Campanella \& Paul, 2000; Huelster et al., 1994). Plants can stimulate rhizosphere dioxin degradation in the same way they stimulate PCB rhizosphere degradation (Campanella et al., 2002). The degradation of dioxins through phytoremediation has not been adequately studied to estimate a remediation time scale.

\section{Metals}

Metal phytoremediation can be pursued as an active bioremediation strategy. There is an abundance of studies that show uptake of heavy metals by plants, and it is estimated that over 500 plant taxa are hyperaccumulators of metals (Ent et al. 2013). Phytoremediation can be effective given enough time, proper harvesting, and adequate planting density/speciation, and any necessary amendments such as chelating agents. However, the specific time for complete remediation can be highly variable depending on these factors. 


\section{Chapter 3 Materials and Methods}

\subsection{Phase I: Field Screening}

The purpose of Phase 1 of this study was to identify a list of plant species as candidates for phytoremediation for further testing. Uptake of COIs by plant growing in the field at SSFL was measured as an indicator of phytoremediation potential. Once the best species were identified they would be grown in the Phase II greenhouse experiments.

\subsubsection{Plant Selection and Tagging for Phase I field sampling}

On a site visit in May 2013, various plants species of trees, shrubs, forbs, and grasses were observed growing on the clearly contaminated areas (CCAs) designated by the DOE based on extensive soil sampling. These species, along with some others that have historically grown on the SSFL site, were combined to form a list of potential phytoremediation candidates (Table 3.1). An ' $\mathrm{A}$ ' in a contaminant column indicates that the plant is an analog of a species listed as a potential phytoremediator in the Sandia Study. Plant species were given priority if they fulfilled the following criteria: (1) native to SSFL, (2) candidate for restoring (revegetating) Area IV, (3) abundant enough in Area IV to allow adequate sampling, (4) high rate of growth, (5) known to uptake contaminants. This list was by no means comprehensive, but served as a starting point for this phytoremediation study. 
Table 3.1. Potential phytoremediation candidates at SSFL

\begin{tabular}{|c|c|c|c|c|c|c|c|c|c|c|c|c|c|}
\hline $\begin{array}{l}\text { 2012Jepson } \\
\text { ManualSciName }^{a}\end{array}$ & Common Name & Origin & Habit & Duration $^{b}$ & Restoration $^{c}$ & Abundance $^{\mathrm{d}}$ & $\begin{array}{l}\text { Annual } \\
\text { Growth } \\
\text { Rate }\end{array}$ & Dioxin & PCB & PAH & TPH & Metals & $\mathbf{H g}^{\mathbf{f}}$ \\
\hline Sambucus nigra & Blue Elderberry & Native & Shrub/Tree & Perennial & Yes & Low & Medium & & & & & & \\
\hline Malosma laurina & Laurel Sumac & Native & Shrub & Perennial & Yes & Medium & Medium & & & & & & \\
\hline $\begin{array}{l}\text { Artemisia } \\
\text { californica }\end{array}$ & California Sagebrush & Native & Shrub & Perennial & Yes & Medium & Low & & & & & A & \\
\hline Baccharis salicifolia & Mule-Fat & Native & Shrub & Perennial & Yes & High & Medium & & & & & A & \\
\hline $\begin{array}{l}\text { Deinandra } \\
\text { minthornii }\end{array}$ & Santa Susanna Tarweed & Native & Shrub & Perennial & Yes & Medium & Low & & & & & A & \\
\hline Ericameria palmeri & Palmer Goldenbush & Native & Shrub & Perennial & Yes & High & Medium & & & & & A & \\
\hline $\begin{array}{l}\text { Heterotheca } \\
\text { grandiflora }\end{array}$ & Telegraphweed & Native & Forb & Annual & NO & Medium & High & & & & & A & \\
\hline Hirschfeldia incana & Summer Mustard & Alien & Forb & Perennial & NO & High & High & & & & & A & $\mathrm{A}$ \\
\hline $\begin{array}{l}\text { Acmispon } \\
\text { americanus }\end{array}$ & Spanish Lotus & Native & Forb & Annual & Yes & Low & Medium & & A & A & A & & \\
\hline Acmispon glaber & Common Deerweed & Native & Shrub & Perennial & Yes & Medium & Medium & & $\mathrm{A}$ & A & $\mathrm{A}$ & & \\
\hline $\begin{array}{l}\text { Eriogonum } \\
\text { fasciculatum }\end{array}$ & California Buckwheat & Native & Shrub & Perennial & Yes & High & Medium & & & & & & \\
\hline Salix lasiolepis & Arroyo Willow & Native & Tree/Shrub & Perennial & Yes & Low & Medium & $\mathrm{A}^{\mathrm{e}}$ & $\mathrm{A}$ & & & & A \\
\hline Avena fatua & Wild Oat & Alien & Grass & Annual & NO & High & High & & & & & A & \\
\hline Stipa cernua & Nodding Needlegrass & Native & Grass & Perennial & Yes & Medium & Low & & & & & & \\
\hline Stipa pulchra & Purple Needlegrass & Native & Grass & Perennial & Yes & Low & Low & & & & & & \\
\hline Rhus ovata & Sugar Bush & Native & Shrub & Perennial & Yes & Low & Medium & & & & & & \\
\hline $\begin{array}{l}\text { Asclepias } \\
\text { fascicularis }\end{array}$ & Narrowleaf Milkweed & Native & Forb & Perennial & Yes & Low & Medium & & & & & & \\
\hline
\end{tabular}




\begin{tabular}{|c|c|c|c|c|c|c|c|c|c|}
\hline Baccharis pilularis & Coyotebrush & Native & Shrub & Perennial & Yes & Medium & Medium & & A \\
\hline $\begin{array}{l}\text { Brickellia } \\
\text { californica }\end{array}$ & California Bricklebush & Native & Shrub & Perennial & Yes & Low & Medium & & $\mathrm{A}$ \\
\hline $\begin{array}{l}\text { Corethrogyne } \\
\text { filaginifolia }\end{array}$ & Common Sandaster & Native & Forb & Perennial & Yes & Medium & Medium & & A \\
\hline Erigeron canadensis & Canadian Horseweed & Native & Forb & Annual & NO & Medium & High & & A \\
\hline $\begin{array}{l}\text { Pseudognaphalium } \\
\text { californicum }\end{array}$ & California Cudweed & Native & Forb & Perennial & Yes & Medium & High & & $\mathrm{A}$ \\
\hline $\begin{array}{l}\text { Eriodictyon } \\
\text { crassifolium }\end{array}$ & Thickleaf Yerba Santa & Native & Shrub & Perennial & Yes & High & Medium & & \\
\hline Ribes malvaceum & Chaparral Current & Native & Shrub & Perennial & Yes & Low & Medium & & \\
\hline Salvia leucophylla & Purple Sage & Native & Shrub & Perennial & Yes & Medium & Medium & & \\
\hline Salvia mellifera & Black Sage & Native & Shrub & Perennial & Yes & Medium & Medium & & \\
\hline Rhamnus ilicifolia & Hollyleaf Redberry & Native & Shrub & Perennial & Yes & Low & Medium & & \\
\hline Prunus ilicifolia & Hollyleaf Cherry & Native & Tree/Shrub & Perennial & Yes & Medium & Medium & & \\
\hline Avena barbata & Slender Wild Oat & Alien & Grass & Annual & NO & High & High & & A \\
\hline Bromus diandrus & Ripgut Brome & Alien & Grass & Annual & NO & High & High & A & A \\
\hline Bromus hordeaceus & Soft Chess & Alien & Grass & Annual & NO & High & High & A & A \\
\hline Bromus madritensis & Red Brome & Alien & Grass & Annual & NO & High & High & A & A \\
\hline
\end{tabular}

${ }^{a}$ Scientific name from the 2012 Jepson Manual: Vascular Plants of California

${ }^{\mathrm{b}}$ Duration indicates the life expectance of the plant

${ }^{c}$ These plants could be used to restore the vegetation of Area IV

${ }^{d}$ The plant abundance in Area IV as observed during May $30^{\text {th }}, 2013$ site visit

e The 'A' indicates that the plant is analogous to a species show to uptake this contaminant and identified by the Sandia Study

${ }^{\mathrm{f}} \mathrm{Hg}$ is the abbreviation for mercury 
After the list was developed, it was further narrowed to nine species that would actually be sampled and analyzed for COIs. Three of each plant species growing in contaminated soil and one of each species growing in uncontaminated soil was needed for harvesting and analysis. The contaminated areas were selected based on the following target contaminant concentrations: TPH 500ppm, PAH 1000ppb, PCBs 1000 ppb, chlorinated dioxins/furans 100 ppt, mercury, silver, lead, and zinc at levels exceeding the Look-Up Table values. The potential control locations were based on previous sampling data points with COI concentrations less than or equal to twice the Look-Up Table value. Using the dataset from CDM Smith, the data were screened to identify concentrations of COIs measured at previous sample locations that fit both the contaminated criteria and control criteria. This process identified suitable previous sampling locations in Area IV so that the near vicinity could be searched for the contaminated or control specimens. HSA $5 \mathrm{~A}, 5 \mathrm{~B}, 5 \mathrm{C}$, were selected as areas in which to search for plant species in contaminated soil. For the control spots the locations of suitable and unsuitable previous sampling points were mapped using the GIS software ArcMap 10.1. Figure 3.1 shows the locations of suitable and unsuitable control sample points. Control points located in BZNW were chosen for the control area for plant specimens. 


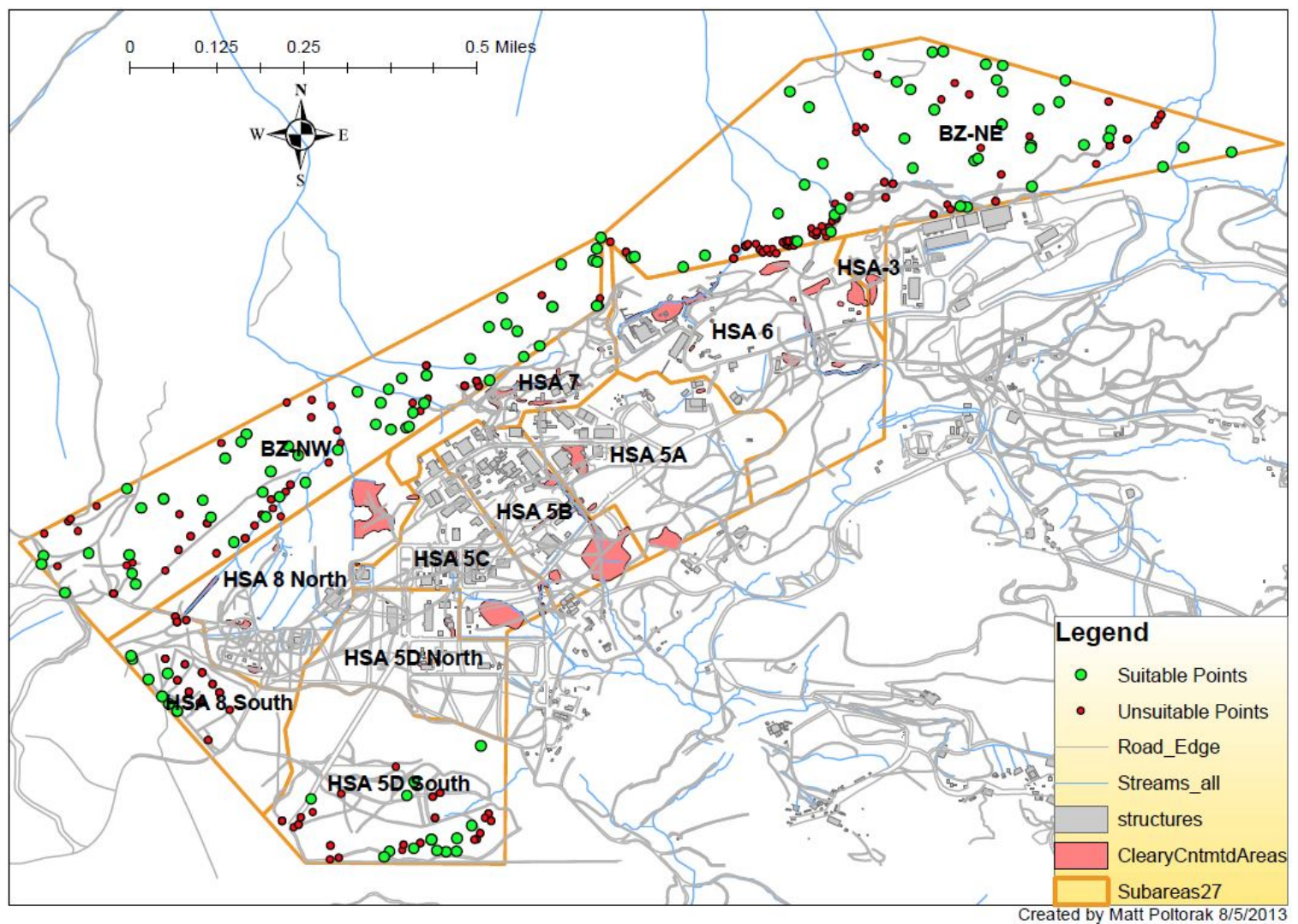

Figure 3.1. Suitable and unsuitable sampling points for plant control sampling in SSFL Area IV

These criteria were used during a site visit on August 8, 2013 to find a mix of shrubs, forbs, and grasses from Table 3.1 that were suitable for sampling. Nine plant species were selected for screening: Purple Needlegrass (Stipa cernua), Blue Elderberry (Sambucus nigra), Laurel Sumac (Malosma laurina), Mule Fat (Baccharis salicifolia), Palmer's Goldenbush (Ericameria palmeri), Summer Mustard (Hirschfeldia incana), Narrowleaf Milkweed (Asclepias fascicularis), Coyote Brush (Baccharis pilularis), and Thickleaf Yerba Santa (Eriodictyon crassifolium). Plants found to be growing in Area IV were labeled using flagging tape and the GPS coordinates recorded. Plant specimens were labeled with a number (1 through 32 ) based on their position in Table 3.1, and a letter (A-D) for each separate specimen within the sample species (Note: Purple 
Needlegrass was accidently actually labeled as \#35, when it was actually \#15). Control specimens were labeled with the letter D. For example, the control specimen for Blue Elderberry was labeled Specimen 1D. Green plants of moderate size were tagged while dried plants were not tagged because some contaminants are likely to have escaped during the drying process. If a tagged plant was no longer suitable for sampling at the actual date of sampling, then a new specimen was found and labeled by adding an additional letter to the tag. For example, Narrowleaf Milkweed 17A was changed to 17AA. Figure 3.2 shows the locations of the plants tagged on August 13, 2013. 


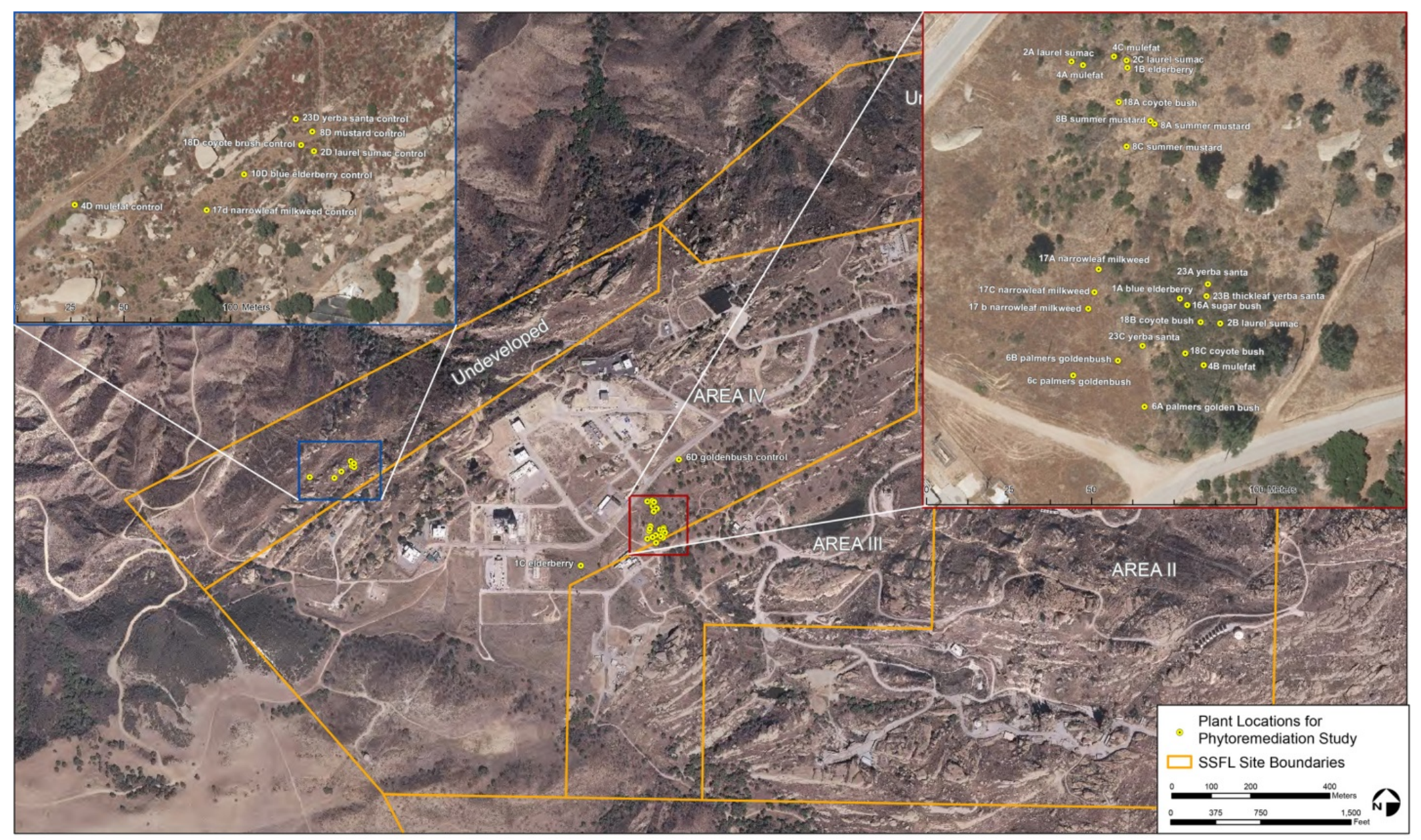

Vegetation Monitoring Sites for Cal Poly

Figure 3.2. Location of tagged plants in Area IV on August 13, 2013 


\subsubsection{Seed Collection}

Seed was collected for propagation of some of the candidate species for the controlled growth experiments. Since the seeds of the candidate species matured at different times, seed collection was conducted at several different times over the period May to November 2013. Seeds from grasses were collected by grasping the grass tops and shaking/hand massaging the seeds into a labeled paper bag. Seeds from forbs and shrubs were collected by grasping the seeded portion of the plant and shaking/picking seeds from the plant into a labeled plastic bag. Seeds were stored in a cool dry place in the EPEL laboratory on the Cal Poly campus.

\subsubsection{Plant Tissue and Root-Zone Soil Sampling}

All of the tagged plant specimens and their root-zone soil were sampled and analyzed for COIs. Due to the different growing seasons of the candidate plants, the soil and plant tissue were collected on two different sampling events so that tissue samples were collected during periods of plant growth when contaminant uptake was expected to be the greatest. The roots and above-ground mass (AGM), comprised of stem and leaves, were analyzed separately.

The whole plant, including roots, was removed from the soil using a stainless steel shovel decontaminated between composite samples. The soil attached to the roots of the plant was brushed into a stainless steel collection bowl. Soil from around the root zone was added to the collection bowl to meet the required mass for the soil sample listed in Table 
3.2. The soil taken from the root zones of the plants was homogenized using the cone and quarter method in the onsite DOE workstation.

After the soil samples were collected, the AGM portion of the plant was separated from the roots with stainless steel plant clippers that were decontaminated between plant samples. Both parts of the plant were placed into separate Ziploc bags and transported to the onsite DOE lab. Once in the lab, any soil attached to the foliage of the plant was rinsed off using deionized (DI) water. The DI water was transported to the site for use in the field sampling events. The cleaned plant was air dried by resting on a paper towel for 1 hour inside an on-site DOE workstation. A composite tissue sample was prepared by cutting stems and leaves from different areas of the plant to meet the mass requirements (Table 3.2). The aliquots were weighed using a balance to ensure sufficient mass was collected, placed in a wide-mouth, 500-mL glass container, and stored in a cooler at $<4^{\circ} \mathrm{C}$. A portion of the collected tissue was set aside for Lancaster laboratories to perform the dioxin/furan, total organic carbon (TOC), moisture, and total nitrogen analysis. The rest of the analytes were analyzed by EMAX laboratories using the remaining plant tissue.

Once in the DOE laboratory, the roots of the plant were soaked in a bucket of DI water and carefully scrubbed with a vegetable brush to separate the roots from any remaining soil. The brush was decontaminated between samples. The cleaned roots were air dried by resting on a paper towel in a shady spot for 1 hour inside the DOE laboratory. A composite sample was prepared by cutting roots from different areas of the plant to meet 
the mass requirements (Table 3.2). The aliquots were weighed using a balance to ensure sufficient mass was collected, placed in a wide mouth 500-ml glass container, and stored in a cooler at $<4{ }^{\circ} \mathrm{C}$. A portion of the collected tissue was set aside for Lancaster laboratories to perform the dioxin/furan, total organic carbon (TOC), moisture, and total nitrogen analysis. The rest of the analytes were analyzed by EMAX laboratories using the remaining plant tissue. The analytical methods used by the laboratories are listed in Table 3.3 .

Table 3.2. Required sample mass for analytical methods

\begin{tabular}{|c|c|c|c|c|c|c|}
\hline & \multicolumn{4}{|c|}{ Laboratory } \\
\hline & & & \multirow{2}{*}{$\begin{array}{l}\text { Day 0 } \\
\text { Soil/Plants }\end{array}$} & \multirow{2}{*}{\begin{tabular}{|l|} 
Day 85 \\
Soil
\end{tabular}} & \multicolumn{2}{|c|}{ Day 211} \\
\hline Contaminant & Soil $^{\text {a }}(\mathrm{g})$ & \begin{tabular}{|l|} 
Plant \\
Tissue (g)
\end{tabular} & & & Soil & Plants \\
\hline PCB & 30 & 5 & EMAX & EMAX & Lancaster & EMAX \\
\hline PAH & 30 & 5 & EMAX & EMAX & Lancaster & EMAX \\
\hline TPH & 15 & 5 & EMAX & EMAX & Lancaster & N/A \\
\hline Metals & 5 & 3 & EMAX & EMAX & Lancaster & EMAX \\
\hline Mercury & 3 & 3 & EMAX & EMAX & Lancaster & EMAX \\
\hline Dioxin & 10 & 5 & Lancaster & Lancaster & Lancaster & EMAX \\
\hline Moisture & 10 & N/A & Lancaster & Lancaster & Lancaster & N/A \\
\hline Nitrogen & 75 & N/A & Lancaster & Lancaster & Lancaster & N/A \\
\hline $\begin{array}{l}\text { Organic } \\
\text { Carbon }\end{array}$ & 50 & N/A & Lancaster & Lancaster & Lancaster & N/A \\
\hline Total & 228 & 26 & & & & \\
\hline
\end{tabular}

${ }^{\mathrm{a}}$ These masses are based on an estimated soil moisture of $12 \%$

${ }^{\mathrm{b}}$ Plant tissue was not sampled on Day 85 
The minimum amount of plant tissue required was 26 grams, but 100 grams were collected as a safety factor. When there was insufficient plant tissue to obtain the required 100 grams, two or more plants in close proximity were collected and homogenized by the contracted laboratories according to their standard procedures.

Table 3.3. EPA methods used to analyze soil and plant samples

\begin{tabular}{|l|l|l|}
\hline Contaminant & Soil & Plant Tissue \\
\hline PCB & EPA Method 1613B & EPA Method 1668C \\
\hline Dioxin & EPA Method 1613B & EPA Method 1613B \\
\hline PAH & EPA Method 8270C/D SIM & $\begin{array}{l}\text { Gas Chromatograph/ High } \\
\text { Resolution Mass Spectroscopy } \\
\text { (GC/HRMS): EPA Method }\end{array}$ \\
\hline TPH & EPA Method 8015B/C/D & $\begin{array}{l}\text { Gas Chromatograph/Flame } \\
\text { Ionization Detector (GC/FID): EPA } \\
\text { Method }\end{array}$ \\
\hline Mercury & $\begin{array}{l}\text { CVAAS: cold vapor atomic } \\
\text { absorption spectroscopy } \\
\text { (EPA Method 7471A) }\end{array}$ & $\begin{array}{l}\text { Cold Vapor Atomic Absorption } \\
\text { (CVAA): EPA Method }\end{array}$ \\
\hline Metals & $\begin{array}{l}\text { EPA Method } \\
\text { 6010C/6020A/7471A }\end{array}$ & $\begin{array}{l}\text { Inductively Coupled Plasma/High } \\
\text { Resolution Mass Spectroscopy } \\
\text { (ICP/HRMS): EPA Method }\end{array}$ \\
\hline
\end{tabular}

\subsection{Phase II: Microcosm Experiments}

\subsubsection{Soil Collection for Microcosms}

Sixty-five gallons of contaminated soil from HSA 5B was collected for use in the microcosm experiments. The top few inches of soil and debris was scraped away using a stainless steel shovel and soil was gathered from a maximum depth of two feet. The soil was mixed in a large container in the field using stainless steel shovels (Figure 3.3). A gallon of DI water was added during mixing to reduce dust formation. The soil was then 
transported to Cal Poly in Teflon-lined 5-gallon buckets. Soil was sieved through a \#4 sieve ( $4.750 \mathrm{~mm}$ openings) to remove debris or large rocks.

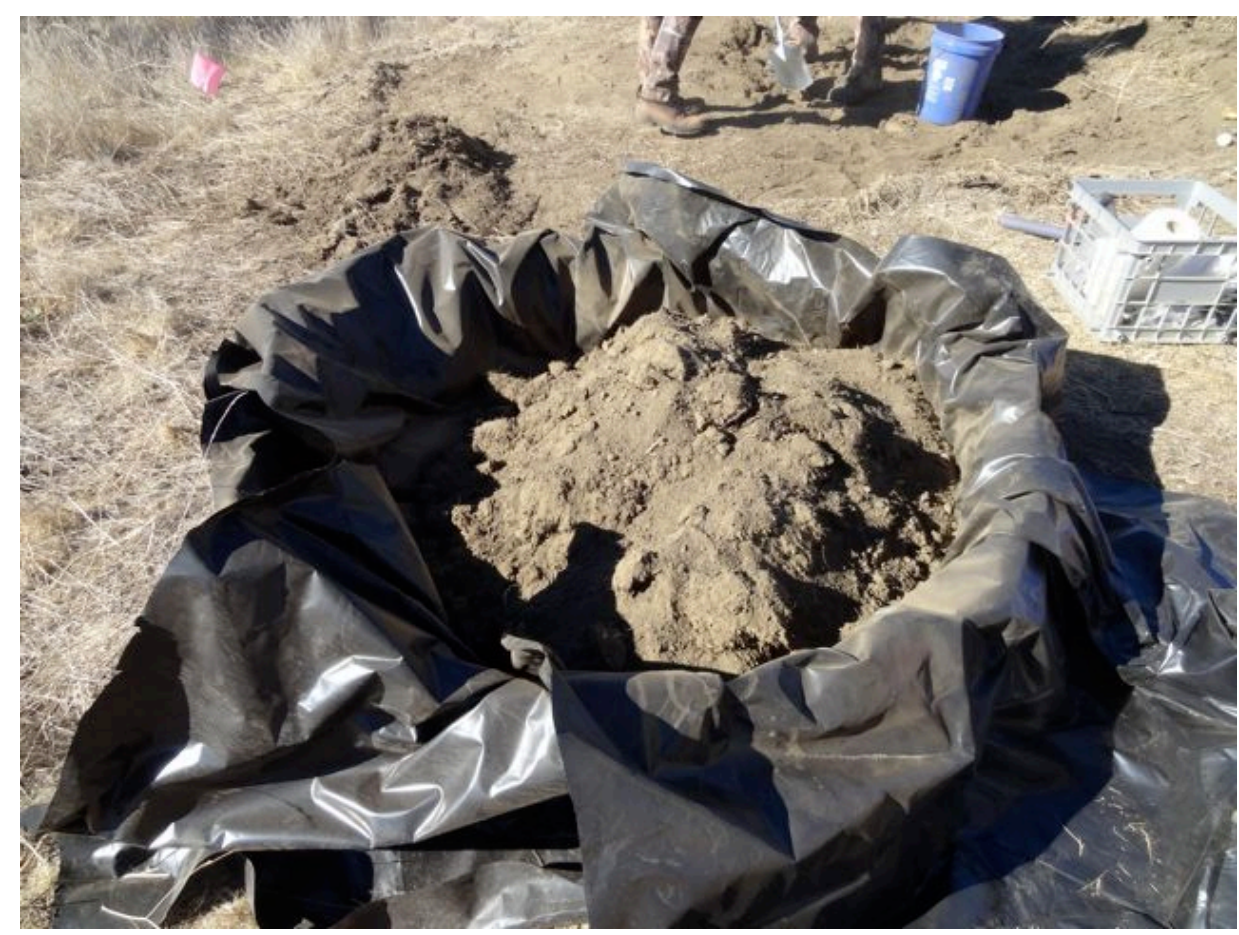

Figure 3.3. Collection of bulk soil for microcosm experiment

\subsubsection{Microcosm Soil Homogenization}

After sieving, additional homogenization was performed using stainless steel shovels.

The soil was separated into four piles, then piles opposite to each other were mixed until one large pile was formed. This process was repeated for several hours to complete the homogenization process (Figure 3.4). 


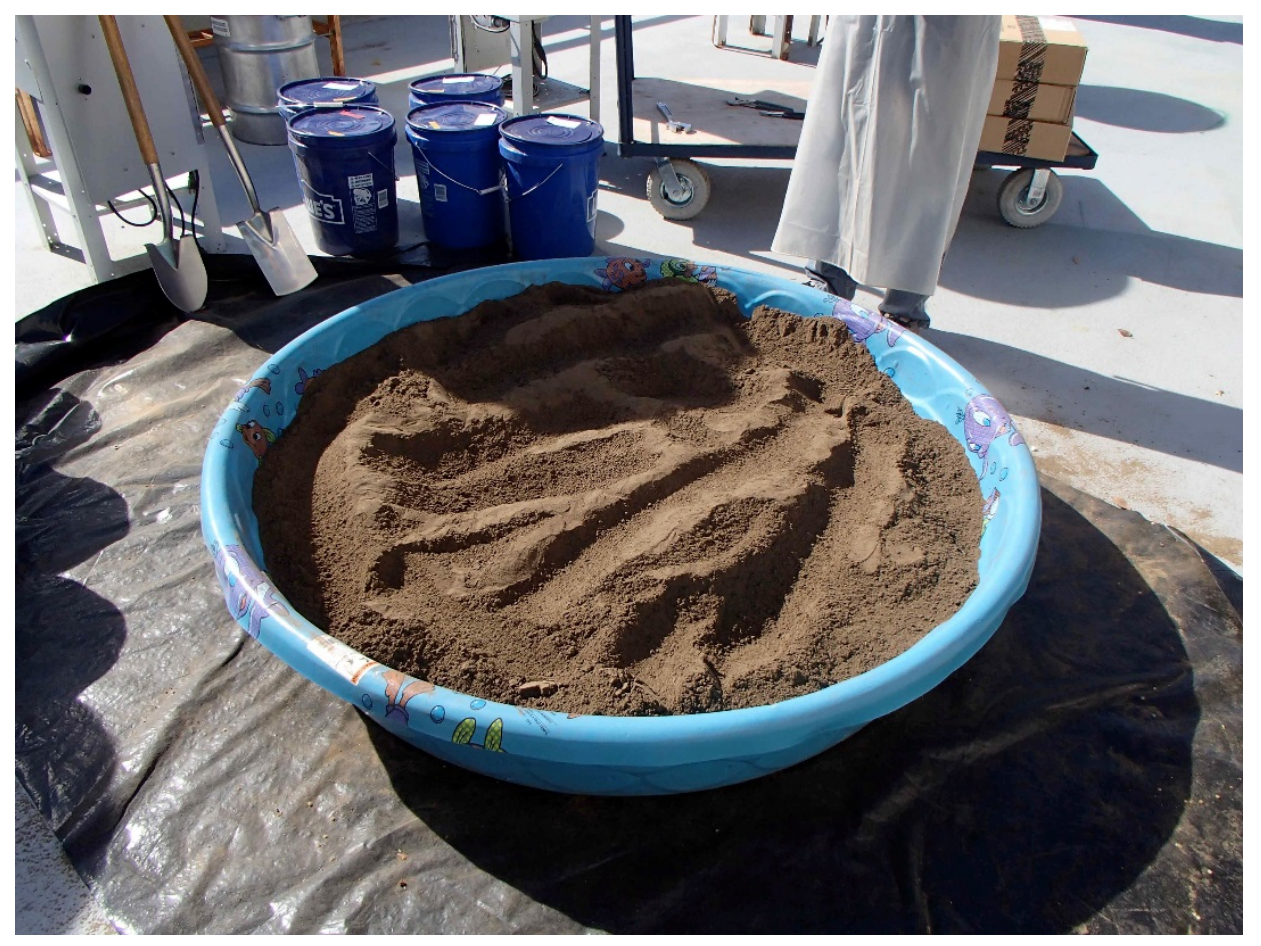

Figure 3.4. Bulk homogenized soil

\subsubsection{Analytical Methods}

The analytical methods used to analyze the microcosm soil and plant tissue are identical to those used for Phase I field sampling (Table 3.3). For volatilization sampling a modified EPA Standard Method \#3550 was used. Section 3.2.8 describes this method in greater detail.

\subsubsection{Decontamination of Sampling Equipment}

All tools that were used during the preparation or sampling in the field or for the laboratory microcosms were decontaminated. An Alconox ${ }^{\circledR}$ detergent solution was prepared in a plastic bucket. The tools were scrubbed thoroughly in the bucket with a sponge soaked in Alconox ${ }^{\circledR}$ solution. The washed tools were then rinsed with DI water and dried with a paper towel. The tools were decontaminated at the following times: (1) 
before contact with the microcosm (2) between duplicate sampling in a microcosm (3) between the sampling of two separate microcosms and (4) before storing the tools.

\subsubsection{Microcosm Construction}

A gallon glass jar served as the microcosm container. Since there was no drainage port, glass marbles were placed at the bottom of the jar and overlaid with a fiberglass to support the soil mass above. This created airspace for water to seep into and await uptake or evaporation. This allowed the soil to be watered and stay aerobic by keeping the soil separate from standing water. A hollow glass tube was inserted from the top of the soil down to the fiberglass mesh to provide passive airflow to prevent anaerobic conditions. Glass was used because it does not react with the COIs or exude any additional contaminants into the soil. All of the glass was washed with an Alconox ${ }^{\circledR}$ solution and then with $10 \%$ nitric acid before contacting the soil from the site. A planted microcosm is depicted in Figure 3.5 and the actual microcosm is shown in Figure 3.6. 


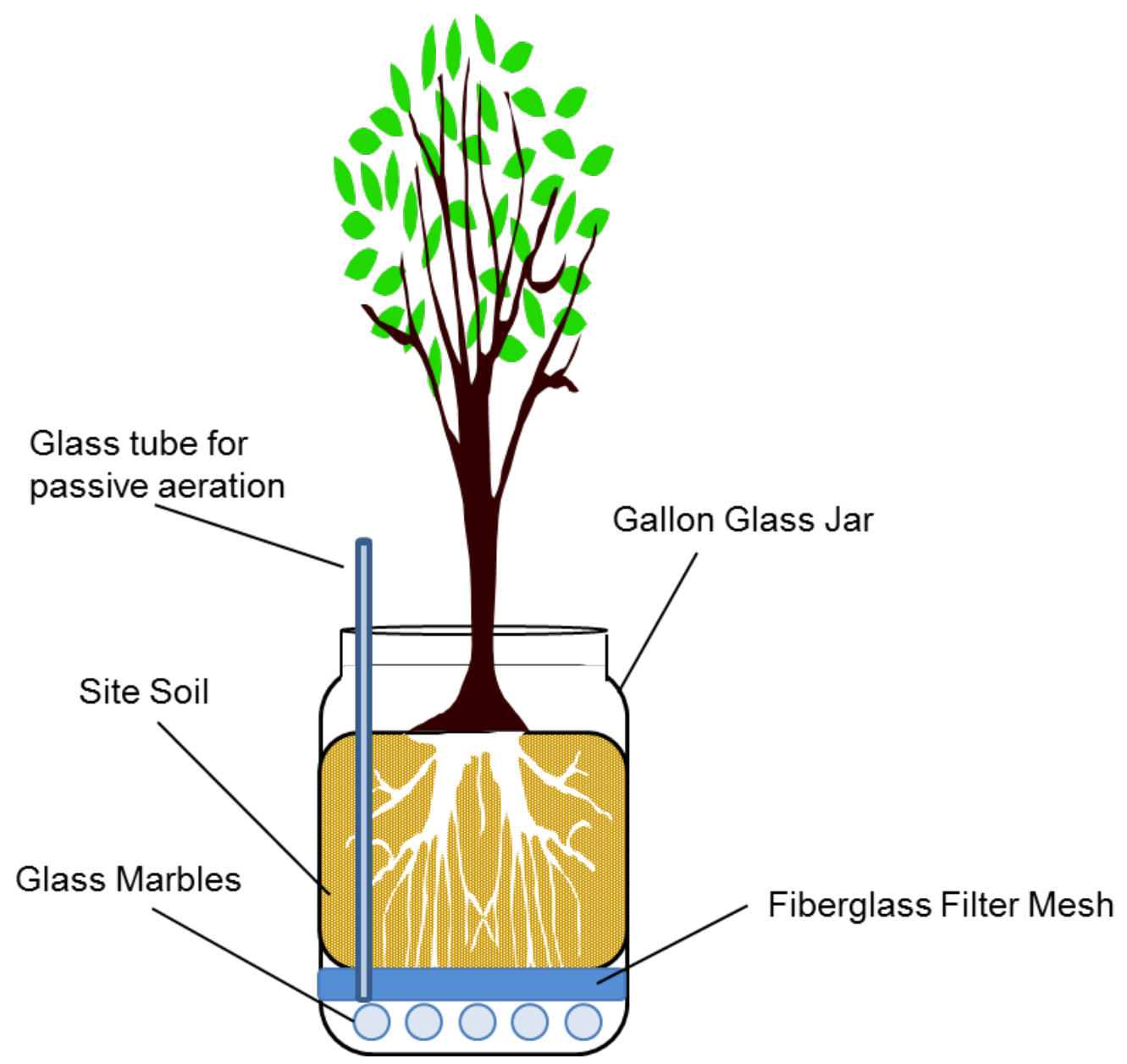

Figure 3.5. Planted Microcosm 


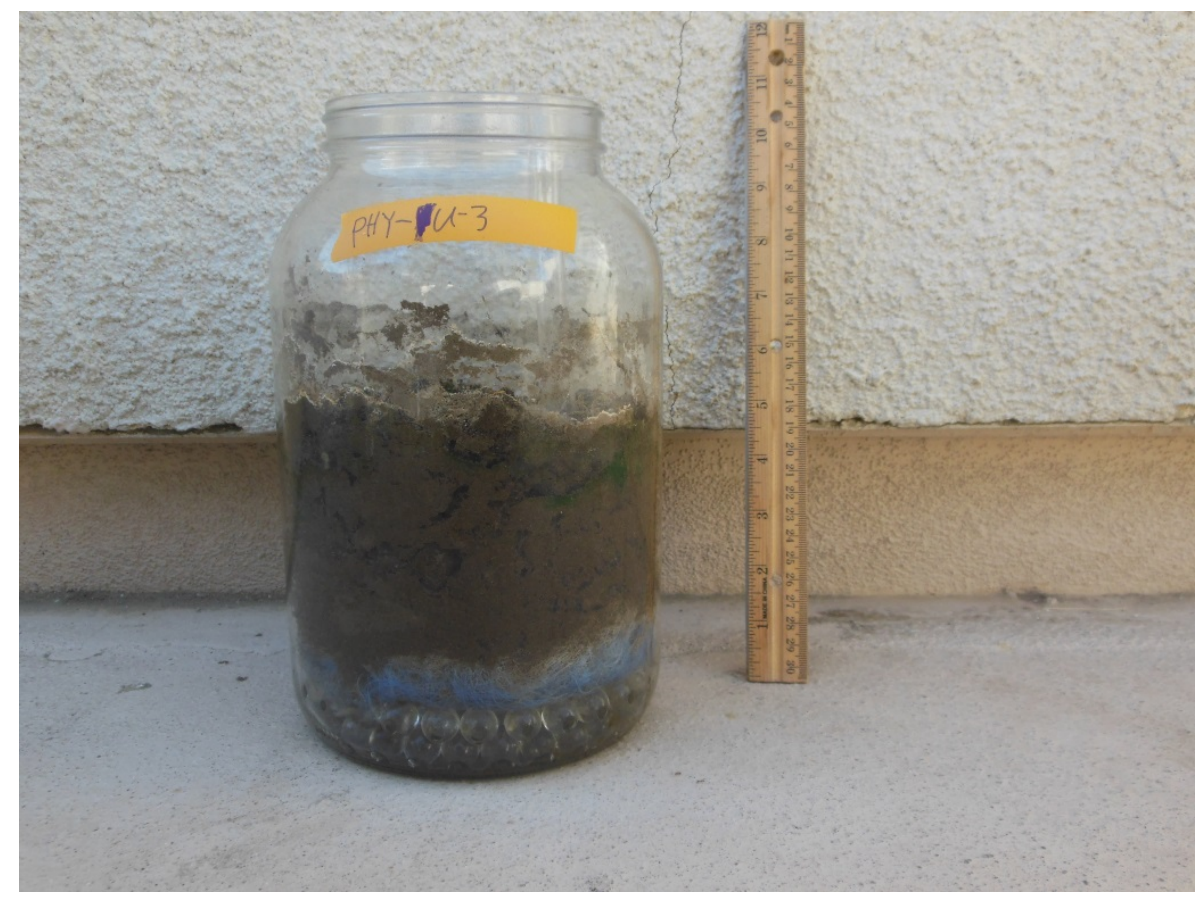

Figure 3.6. Microcosm profile view

\subsubsection{Microcosm Overview}

The microcosms used in the controlled laboratory growth experiments were designed to mimic the following Area IV field conditions:

1. Temperature

2. Humidity

3. Sunlight

4. Soil moisture

5. Soil type

This Phase II of the experimental plan consisted of 40 total microcosms. Three plant species exhibiting the greatest contaminant uptake in the field based on the Phase I analytical results were selected for growth in laboratory microcosms to determine phytoremediation rates and mechanisms. Coyote Brush (Baccharis pilularis), Mule Fat 
(Baccharis salicifolia), and Purple Needlegrass (Nassella pulchra) species were chosen and grown with 5 replicates for each microcosm treatment (Table 3.4).

Table 3.4. Overview of the microcosm laboratory experiment

\begin{tabular}{|c|c|c|c|c|}
\hline $\begin{array}{l}\text { Sample } \\
\text { Identification }\end{array}$ & $\begin{array}{l}\text { Plant tissue } \\
\text { sampled? }\end{array}$ & $\begin{array}{l}\text { Chelating } \\
\text { additive? }\end{array}$ & $\begin{array}{l}\text { TRF }^{\mathrm{a}} \\
\text { analysis? }\end{array}$ & $\begin{array}{l}5 \text { extra } \\
\text { microcosms? }\end{array}$ \\
\hline Coyote Brush & Yes & No & No & Yes \\
\hline Mule Fat & Yes & No & No & Yes \\
\hline $\begin{array}{l}\text { Purple } \\
\text { Needlegrass }\end{array}$ & Yes & No & Yes & Yes \\
\hline $\begin{array}{l}\text { Coyote Brush } \\
\text { w/fertilizer }\end{array}$ & Yes & No & No & Yes \\
\hline $\begin{array}{l}\text { Coyote Brush } \\
\text { w/chelation }\end{array}$ & Yes & Yes & No & Yes \\
\hline $\begin{array}{l}\text { Purple } \\
\text { Needlegrass } \\
\text { Sterilized Planted } \\
\text { Control }\end{array}$ & Yes & No & Yes & Yes \\
\hline Unplanted Control & No & No & Yes & No \\
\hline $\begin{array}{l}\text { Sterilized } \\
\text { Unplanted Control }\end{array}$ & No & No & Yes & No \\
\hline
\end{tabular}

One microcosm set (5 replicates, plus 5 extra for microcosms containing plants) of each of the three species was planted in the microcosm soil with no amendment additions or sterilization. One set of Coyote Brush microcosms was fertilized with Miracle-Gro ${ }^{\circledR}$ to increase the nutrients available and allow for the production of the maximum amount of biomass for tissue analysis in the short time frame of this study. The active constituents of Miracle-Gro ${ }^{\circledR}$ are nitrogen $24 \%$, Phosphate $\left(\mathrm{P}_{2} \mathrm{O}_{5}\right) 8 \%$, soluble potash $\left(\mathrm{K}_{2} \mathrm{O}\right) 16 \%$, 
boron $2 \%$, soluble copper $0.07 \%$, chelated iron $0.15 \%$, chelated manganese $0.05 \%$, molybdenum $0.0005 \%$, and soluble zinc $0.06 \%$. Miracle-Gro ${ }^{\circledR}$ fertilizer was dissolved in DI water and added in 5 doses for a final concentration of $0.237 \mathrm{~g}$ fertilizer $/ \mathrm{kg}$ of soil. The chelating agent EDTA was added to another set of Coyote Brush microcosms to test if it aided in the phytoremediation process by increasing the bioavailability of metals in the microcosm soil. Hydrated ethylenediaminetetraacetic acid $\left(\mathrm{C}_{10} \mathrm{H}_{12} \mathrm{~N}_{2} \mathrm{O}_{8} \mathrm{Na}_{4}\right)$ with a drying loss of $9.4 \%$ and a molecular weight of $380.2 \mathrm{~g} / \mathrm{mol}$ was dissolved in DI water and added in 4 doses for a final concentration of $6 \mathrm{mmol}$ EDTA $/ \mathrm{kg}$ of soil. A set of unplanted microcosms was operated with soil from the site to observe biodegradation rates associated with soil microbes only, without any phytoremediation mechanisms. The results from the unplanted soil control were compared with those from the planted microcosms to determine biodegradation rates in soil independently from any plant effects.

Sterilized controls were also run using soil sterilized by gamma irradiation using cobalt60 from the Sterigenics sterilization facility in Gilroy, CA. The soil was irradiated until it was exposed to at least $25 \mathrm{kGy}$ (and as high as $62 \mathrm{kGy}$ ). Purple Needlegrass was selected for growth in one sterilized set because it exhibited greatest rhizostimulation potential indicated by the literature review. The other sterilized microcosm set was unplanted and covered with a lid to prevent the escape of contaminants. The two purposes of these sterilized controls were (1) to help elucidate the mechanisms of phytoremediation by comparing biodegradation rates in planted microcosms with and without active soil microbes, thus quantifying the role of the soil microbes in contaminant degradation, and 
(2) to control for any abiotic contaminant losses from unplanted sterile soil using the same experimental set-up.

The combined results of the sterile unplanted controls, sterile planted controls and planted microcosms with active soil microbes were used to test for stimulation of microbial biodegradation by the plants. By simply comparing planted to unplanted (both with active microbes), any additional contaminant loss in the soil with plants could either be from the plant stimulating the soil microbes or the plant itself extracting or degrading the contaminants. However, by comparing results from the plant in sterile soil to the plant in soil with active microbes, the role of the plant could be identified. By the difference in contaminant concentrations in the microcosms, any increase in microbial degradation in the soil due to phytostimulation of the microbial community could be observed.

The effect of plants on the microbial community of the root zone was characterized by comparing terminal restriction fragment (TRF) analyses on soils from the plant root zone to control soils without plants (from the microcosm experiments). The TRF method uses restriction enzymes to produce different lengths of DNA associated with each bacterial/fungal species. The differences in patterns of these DNA strands were used to compare the microbial community structure of planted and unplanted soil. This was used to provide possible evidence for phytostimulation of root-zone biodegradation. 


\subsubsection{Midpoint Microcosm Sampling (85 days)}

The midpoint microcosm soil-sampling event was conducted on June 18 and 19, 2014, about 85 days after planting. Table 3.5 lists all of the microcosm treatments that were sampled. The following procedure was used to sample each type of microcosm:

1. The soil samples were taken from an area between the three plants and from a depth of 0.0 to $0.5 \mathrm{ft}$ with as little disturbance of the plants as possible. It was impossible to avoid the grass during the sampling as it covered the entire soil surface.

2. Two stainless steel spoons were used to scoop soil from the microcosms into the sampling jars.

3. At least $120 \mathrm{~g}$ of soil was collected in an 8-oz jar for Lancaster, and at least $40 \mathrm{~g}$ of soil was collected in a 4-oz jar for EMAX for each microcosm jar. Samples were weighed using a GEOTEST balance.

4. The stainless steel spoons were decontaminated between microcosm types

5. Steps 1-4 were repeated for each type of microcosm

6. For the Purple Needlegrass soil was taken carefully to avoid disrupting the grass. Any grass that was ripped out was placed back into the jar.

7. Duplicate soil samples were taken from PA05 and U05 jars for QA/QC.

For transport the $4 \mathrm{oz}$ and $8 \mathrm{oz}$ jars were placed into padded bags and sealed in a quart sized Ziploc bag. An equipment blank was prepared for the sampling event by running DI water over the stainless steel spoons and into the sample jar. The samples were shipped on ice with a holding time of two days allowed. 
Table 3.5. List of sampled microcosms

\begin{tabular}{|l|l|r|r|}
\hline & Sampled Microcosm Types & & \\
\hline Label & Description & $\begin{array}{l}\text { Number of jars } \\
\text { sampled }\end{array}$ & \multicolumn{1}{l|}{ Date Sampled } \\
\hline PHY-PA-1 & Unamended Coyote brush & 5 & $6 / 18 / 19$ \\
\hline PHY-PB-1 & Unamended Mule-fat & 5 & $6 / 18 / 19$ \\
\hline PHY-PC-1 & Unamended Purple needlegrass & 5 & $6 / 18 / 19$ \\
\hline PHY-CPA-1 & Chelated Coyote brush & 5 & $6 / 18 / 19$ \\
\hline PHY-FPA-1 & Fertilized Coyote brush & 5 & $6 / 19 / 14$ \\
\hline PHY-SP-1 & Sterilized Purple needlegrass & 5 & $6 / 18 / 19$ \\
\hline PHY-U-1 & Unplanted & 5 & $6 / 19 / 14$ \\
\hline & Total & 35 & \\
\hline
\end{tabular}

\subsubsection{Phytovolatilization}

A microcosm apparatus was constructed to test for the phytovolatilization of COIs. The

apparatus consisted of a dual port Tedlar ${ }^{\circledR}$ bag that was cut open on one end to fit over the plant and around the opening of the microcosm jar. The bag was sealed around the rim of the jar using foam strips overlaid on the outside of the bag and tightened against the jar using zipties and a hose clamp (Figure 3.7). An aquarium pump was attached to a sorbent tube (Anasorb CSC, coconut charcoal, 6 X $70 \mathrm{~mm}$ size, 2-section, 50/100 mg sorbent) which was attached to the inlet port on the Tedlar ${ }^{\circledR}$ bag. The pump would push ambient air through the first sorbent tube and then start to fill up the bag. Once the pressure in the bag built up, any volatilized contaminants would travel through the exit port and be captured in another carbon sorbent tube. All connections were made with Teflon ${ }^{\circledR}$ tubing. 


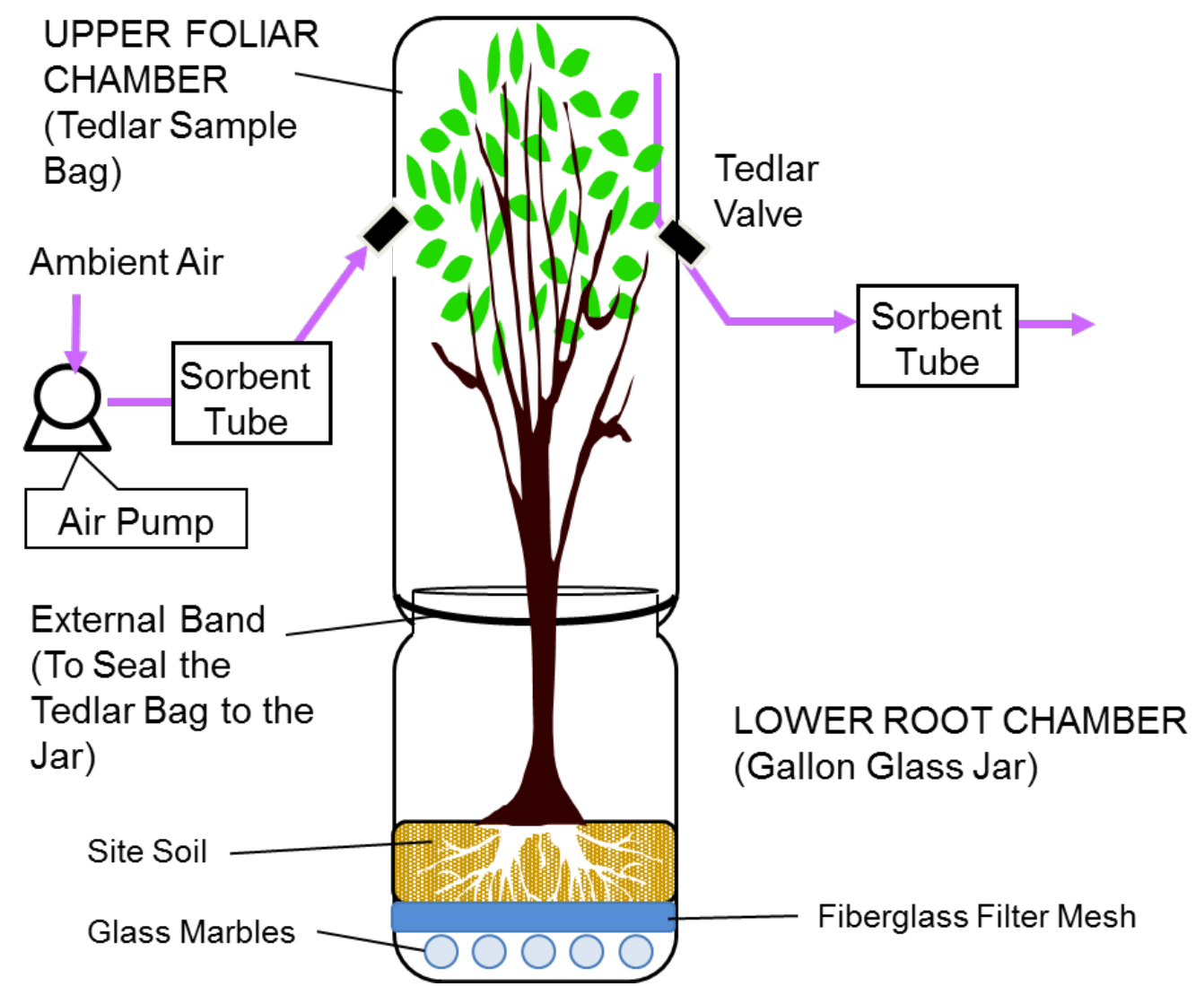

Figure 3.7. Phytovolatilization sampling setup

The flow rate and duration used for phytovolatilization sampling varied greatly in the literature. The target flow rate for this volatilization testing was between $10 \mathrm{~mL} / \mathrm{min}$ to $200 \mathrm{~mL} / \mathrm{min}$ based on the NIOSH 1500 air sampling method for hydrocarbons.

Microcosms from the different treatments were sampled for 5 days. The flow rate was not constant through the 5-day sampling because of leaks around the rim of the jar. The flow rate out of the exit sorbent tube was measured once each day using a BIOS DryCal DC-2 Air Flow Calibrator with a model DC-MC-1 flow cell, and then the daily values were averaged (Table 3.6). 
Table 3.6. Average flow rates for microcosm phytovolatilization sampling

\begin{tabular}{|l|l|}
\hline Treatment & Average Flow Rate (mL/min) \\
\hline Planted Coyote Brush & 75 \\
\hline Planted Mule Fat & 74 \\
\hline Planted Needlegrass & $<10$ \\
\hline $\begin{array}{l}\text { Chelated Coyote } \\
\text { Brush }\end{array}$ & 21 \\
\hline Unplanted & 183 \\
\hline Empty Jar (no soil) & 92 \\
\hline
\end{tabular}

The extract of contaminants from the sorbent material was a modified version of the EPA Standard Method \#3550. The sorbent was placed in a $100-\mathrm{mL}$ sample bottle and $2 \mathrm{~mL}$ of 5-g/L hexacosane in methylene chloride $(\mathrm{MeCl})$ was added to the sample to serve as an internal recovery standard. $25 \mathrm{~mL}$ of $\mathrm{MeCl}$ was added to the sample bottle containing the sorbent and sonicate for $3 \mathrm{~min}$ at $60,000 \mathrm{~Hz}$ using a Sonifier 250 (Branson Ultrasonics Corp., Danbury, Connecticut). Sodium sulfate $\left(\mathrm{Na}_{2} \mathrm{SO}_{4}\right)$ was added to the extract solution to absorb any moisture. The extract solution was filtered through a 24-cm (diameter) 802 Fluted Grade Whatman filter paper mounted in a glass funnel with sodium sulfate to remove water from the extracts. The final solution was filtered through a Millipore API 04200 glass fiber filter into a test tube. The extraction was repeated with another $25 \mathrm{~mL}$ of $\mathrm{MeCl}$ added to the sorbent sample. The sample was sonicated and filtered as be as described above and the filtrate was added to the previous $25 \mathrm{~mL}$ of $\mathrm{MeCl}$ for a total 
extract volume of about $50 \mathrm{~mL}$. The extract solution was pipetted into a 2-mL vial with Teflon-lined crimp seal.

Samples from each extract were run through an Agilent Technologies 6890N Gas Chromatograph (splitless inlet) with an Agilent 5975B inert Mass Selective Detector. A 50-m fused silica column 250 microns in diameter was used (Agilent Catalog \#19091S433) in the chromatograph. Samples were automatically loaded using an Agilent 7683B Series Injector capable of holding eight GC vials, two solvent vials, and a waste vial. The sample injection volume was $2 \mu \mathrm{L}$ from a $10-\mu \mathrm{L}$ syringe. To ensure no samples were cross-contaminated, the Agilent Injector was programmed to rinse the syringe twice with $\mathrm{MeCl}$ before taking sample extract from the $\mathrm{GC}$ vial. The temperature ramped from $45^{\circ} \mathrm{C}$ to $275^{\circ} \mathrm{C}$ at a rate of $12^{\circ} \mathrm{C}$ per minute and was then held at $275^{\circ} \mathrm{C}$ for the remainder of the 34-minute run time. The front inlet where the samples were injected was pressurized to $12.26 \mathrm{psi}$ at a temperature of $200^{\circ} \mathrm{C}$. Helium was used as the carrier gas.

\subsubsection{Final Microcosm Sampling (211 days)}

The final microcosm sampling event was conducted on October $15^{\text {th }}$ and $16^{\text {th }}, 2014$, about 126 days after the midpoint sampling event and 211 days after planting. All of the microcosm treatments were sampled. Each of the planted microcosms had 10 replicates available for sampling. Replicates within each treatment group were combined to ensure that there was sufficient root mass for the laboratory analysis. For instance, soil, roots, and foliage from the chelated Coyote Brush replicates CPA01, CPA03, and CPA06 were combined to form a composite sample named CPA01 for the soil, roots, and foliage 
respectively. Table 3.7 lists the replicate combinations and new sample IDs. The following procedure was used to sample each type of microcosm:

1. The foliage portion of the plant (above ground tissue) was separated from the roots using stainless steel clippers. All of the foliage tissue from each replicate was used to form the composite sample.

2. The foliage was cut into 1-inch pieces and rinsed with DI water to remove any soil. The rinsed foliage was laid onto paper towels to dry for 45 minutes and then placed into a 16-oz sampling jar (Figure 3.8).

3. Stainless steel trowels were used to loosen the soil and root mass from the glass microcosm jar. The soil was separated from the roots by hand and placed into a stainless steel bowl. All of the root tissue from each replicate was used to form the composite sample.

4. The roots were rinsed thoroughly with DI water to remove attached soil particles. The rinsed roots were placed onto paper towels to dry for 45 minutes and then placed into a 16-oz sampling jar.

5. The soil from each replicate was combined and homogenized in a stainless steel tray (Figure 3.9). A composite sample was placed into a 16-oz sampling jar and also in a 4-oz sampling jar for separate EFH analysis.

6. All of the sampling tools were decontaminated between sampling different microcosm treatment types.

7. Duplicate soil samples were taken from the unplanted and sterilized unplanted jars for QA/QC. 


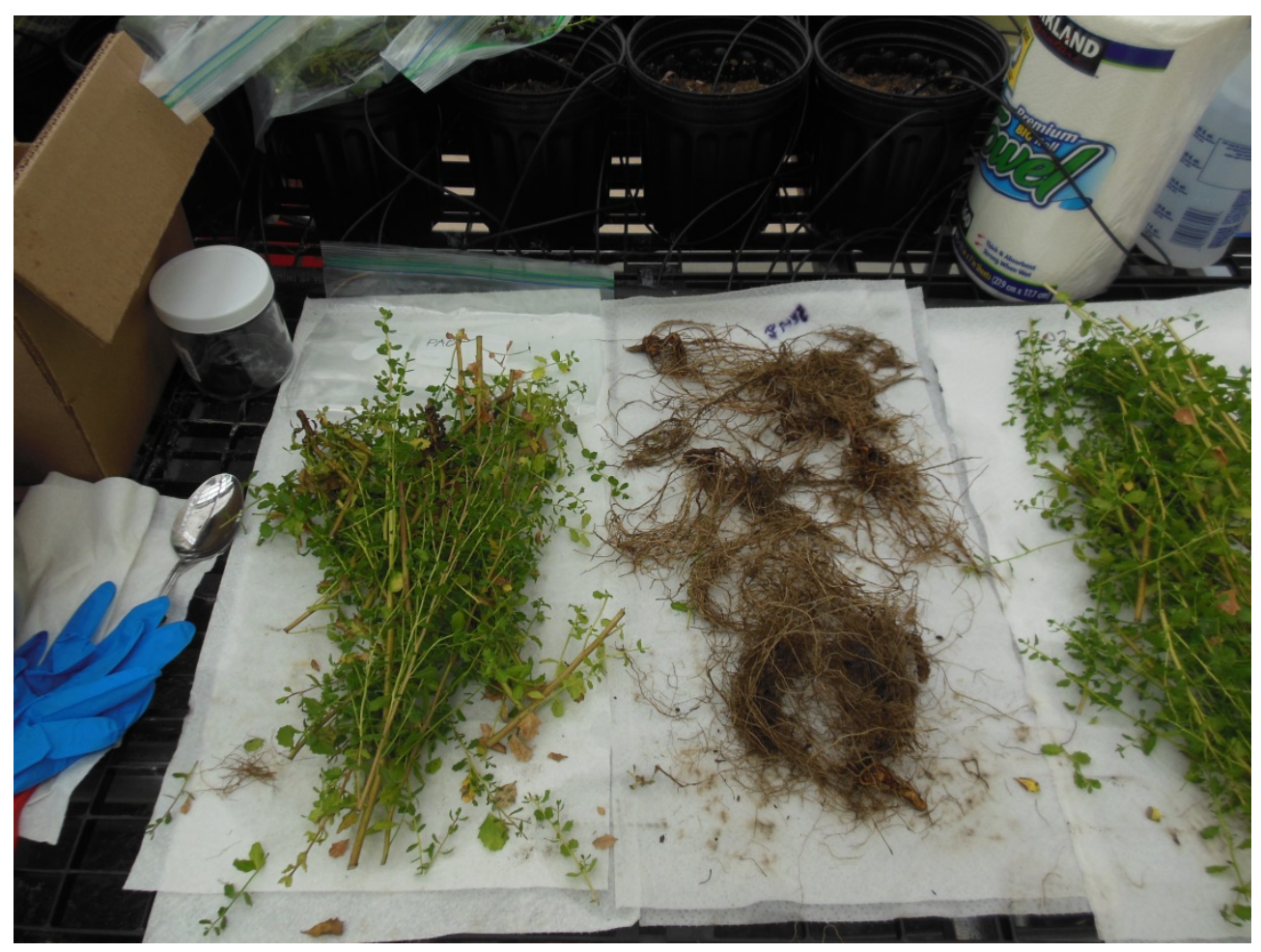

Figure 3.8. Roots and foliage drying

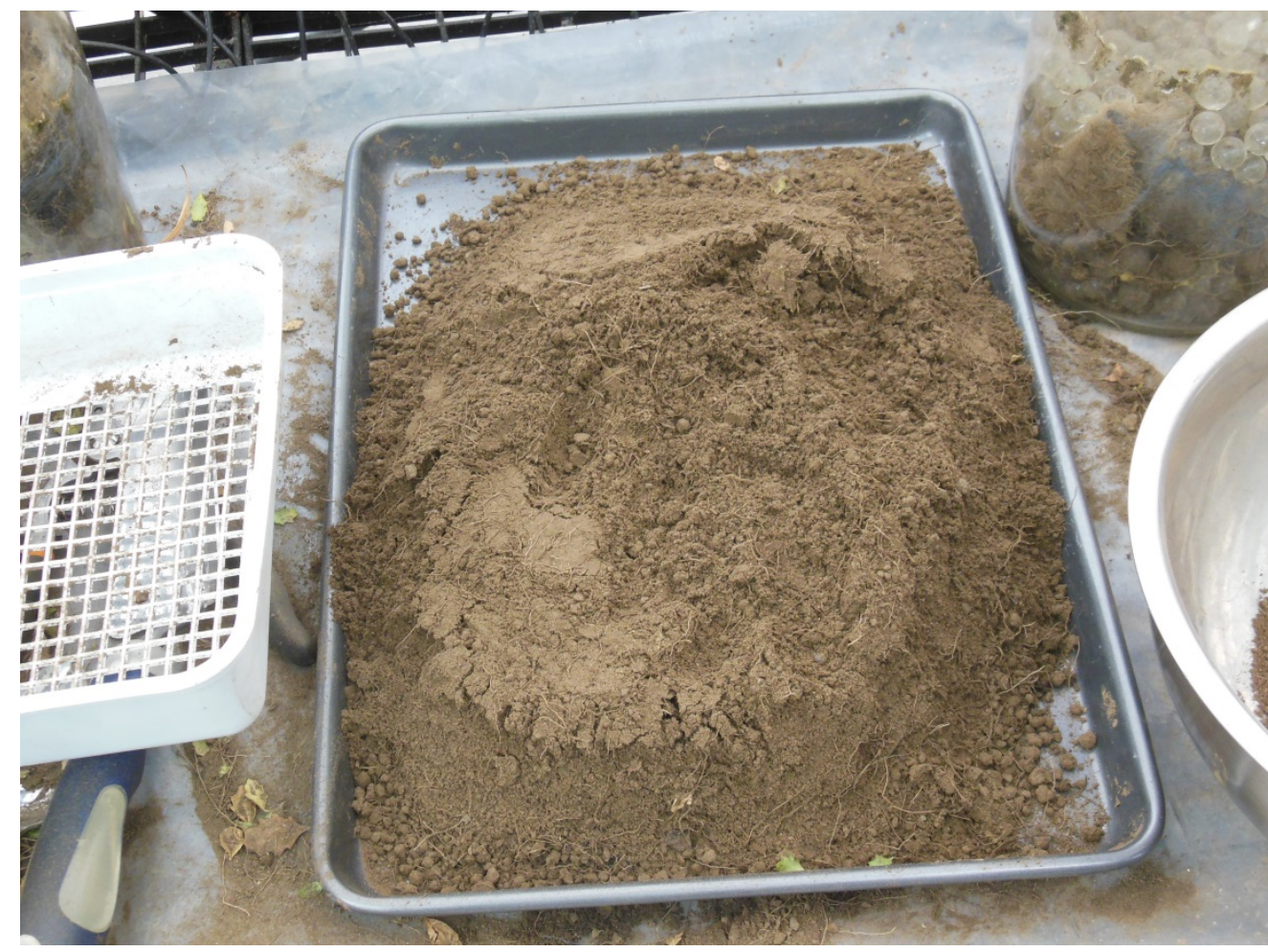

Figure 3.9. Soil mixed in stainless steel tray 
For transport the $4 \mathrm{oz}$ and $16 \mathrm{oz}$ jars were placed into padded bags and sealed in a quart sized Ziploc bag. An equipment blank was prepared for the sampling event by running DI water over the stainless steel trowels and into the sample jar. The samples were shipped on ice with a holding time of two days allowed. An additional $160 z$ jar of soil was collected from the PC, SP, U, and SU microcosm for TRF analysis.

Table 3.7. Replicate combinations for new composite sample IDs

\begin{tabular}{|l|l|l|}
\hline Treatment Type & Replicate Combinations & $\begin{array}{l}\text { New Composite Sample } \\
\text { ID }\end{array}$ \\
\hline Coyote Brush & $\begin{array}{l}\text { PA01 and 06; PA02 and } \\
\text { 07; PA03 and 08; PA04 } \\
\text { and 09; PA05 and 10 }\end{array}$ & $\begin{array}{l}\text { PA01; PA02; PA03; PA04; } \\
\text { PA05 }\end{array}$ \\
\hline Mule Fat & $\begin{array}{l}\text { PB01 and 06; PB02 and 07; } \\
\text { PB03 and 08; PB04 and 09; } \\
\text { PB05 and 10 }\end{array}$ & $\begin{array}{l}\text { PB01; PB02; PB03; PB04; } \\
\text { PB05 }\end{array}$ \\
\hline Purple Needlegrass & $\begin{array}{l}\text { PC02 and 03 and 05 and 09 } \\
\text { and 10; PC01 and 04 and } \\
06 \text { and 07 and 08 }\end{array}$ & PC01; PC02 \\
\hline Fertilized Coyote Brush & $\begin{array}{l}\text { FPA01 and 06; FPA02 and } \\
07 ; \text { FPA03 and 08; FPA04 } \\
\text { and 09; FPA05 and 10 }\end{array}$ & FPA01; FPA02; FPA03; \\
\hline Chelated Coyote Brush & $\begin{array}{l}\text { CPA01 and 03 and 06; } \\
\text { CPA02 and 04 and 07; } \\
\text { CPA05 and 08 and 09 }\end{array}$ & CPA01; CPA02; CPA03 \\
\hline $\begin{array}{l}\text { Sterilized Purple } \\
\text { Needlegrass }\end{array}$ & $\begin{array}{l}\text { SP2 and 03 and 05 and 09 } \\
\text { and } 10 ; \text { SP01 and 04 and 06 } \\
\text { and 07 and 08 }\end{array}$ & SP01; SP02 \\
\hline
\end{tabular}

\subsubsection{Terminal Restriction Fragment (TRF) Analysis}

TRF is a molecular method that provides a genetic snapshot of microbial communities.

This studied used the method used by Kaplan and Kitts (2004). DNA was extracted from soil by washing the cells out of soil samples, filtering them, and lysing them. The DNA extracted from the soil was then amplified using PCR and digested by restriction 
enzymes, creating a wide range of DNA fragment sizes which were then analyzed on a fragment analyzer to allow identification of the microbial communities.

\subsubsection{Statistical Methods for Microcosm Analysis}

All statistical analysis was performed using Minitab 16 Statistical Software (except for TRF statistical analysis). One-way analysis of variance (ANOVA) was performed to compare the contaminant soil concentrations between treatments at Day 85 or Day 211 of the experiment. The response variable was the contaminant concentration, the factor was the treatment type, and the confidence level was $95 \%$. Tukey comparisons were performed with a family error rate set to $5 \%$.

Two sample t-tests were performed to compare the contaminant concentrations in soil at Day 0 and Day 211. The response variable was contaminant concentration, the factor was the sampling day, and the confidence level was $95 \%$.

Two sample t-tests were also performed to compare the contaminant concentrations in the roots or foliage of different planted microcosm treatments. The response variable was contaminant concentration, the factor was the type of treatment, and the confidence level was $95 \%$. 


\section{Chapter 4 Results/Discussion}

\subsection{Phase I: Field Screening Results}

The field screening was designed to identify which plant species extracted contaminants into their roots or foliage. The soil nearby the plant specimens was sampled to give an indication of the contamination concentrations that the plants were exposed to. The soil concentration is only an indicator because the root systems were usually very extensive and soil was only collected from some of the areas in contact with the roots. The control locations were selected based on historical sampling data to identify an area where contaminant levels in the soil were non-detect. Some of the control locations were discovered to contain COIs while some of the contaminated soil were non-detect which made them the new controls. The following sections describe the screening results for each contaminant type.

\subsubsection{Petroleum Hydrocarbon Phytoextraction in the Field}

The field results for petroleum hydrocarbon phytoextraction were similar for all plant species screened. Extractable fuel hydrocarbon $(\mathrm{EFH})$ concentrations in the soil around the specimens were $200 \mathrm{mg} / \mathrm{kg}$ or lower, while many of the root concentrations were above $1000 \mathrm{mg} / \mathrm{kg}$ and many foliage concentrations were above $4000 \mathrm{mg} / \mathrm{kg}$ (Figures 4.1 to 4.9). For example, Palmer's Goldenbush (PG), EFH concentrations in the foliage were as high as $59000 \mathrm{mg} / \mathrm{kg}$ while the soil concentration was only $4.7 \mathrm{mg} / \mathrm{kg}$ (Figure 4.1 ). It is likely that phytogenic compounds are contributing to the relatively high EFH concentrations in the plant tissue of all the species. The soil contained hydrocarbons in 
the $\mathrm{C} 21$ to $\mathrm{C} 40$ carbon range while the roots and foliage of the plants showed concentrations of hydrocarbons in the $\mathrm{C} 5$ through $\mathrm{C} 40$ range. Also, even the plants growing in control soils with little or no EFH in the soil exhibited high EFH concentrations in the roots and foliage.

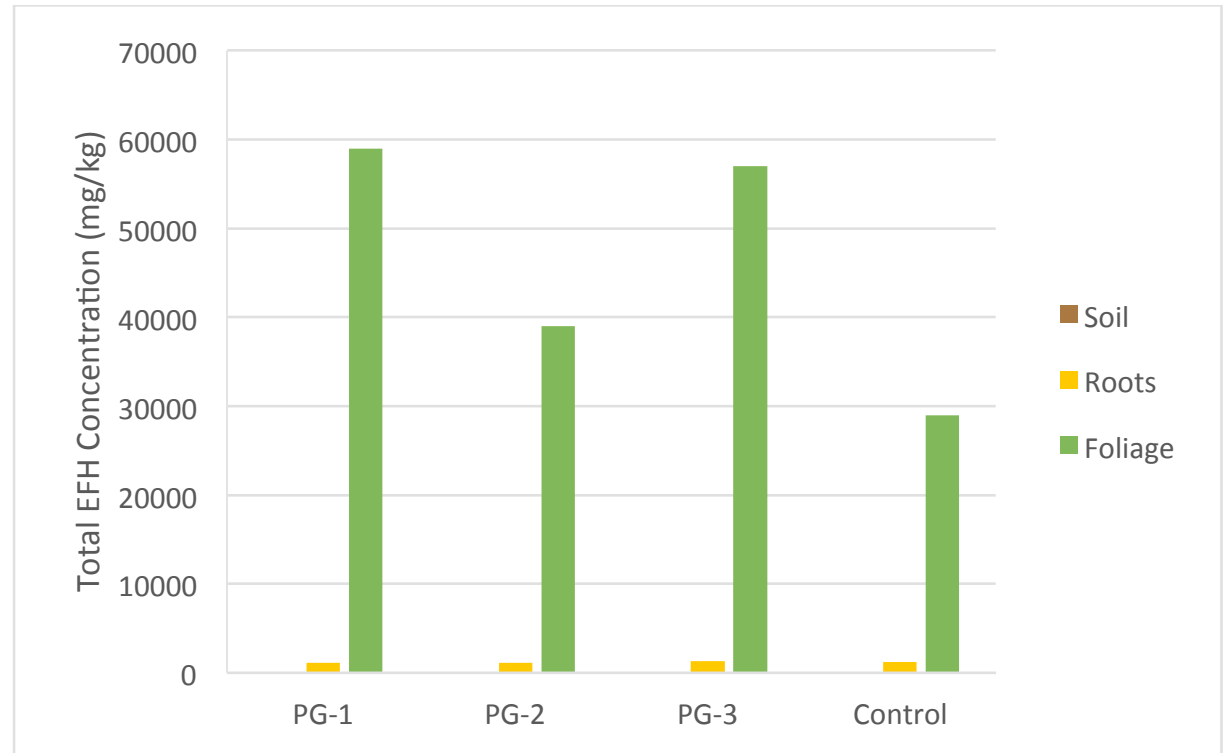

Figure 4.1. Total EFH concentrations for Palmer's Goldenbush 


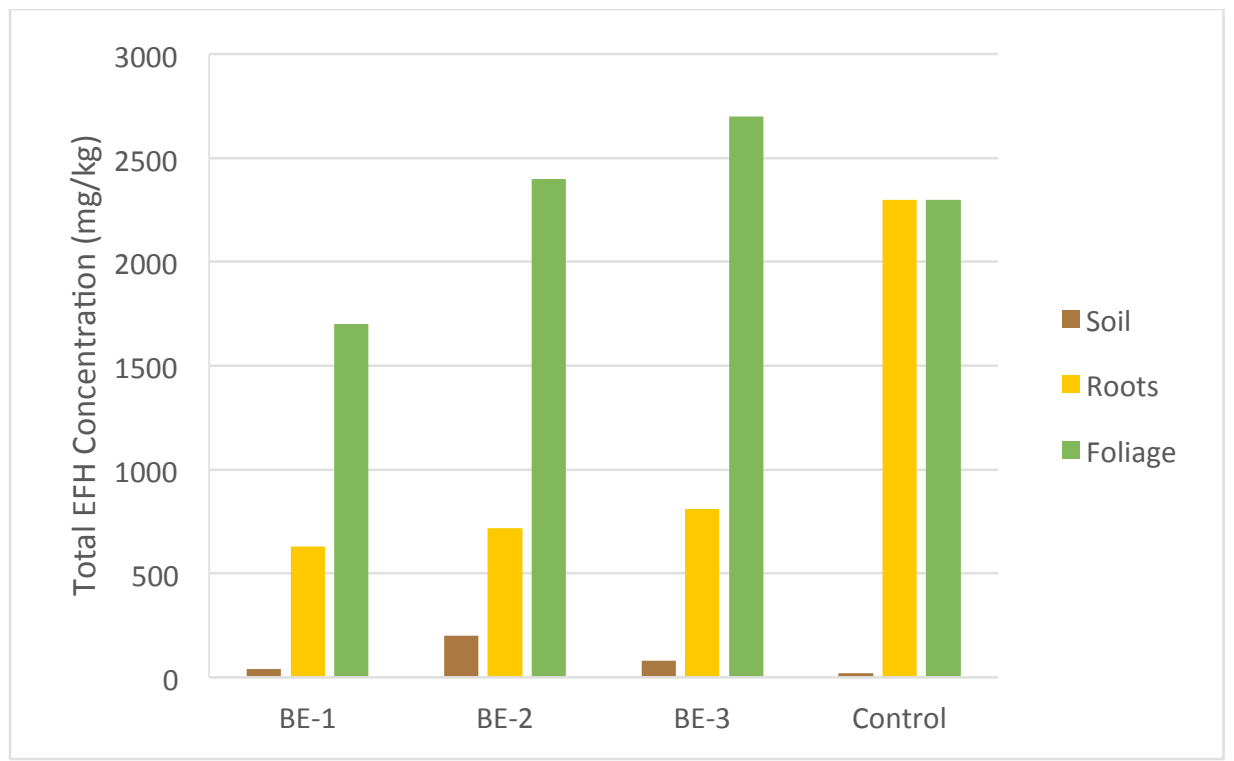

Figure 4.2. Total EFH concentrations for Blue Elderberry

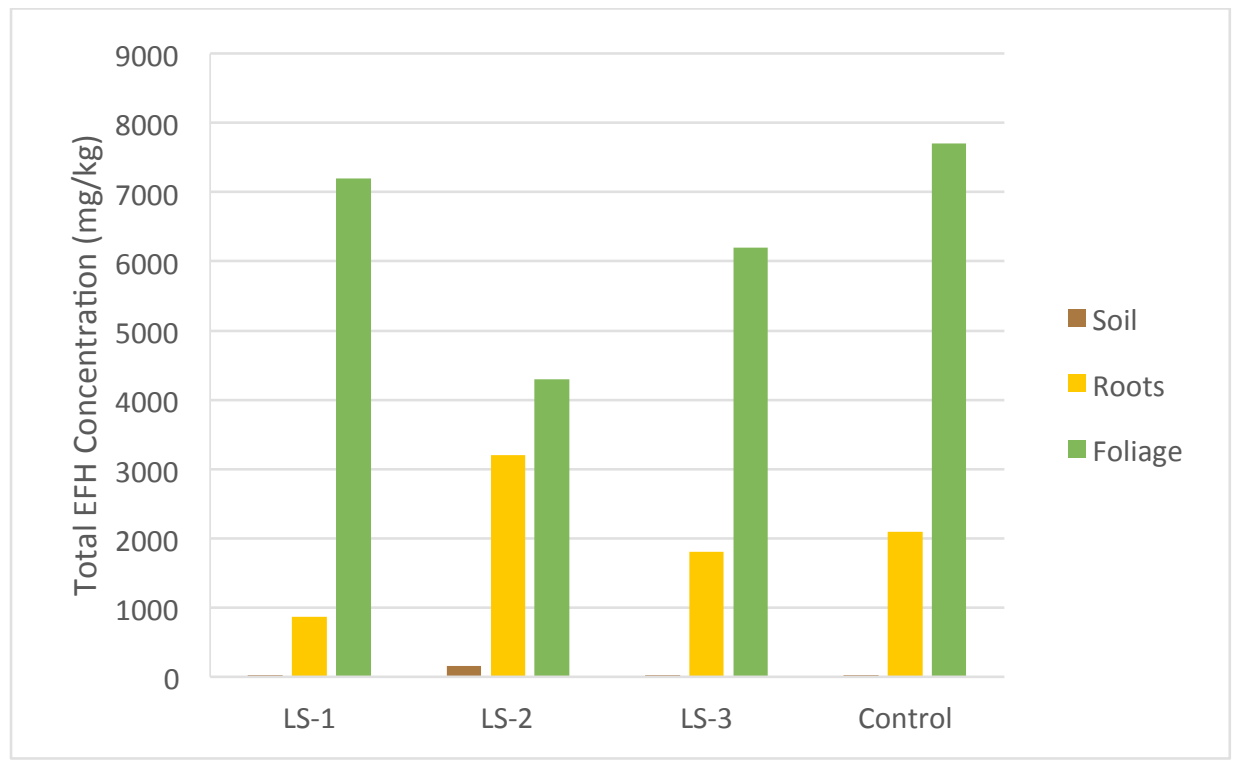

Figure 4.3. Total EFH concentrations for Laurel Sumac 


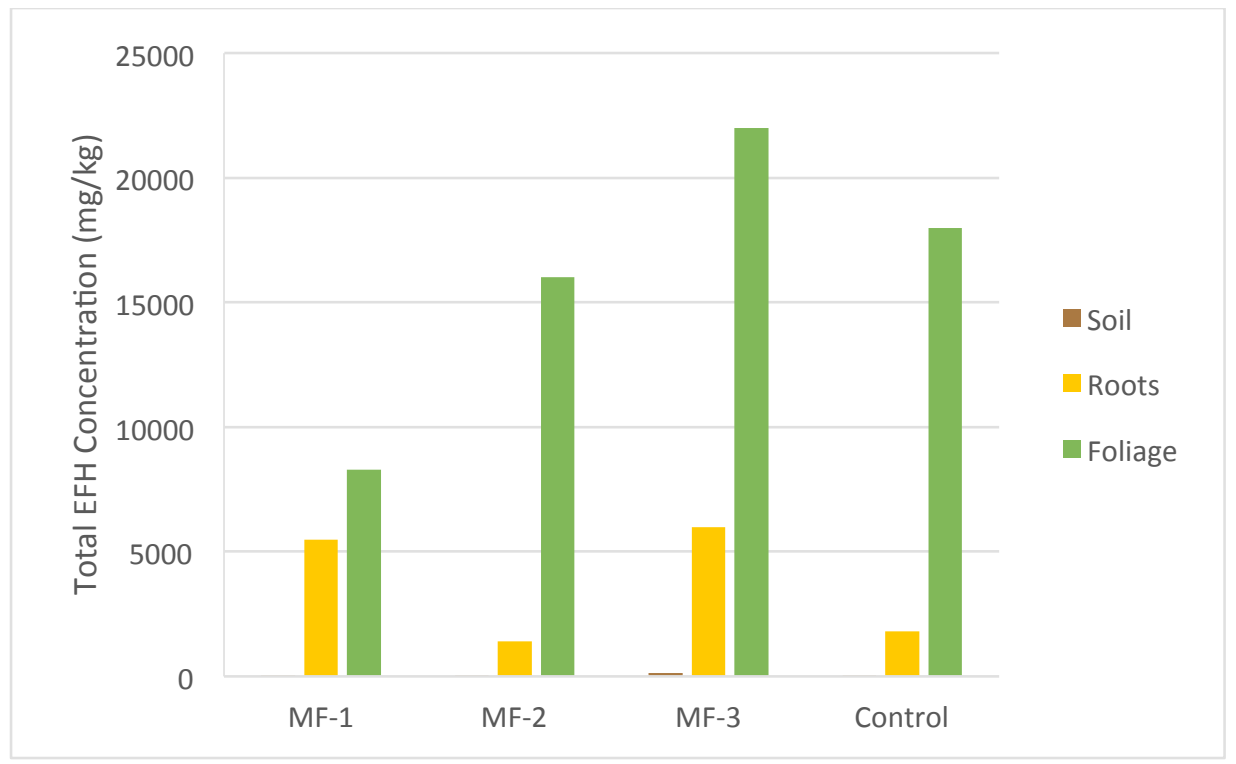

Figure 4.4. Total EFH concentrations for Mule Fat

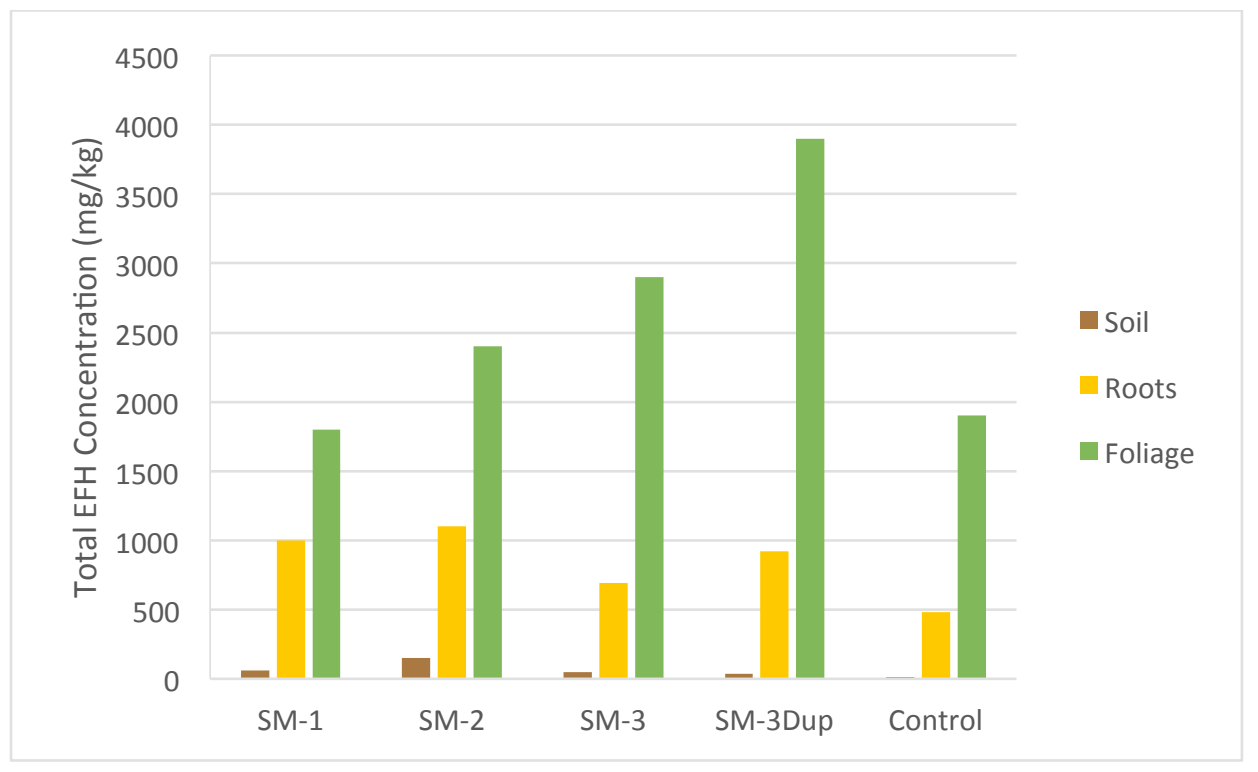

Figure 4.5. Total EFH concentrations for Summer Mustard 


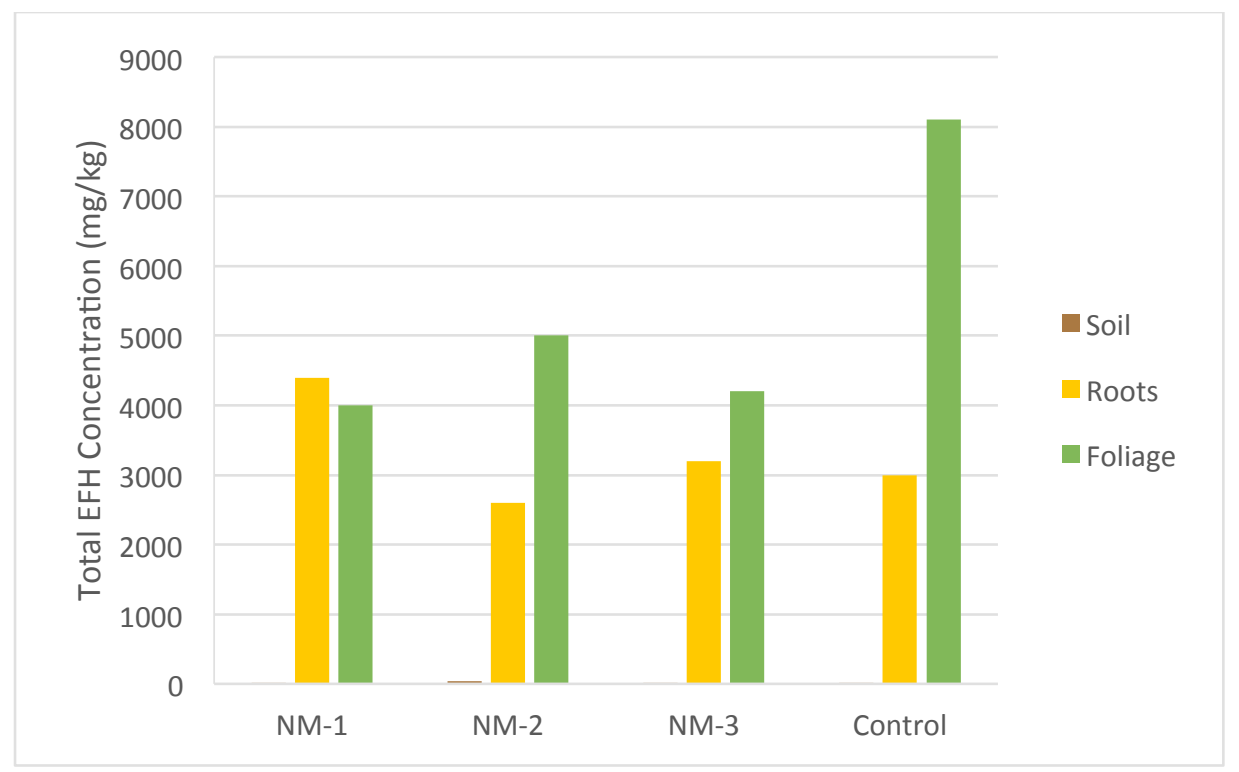

Figure 4.6. Total EFH concentrations for Narrowleaf Milkweed

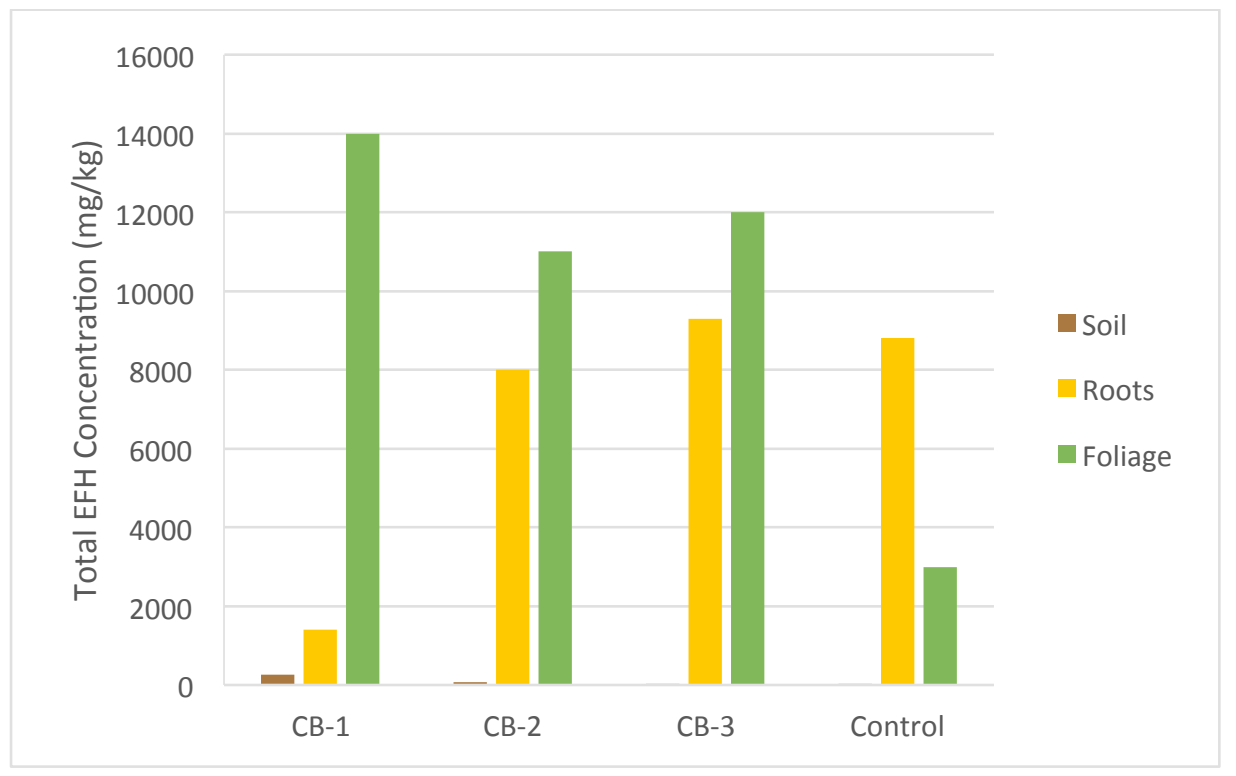

Figure 4.7. Total EFH concentrations for Coyote Brush 


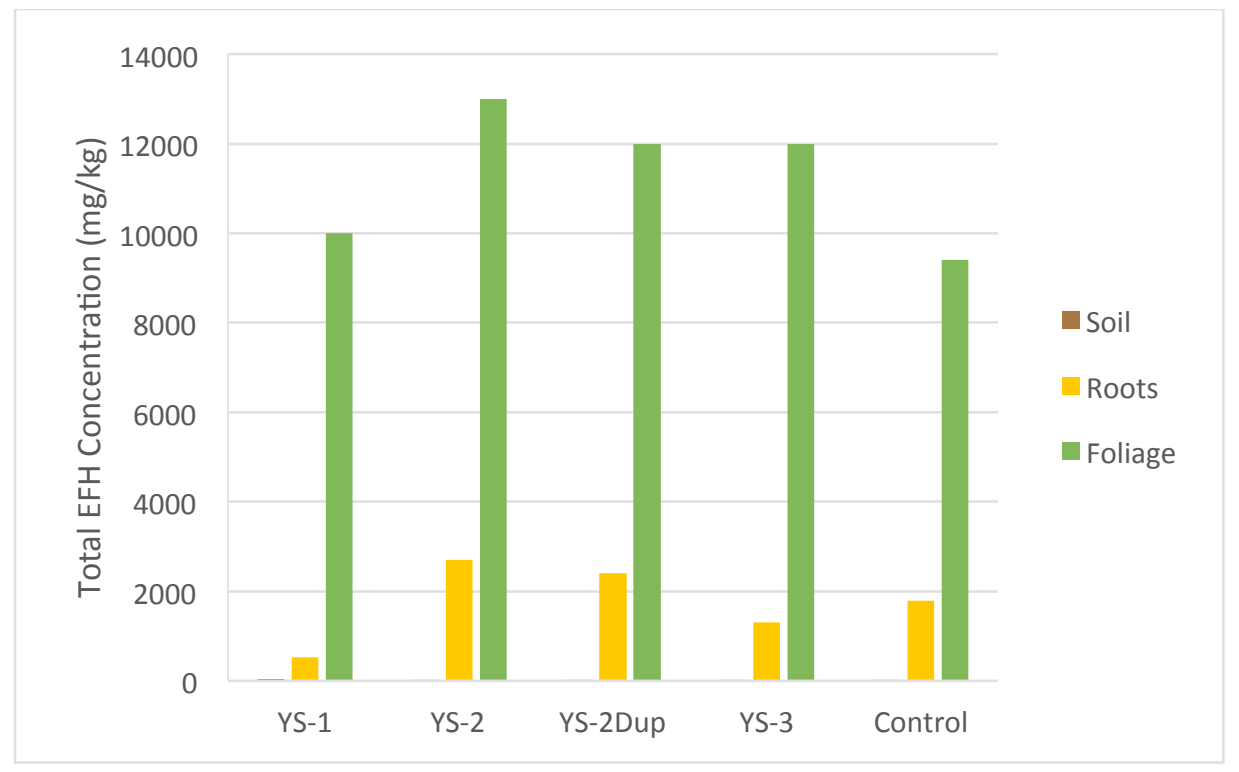

Figure 4.8. Total EFH concentrations for Yerba Santa

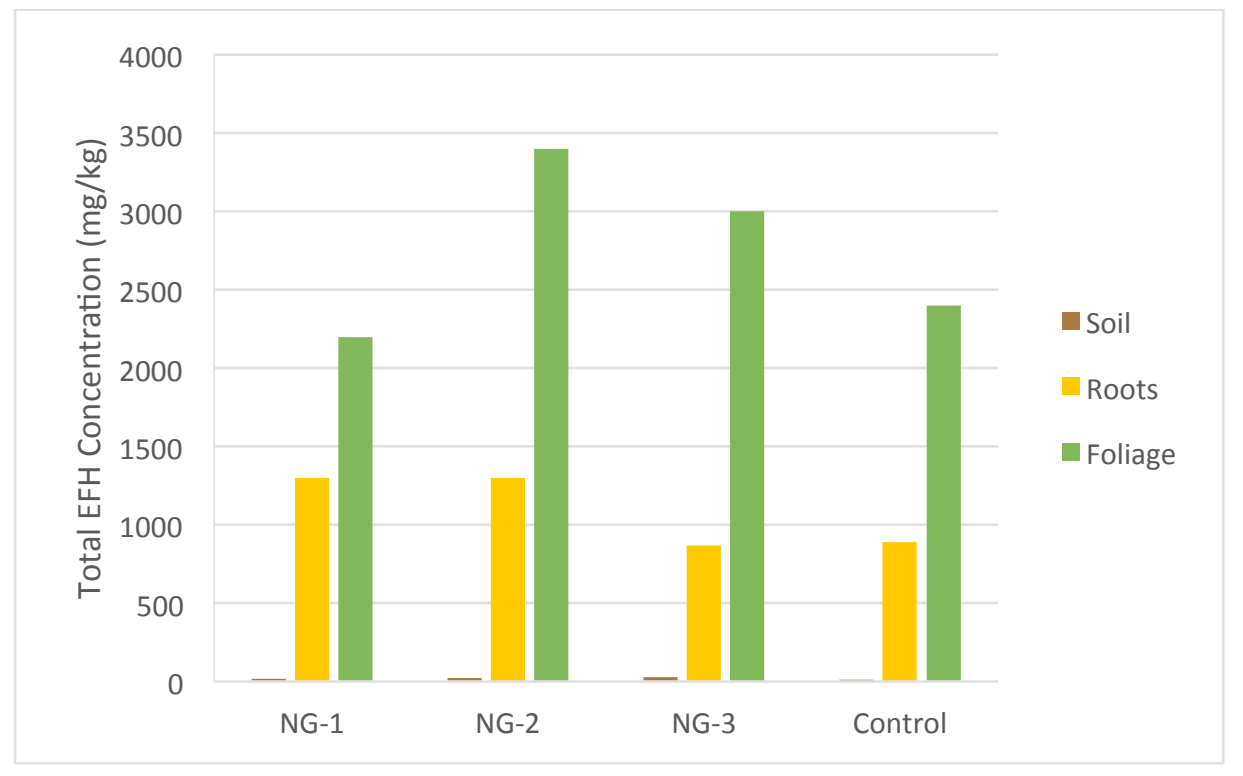

Figure 4.9. Total EFH concentrations for Purple Needlegrass 


\subsubsection{Polyaromatic Hydrocarbon Phytoextraction in the Field}

PAHs were detected in the roots and foliage of some species (Figures 4.10 to 4.18). Blue Elderberry (BE), Yerba Santa (YS), and Purple Needlegrass (NG) showed the most promise for PAH uptake (Figures 4.10 to 4.12). One of the Blue Elderberry specimens (BE-2) had very high PAH concentrations in the soil, and for this specimen the total PAH concentration in the roots was $1740 \mathrm{ug} / \mathrm{kg}$ (Figure 4.10). The PAHs observed in this specimen do not appear to be phytogenic since the other 3 plant specimens sampled were non-detect for PAHs in the plant tissue (as well as the soil). The PAHs observed in the Blue Elderberry roots were: benzo(a)pyrene, benzo(b)fluoranthene, benzo(e)pyrene, benzo(g,h,i)perylene, benzo(k)fluoranthene, chrysene. dibenzo(a,h)anthracene, fluoranthene, fluorene, and indeno(1,2,3-cd)pyrene which were all present in the soil.

Concentrations of PAHs in the roots of one specimen of Yerba Santa (YS-2) were about $6-8 \mathrm{x}$ higher than that of the surrounding soil (Figure 4.11) indicating a possible bioconcentration factor greater than 1 . These PAHs also do not appear to be phytogenic since the other specimens did not have any PAHs in the plant tissue. However, the PAH measured in the roots was anthracene which was not detected in the nearby soil.

PAHs were detected in the roots of one Purple Needlegrass specimen and the foliage of one specimen as well. Concentrations of PAHs in these root and foliage specimens of Purple Needlegrass were $703 \mathrm{ug} / \mathrm{kg}$ in specimen NG-2 and $4400 \mathrm{ug} / \mathrm{kg}$ in specimen NG1, respectively (Figure 4.12). This is curious, since PAHs would have to travel through the roots to enter the foliage and thus NG-1 should have PAHs in the roots as well as the 
foliage. Specimen NG-1 showed benzo(a)anthracene, benzo(a)pyrene, benzo(b)fluoranthene, benzo(e)pyrene, benzo(g,h,i)perylene, benzo(k)fluoranthene, chrysene, fluoranthene, indeno(1,2,3-cd)pyrene, and pyrene present in the foliage. Specimen NG-2 had benzo(a)pyrene, benzo(b)fluoranthene, benzo(e)pyrene, benzo(g,h,i)perylene, chrysene, indeno(1,2,3-cd)pyrene, and pyrene in the roots. Most of these PAHs were also observed in the soil at lower concentrations.

PAHs were present in the foliage of all of the Mule Fat specimens, including the control, despite an absence PAHs in soil (Figure 4.13). This indicates that the PAHs are most likely phytogenic compounds that are eluting at similar times as PAHs . In addition, none of the specimens showed PAHs in the roots. MF-1 foliage has benzo(a)anthracene and a small amount of benzo(e)pyrene. MF-3 foliage has only benzo(a)anthracene. MF- 2 and the control only have chrysene. These differences indicate that the type of phytogenic compound produced may be different between Mule Fat specimens. No PAHs were observed in the roots of foliage of Palmer's Goldenbush. 


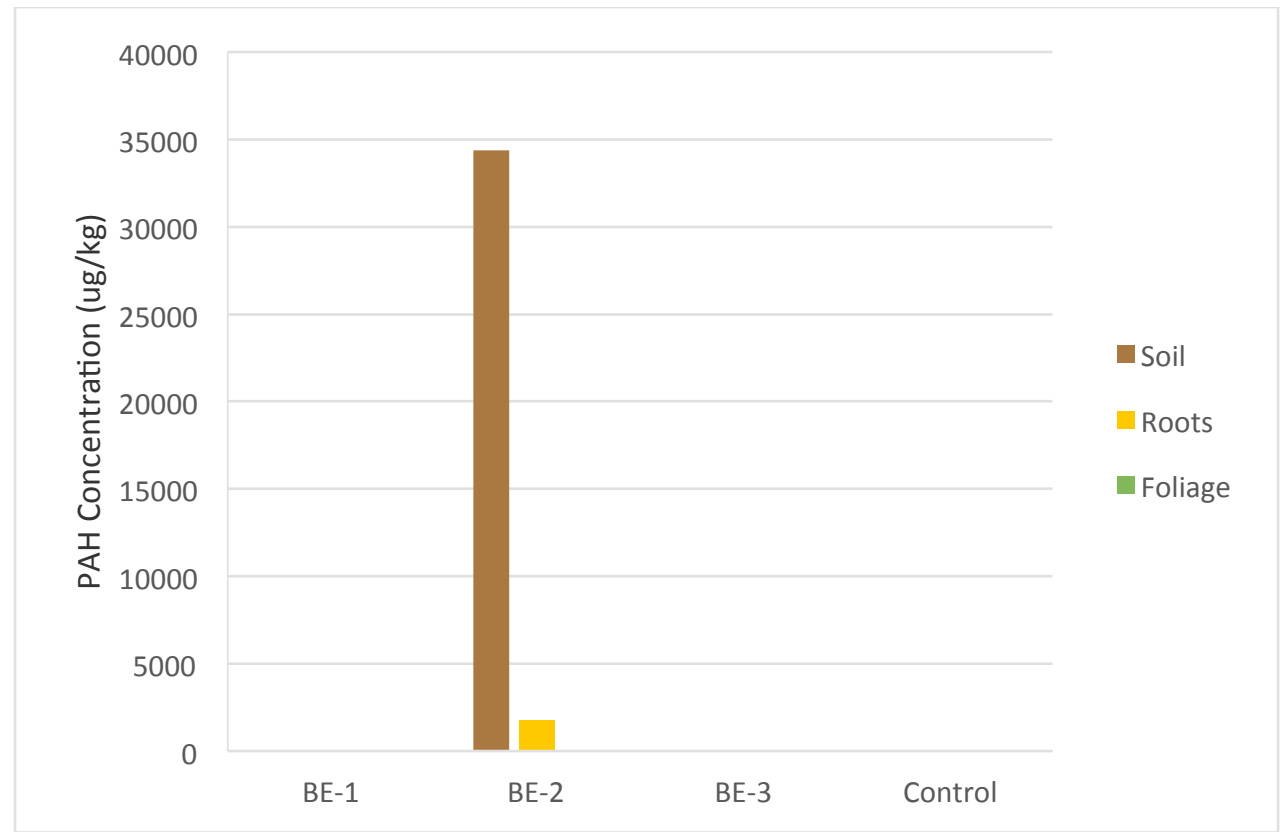

Figure 4.10. Total PAH concentrations for Blue Elderberry

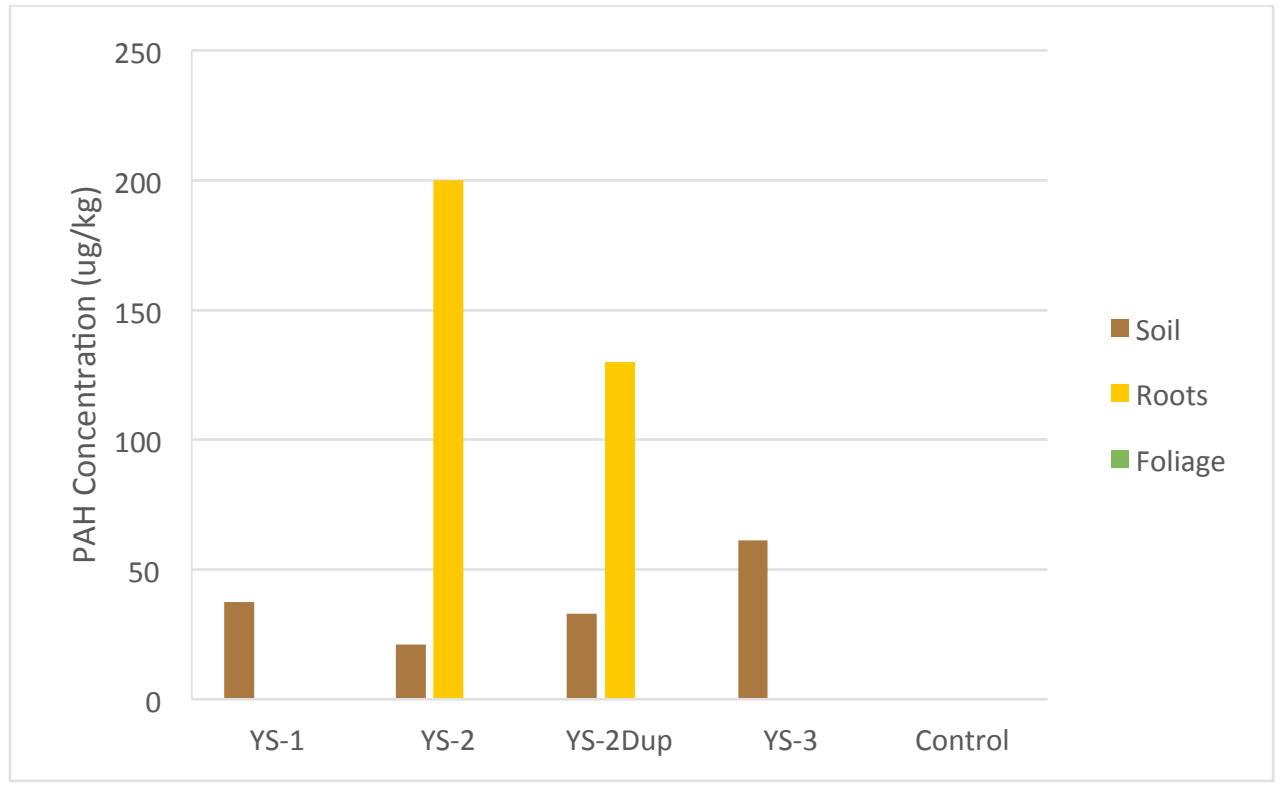

Figure 4.11. Total PAH concentrations for Yerba Santa 


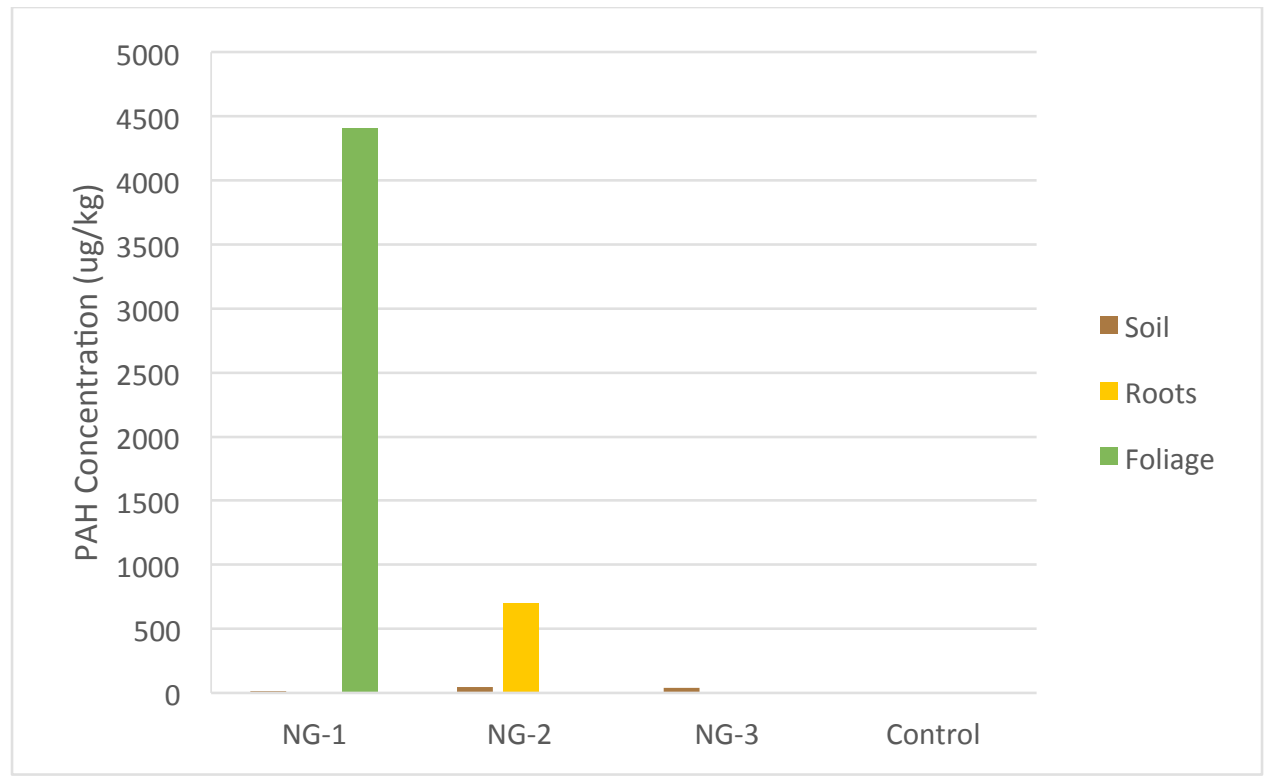

Figure 4.12. Total PAH concentrations for Purple Needlegrass

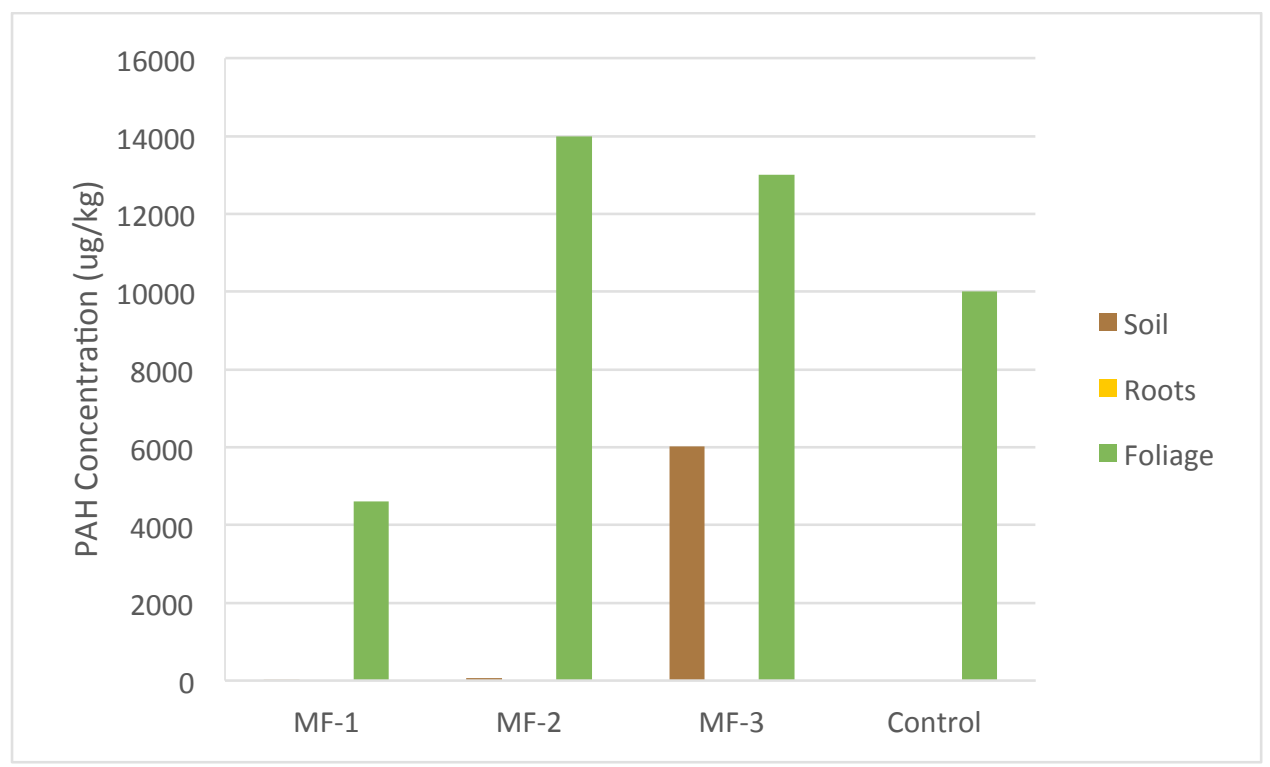

Figure 4.13. Total PAH concentrations for Mule Fat 


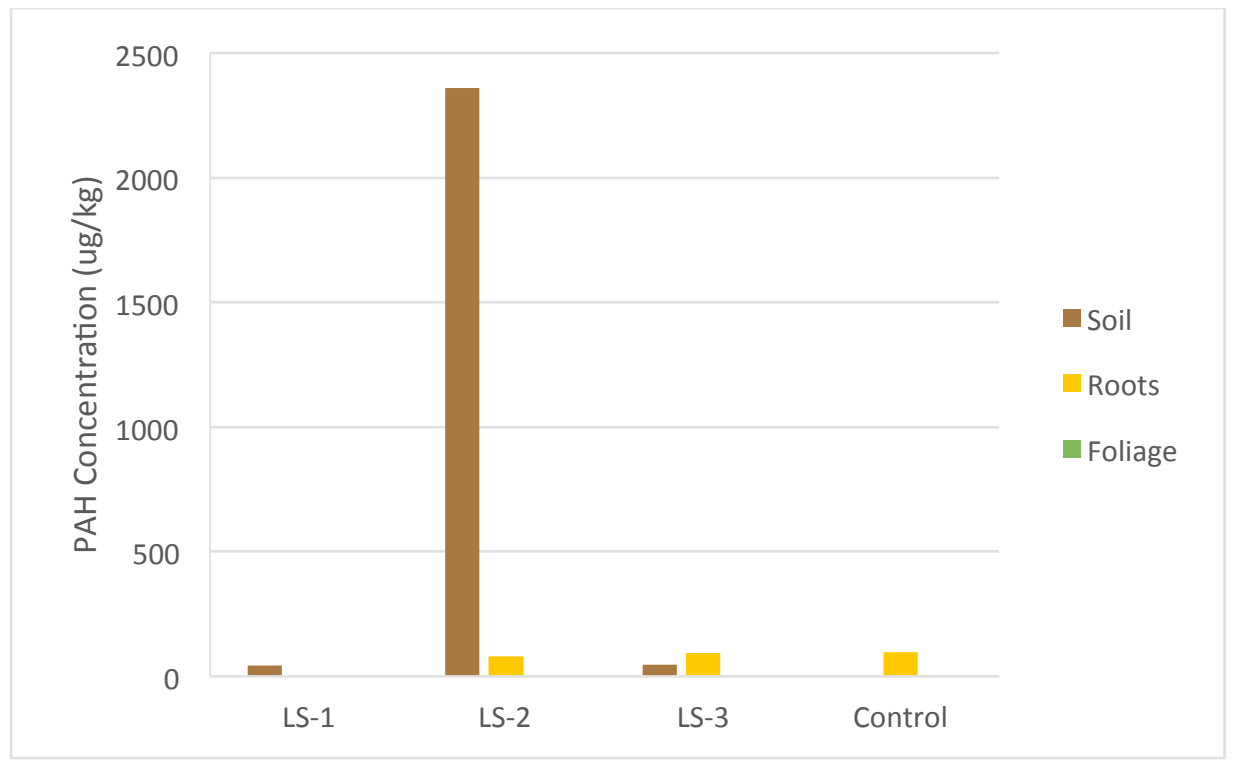

Figure 4.14. Total PAH concentrations for Laurel Sumac

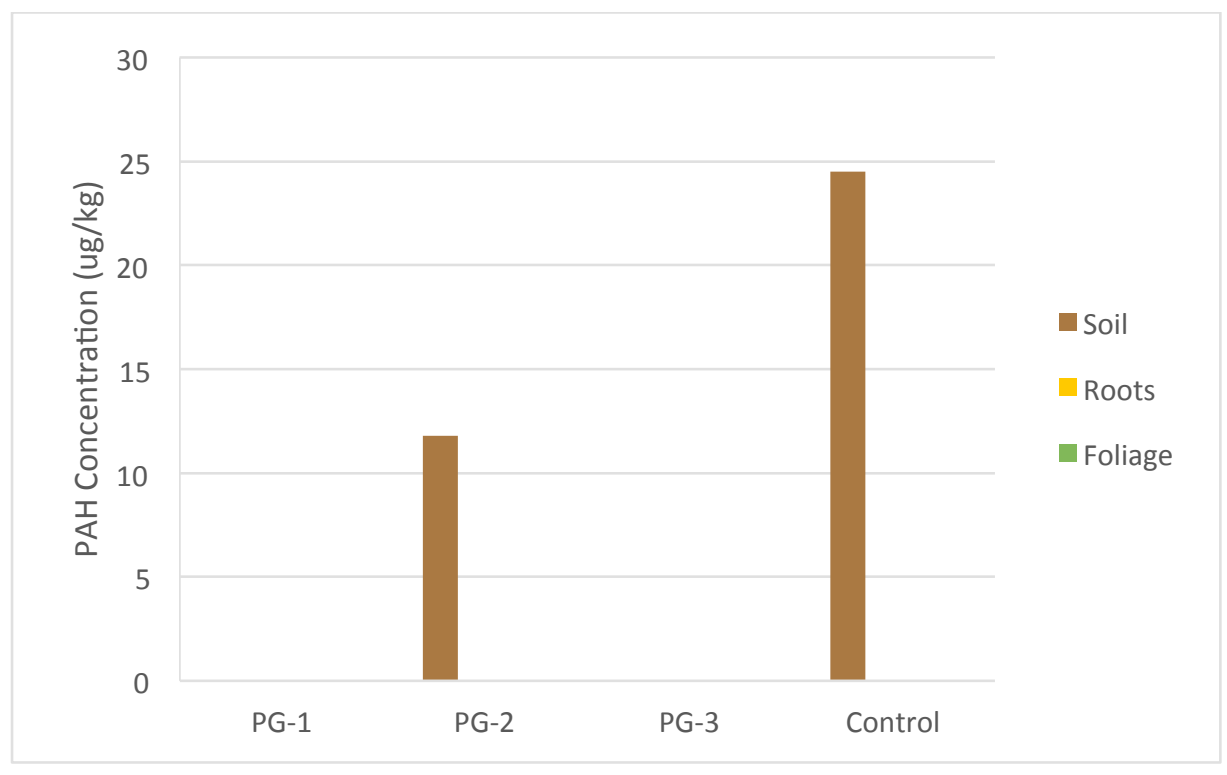

Figure 4.15. Total PAH concentrations for Palmer's Goldenbush 


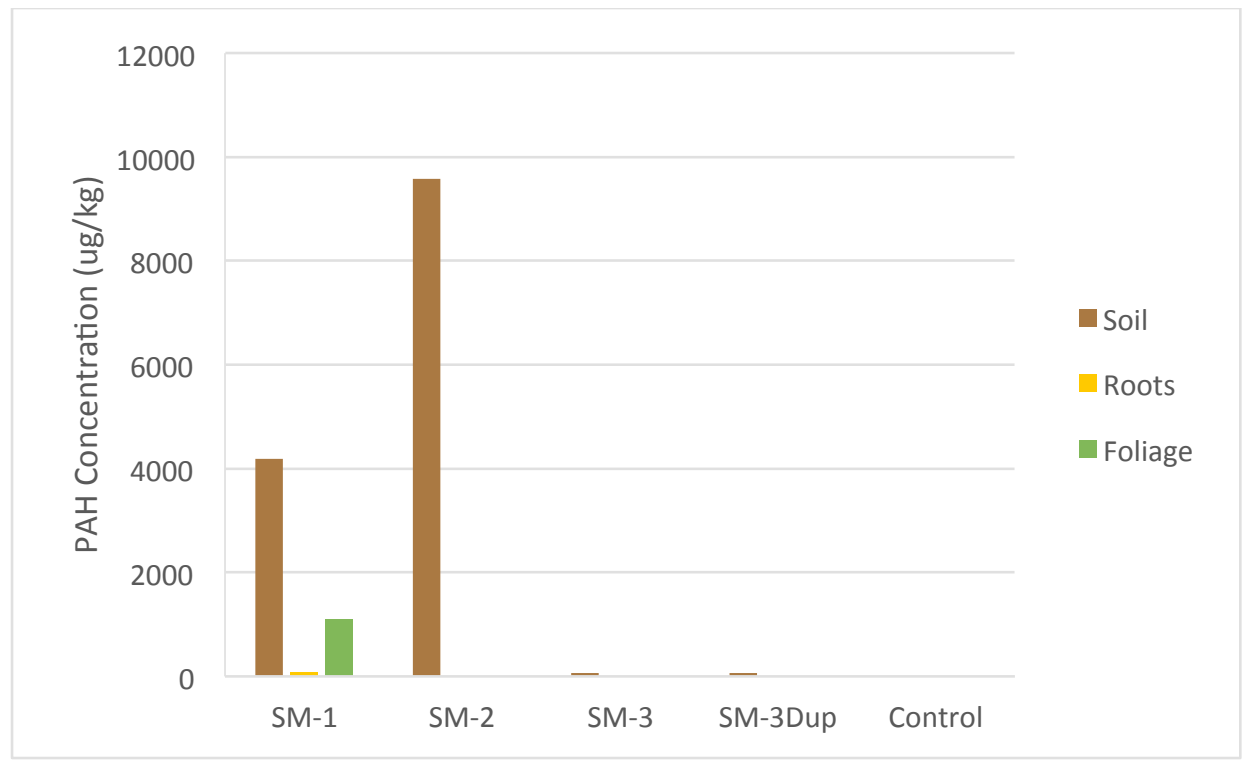

Figure 4.16. Total PAH concentrations for Summer Mustard

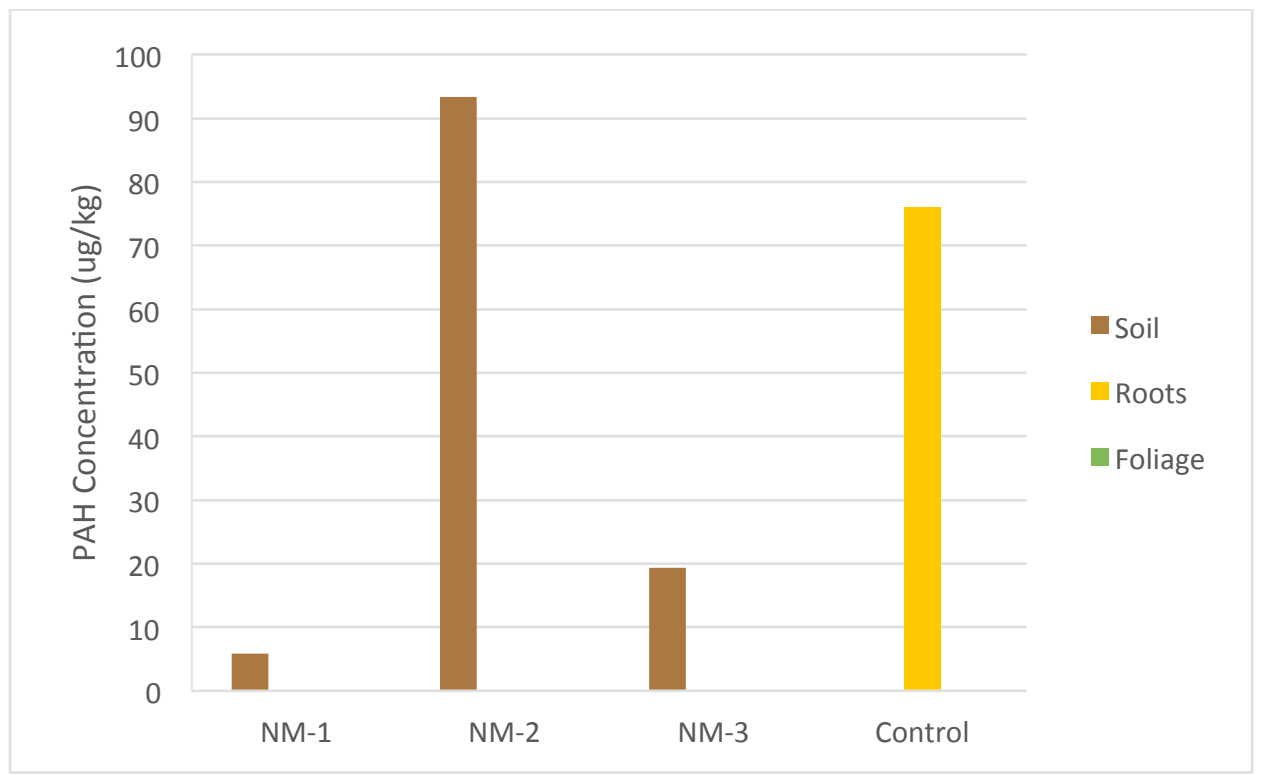

Figure 4.17. Total PAH concentrations for Narrowleaf Milkweed 


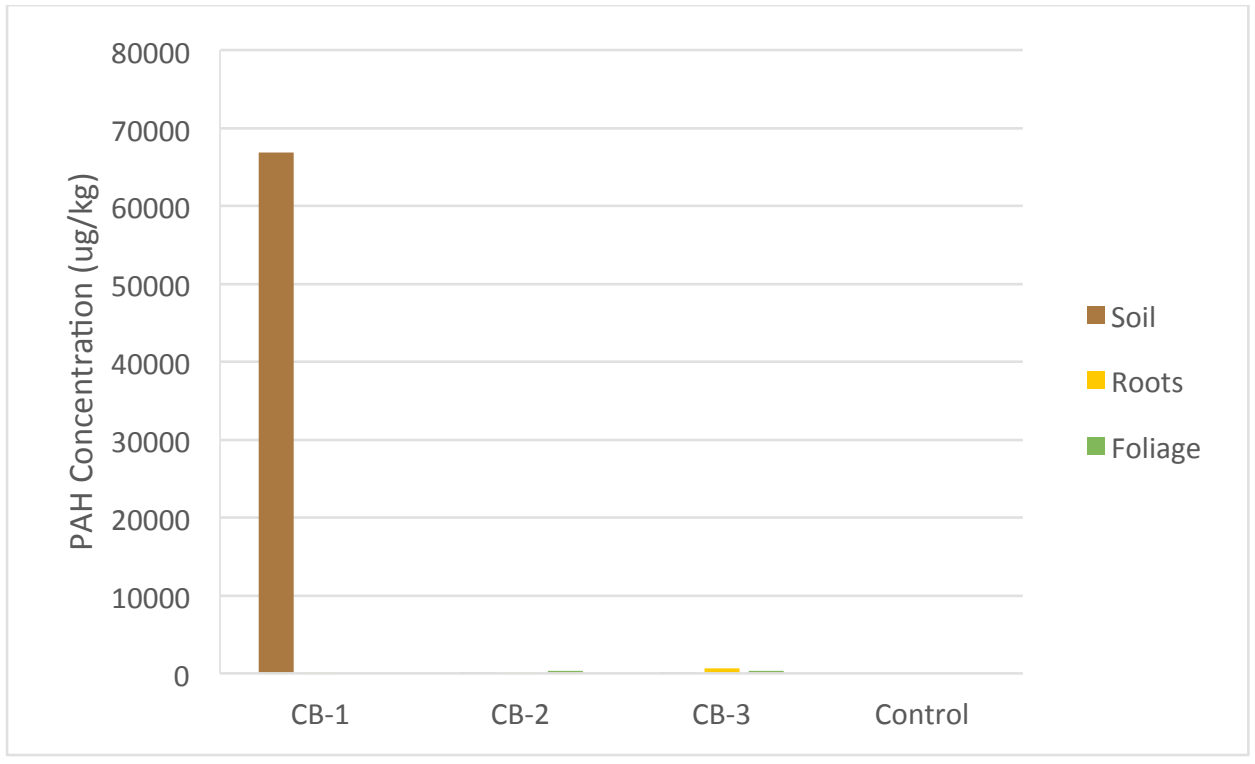

Figure 4.18. Total PAH concentrations for Coyote Brush 


\subsubsection{Polychlorinated Biphenyl Phytoextraction in the Field}

None of the plants species showed any phytoextraction of PCBs from the soil. All of the root and foliage had PCB concentrations below the detection limit of 50-200 ug/ $\mathrm{kg}$. PCBs were not detected in the soils associated with Palmer's Goldenbush and Purple Needlegrass specimens, so it is not known if these species could phytoextract PCBs if they were present in the soil.

\subsubsection{Chlorinated Dioxins/Furans Phytoextraction in the Field}

Blue Elderberry, Palmer's Goldenbush, Yerba Santa, and Purple Needlegrass showed potential uptake of chlorinated dioxins/furans in either roots, foliage, or both (Figures 4.19 to 4.22 ). Purple Needlegrass had a total dioxin/furan concentration of $2237 \mathrm{ng} / \mathrm{kg}$ in the roots of one specimen, and a total dioxin/furan concentration of $694 \mathrm{ng} / \mathrm{kg}$ in the foliage of another specimen (Figure 4.19). The amount of dioxin/furan uptake by Purple Needlegrass appeared to be positively correlated to the concentration of dioxins/furans in the nearby soil. Blue Elderberry had a dioxin/furan concentration of $1026 \mathrm{ng} / \mathrm{kg}$ in the roots of specimen BE-2 (Figure 4.20). Dioxin/furan concentrations in soil associated with this specimen were very high. Yerba Santa had a concentration of $421 \mathrm{ng} / \mathrm{kg}$ in the roots of one specimen (YS-2Dup) and a concentration of $901 \mathrm{ng} / \mathrm{kg}$ in the foliage of another specimen (YS-3) (Figure 4.21). All of the controls except for Palmer's Goldenbush had very small dioxin/furan concentrations in the soil (Figure 4.22). The congeners that make up most of the total dioxin/furan concentrations in the soil are octachlorodibenzo-pdioxin and 1, 2, 3, 4, 6, 7, 8-heptachlorodibenzo-p-dioxin. These highly chlorinated 
dioxins were also the primary congeners seen in the plant roots and foliage of the screened species (Figures 4.19 to 4.27).

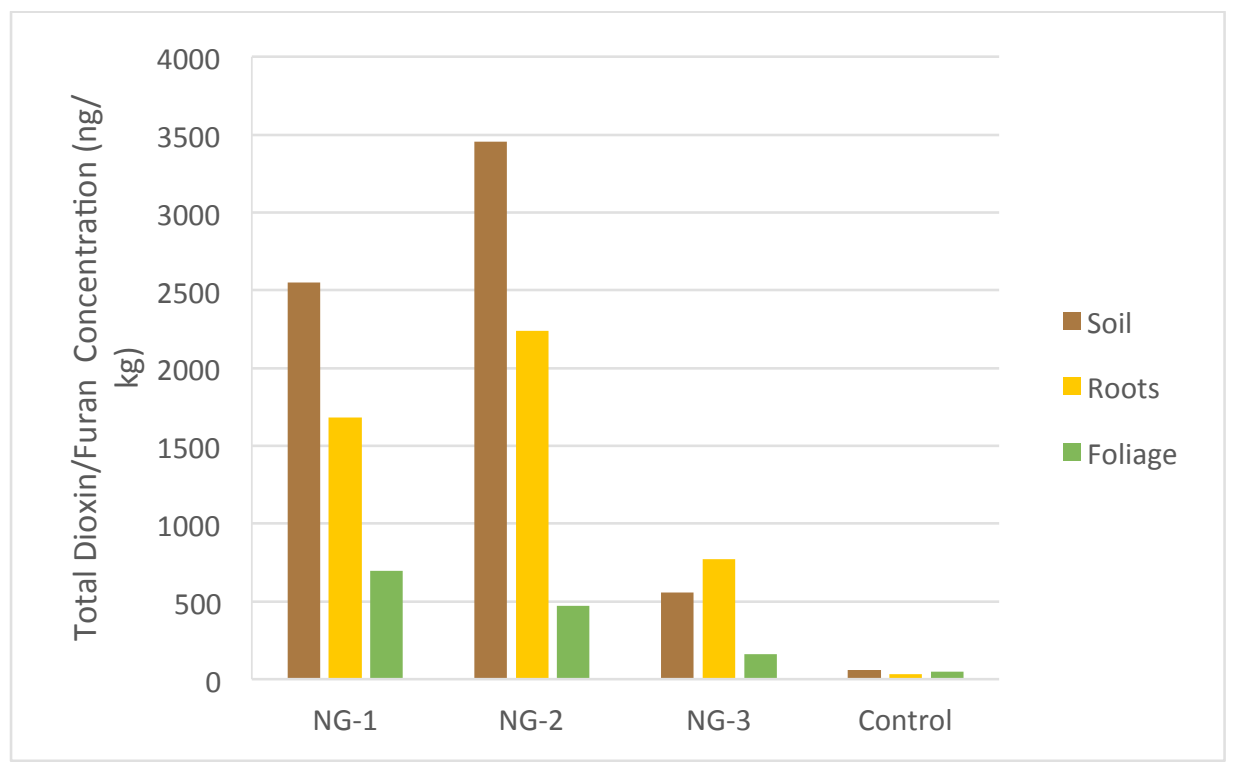

Figure 4.19. Total dioxin/furan concentrations for Purple Needlegrass

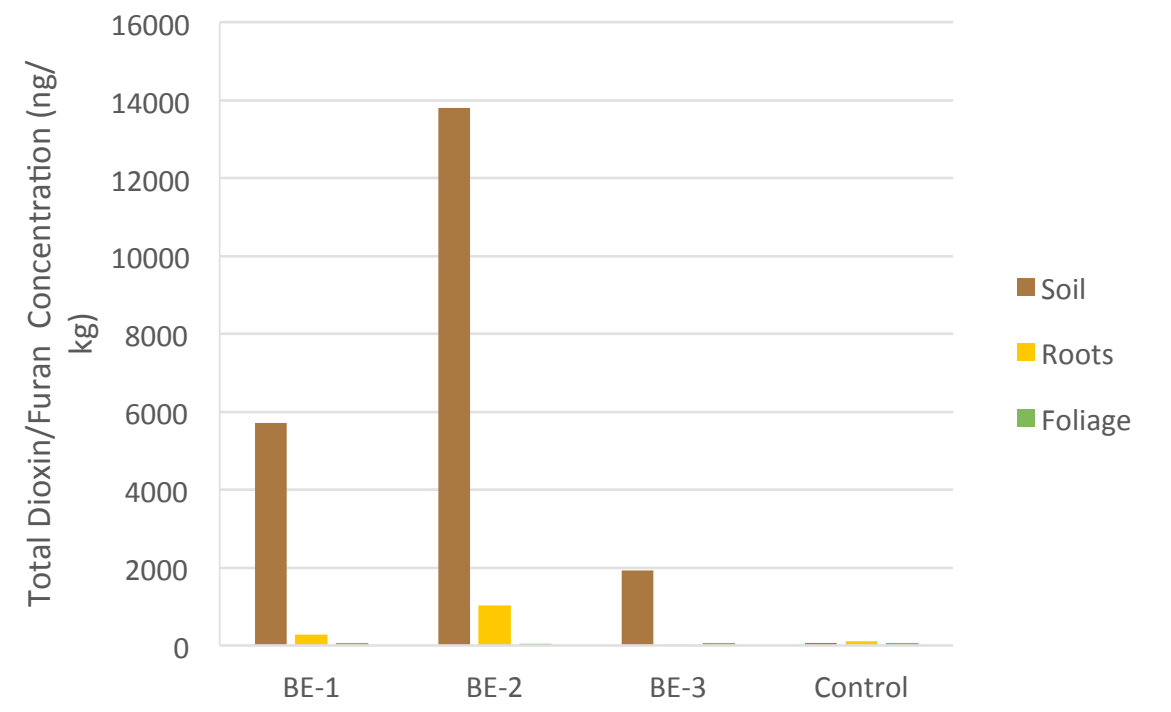

Figure 4.20. Total dioxin/furan concentrations for Blue Elderberry 


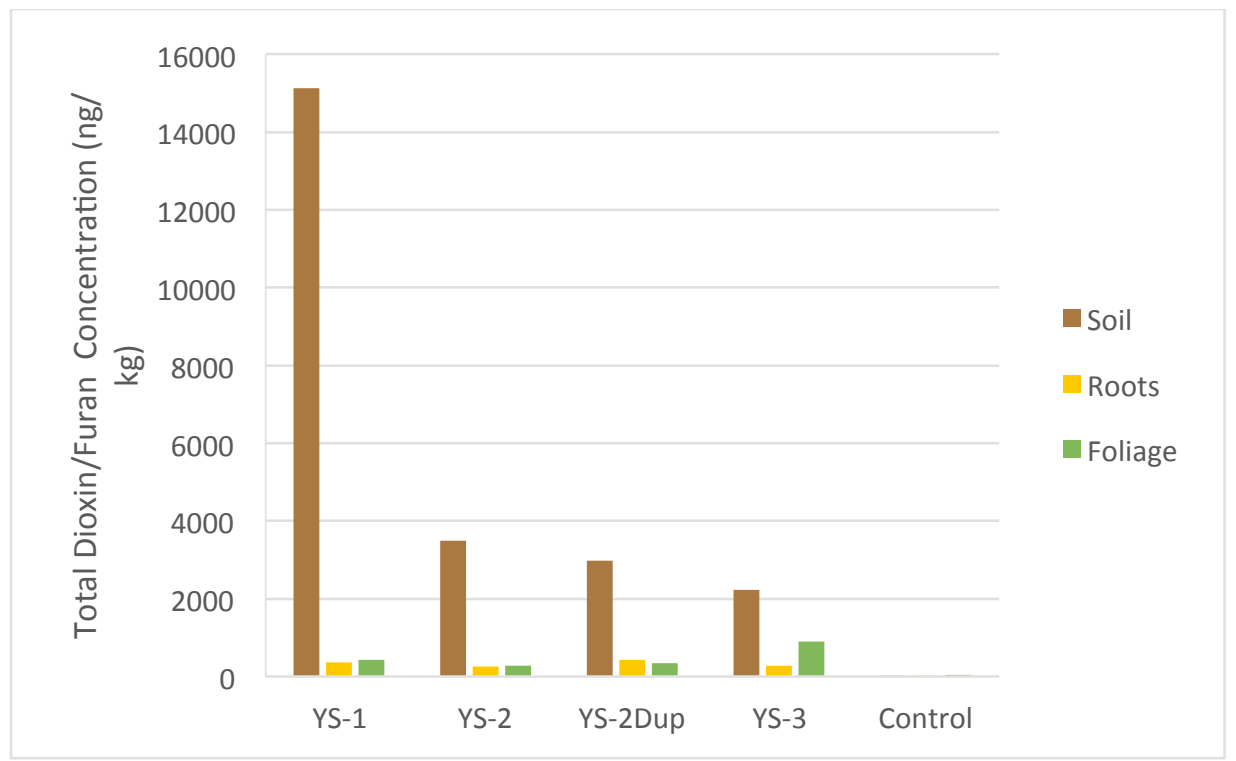

Figure 4.21. Total dioxin/furan concentrations for Yerba Santa

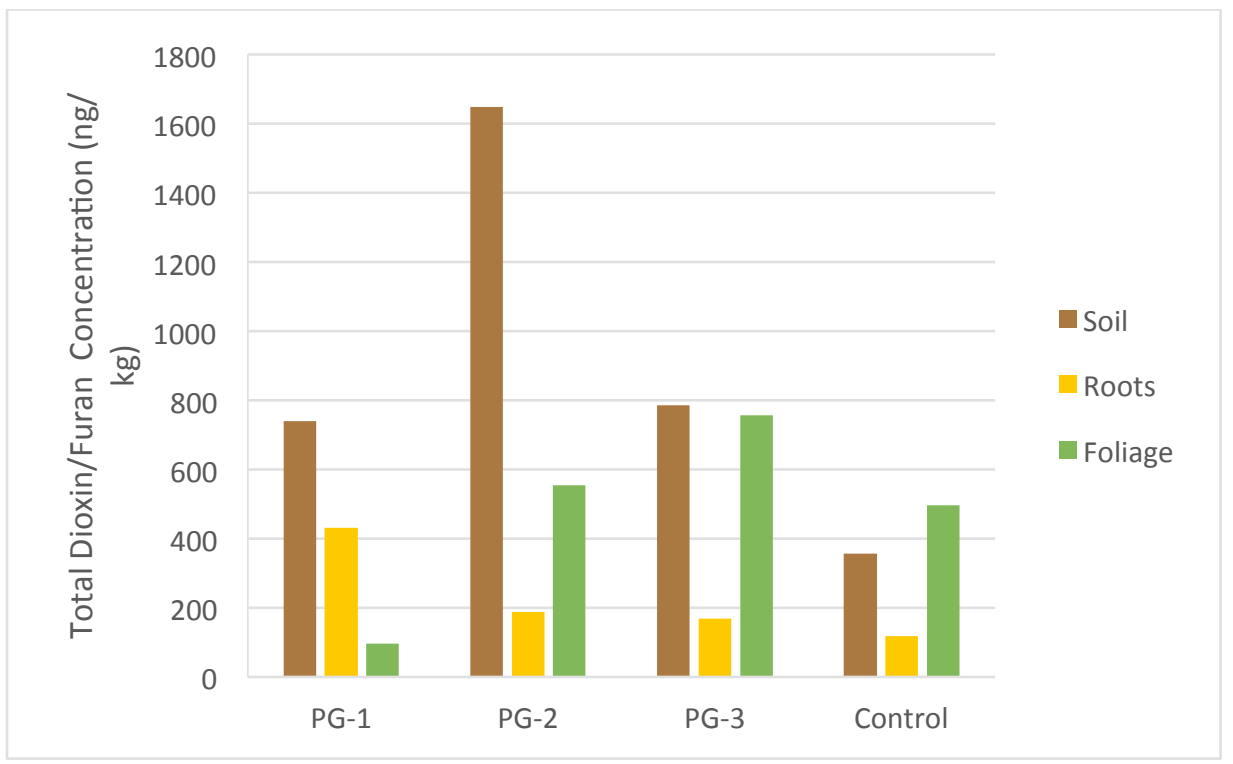

Figure 4.22. Total dioxin/furan concentrations for Palmer's Goldenbush 
Figure 4.23. Total dioxin/furan concentrations for Laurel Sumac

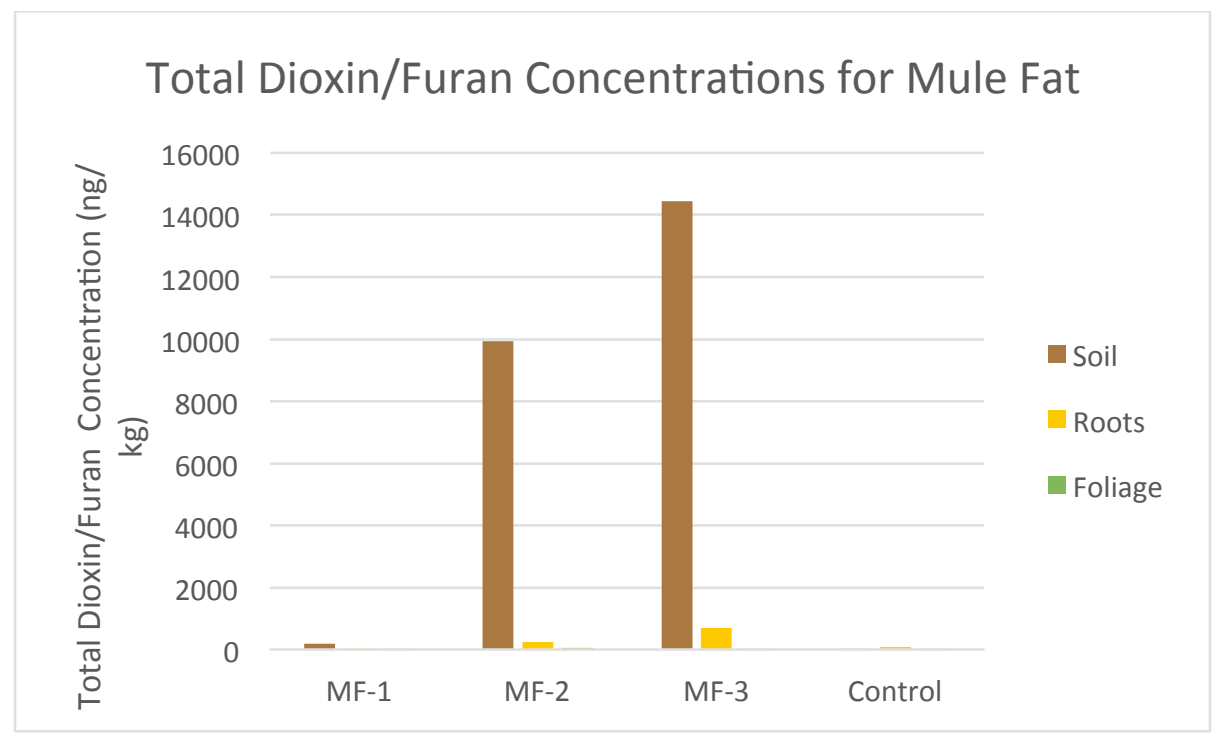

Figure 4.24. Total dioxin/furan concentrations for Mule Fat 


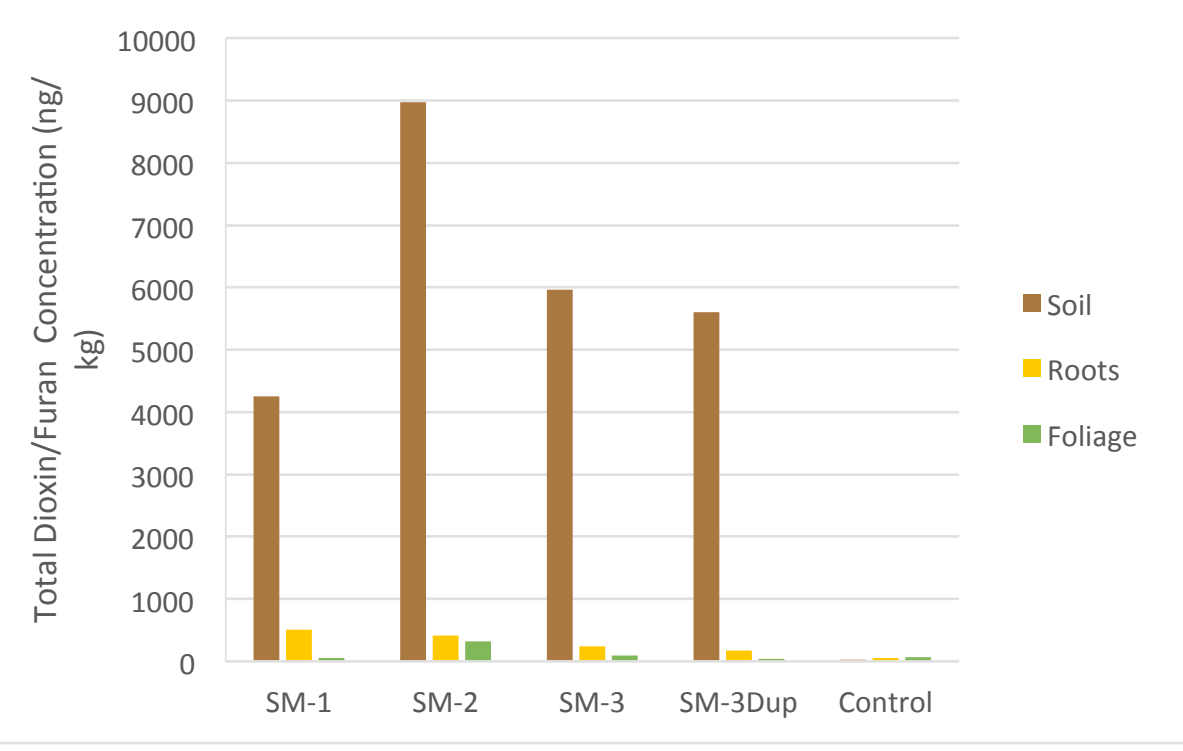

Figure 4.25. Total dioxin/furan concentrations for Summer Mustard

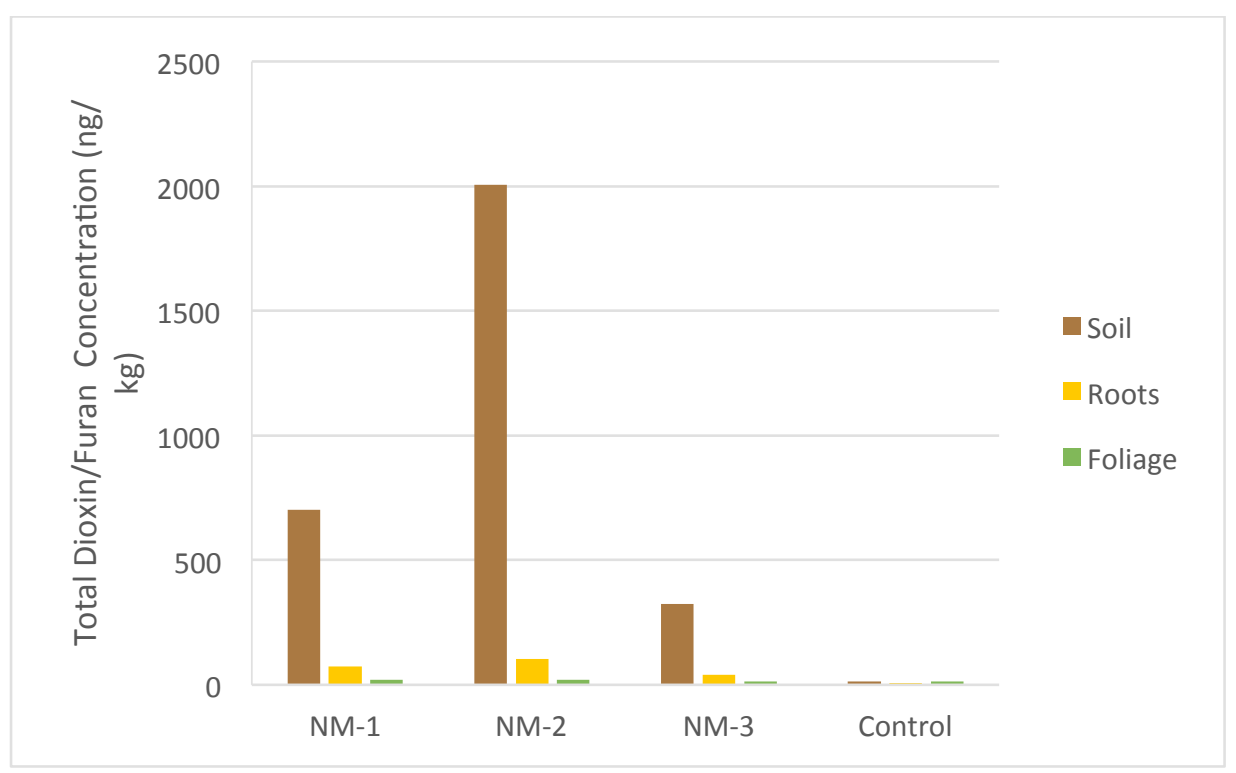

Figure 4.26. Total dioxin/furan concentrations for Narrowleaf Milkweed 


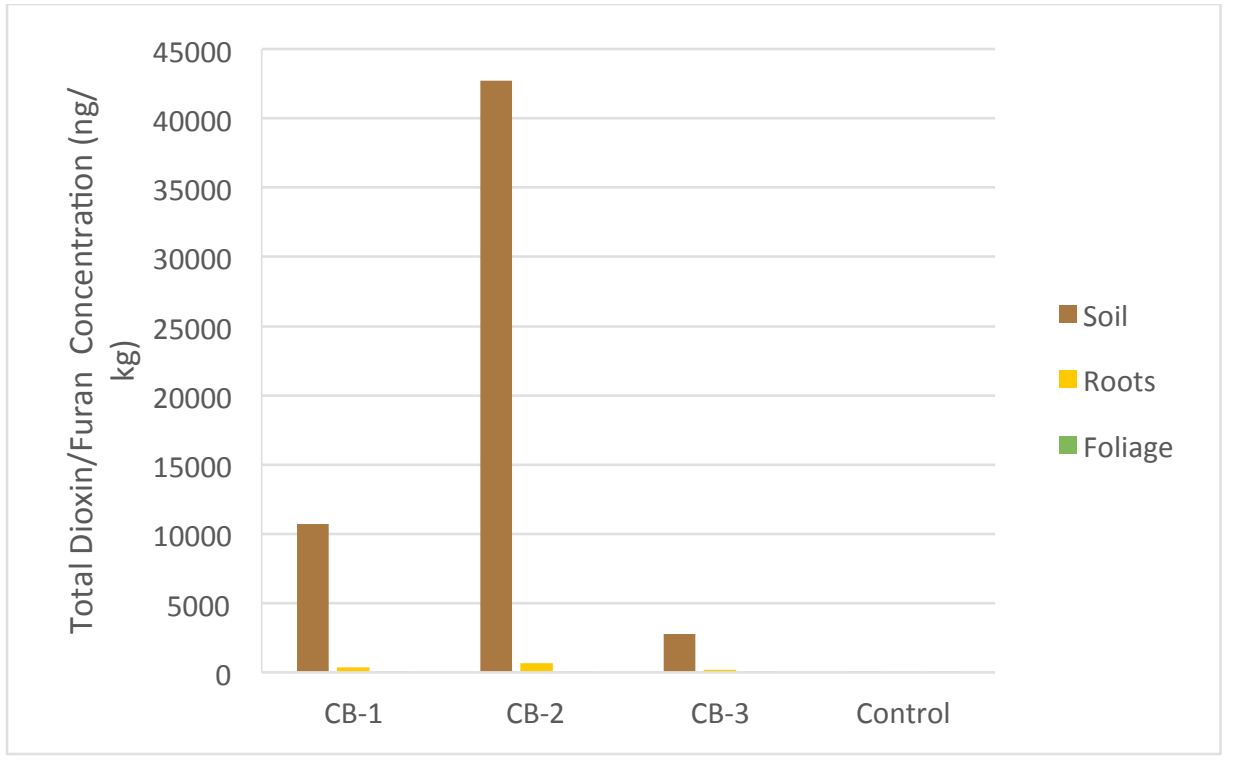

Figure 4.27. Total dioxin/furan concentrations for Coyote Brush 


\subsubsection{Mercury Phytoextraction in the Field}

Root and foliage mercury concentrations were below the detection limit of $0.1 \mathrm{mg} / \mathrm{kg}$ for all species. Mercury was present in most of the soil samples at concentrations ranging from $0.0572 \mathrm{mg} / \mathrm{kg}$ to $0.272 \mathrm{mg} / \mathrm{kg}$, but mercury was below the detection limits in soil associated with Palmer's Goldenbush, Narrowleaf Milkweed, and Purple Needlegrass.

\subsubsection{Silver Phytoextraction in the Field}

Silver was observed in the roots of all plant species except for Palmer's Goldenbrush and Purple Needlegrass (Figures 4.28 to 4.36). One of the Laurel Sumac specimens (LS-3) showed the highest uptake of silver into the roots with a concentration of $7.34 \mathrm{mg} / \mathrm{kg}$ (Figure 4.28). Summer Mustard (SM) was the only species that showed uptake of silver into the foliage, and this was at a concentration of $0.405 \mathrm{mg} / \mathrm{kg}$ in one specimen (SM-3) (Figure 4.29).

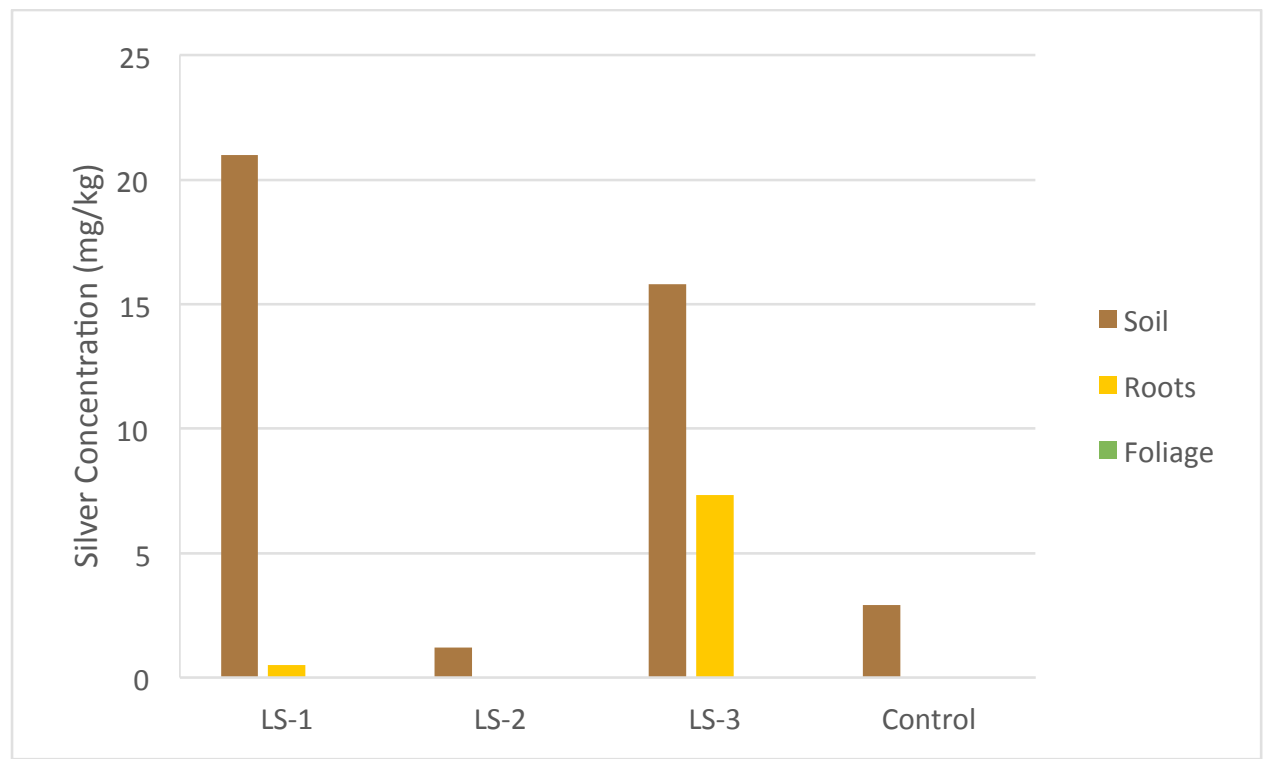

Figure 4.28. Silver concentrations for Laurel Sumac 


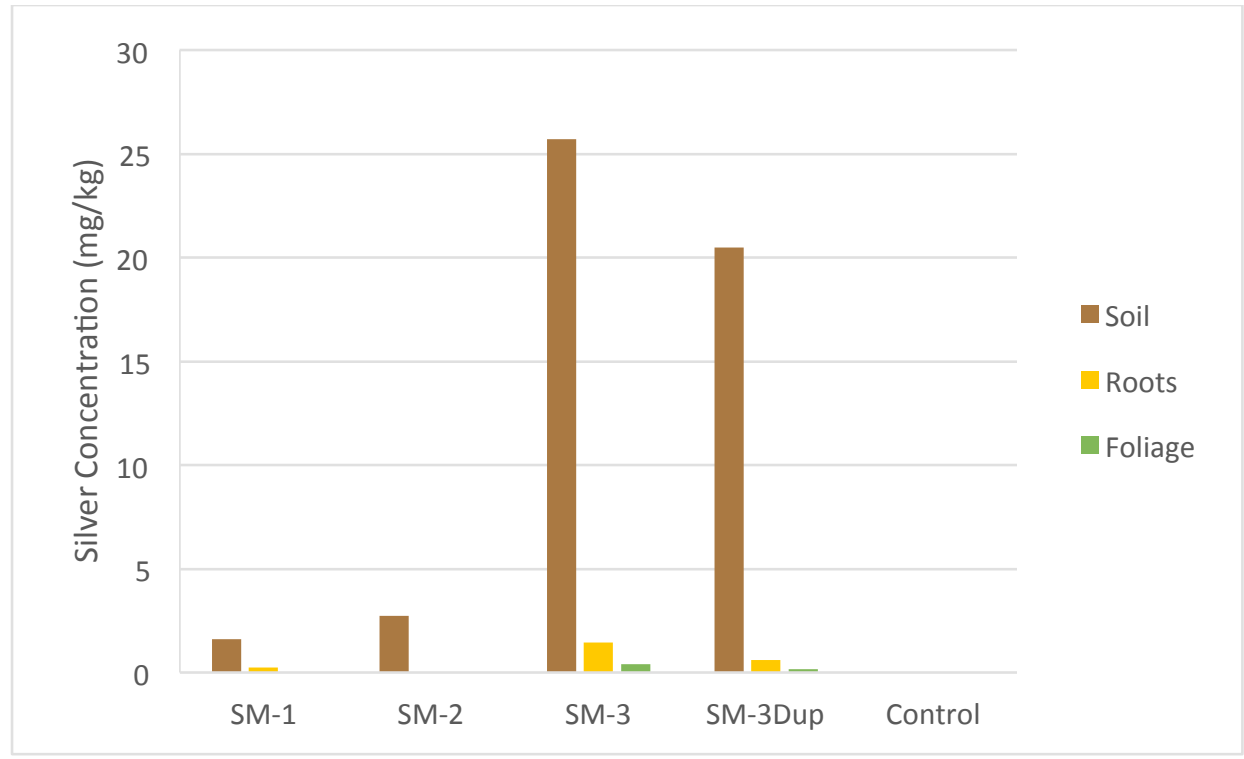

Figure 4.29. Silver concentrations for Summer Mustard

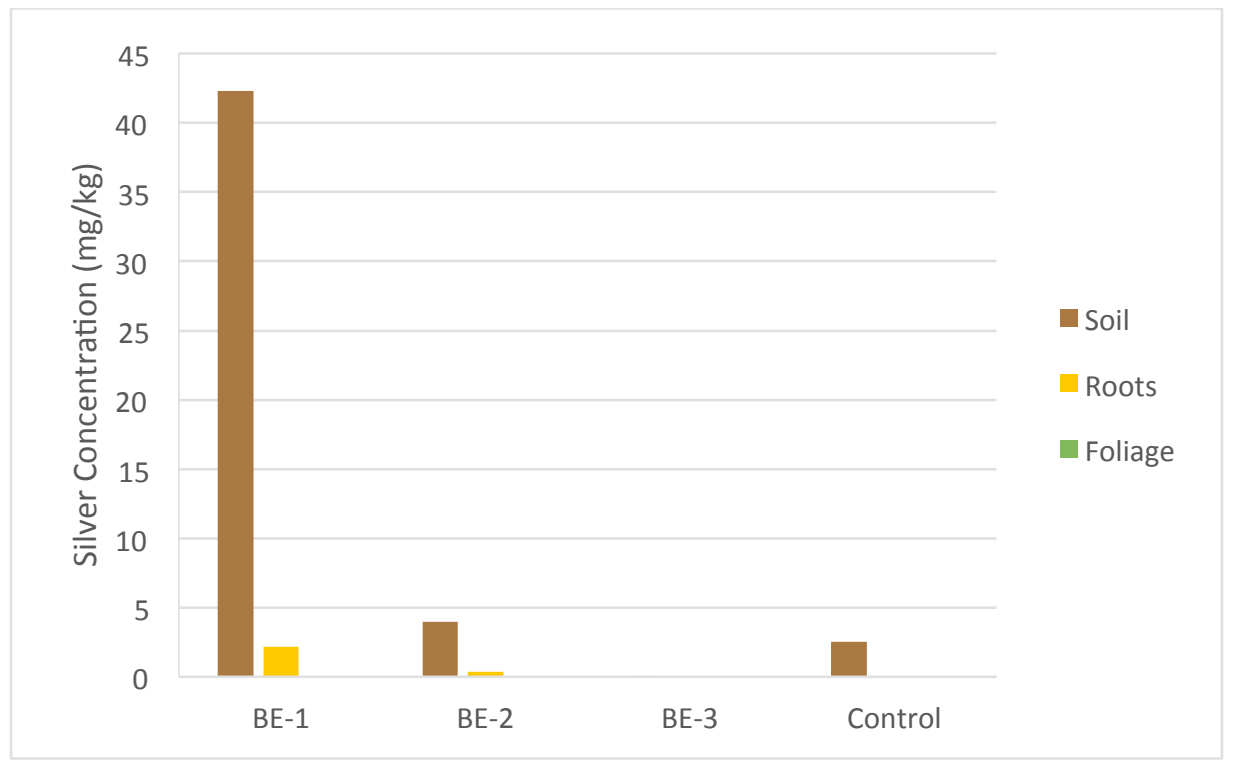

Figure 4.30. Silver concentrations for Blue Elderberry 


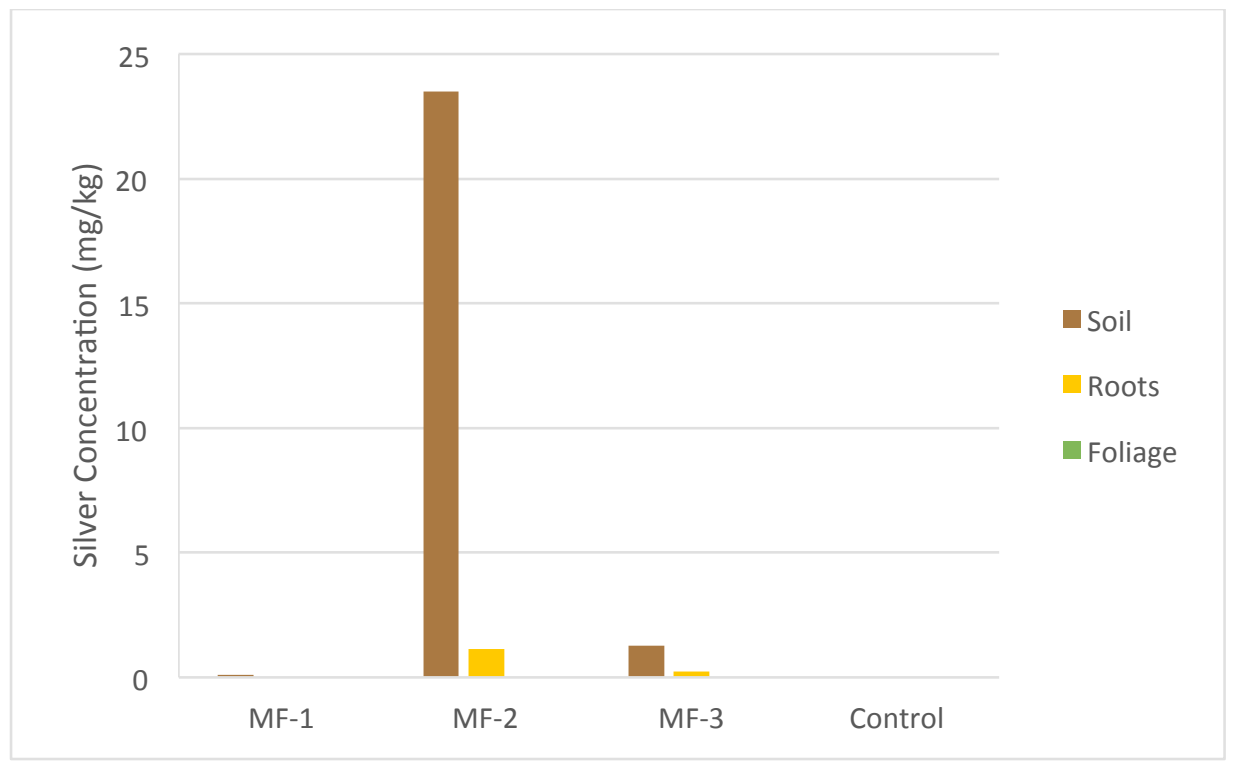

Figure 4.31. Silver concentrations for Mule Fat

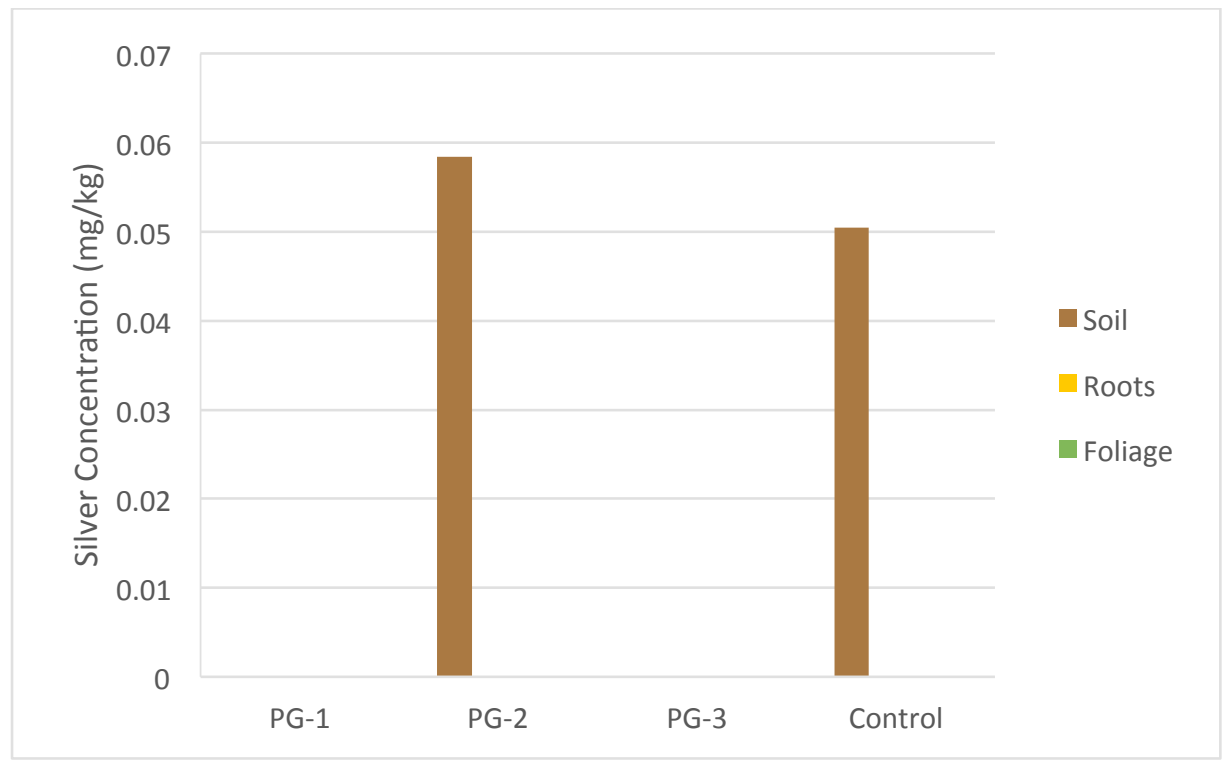

Figure 4.32. Silver concentrations for Palmer's Goldenbush 
Figure 4.33. Silver concentrations for Narrowleaf Milkweed

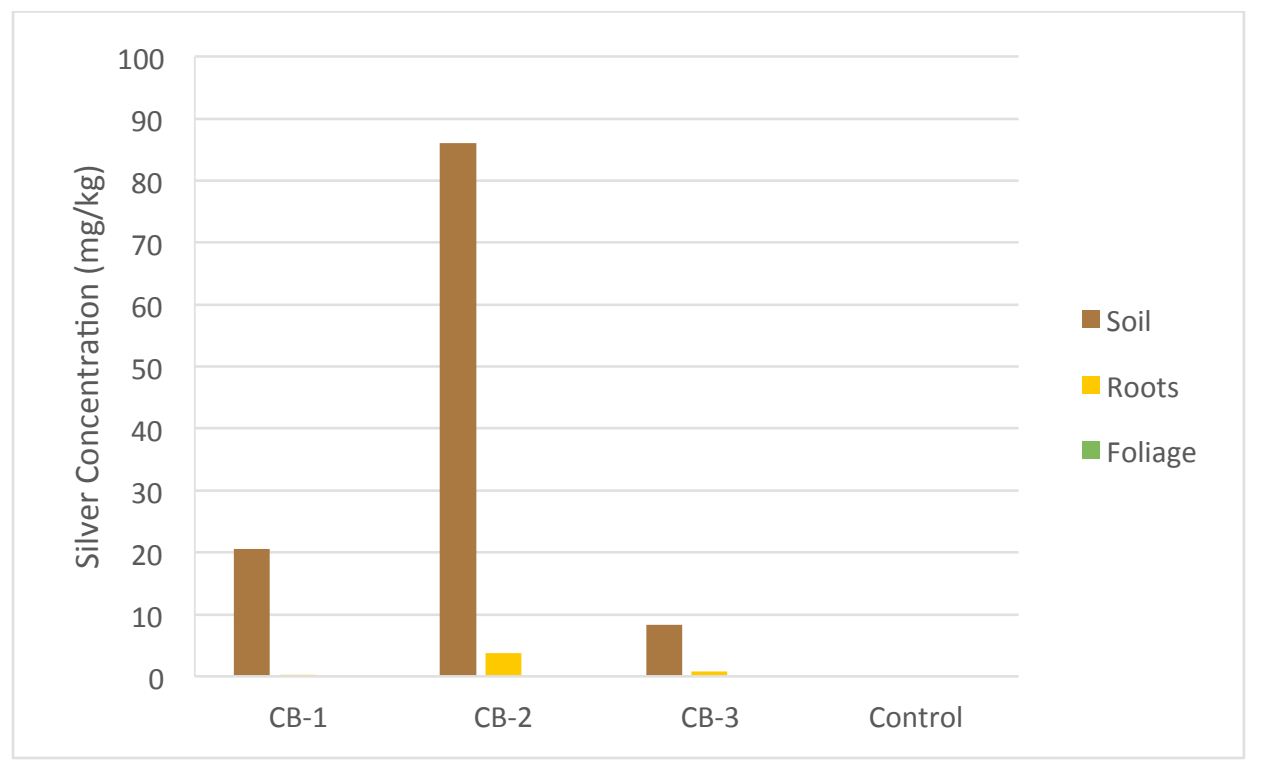

Figure 4.34. Silver concentrations for Coyote Brush 


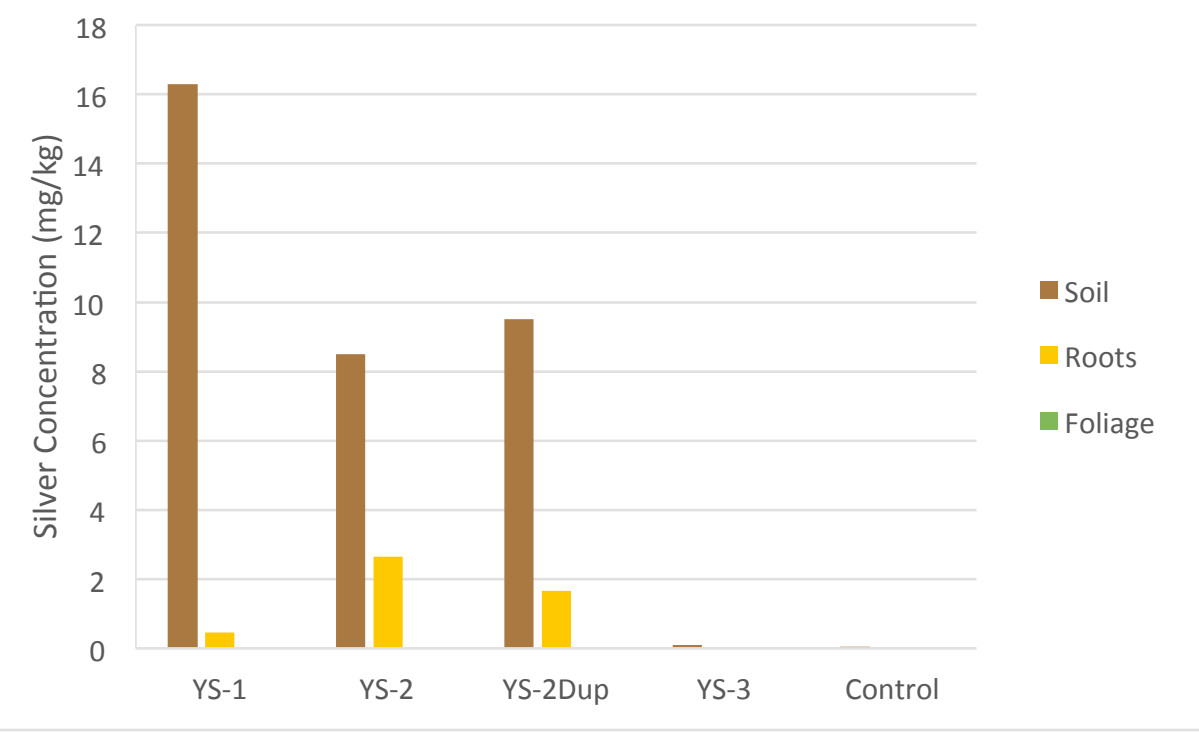

Figure 4.35. Silver concentrations for Yerba Santa

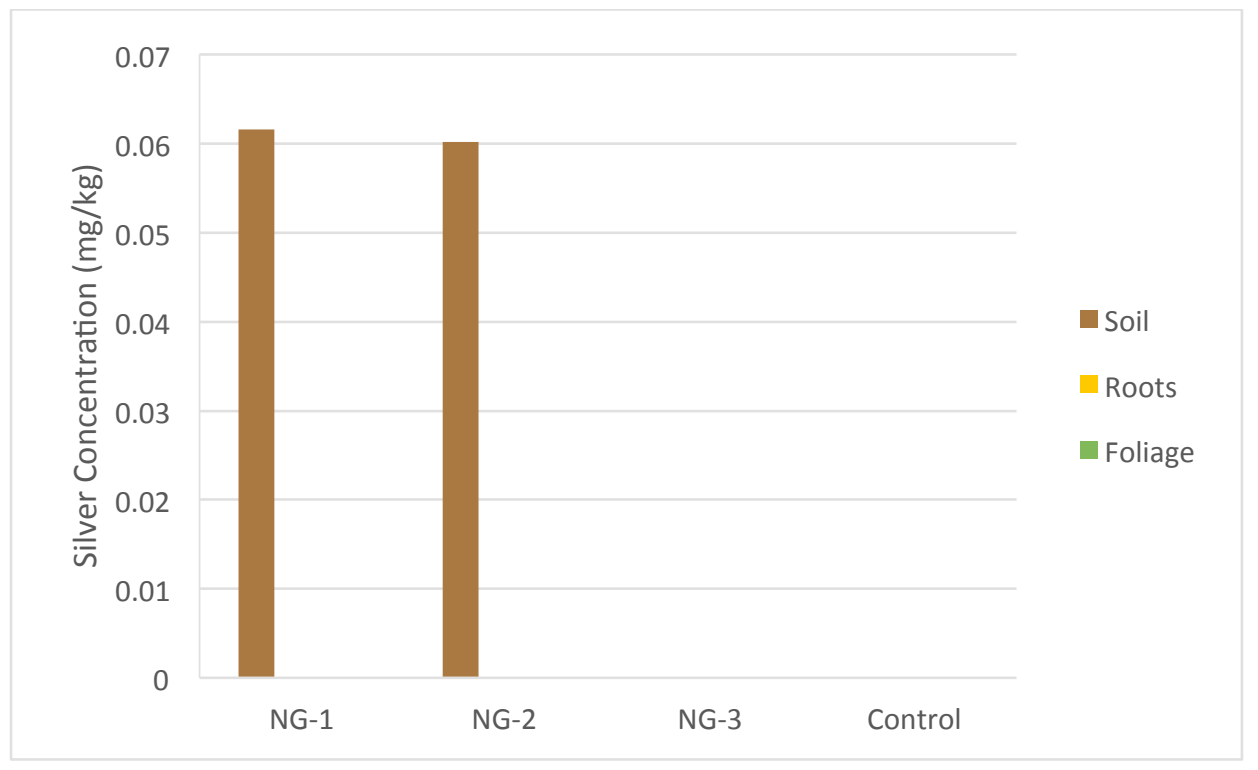

Figure 4.36. Silver concentrations for Purple Needlegrass 


\subsubsection{Cadmium Phytoextraction in the Field}

Most of the soil concentrations for cadmium were at or below the action level of 0.7

$\mathrm{mg} / \mathrm{kg}$ (Figures 4.37 to 4.45). At these low levels Mule Fat showed the greatest uptake of cadmium in the field screening. One specimen (MF-2) had a concentration of $1.84 \mathrm{mg} / \mathrm{kg}$ in the roots, and a concentration of $3.64 \mathrm{mg} / \mathrm{kg}$ in the foliage compared to a soil concentration of $1.01 \mathrm{mg} / \mathrm{kg}$ (Figure 4.37). Coyote Brush showed uptake and translocation of cadmium with soil levels below and above $0.7 \mathrm{mg} / \mathrm{kg}$. Specimens CB-1, 3 , and the control showed higher concentrations of cadmium in the plant tissue than in the soil (Figure 4.38).

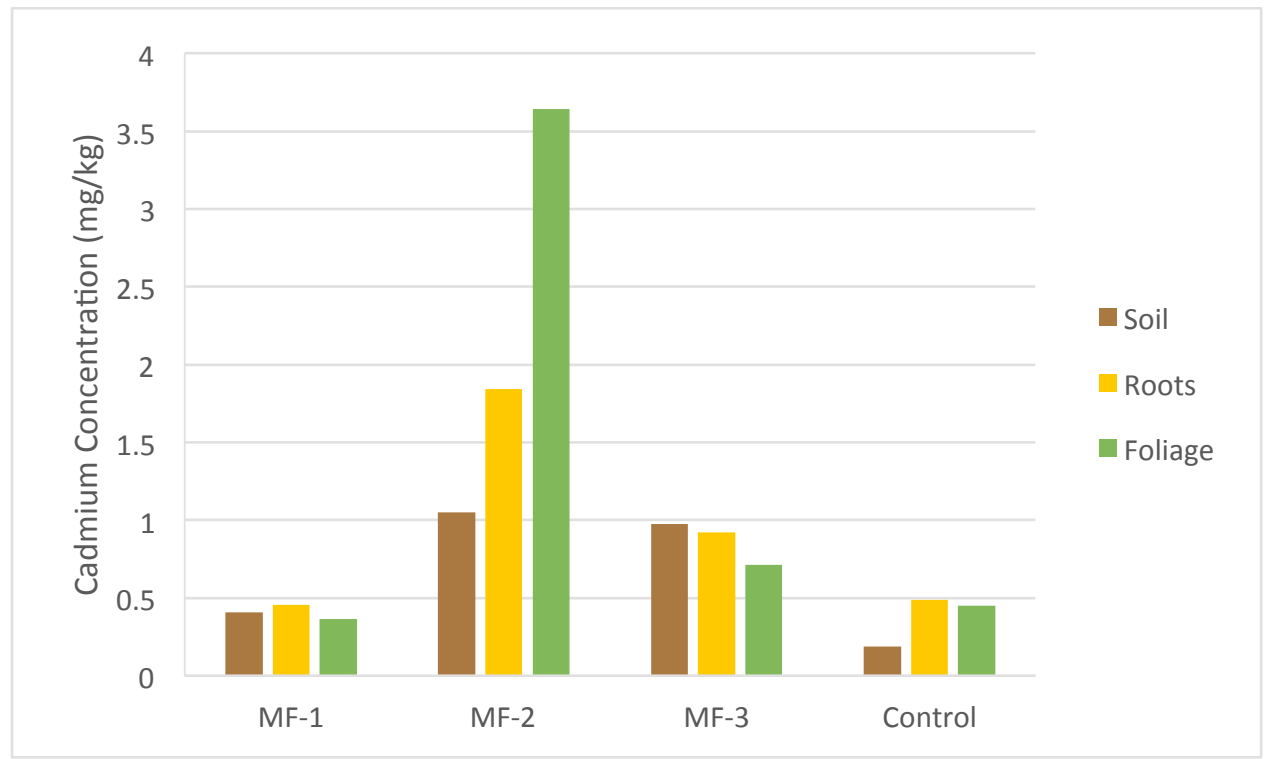

Figure 4.37. Cadmium concentration for Mule Fat 


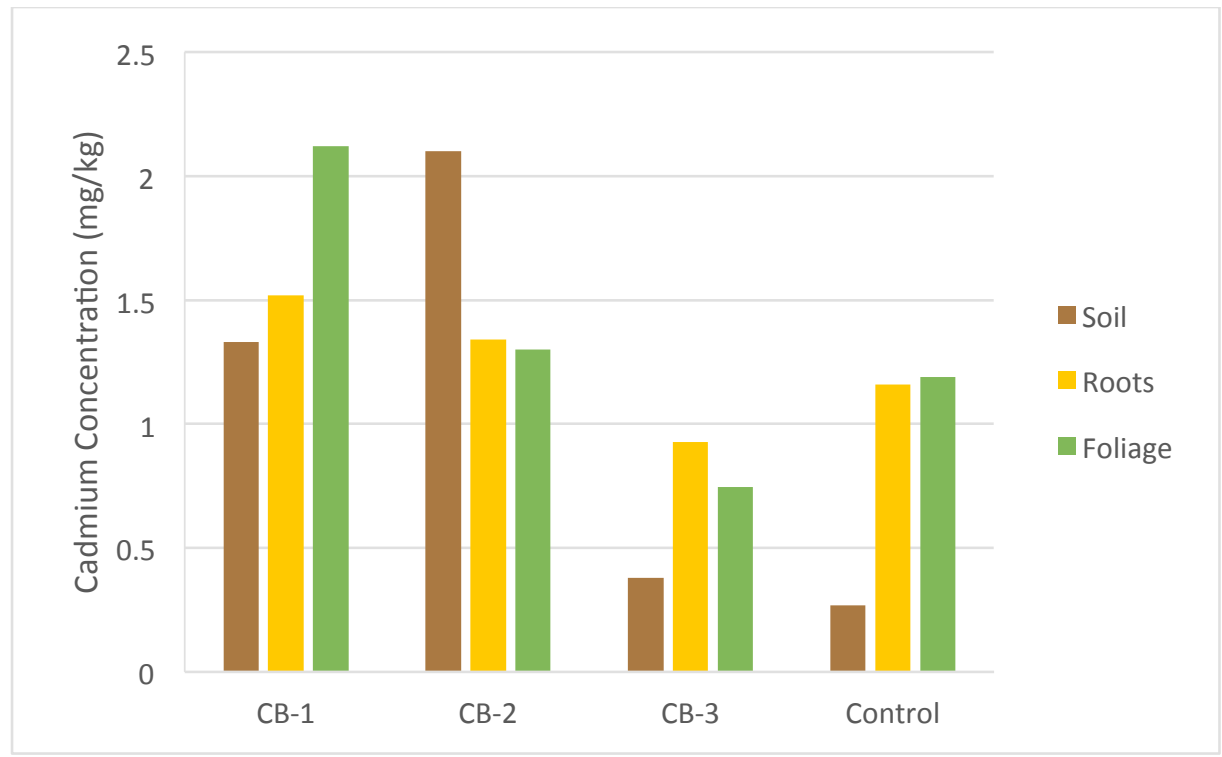

Figure 4.38. Cadmium concentrations for Coyote Brush

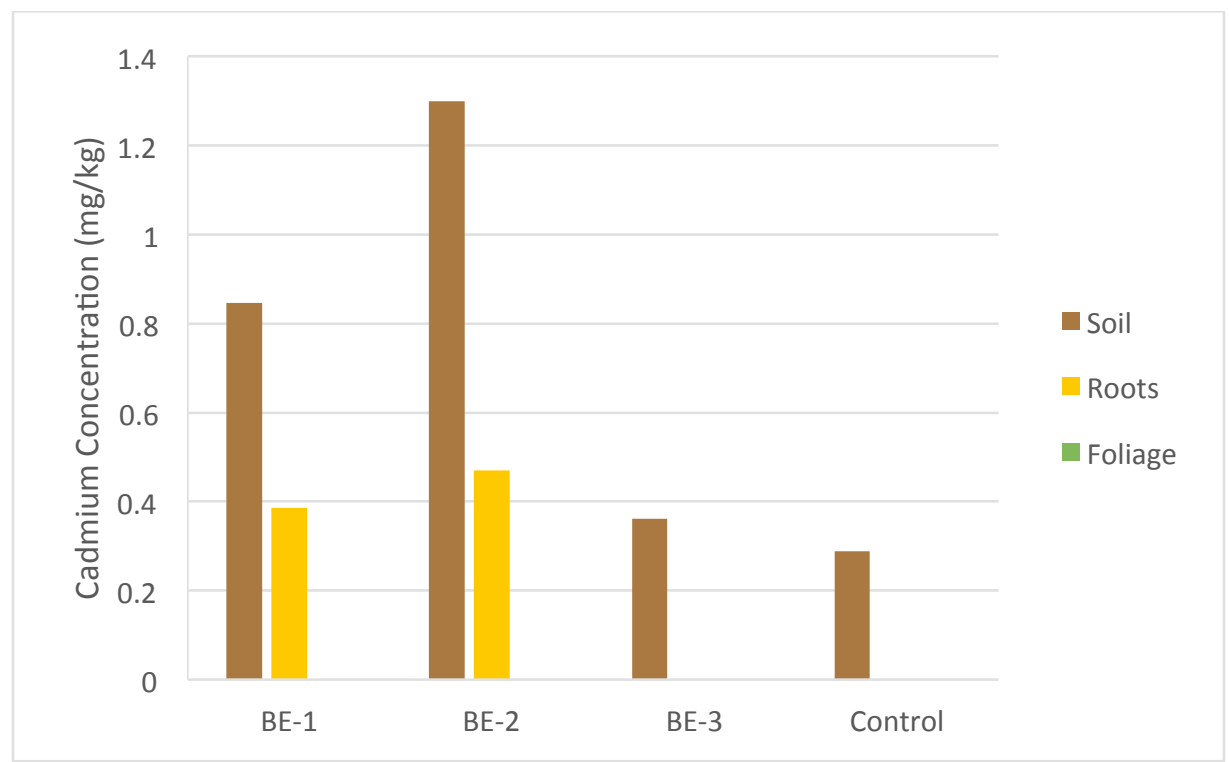

Figure 4.39. Cadmium concentrations for Blue Elderberry 


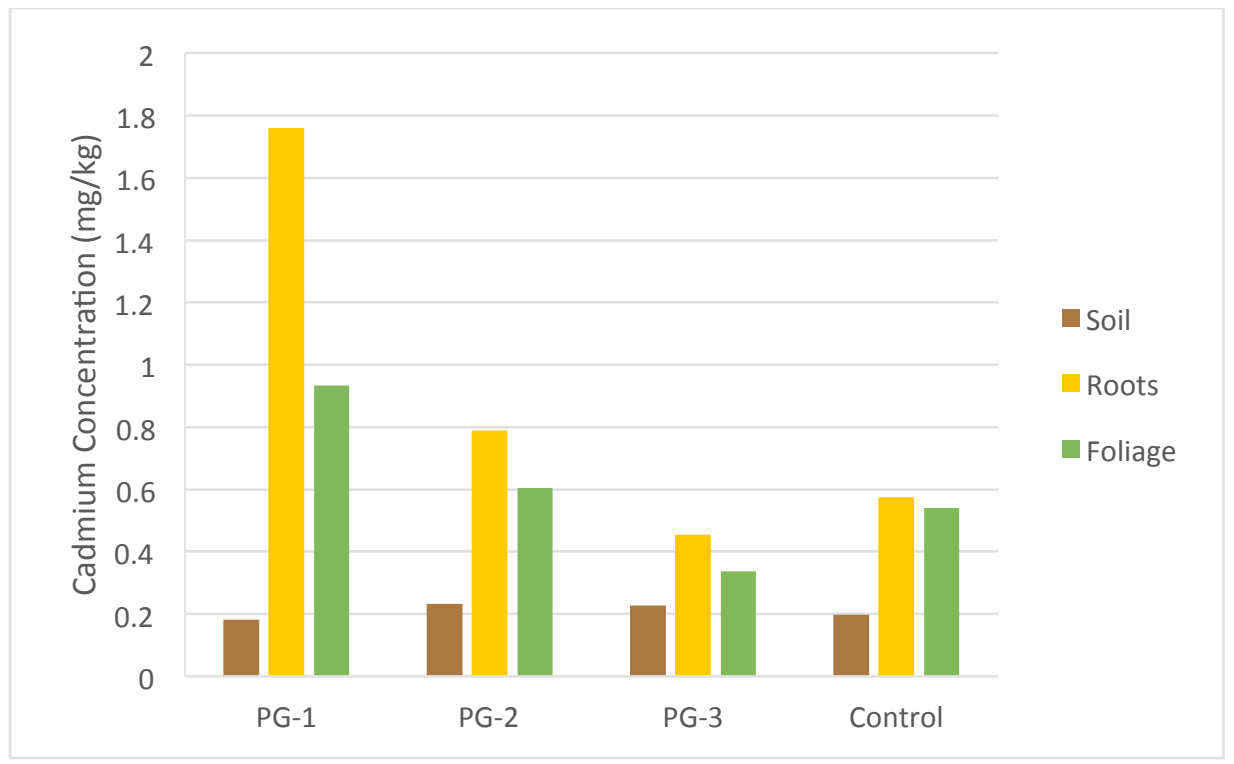

Figure 4.40. Cadmium concentrations for Palmer's Goldenbush

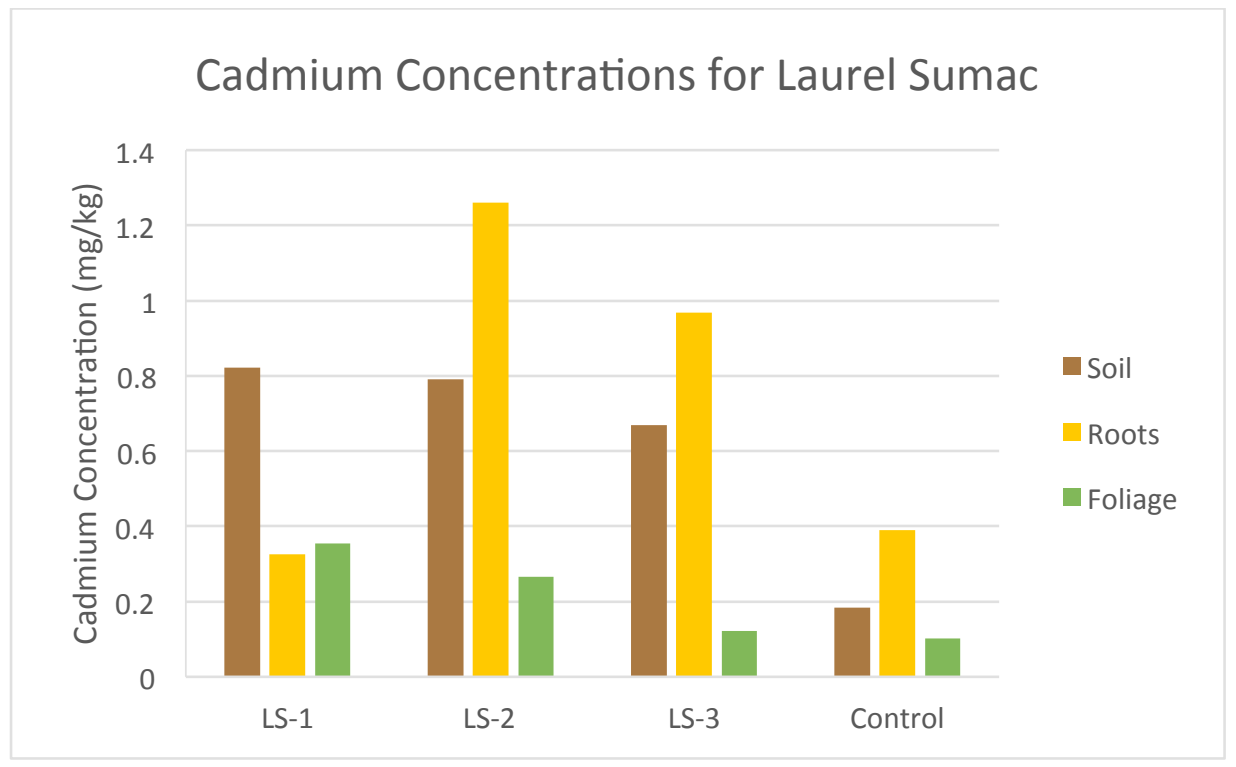

Figure 4.41. Cadmium concentrations for Laurel Sumac 


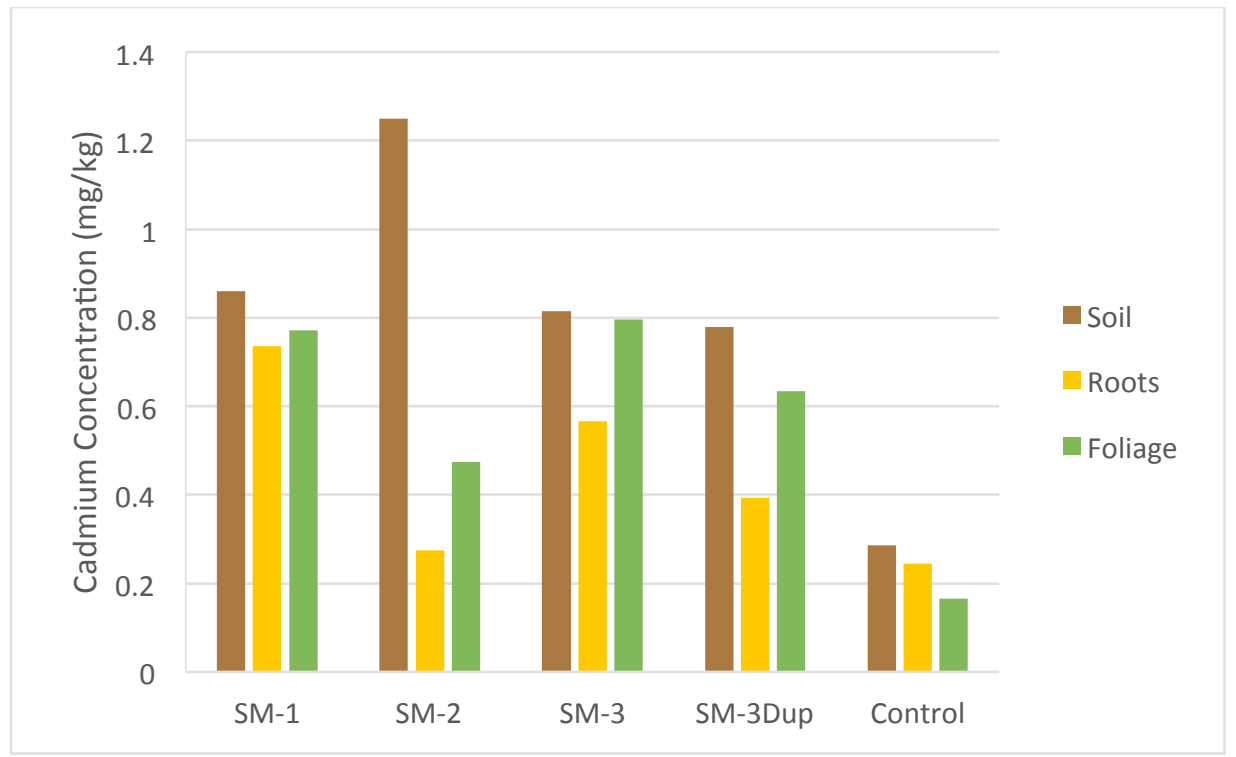

Figure 4.42. Cadmium concentrations for Summer Mustard

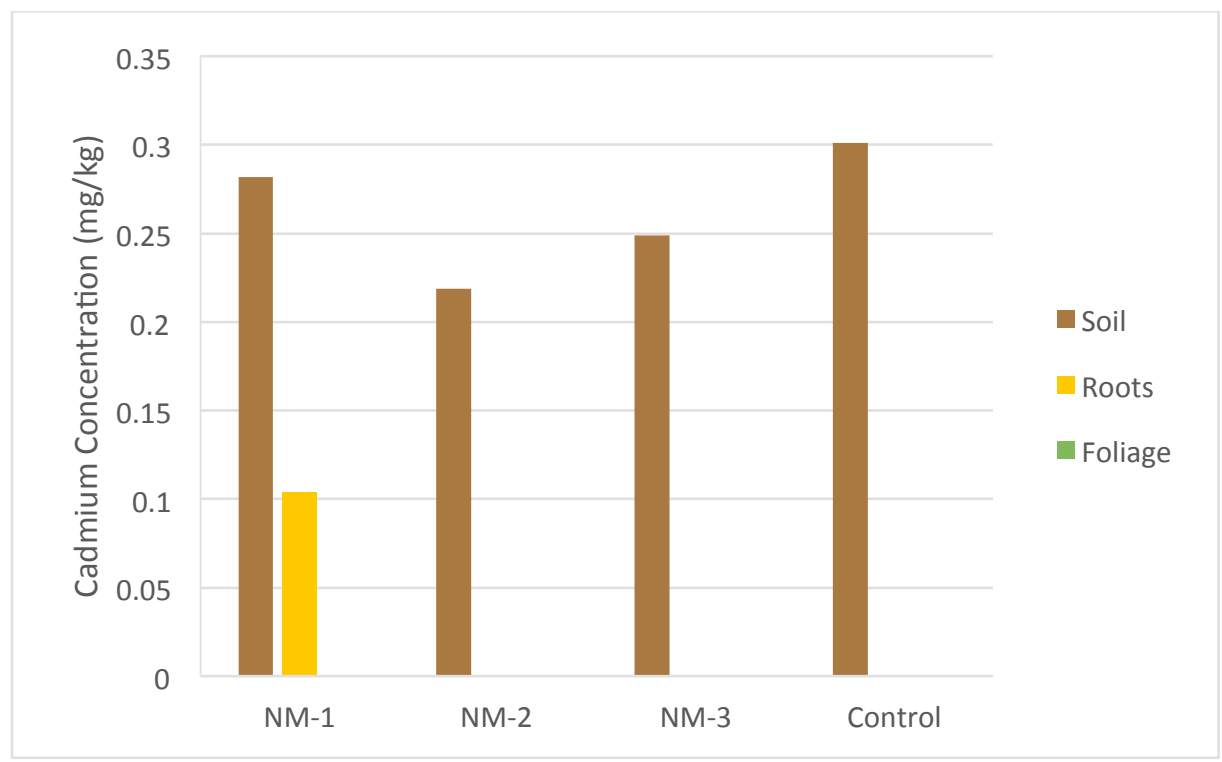

Figure 4.43. Cadmium concentrations for Narrowleaf Milkweed 


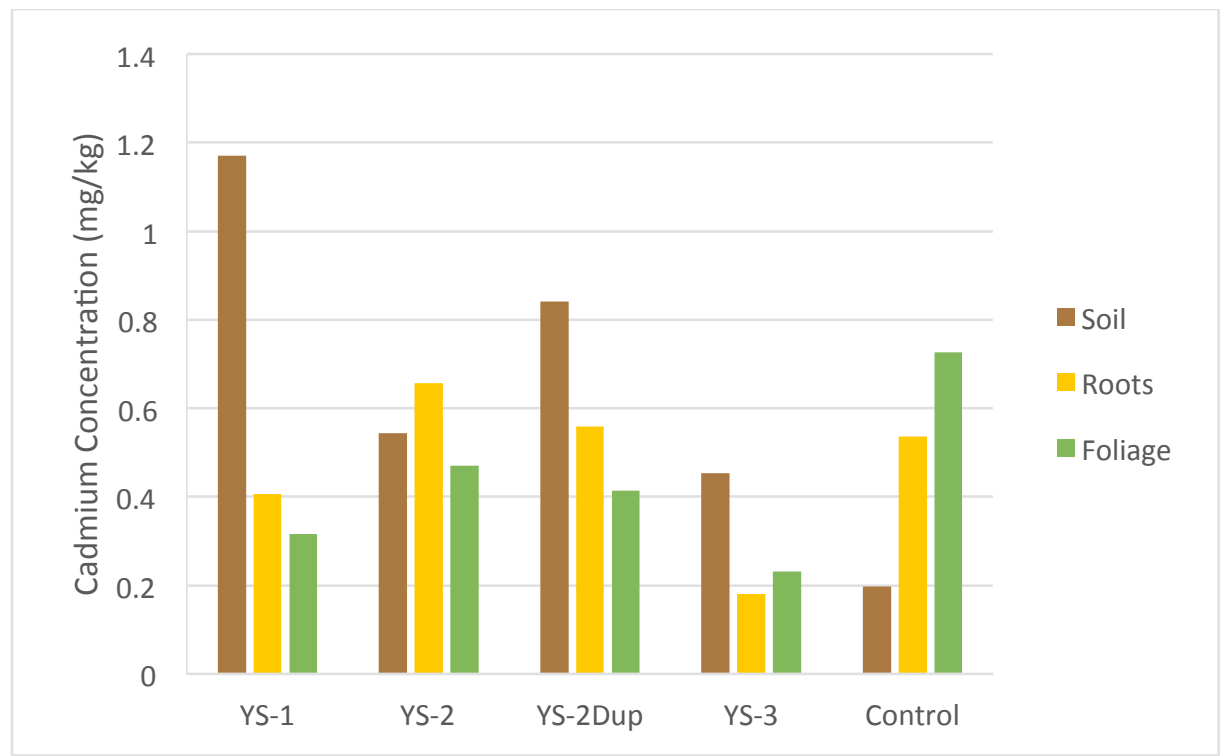

Figure 4.44. Cadmium concentrations for Yerba Santa

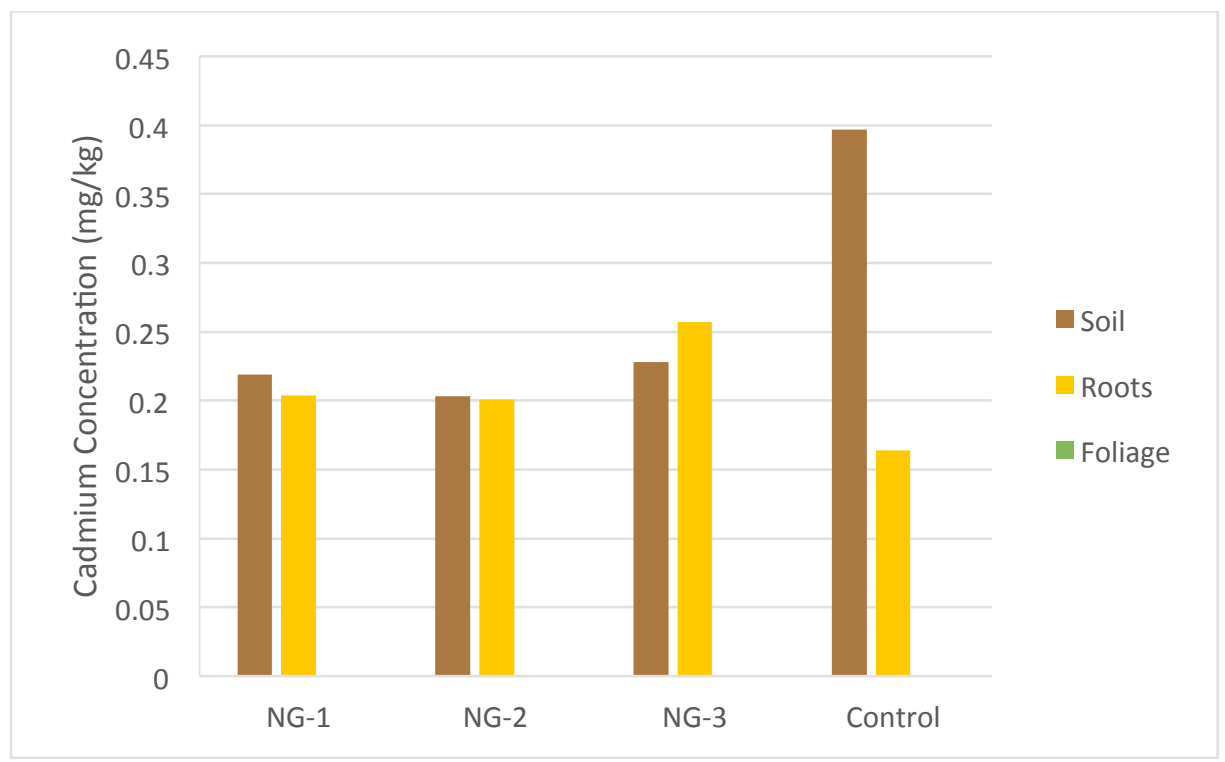

Figure 4.45. Cadmium concentrations for Purple Needlegrass 


\subsubsection{Lead Phytoextraction in the Field}

The lead concentrations in the soil associated with the plant specimens collected were much lower than the action level of $49 \mathrm{mg} / \mathrm{kg}$ (Figures 4.46 to 4.54 ). At these low levels Purple Needlegrass showed the greatest plant tissue lead concentrations. Specimen NG-3 had a root cadmium concentration of $8.92 \mathrm{mg} / \mathrm{kg}$ and specimen NG-1 had a foliage cadmium concentration of $1.17 \mathrm{mg} / \mathrm{kg}$ (Figure 4.46) compared to a soil level of 16.8 $\mathrm{mg} / \mathrm{kg}$ and $11.1 \mathrm{mg} / \mathrm{kg}$ respectively.

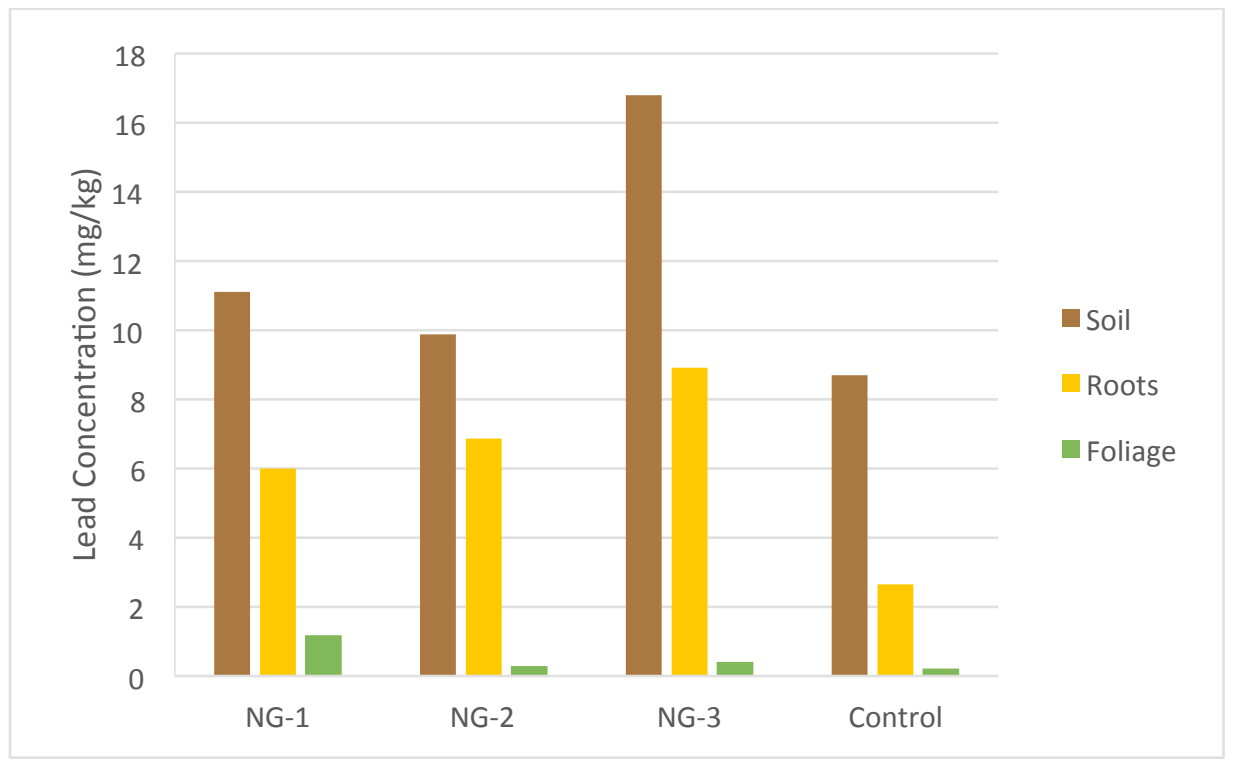

Figure 4.46. Lead concentrations for Purple Needlegrass 


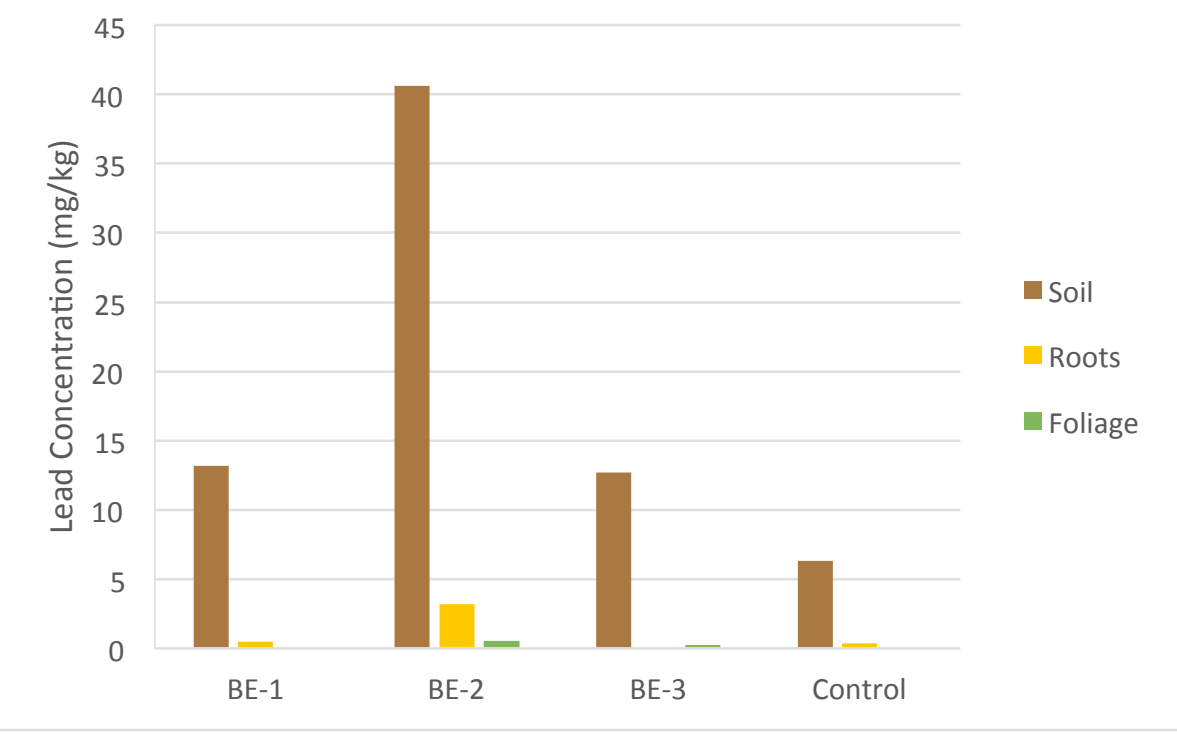

Figure 4.47. Lead concentrations for Blue Elderberry

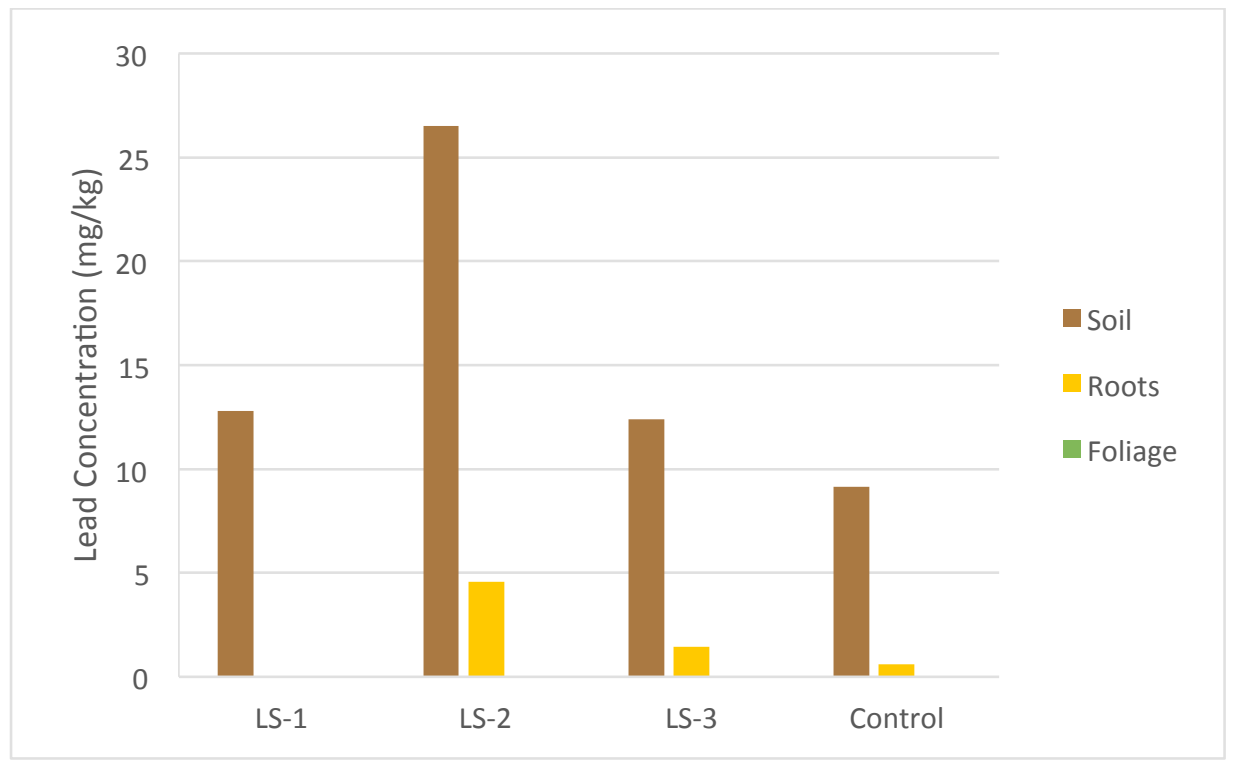

Figure 4.48. Lead concentrations for Laurel Sumac 


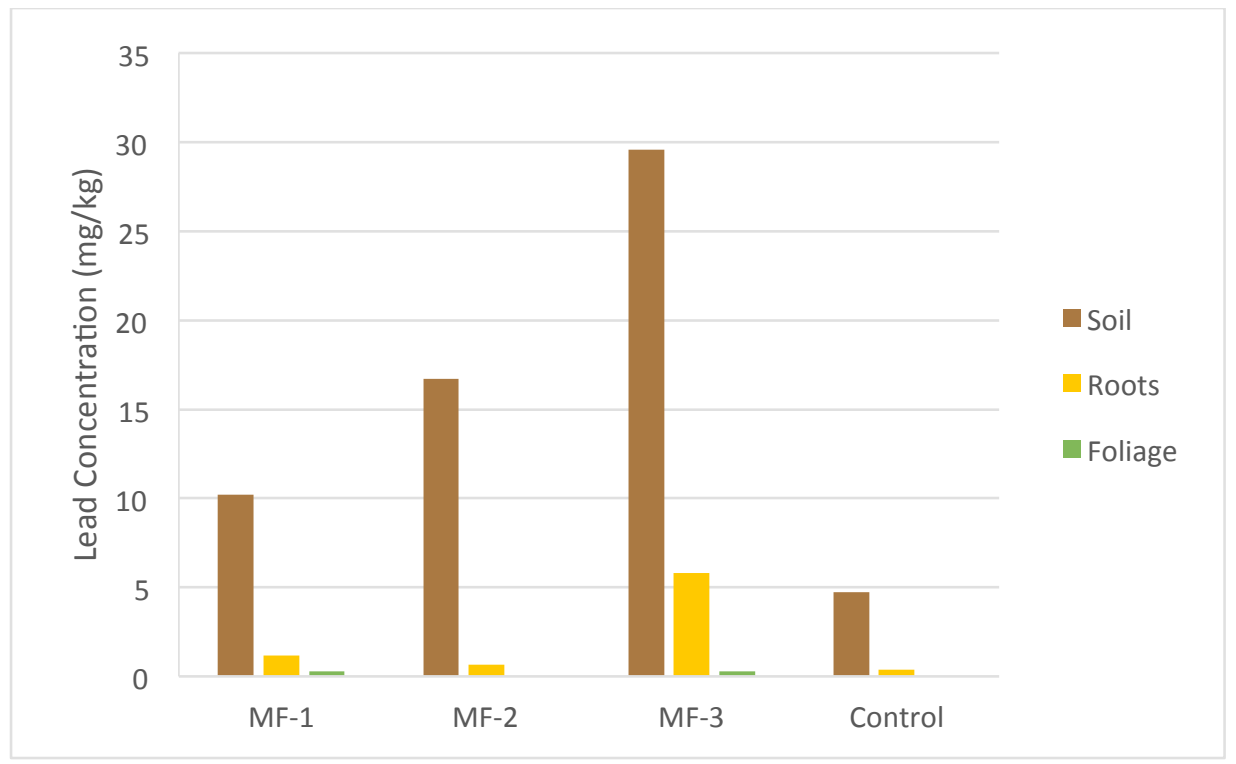

Figure 4.49. Lead concentrations for Mule Fat

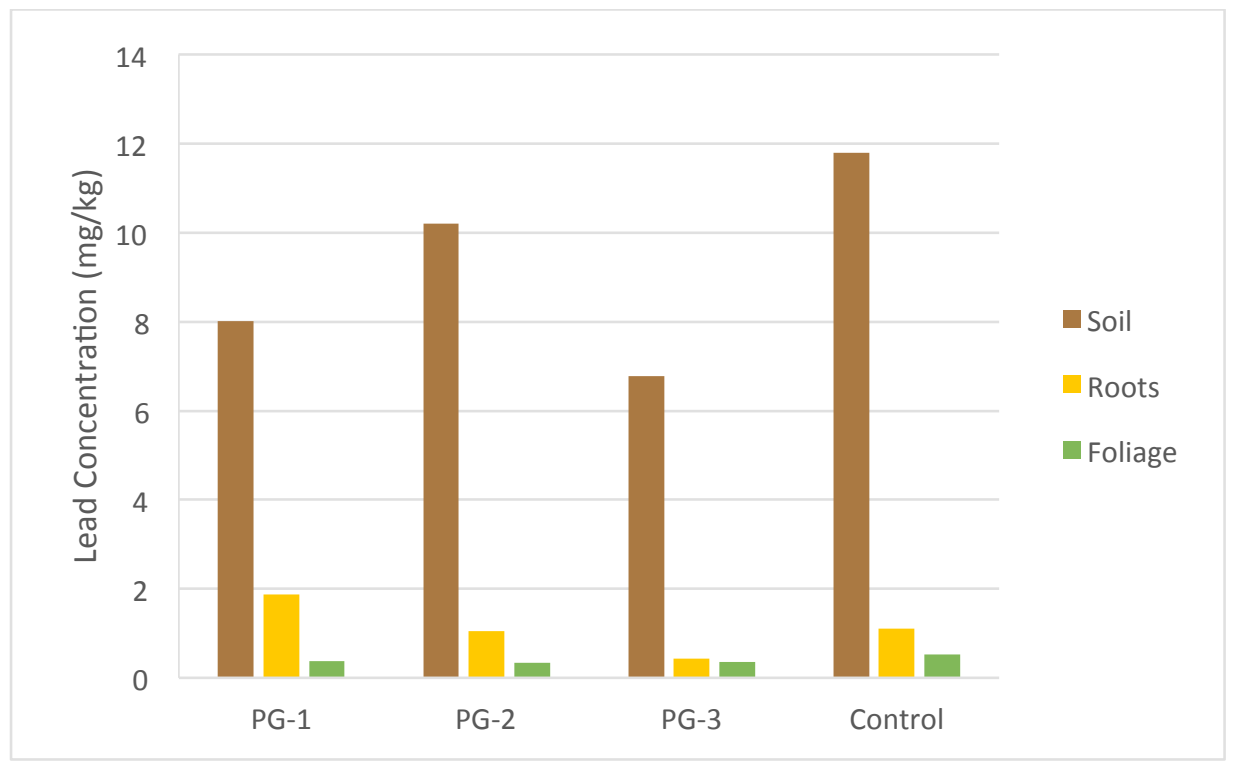

Figure 4.50. Lead concentrations for Palmer's Goldenbush 


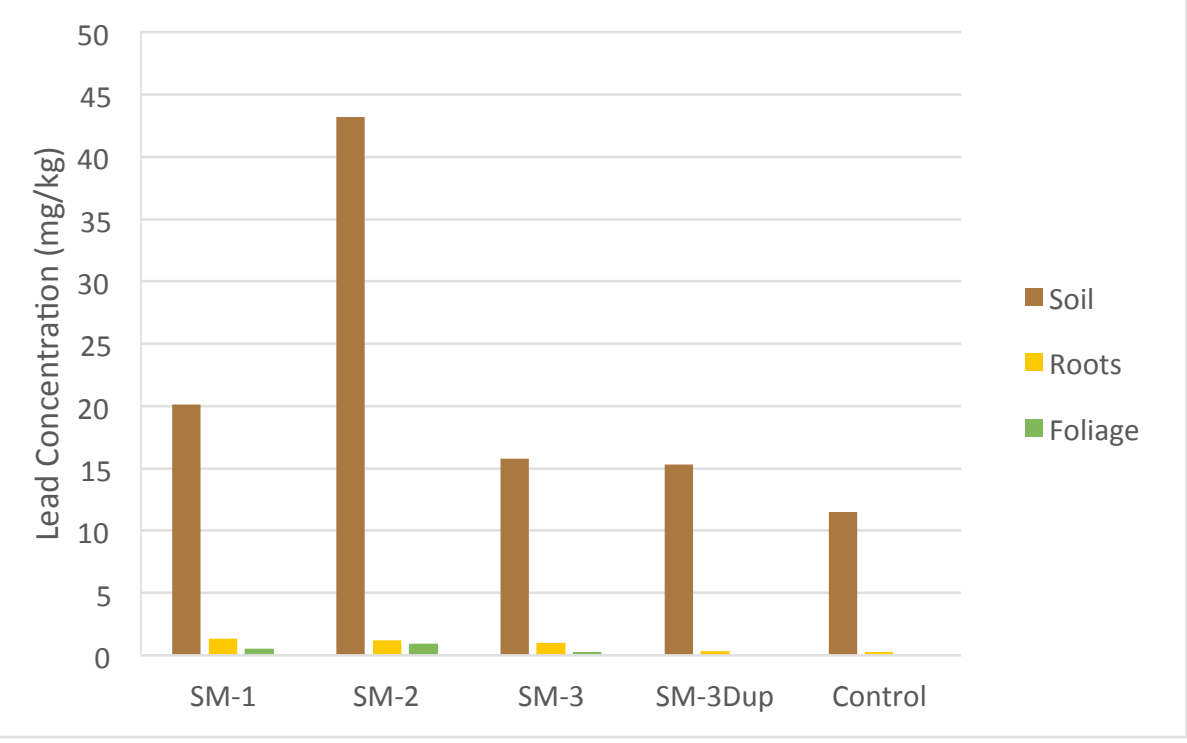

Figure 4.51. Lead concentrations for Summer Mustard

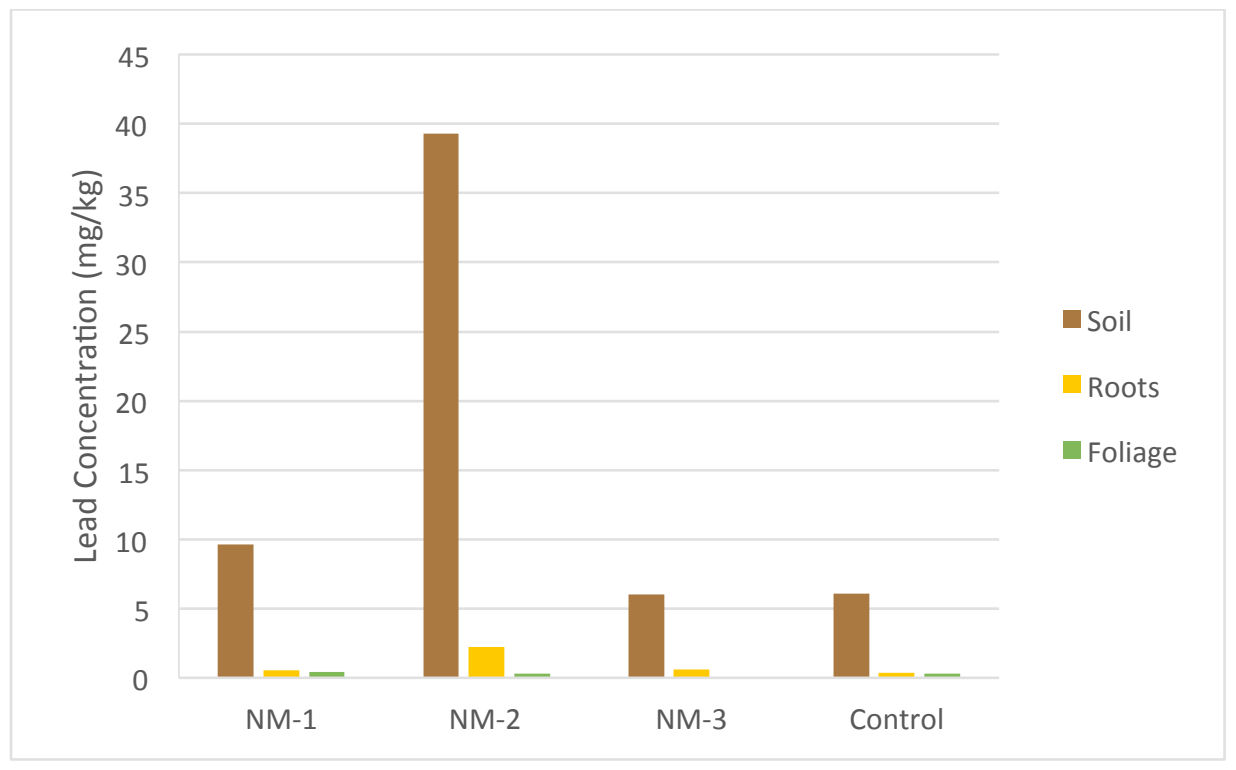

Figure 4.52. Lead concentrations for Narrowleaf Milkweed 


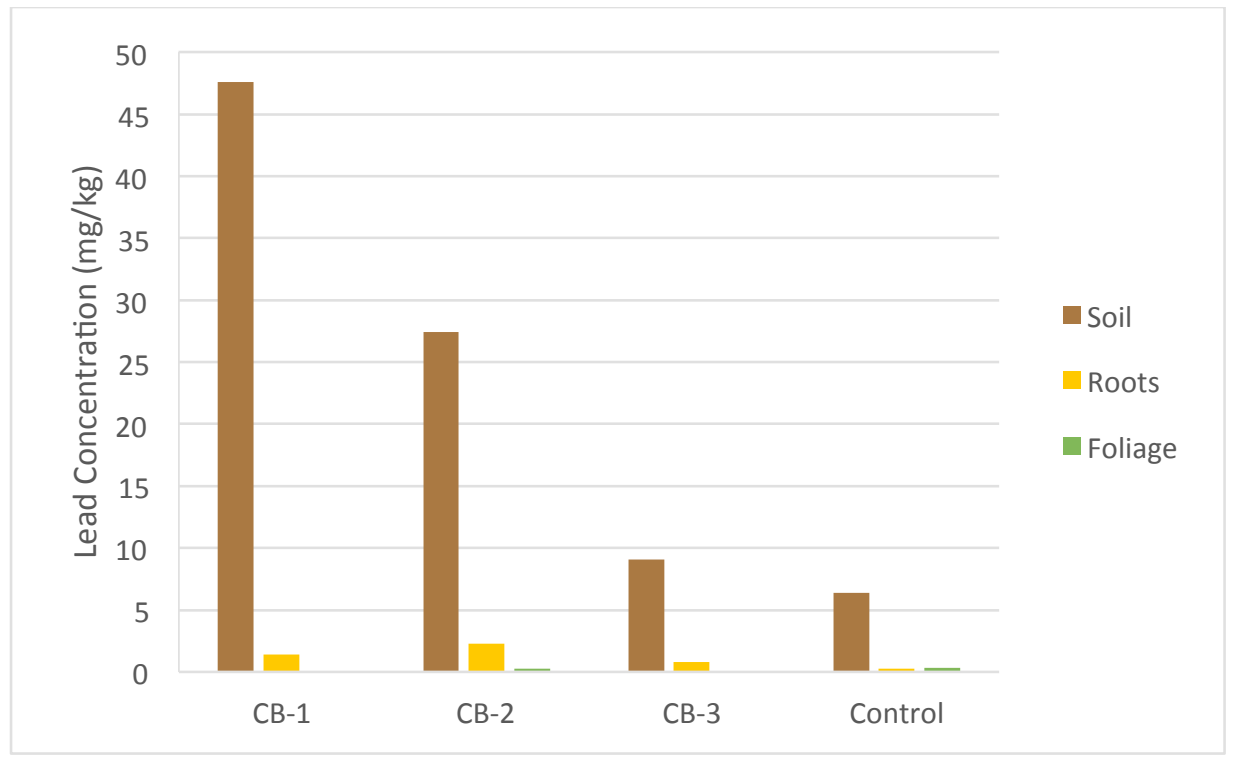

Figure 4.53. Lead concentrations for Coyote Brush

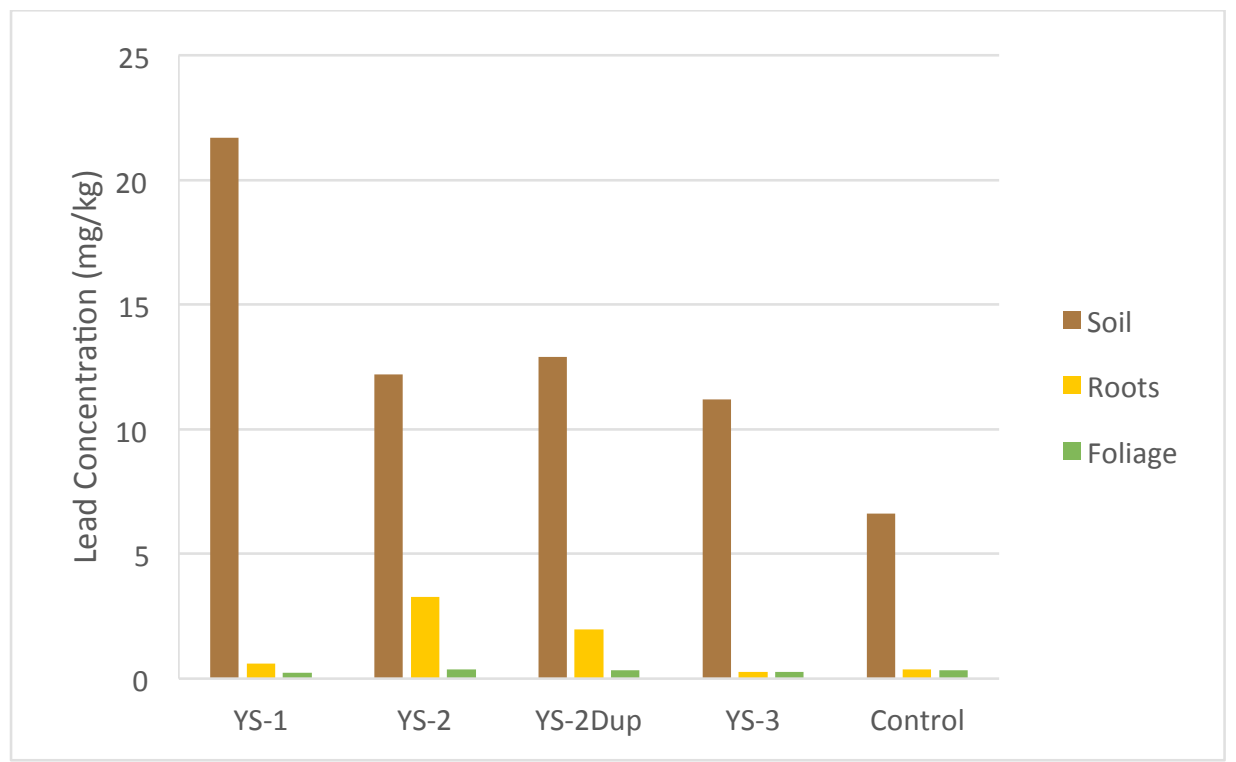

Figure 4.54. Lead concentrations for Yerba Santa 


\subsection{Phase II: Microcosm Results}

The initial homogenized bulk soil was sampled at the beginning of the experiment. The microcosm soil was sampled again at 85 days after planting, and the soil, roots, and foliage were sampled at 211 days after planting. A summary of the microcosm sampling events is shown in Table 4.1. The sealed sterilized unplanted microcosms were not sampled at 85 days to prevent any introduction of microbes into the sterile soil.

Results for each COI are described below in the following sections. Additional graphs of specific contaminant concentrations in soil are shown in Appendix A. All of the statistical test results are shown in Appendix B. 
Table 4.1. Summary of microcosm sampling events

\begin{tabular}{|c|c|c|c|c|c|c|}
\hline & \multicolumn{6}{|c|}{ Number of Replicates Sampled } \\
\hline & \multicolumn{2}{|r|}{0 Days } & \multicolumn{2}{|c|}{85 Days } & \multicolumn{2}{|c|}{211 Days } \\
\hline Microcosm & Soil & Roots/Foliage & Soil & Roots/Foliage & Soil & Roots/Foliage \\
\hline $\begin{array}{l}\text { Coyote } \\
\text { Brush (PA) }\end{array}$ & 15 & - & 5 & - & 5 & 5 \\
\hline $\begin{array}{l}\text { Mule Fat } \\
\text { (PB) }\end{array}$ & 15 & - & 5 & - & 5 & 5 \\
\hline $\begin{array}{l}\text { Purple } \\
\text { Needlegrass } \\
(\mathrm{PC})\end{array}$ & 15 & - & 5 & - & 2 & 2 \\
\hline $\begin{array}{l}\text { Fertilized } \\
\text { Coyote } \\
\text { Brush } \\
\text { (FPA) }\end{array}$ & 15 & - & 5 & - & 5 & 5 \\
\hline $\begin{array}{l}\text { Chelated } \\
\text { Coyote } \\
\text { Brush } \\
(\mathrm{CPA})\end{array}$ & 15 & - & 5 & - & 3 & 3 \\
\hline $\begin{array}{l}\text { Sterilized } \\
\text { Purple } \\
\text { Needlegrass } \\
\text { (SP) }\end{array}$ & 15 & - & 5 & - & 2 & 2 \\
\hline $\begin{array}{l}\text { Unplanted } \\
\text { (U) }\end{array}$ & 15 & - & 5 & - & 5 & 5 \\
\hline $\begin{array}{l}\text { Sterilized } \\
\text { Unplanted } \\
\text { (SU) }\end{array}$ & 15 & - & - & - & 5 & 5 \\
\hline
\end{tabular}

\subsubsection{Plant Growth in the Microcosms}

Most of the plants were healthy with the exception of the chelated Coyote Brush. The plants in this treatment exhibited lower biomass production, reduced water uptake, and more dead leaves and stems than the Coyote Brush in other treatments (Figure 4.55). 


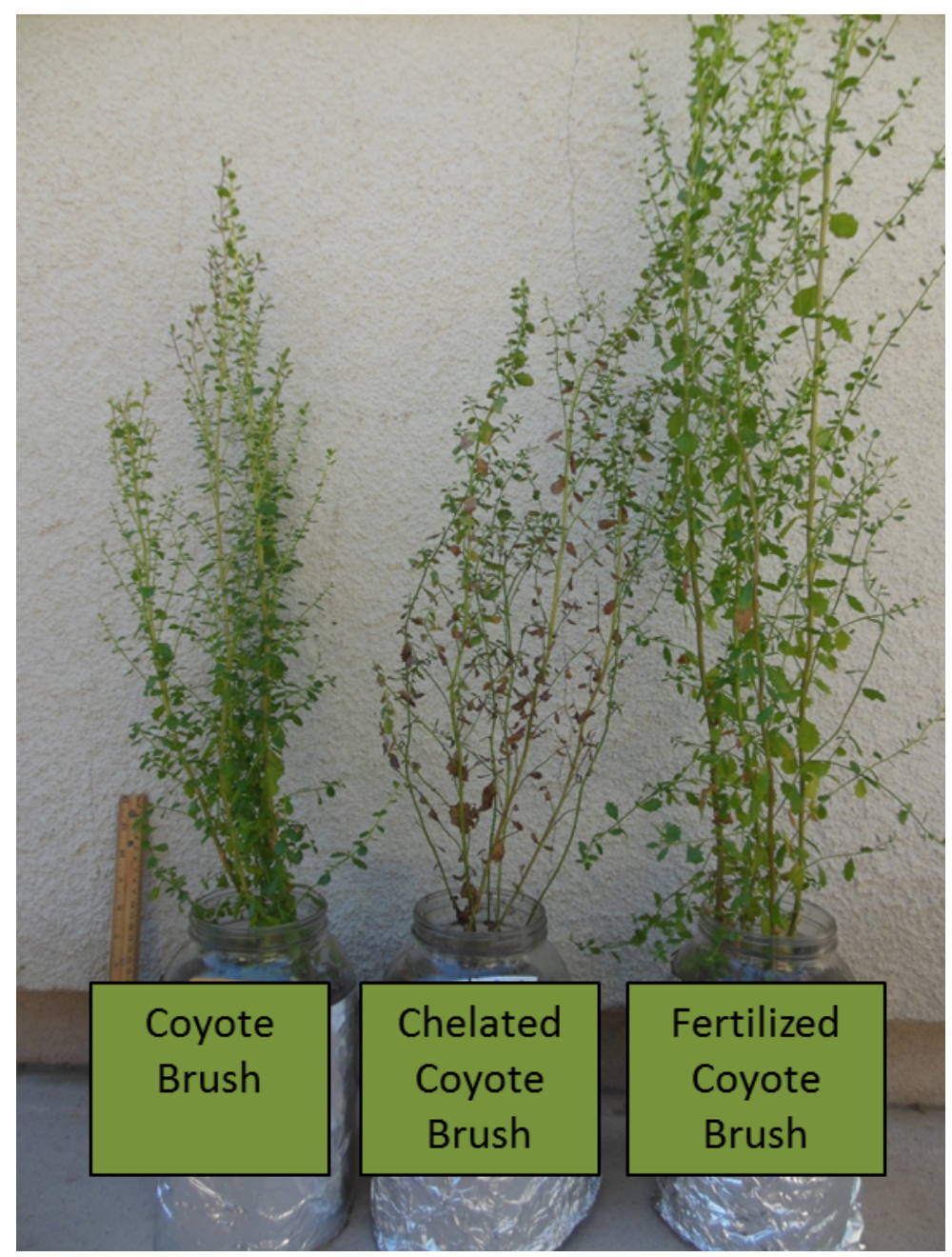

Figure 4.55. Normal, chelated, and fertilized Coyote Brush plants

\subsubsection{Petroleum Hydrocarbons}

EFH concentrations were not measured for the microcosm plant tissue since the field screening showed that plant-produced compounds completely masked any petroleum hydrocarbons that might have been taken into the plant. Total EFH concentrations in the soil of each microcosm are shown in Figure 4.56 for the duration of the experiment. All of the treatments showed a large and similar increase in EFH soil concentrations at Day 211 of the experiment. Most likely the observed increase was due to laboratory method differences when integrating the chromatograms. The initial and midpoint analyses were 
performed by EMAX labs while the final analysis on Day 211 was performed by Lancaster labs. However, since all treatments started with the same soil with the same EFH concentrations, differences in EFH concentrations of final soil samples could be used to identify differences in EFH degradation caused by the treatment, even if it could not be used to show degradation relative to initial concentration. However, the sterilized unplanted control exhibited the lowest final EFH concentrations, indicating no effect of plants or soil microbes on EFH degradation. Statistical analysis of the final EFH soil concentrations reveals that none of the treatments had any significant effect except that the sterilized unplanted control had a lower total EFH concentration than the fertilized Coyote Brush treatment (Appendix B). These results indicate that the plants did not enhance the degradation of petroleum hydrocarbons. Also, since the final EFH concentration in the unplanted soil was not lower than that of the sterilized control biodegradation of EFH in the soil was probably also minimal. 


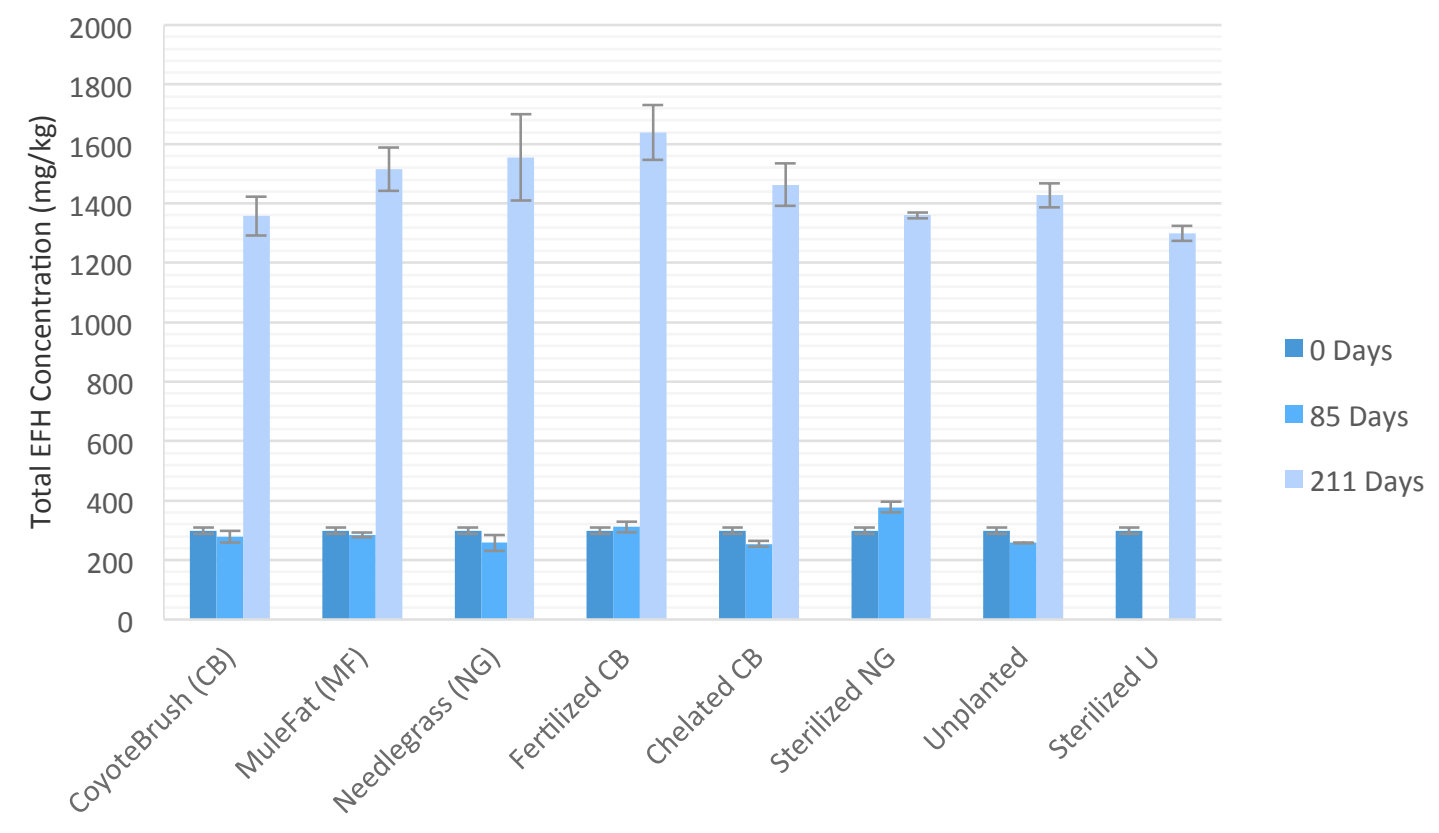

Figure 4.56. Total EFH concentrations in microcosm soil after 0,85 , and 211 days (error bars denote standard error of the mean)

\subsubsection{Polyaromatic Hydrocarbons}

The total PAH concentration in the soil of each microcosm treatment decreased from 0 to 85 days (Figure 4.57). However, all of the total PAH concentrations increased by Day 211 to concentrations greater than the initial concentration except in the sterilized unplanted control. These increases could be a laboratory anomaly similar to the EFH analysis, but again the relative decreases between treatments can still be analyzed. An analysis of variance between the treatments at 211 days showed that none of the total PAH concentrations were statistically different at the $95 \%$ confidence interval $(p=$ 0.094). An analysis of variance between the treatments at 85 days also showed that none of the total PAH concentrations were statistically different at the $95 \%$ confidence interval $(p=0.868)$ 


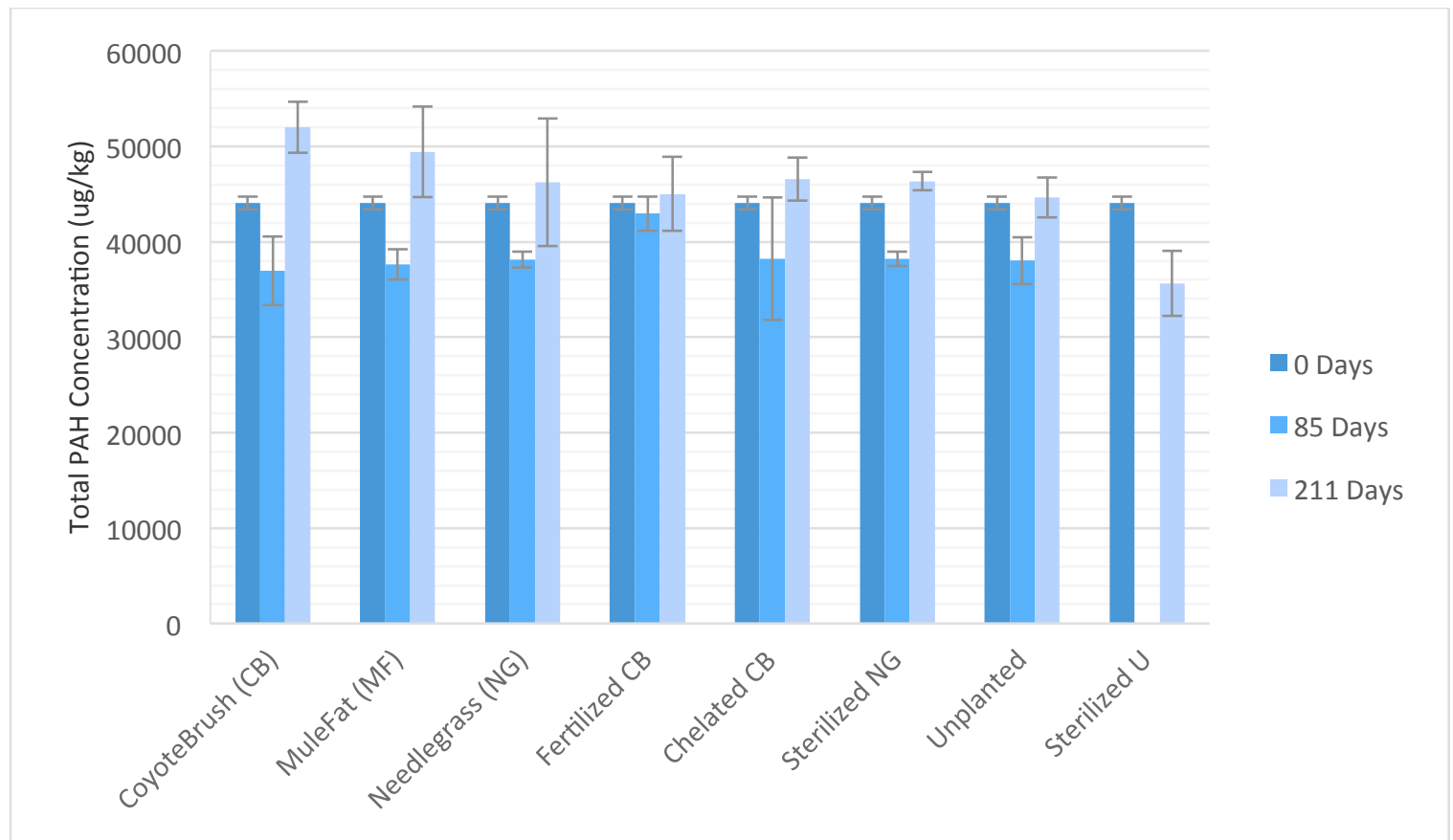

Figure 4.57. Total PAH concentrations in microcosm soil after 0,85 , and 211 days

All of the planted treatments showed some uptake of PAHs into the roots (Figure 4.58). Sterilized Purple Needlegrass (SP) and Purple Needlegrass (PC) showed the highest average concentration in the root tissue out of all the treatments. The root uptake for Purple Needlegrass with and without sterilized soil are not statistically different $(\mathrm{p}=$ 0.358, 2-sample t-test, 95\% confidence) indicating the root uptake by Purple Needlegrass was not affected by soil microbes. Purple Needlegrass in the microcosms did not show any uptake into the foliage so the foliage of specimen NG-1 in the field study was likely a part of the root that was mistaken for foliage and included in the analysis. Coyote Brush, chelated Coyote Brush, fertilized Coyote Brush, and Mule Fat showed slight uptake of PAHs into the foliage. However, the uptake of PAHs into the plant did not significantly reduced the soil concentrations during this time frame as described above. Since the unplanted control was not lower than that of the sterilized control, biodegradation of 
PAHs in the soil was probably minimal. In the field screening Mule Fat specimens showed PAH concentrations greater than $4000 \mathrm{ug} / \mathrm{kg}$ in their foliage and no PAHs in their roots. This measure of PAH was attributed to production of phytogenic compounds by Mule Fat as described above. In contrast, in the microcosms the average foliage concentration was only $209 \mathrm{ug} / \mathrm{kg}$ while the average root concentration was $6500 \mathrm{ug} / \mathrm{kg}$. The Mule Fat in the microcosms may have been too young to produce the phytogenic compounds that were observed in the field screening, or perhaps field conditions influenced the production of these compounds. Regardless of the production of phytogenic compounds observed in the field, Mule Fat does phytoextract PAHs from the soil based on soil and root PAH concentrations (Figure 4.58).

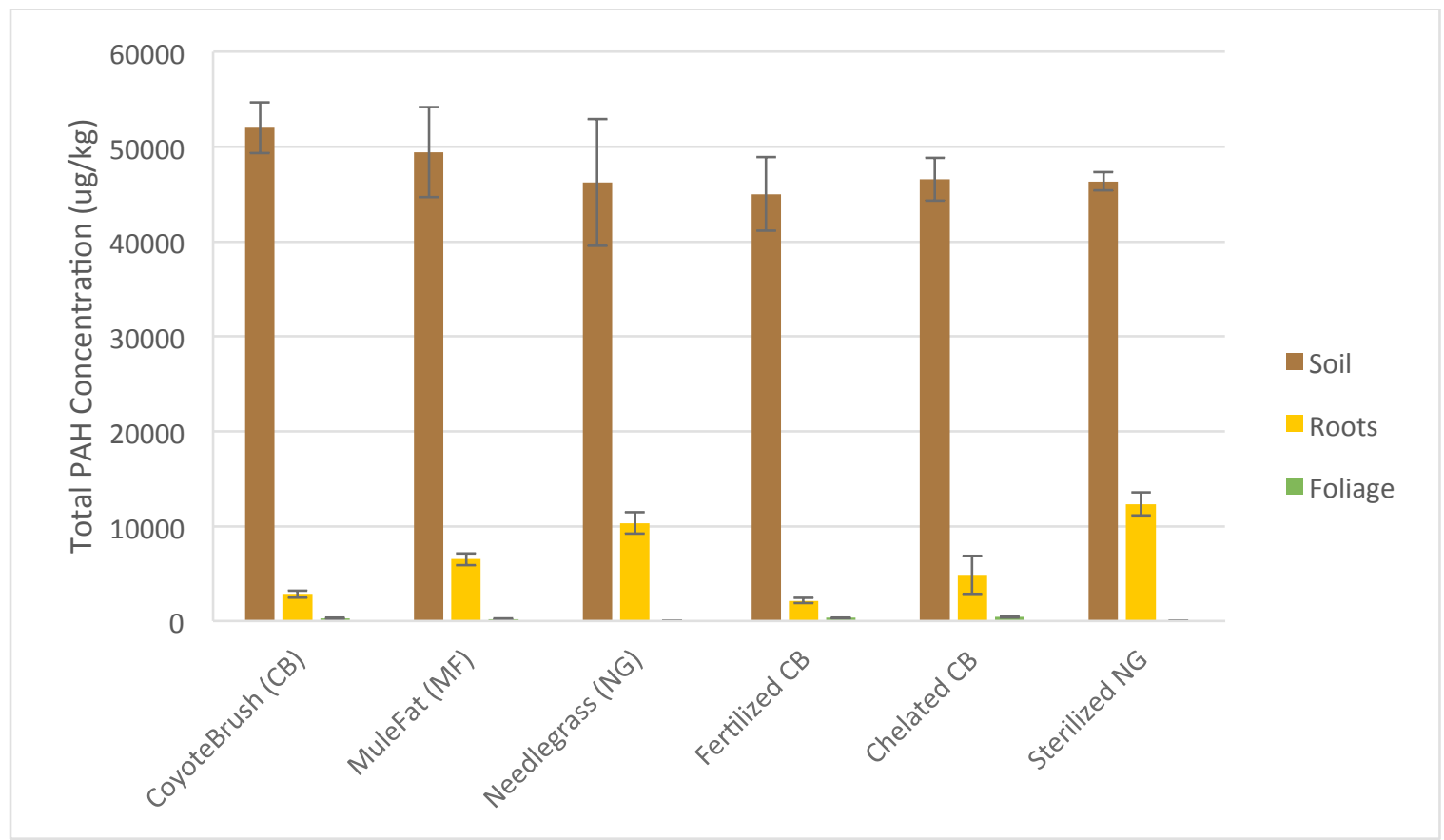

Figure 4.58. Total PAH concentrations in soil, roots, and foliage across treatments 


\subsubsection{Polychlorinated Biphenyls}

All of the microcosm treatments showed an average decrease in Aroclor 1260 concentration in soil relative to the initial soil concentration (Figure 4.59). None of the treatments showed an Aroclor 1260 concentration in soil that was statistically lower than the sterilized control (Appendix B). There were significant decreases of Aroclor 1260 concentrations in soil from the initial to the final sampling date. The unplanted control had a $29.7 \%$ decrease, sterilized Purple Needlegrass had a 31.1\% decrease, sterilized unplanted had a $36.6 \%$ decrease, and Purple Needlegrass had a 49.4\% decrease. While not statistically significant, Purple Needlegrass had showed a trend of lower Aroclor 1260 concentrations in the soil than both the unplanted control and the sterilized Purple Needlegrass. The combination of native microbes and Needlegrass may have synergistically enhanced the degradation process. The EDTA chelating agent addition to the Coyote Brush also appears to have enhanced the reduction of PCBs relative to unchelated Coyote Brush. The average percent Aroclor 1260 concentration decrease for chelated Coyote Brush was 51.4\%. 


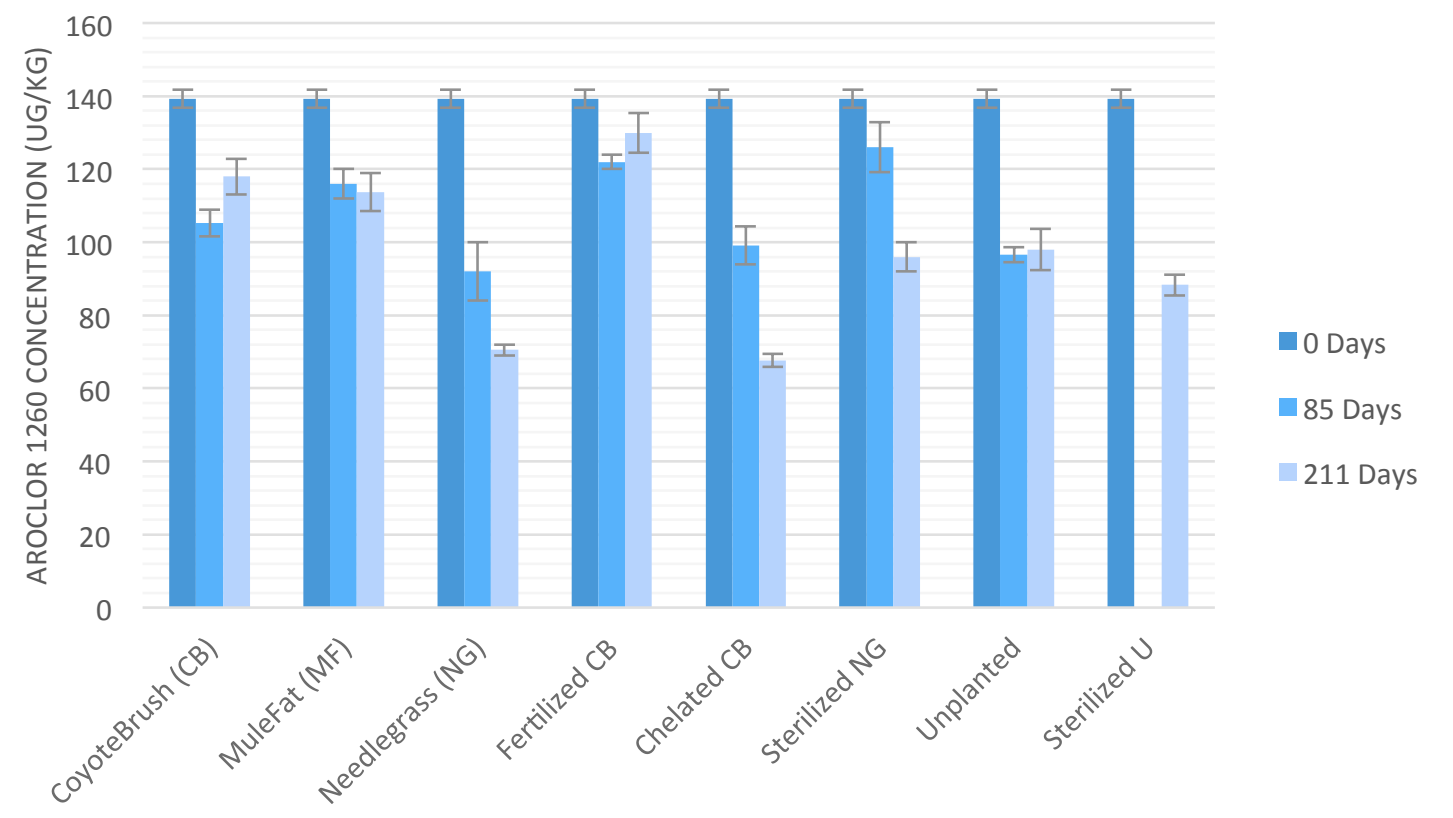

Figure 4.59. Aroclor 1260 concentrations in microcosm soil after 0,85 , and 211 days

During the field screening, none of the Purple Needlegrass specimens had PCBs in the associated soil, thus it was especially important to test the plant tissue for PCBs in the final microcosm sampling event. None of the other species sampled in the field showed uptake of PCBs into their tissue. The microcosm analysis showed no PCBs in the roots or foliage of Purple Needlegrass after 211 days, indicating that Purple Needlegrass did not phytoextract PCBs from the soil. Roots and foliage of Coyote Brush and Mule Fat were not tested for PCBs in the microcosm experiment since previous field screening results showed that these species did not phytoextract PCBs. Thus the PCB reductions seen in soil planted with Purple Needlegrass, chelated Coyote Brush, and sterilized Purple Needlegrass do not appear to be a result of phytoextraction. A possible mechanism could be phytostimulation of microbes in the rhizosphere, particularly fungi. 


\subsubsection{Chlorinated Dioxins/Furans}

Coyote Brush with and without fertilizer showed significantly lower dioxin/furan concentrations than the unplanted control (Figure 4.60). Purple Needlegrass and chelated Coyote Brush showed an apparent increase in soil dioxin/furan concentration at Day 211 relative to the initial bulk soil. Coyote Brush and fertilized Coyote Brush had the lowest concentrations at Day 211 indicating that this species may be enhancing the dioxin/furan degradation. In comparison the unplanted control did not show significant dioxin/furan reduction. Some of the changes observed could be attributed to contaminant concentration variability in the soil. While most of the sampling replicates from the initial soil were around $28,000 \mathrm{ng} / \mathrm{kg}$, one individual replicate had a total dioxin/furan concentration of over $43,000 \mathrm{ng} / \mathrm{kg}$. It is possible that there were concentrated clusters of dioxins/furans that increased the concentration of a particular replicate as described for PCBs above. 


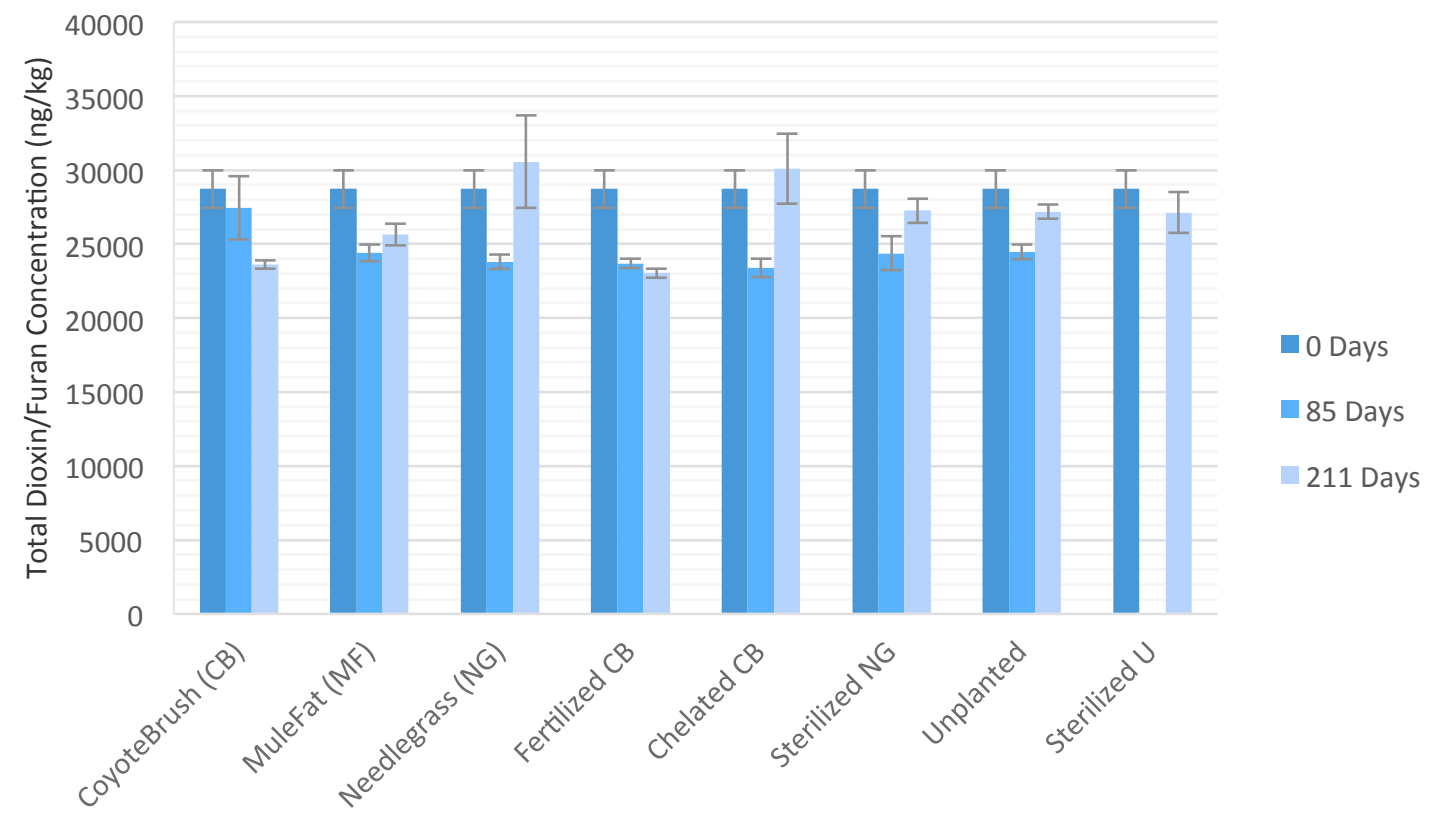

Figure 4.60. Total dioxin/furan concentrations in microcosm soil after 0,85 , and 211 days Sterilized Purple Needlegrass and Purple Needlegrass showed the highest average chlorinated dioxin/furan concentrations in the root tissue out of all the treatments (Figure 4.61). The dioxin/furan root uptake for Purple Needlegrass and sterilized Purple Needlegrass are not statistically different $(p=0.680)$ which indicates no effect of soil microbes on plant uptake. Purple Needlegrass also showed the greatest uptake of dioxins/furans into the foliage although much less than that observed in the roots (Figure 4.61). OCDD was the highest concentration congener in the soil and also was the highest concentration of the dioxin in the Purple Needlegrass roots. Although significant root uptake was observed for Purple Needlegrass and sterilized Purple Needlegrass this uptake apparently did not affect the concentration of dioxins/furans in the soil since soil concentrations were not reduced. This could have been the results of low biomass production. Coyote Brush and fertilized Coyote Brush exhibited the greatest significant 
$(\mathrm{p}=0.036, \mathrm{p}=0.022)$ decrease of dioxins/furans concentrations $(17.8 \%$ and $19.8 \%$ respectively) in the soil that could have been caused by the uptake of dioxins/furans into the plant tissue and subsequent phytodegradation within the plant. It seems unlikely that contaminant uptake alone is the sole mechanism of remediation, since Purple Needlegrass showed the greatest root dioxin/furan concentrations but did not significantly reduce the soil dioxin/furan concentrations. Phytostimulation of the rhizosphere is a possible remediation mechanism as described for PCBs above. The chelated Coyote Brush soil didn't show the same reduction of dioxins/furans as the other Coyote Brush treatments.

The fertilized plants showed the most biomass production and vigor and the most rapid reduction in soil dioxin/furan concentrations. Mule Fat might also be reducing dioxins/furans with the same mechanism as Coyote Brush although the final total dioxin/furan concentration was not significantly different from the initial $(p=0.114)$. Graphs of individual dioxin/furan congener concentrations that were significantly high in the soil are listed in Appendix A. 


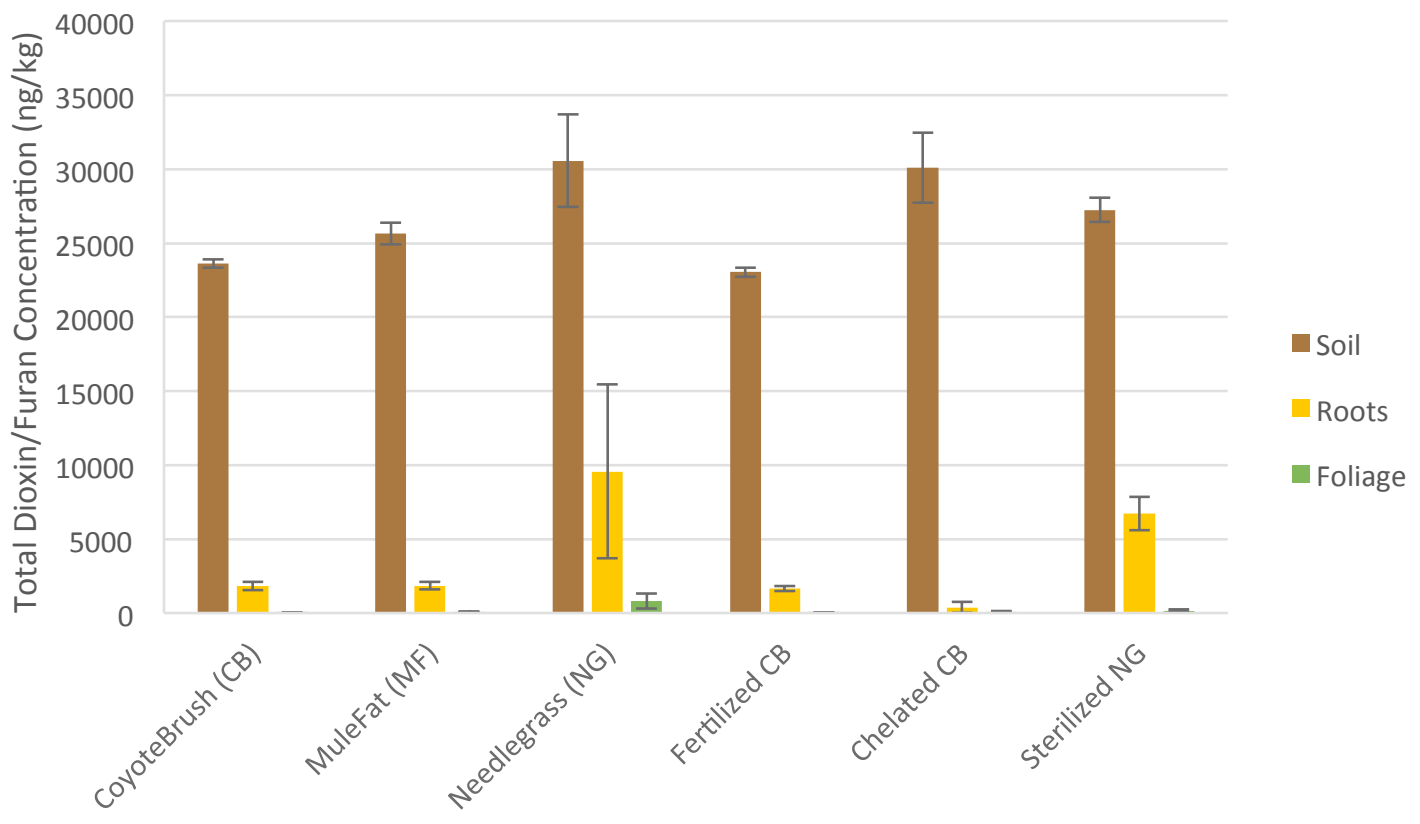

Figure 4.61. Total dioxin/furan concentrations in soil, roots, and foliage across treatments

\subsubsection{Mercury}

All of the treatments, including the sterilized unplanted microcosms, showed a slight decrease in mercury concentration (Figure 4.62). However, since the sterilized unplanted control also showed a decrease, these reductions seem to be the result of sampling variability and there was no statistical difference in final mercury soil concentrations between treatments $(\mathrm{p}=0.110,95 \%$ confidence $)$. The action level for mercury in soil is $0.13 \mathrm{mg} / \mathrm{kg}$. 


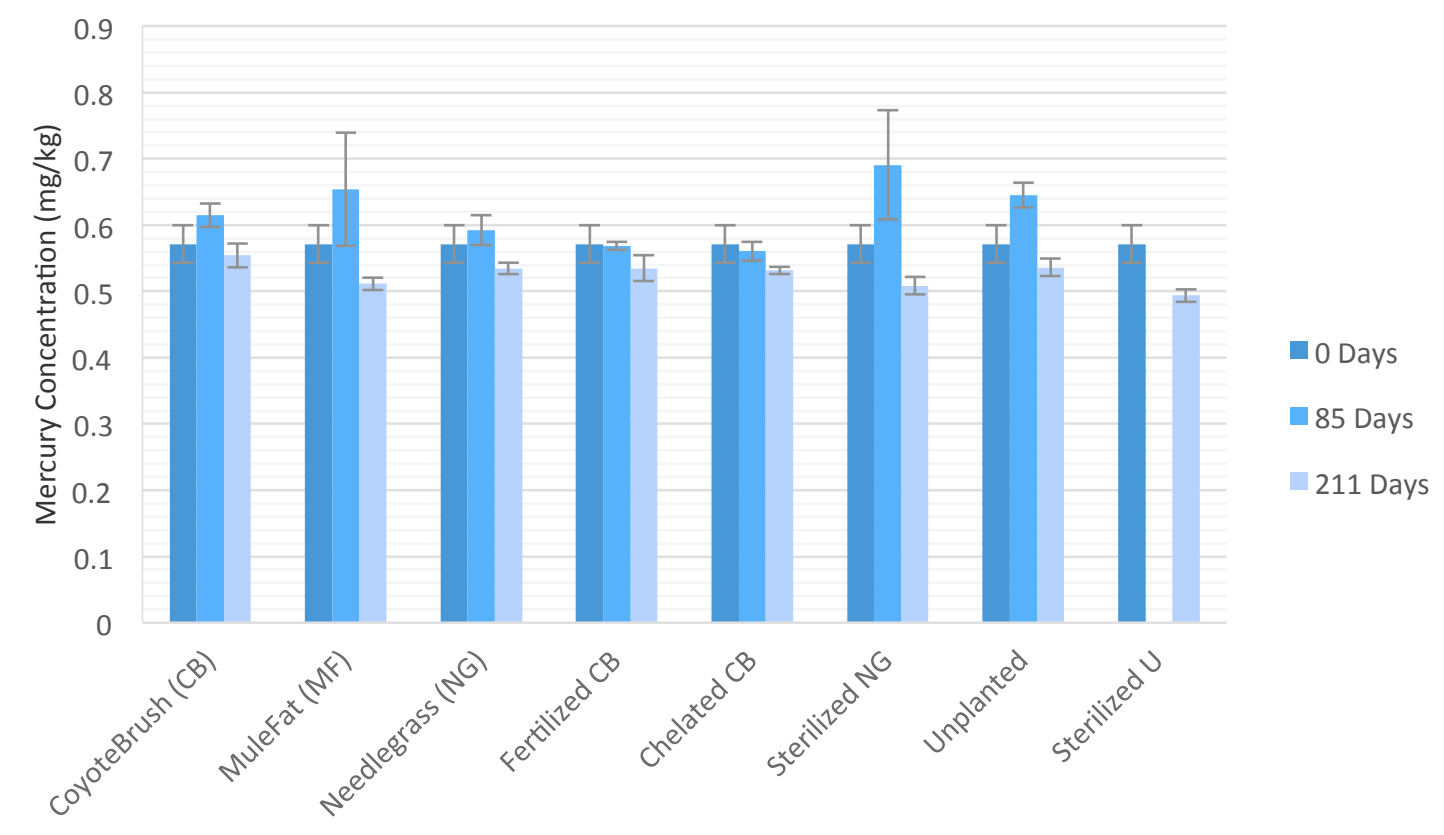

Figure 4.62. Mercury concentrations in microcosm soil after $\mathbf{0 , 8 5}$, and 211 days Mercury was detected in the roots of Mule Fat, fertilized Coyote Brush, Purple Needlegrass, and sterilized Purple Needlegrass (Figure 4.63). It was also detected in the foliage of Purple Needlegrass and sterilized Purple Needlegrass. However, it was difficult to precisely separate the roots from the foliage for Purple Needlegrass. Also, since the concentration in the roots and foliage was below $0.1 \mathrm{mg} / \mathrm{kg}$ in most cases, it seems unlikely that mercury uptake is the cause of contaminant reductions since all of the treatments have similar soil concentrations at Day 211. The EDTA amendment did not enhance uptake of mercury into Coyote Brush, in fact there was less mercury uptake for Coyote Brush with EDTA than for fertilized Coyote Brush without EDTA (Figure 4.63). 


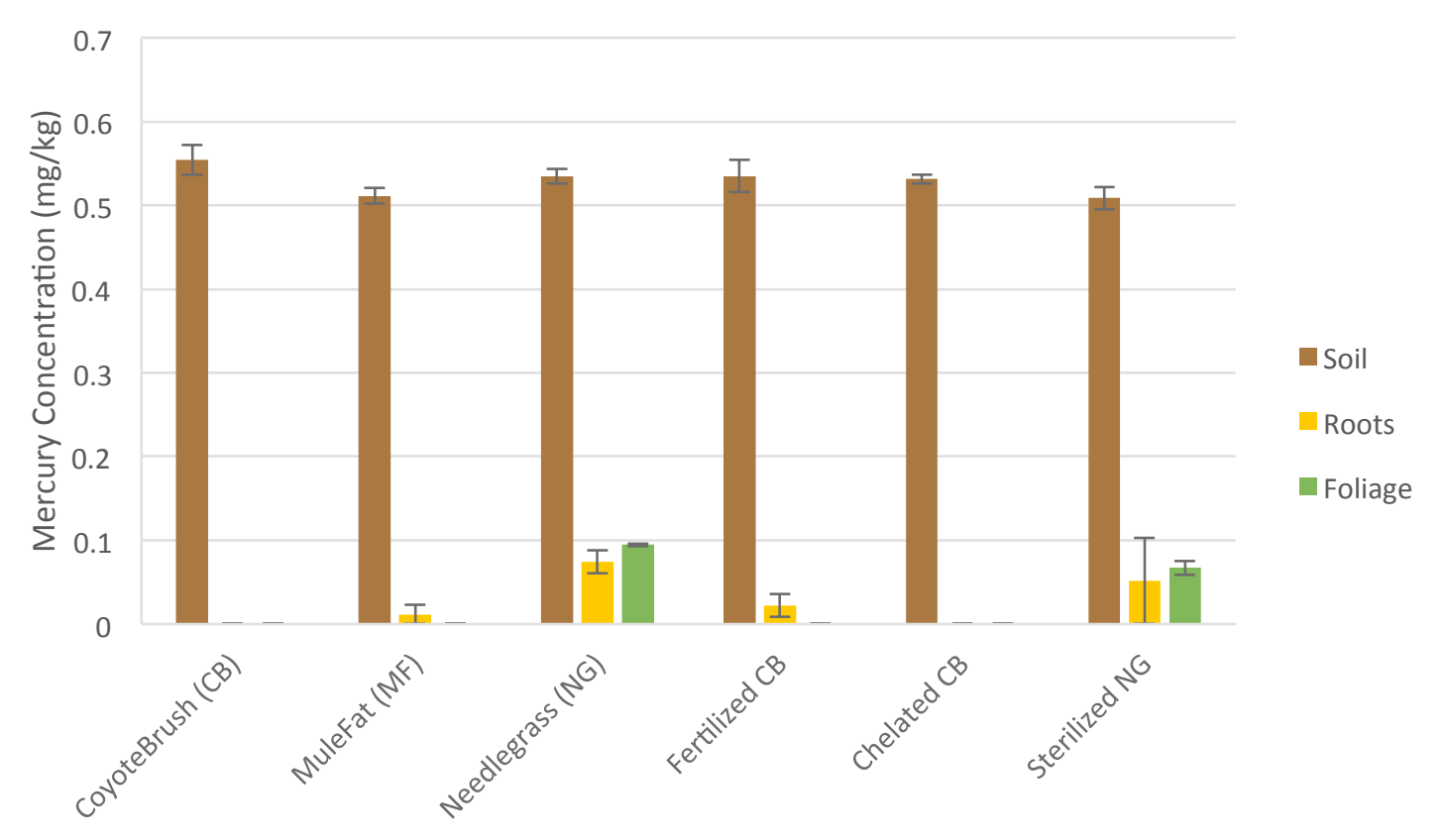

Figure 4.63. Mercury concentrations in soil, roots, and foliage across treatments

\subsubsection{Silver}

All of the treatments at 211 days showed higher soil concentrations for silver than the initial bulk soil (Figure 4.64). Despite the lack of reduction of silver in the soil, silver was observed in the root tissue of all plant species tested (Figure 4.65). The Purple Needlegrass treatment showed statistically greater concentrations of silver into the roots compared to the other treatments ( $\mathrm{p}<0.05$, one way ANOVA). Purple Needlegrass and sterilized Purple Needlegrass were the only treatments that showed uptake into the foliage, although in very small concentrations and it could be attributed to the difficulty in distinguishing/separating the roots from the foliage for grass samples. EDTA did not enhance silver uptake into the Coyote Brush roots since the root concentrations for Coyote Brush and the chelated Coyote Brush were not statistically different $(\mathrm{p}=0.553)$. The action level for silver in soil is $0.2 \mathrm{mg} / \mathrm{kg}$. 


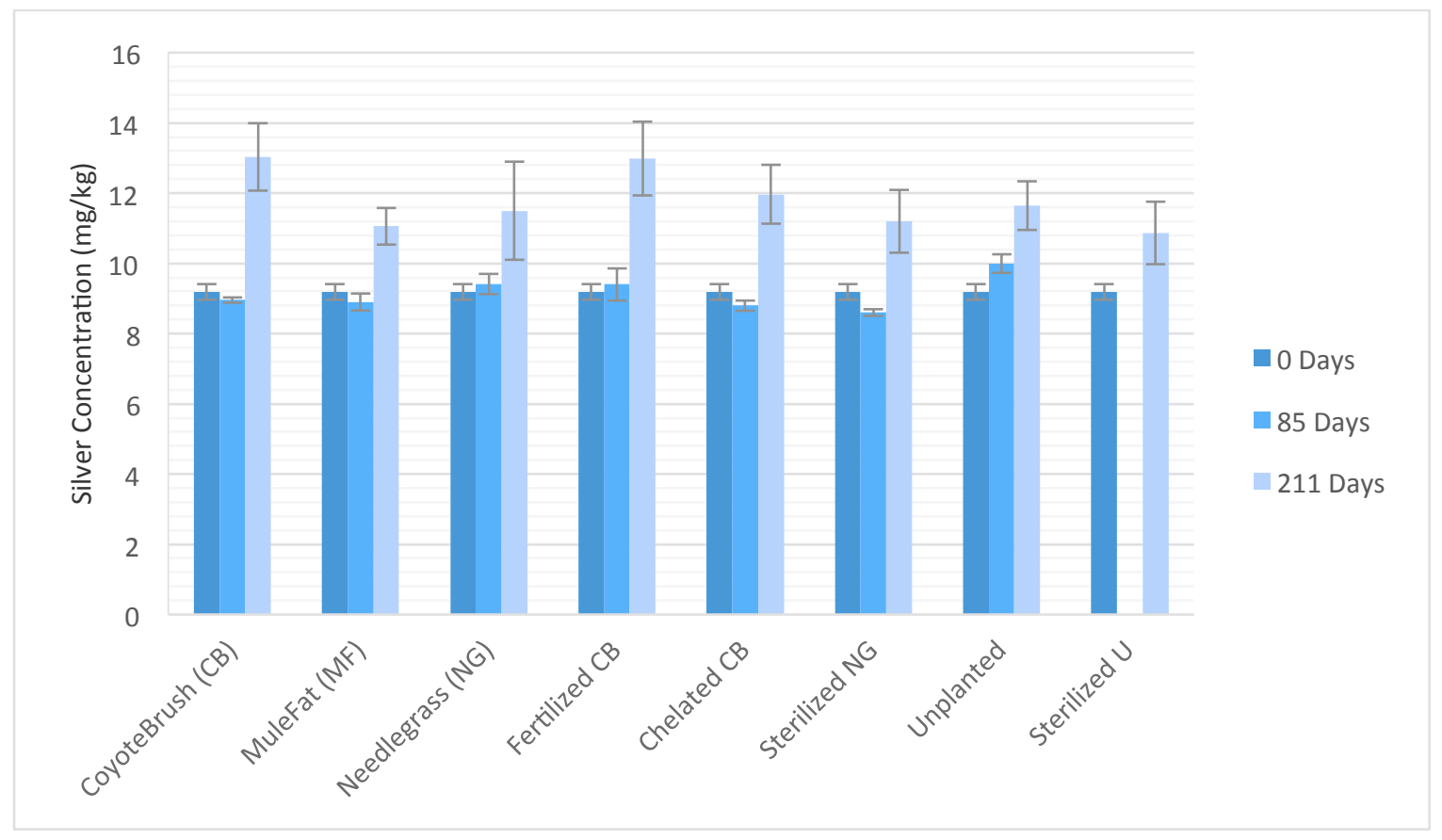

Figure 4.64. Silver concentrations in microcosm soil after 0,85 , and 211 days

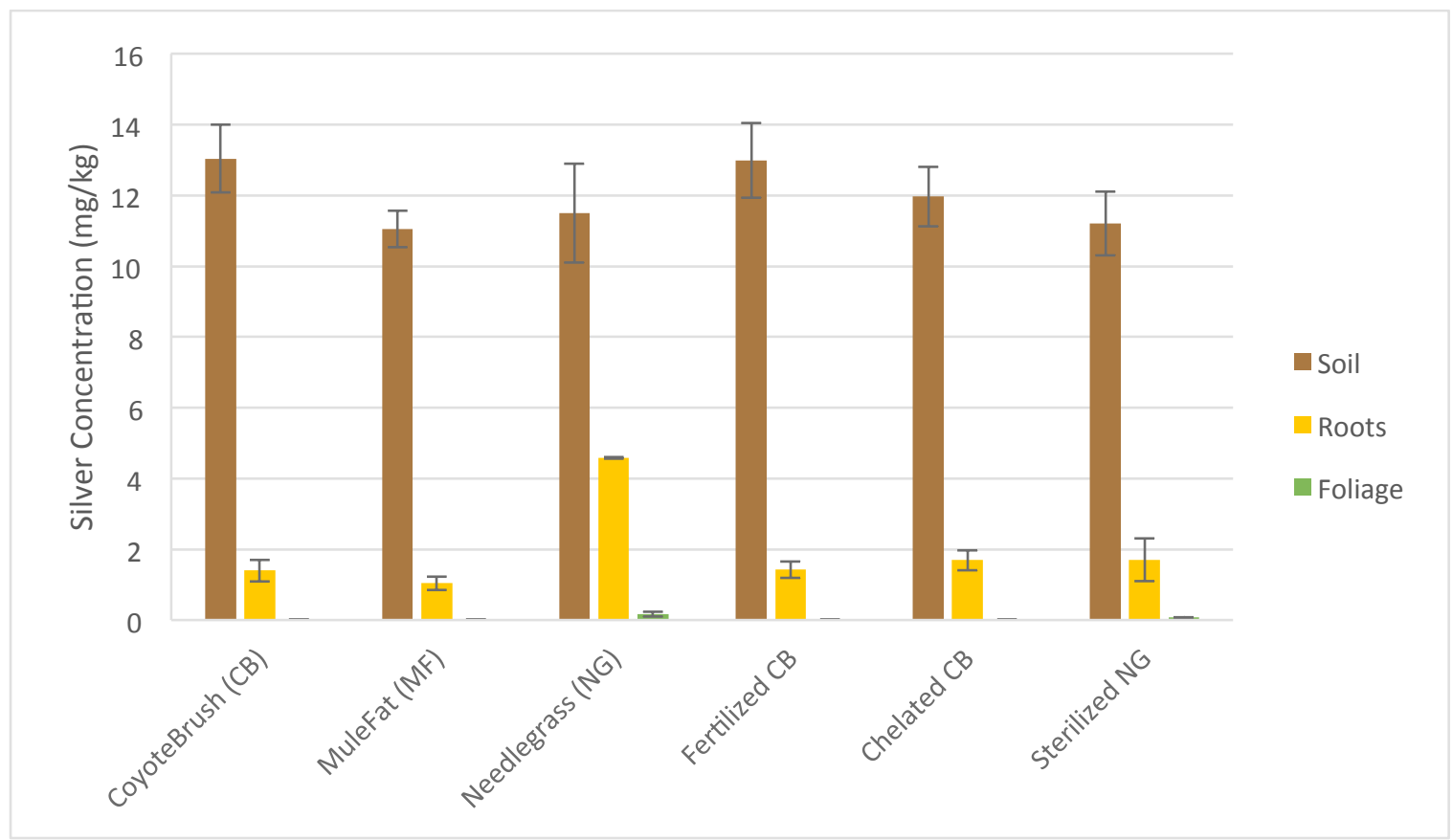

Figure 4.65. Silver concentrations in soil, roots, and foliage across treatments 


\subsubsection{Cadmium}

All of the treatments had statistically similar soil concentrations of cadmium at Day 211 which indicates that none of the plant species significantly enhanced the removal of cadmium from the soil (Figure 4.66). All of the treatments showed an average root concentration of cadmium that was similar or greater than the soil concentration (Figure 4.67) which in turn was only slightly above the action level of $0.7 \mathrm{mg} / \mathrm{kg}$. All of the treatments also showed uptake into the foliage. The chelated Coyote Brush, Purple Needlegrass, and sterilized Purple Needlegrass had the highest root concentrations while the Mule Fat and chelated Coyote Brush had the highest foliage concentrations. The addition of the EDTA did not increase the uptake of cadmium into the roots of Coyote Brush since the root concentrations were not statistically different $(p=0.207)$. The EDTA did not increase the translocation of cadmium from the roots into the foliage of Coyote Brush $(\mathrm{p}=0.338)$. None of the uptake reduced the cadmium concentration in the microcosm soil since all of the treatments, particularly the unplanted control, have similar cadmium concentrations. 


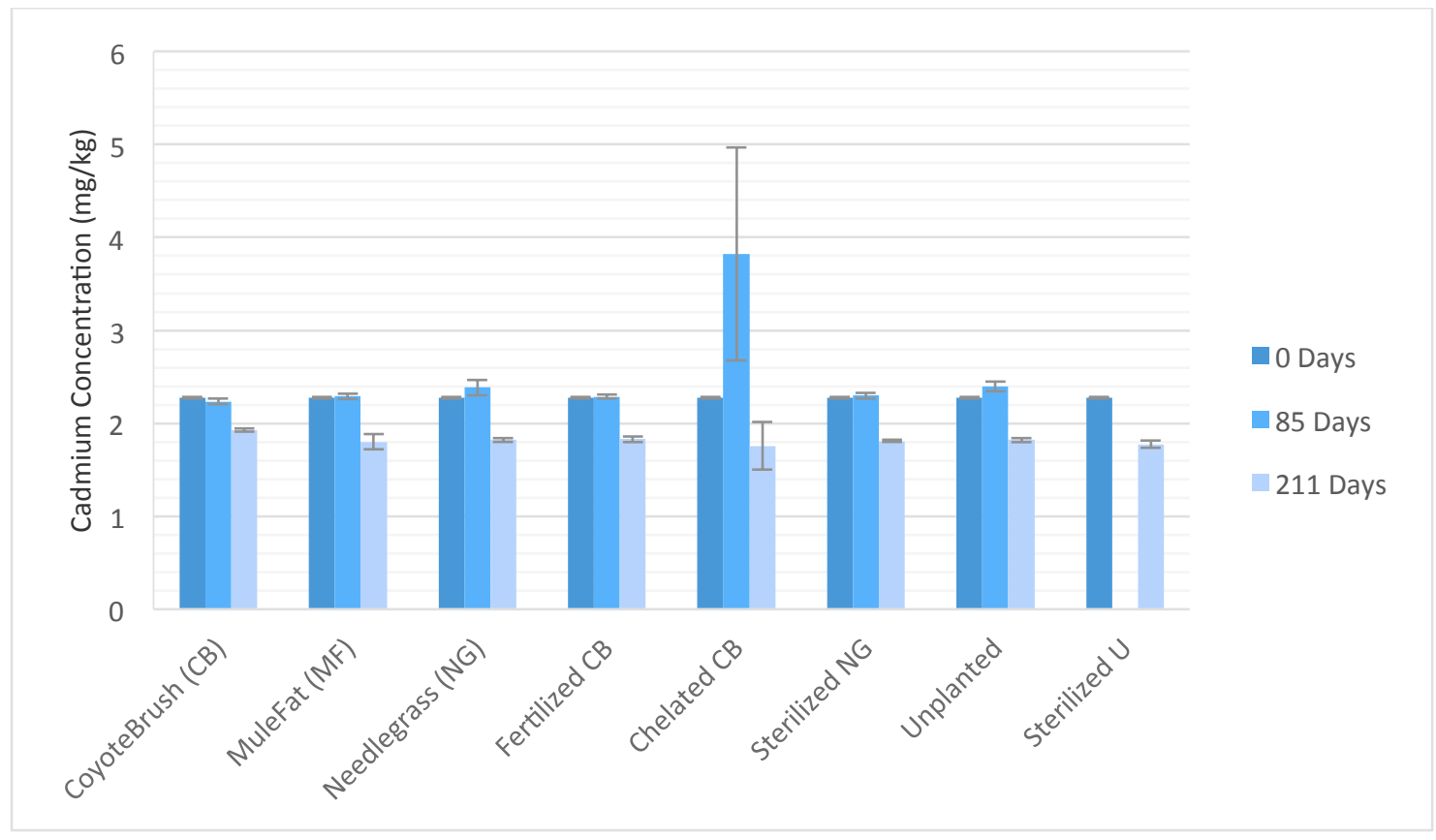

Figure 4.66. Cadmium concentrations in microcosm soil after 0,85 , and 211 days

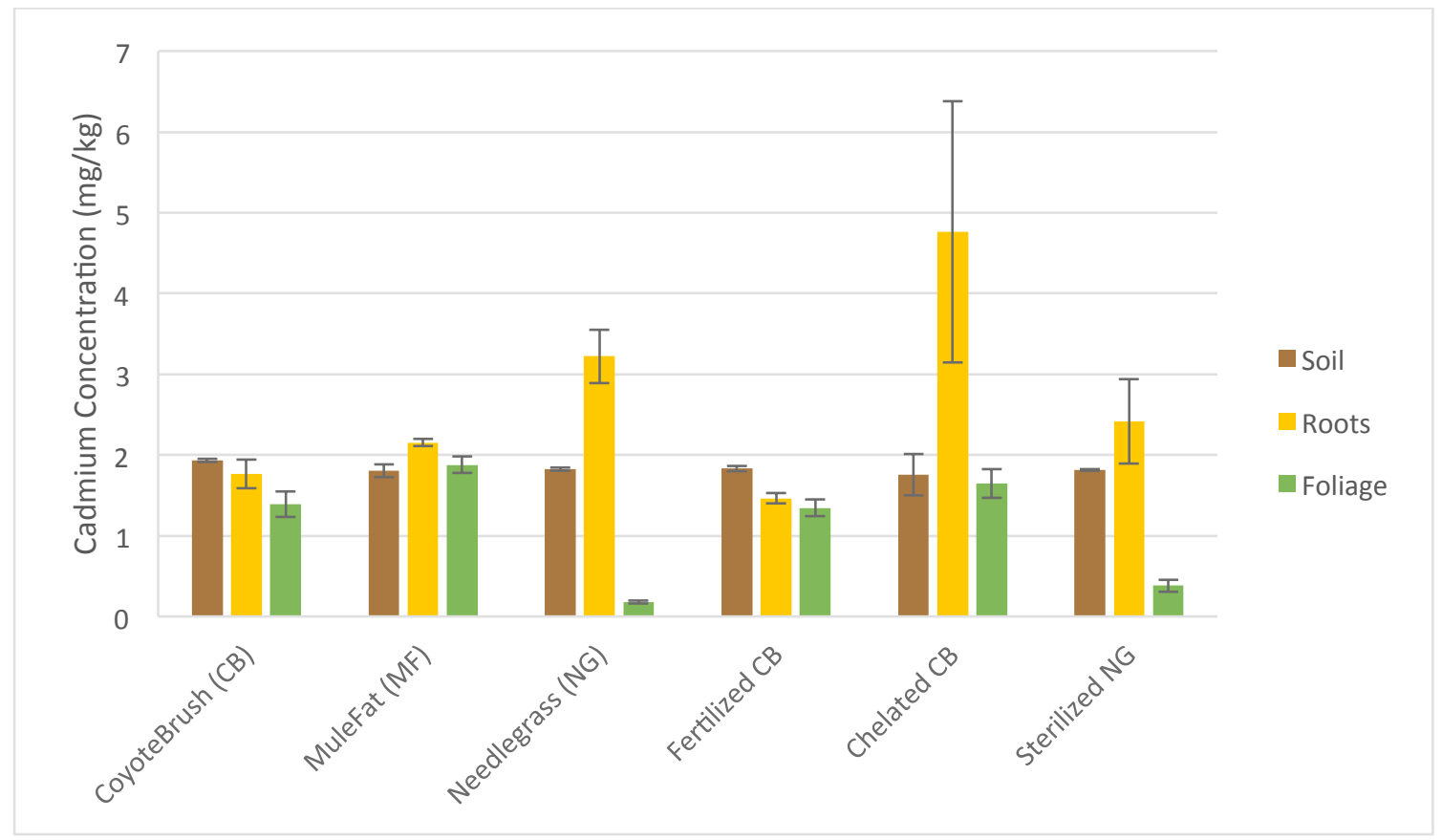

Figure 4.67. Cadmium concentrations in soil, roots, and foliage across treatments 


\subsubsection{Lead}

Lead concentrations in the soil were unchanged over 211 days and were not statistically different (Figure 4.68). The plants clearly did not contribute to any lead concentration reductions in the soil which had lead concentrations slightly higher than the action level of $49 \mathrm{mg} / \mathrm{kg}$. Although no changes in soil concentrations were observed, lead was detected in the roots and foliage of some plants (Figure 4.69). The chelated Coyote Brush, Purple Needlegrass, and sterilized Purple Needlegrass had the highest root concentrations and also the highest foliage concentrations (Figure 4.69). The EDTA enhanced the phytoextraction of lead with a $6.53 \mathrm{mg} / \mathrm{kg}$ to $42.20 \mathrm{mg} / \mathrm{kg}(95 \%$ confidence $)$ increase in root concentration $(p=0.016)$. EDTA also enhanced the translocation with a $3.725 \mathrm{mg} / \mathrm{kg}$ to $5.760 \mathrm{mg} / \mathrm{kg}$ (95\% confidence) increase in the foliage concentration $(p<0.05)$ in the Coyote Brush specimens. This increase of lead uptake by the chelated specimens may have caused the physiological damage that was observed for this treatment (Figure 4.55). Lead accumulation in plant tissue has been shown to impair various morphological, physiological, and biochemical functions in plants, either directly or indirectly (Pourrut et al. 2011). 


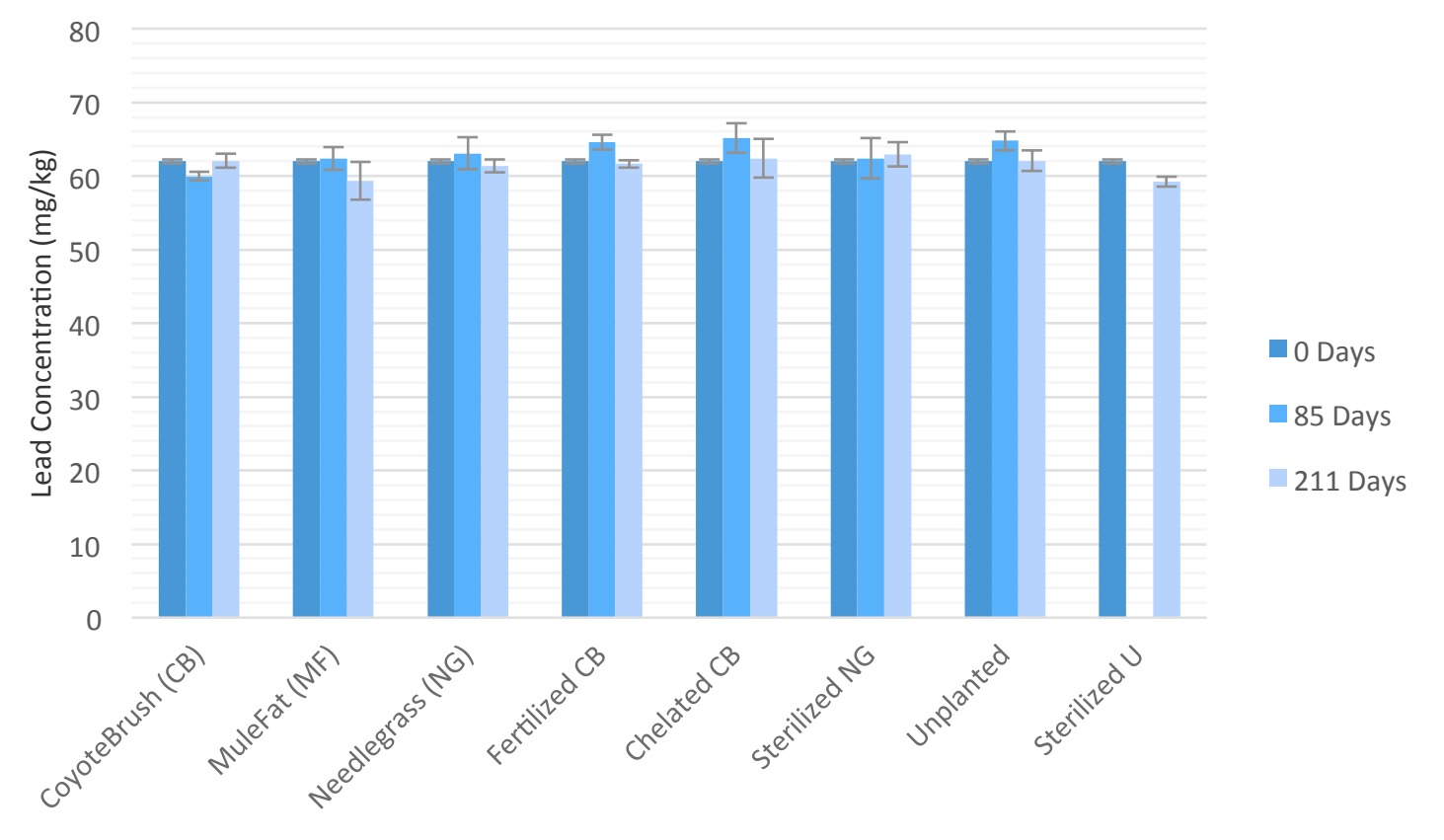

Figure 4.68. Lead concentrations in microcosm soil after 0,85 , and 211 days

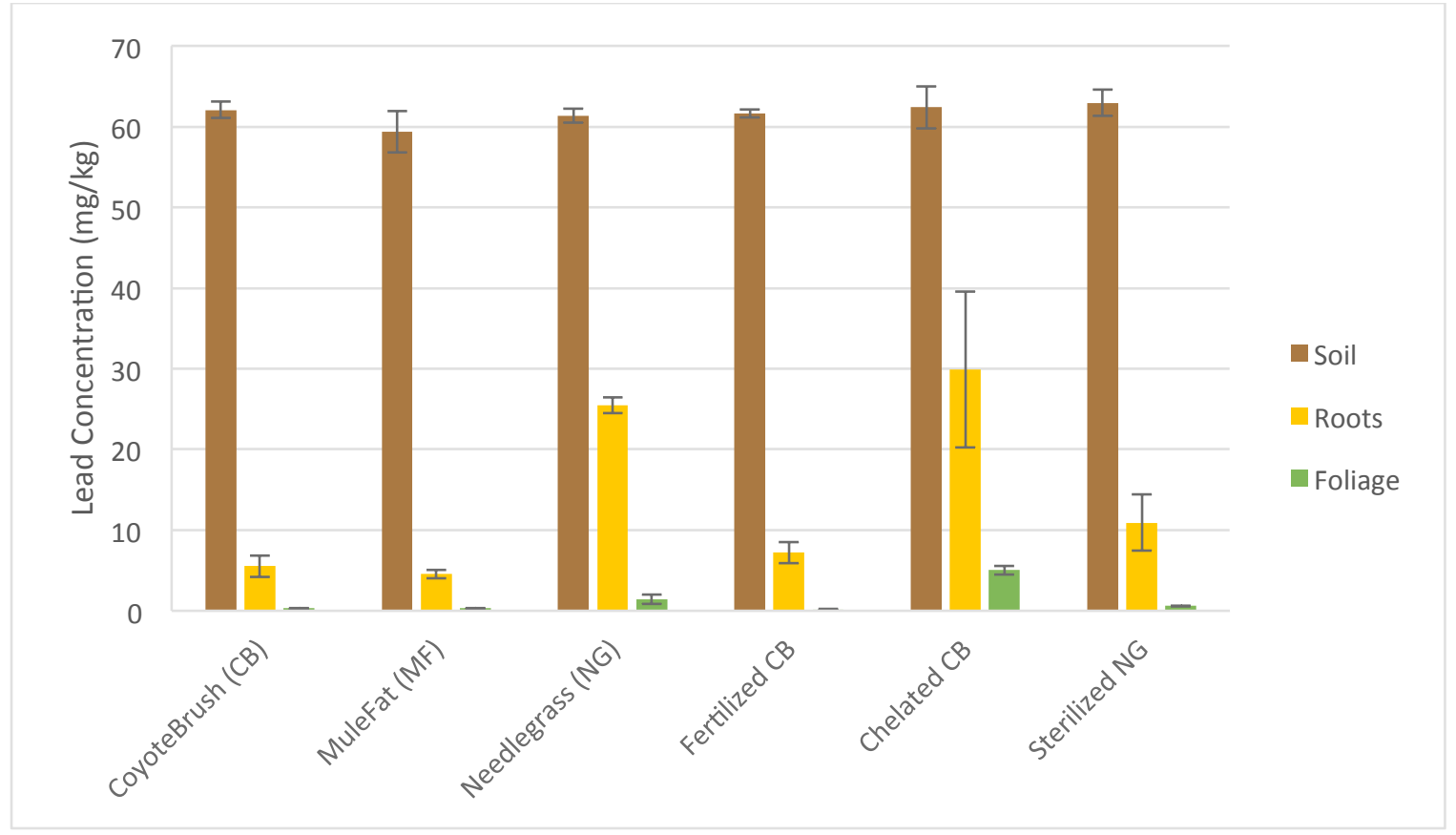

Figure 4.69. Lead concentrations in soil, roots, and foliage across treatments 


\subsubsection{Phytovolatilization}

The chemicals that were detected in off gas from plants growing in contaminated soil included d-limonene, stearic and oleic acids, and stigmastan-3, 5-diene. Limonene is an essential oil produced by select plants of the Baccharis genus, d-limonene being the more commonly found enantiomer in plants (Concha et al. 2014). Stearic and oleic acids are fatty acids that are also produced by plants of the Baccharis genus and also found on human skin (Chang et al. 2008). Stigmastan-3, 5-diene is an antimicrobial compound emitted from avocado roots and appears to be produced by the greenhouse plants (Sánchez-Pérez et al. 2009). These compounds were detected in the ambient greenhouse air and the air from the bags enclosing the planted microcosms (Figure 4.70). However, these compounds were not detected from the bags enclosing the empty jar or unplanted soil, thus it can be concluded that the plants in the greenhouse are producing the detected chemicals.

None of the COIs were detected in the GC/MS analysis of the extract from the carbon sorbent tubes. Mercury volatilization was not tested for. Other air sampling methods use alternative sorbents for adsorbing PCBs and chlorinated dioxins/furans (Centers for Disease Control and Prevention 2014). 


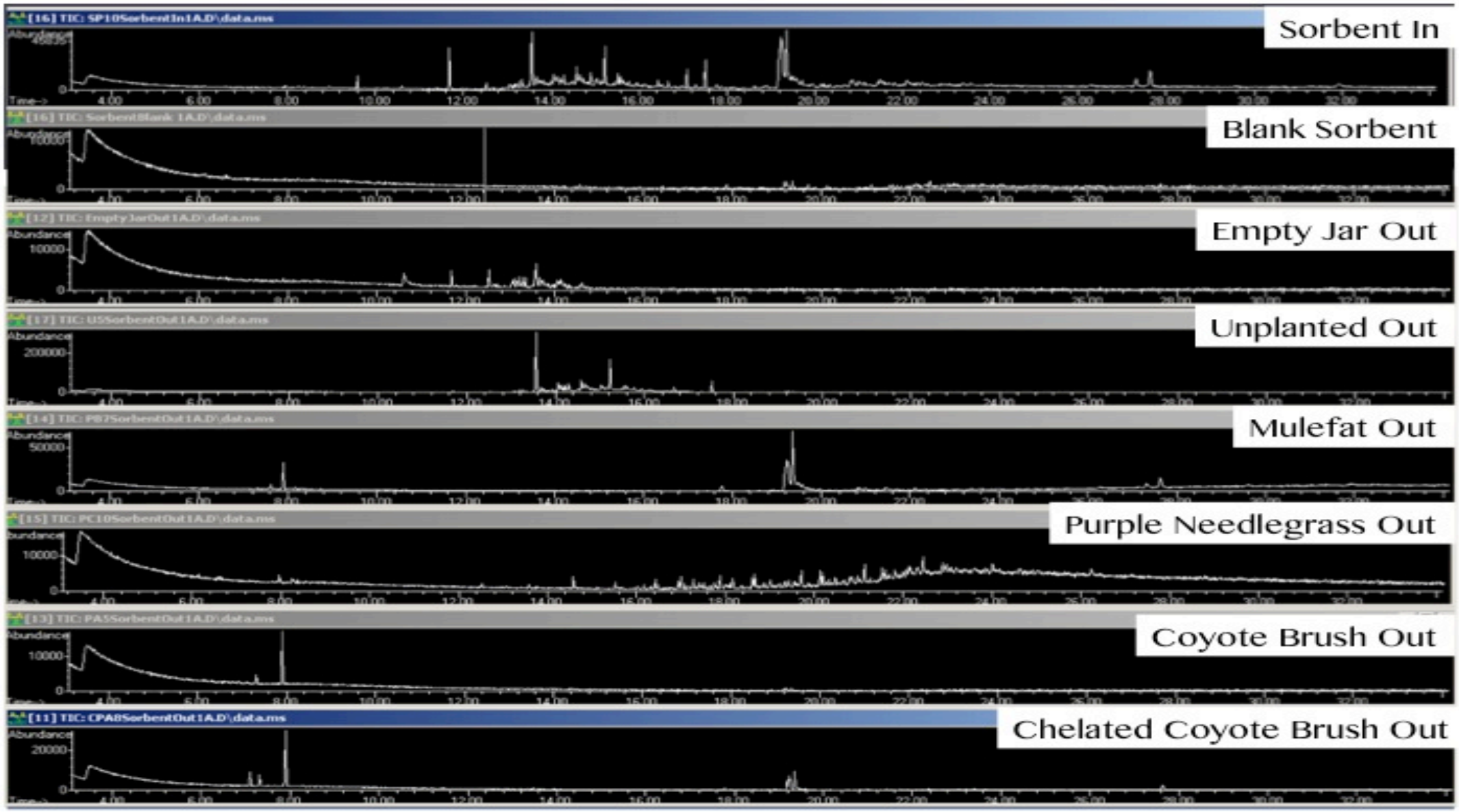

Figure 4.70. Gas chromatography peaks from volatilization sampling 


\subsubsection{Soil Microbial Characterization Using Terminal Restriction Fragment Analysis}

The terminal restriction fragment analysis was performed on soil from Purple

Needlegrass, sterilized Purple Needlegrass, unplanted, and sterilized unplanted treatments

to compare the make-up of the soil microbial communities in the microcosm soils. Multidimensional scaling (MDS) analysis indicates that the microbial populations in the sterilized unplanted soil are grouped very separately from the other treatments (Figure 4.71). This is expected because the sterilization process probably killed most bacterial and fungal species. MDS analysis without the sterilized unplanted treatment indicates differences between the remaining three treatments (Figure 4.72). The sterilized Purple Needlegrass is grouped together separate from the other treatments with the Purple Needlegrass located between both the unplanted and sterilized Purple Needlegrass treatments. The unplanted control is just over $60 \%$ similar with the Purple Needlegrass which indicates that the Purple Needlegrass could have stimulated the rhizosphere and altered the soil microbial community to allow microbes to more readily access and degrade PCBs (Figure 4.73). But although a trend toward difference is visible, an analysis of similarities (ANOSIM) indicates that the variability in the data did not allow for significance between the Purple Needlegrass and unplanted control because there were too few replicates (Appendix B). 


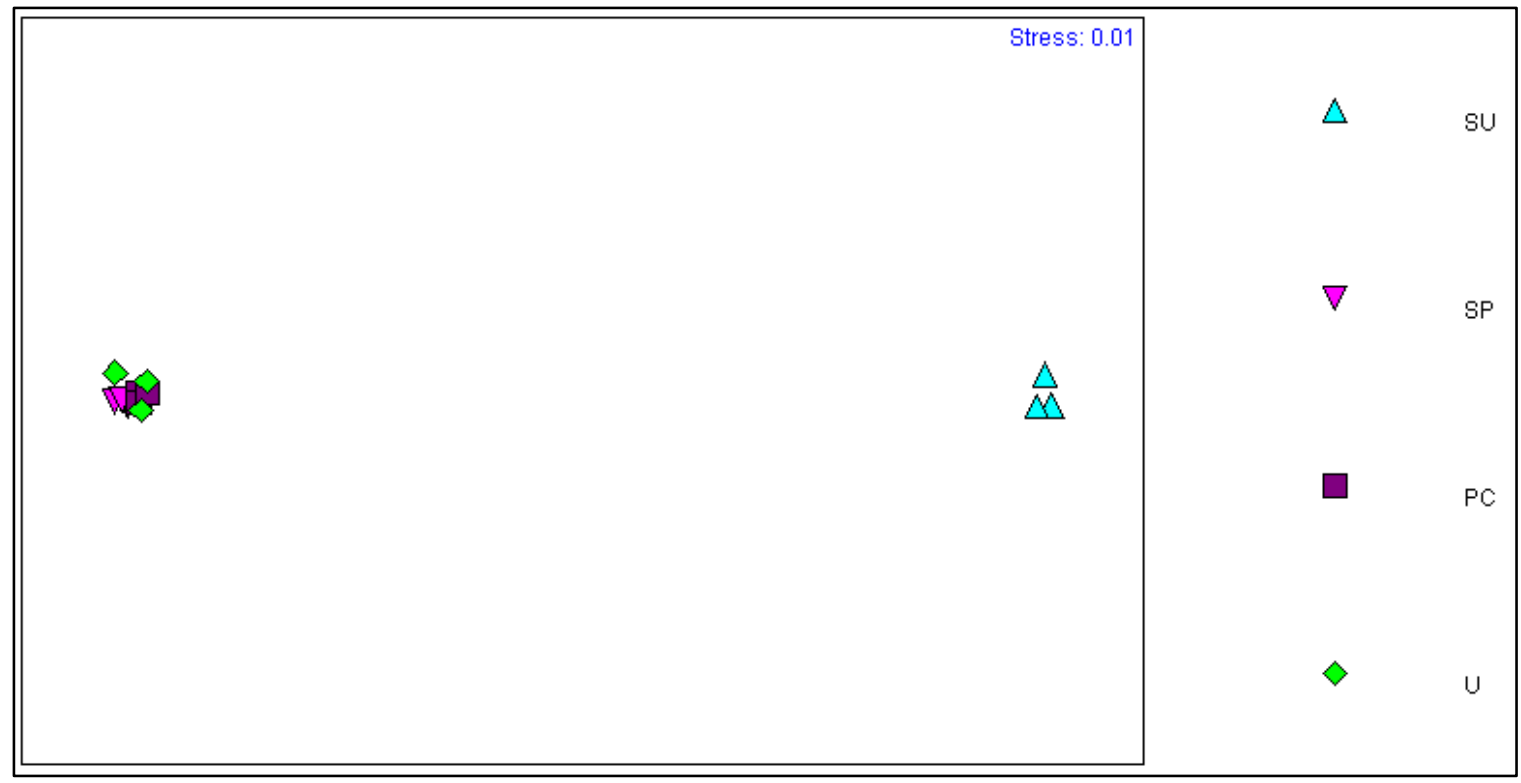

Figure 4.71. Microbial population groupings (MDS) as determined by TRF analysis of Purple Needlegrass (PC), sterilized Purple Needlegrass (SP), unplanted (U), and sterilized unplanted (SU) treatments

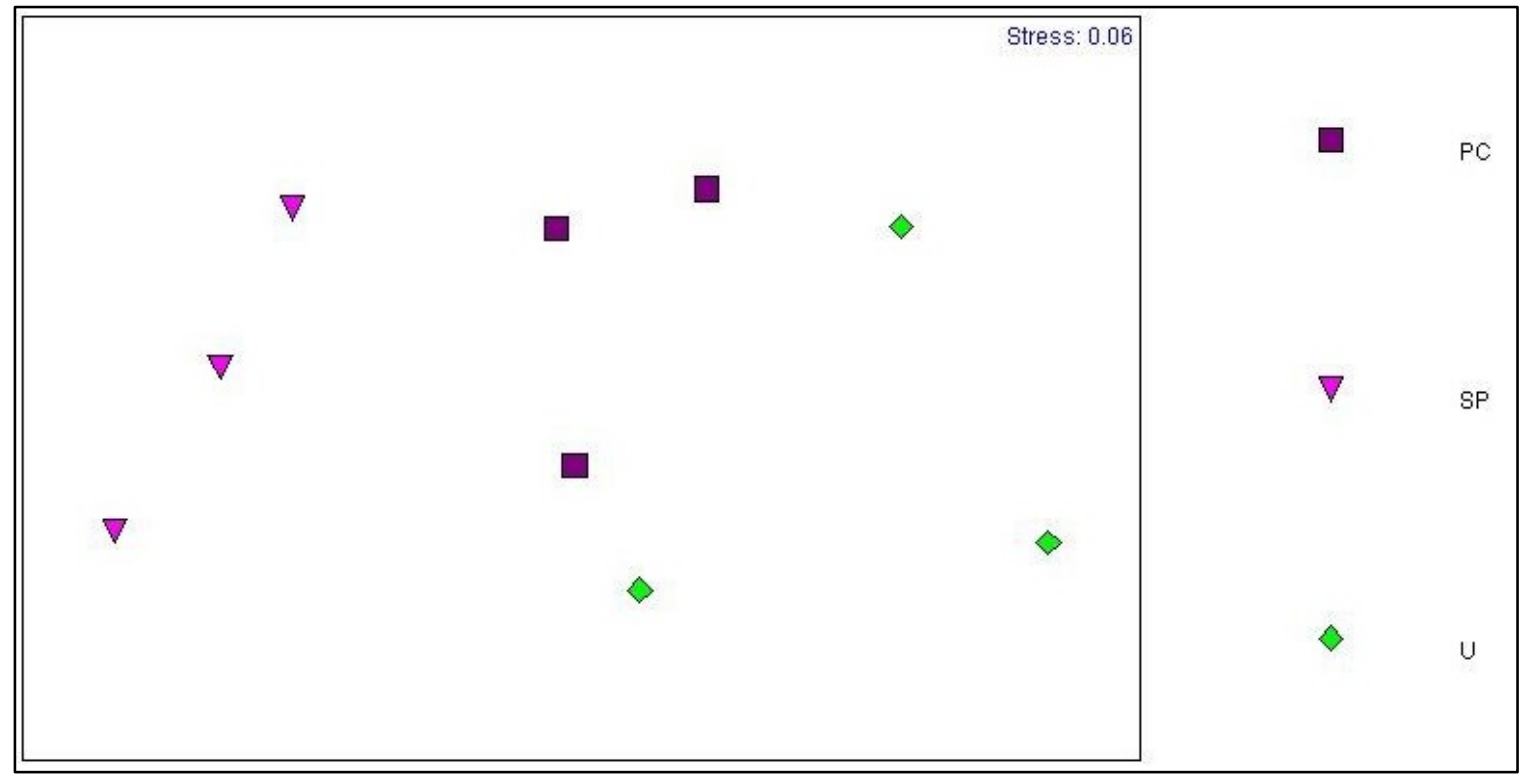

Figure 4.72. Microbial population groupings (MDS) as determined by TRF analysis of Purple Needlegrass (PC), sterilized Purple Needlegrass (SP), and unplanted (U) treatments 


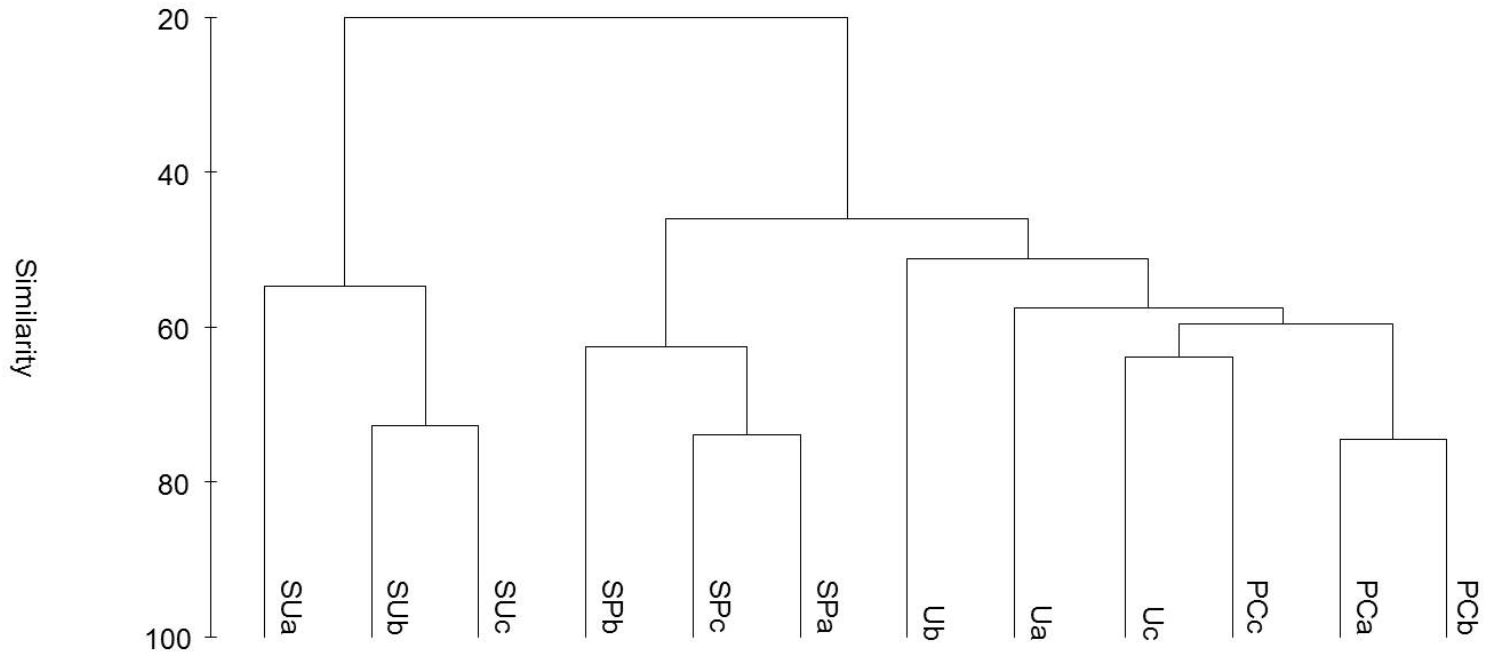

Figure 4.73. Dendogram for Purple Needlegrass (PC), sterilized Purple Needlegrass (SP), unplanted $(\mathrm{U})$, and sterilized unplanted (SU) treatments showing groupings of microbial communities by treatment 


\section{Chapter 5 Conclusions}

The field screening aimed to identify plant species that extracted contaminants from the soil which might be suitable for further research in the controlled greenhouse experiments. Based on preliminary screening data available at the time, Coyote Brush, Mule Fat, and Purple Needlegrass were chosen for the microcosm experiments. The completed field screening data indicated that Coyote Brush and Mule Fat may not have been the most effective phytoextractors. However, Coyote Brush showed uptake of dioxins/furans, silver, and cadmium into the roots and Mule Fat also showed uptake of dioxins/furans, silver, and cadmium into the roots of the plant. In addition, subsequent field data identified Purple Needlegrass as one of the best choices for phytoextraction of dioxins/furans, PAHs, and lead, and this species was used in the microcosm study. After completion of field data collection, Purple Needlegrass, Blue Elderberry, Mule Fat and Yerba Santa were determined to be the best species for phytoextraction of contaminants in the field (Table 5.1 lists the species with the greatest concentration of specific contaminants in their roots or foliage). Based on the complete field data, greater decreases of PAHs and chlorinated dioxins/furans might have been observed in the microcosms if Blue Elderberry or Yerba Santa was planted instead of Coyote Brush or Mule Fat. However, phytoextraction alone was not a primary mechanism of phytoremediation for any of the COI decreases observed in microcosm soil. Therefore it is not clear if Blue Elderberry or Yerba Santa would reduce the COI concentrations in the soil based on improved uptake alone. Further study would have to be conducted to see if Blue Elderberry and Yerba Santa utilized other mechanism(s) besides phytoextraction to 
reduce COI concentrations in the soil. Phytoextraction of PCBs and mercury was not observed in the field screening.

Table 5.1. The greatest contaminant concentrations observed in plant tissue from the field screening

\begin{tabular}{|l|l|l|l|}
\hline Contaminant & Plant Species & Root Conc. & Foliage Conc. \\
\hline \multirow{5}{*}{ PAHs } & Blue Elderberry & $1740 \mathrm{ug} / \mathrm{kg}$ & - \\
\cline { 2 - 4 } & Yerba Santa & $200 \mathrm{ug} / \mathrm{kg}$ & - \\
\cline { 2 - 4 } & Purple Needlegrass & $703 \mathrm{ug} / \mathrm{kg}$ & - \\
\hline \multirow{3}{*}{$\begin{array}{l}\text { Dhlorinated } \\
\end{array}$} & Blue Elderberry & $1026 \mathrm{ng} / \mathrm{kg}$ & - \\
\cline { 2 - 4 } & Yerba Santa & $421 \mathrm{ng} / \mathrm{kg}$ & $901 \mathrm{ng} / \mathrm{kg}$ \\
\cline { 2 - 4 } & Purple Needlegrass & $2237 \mathrm{ng} / \mathrm{kg}$ & $694 \mathrm{ng} / \mathrm{kg}$ \\
\cline { 2 - 4 } & Palmer's Goldenbush & $432 \mathrm{ng} / \mathrm{kg}$ & $757 \mathrm{ng} / \mathrm{kg}$ \\
\hline \multirow{3}{*}{ Silver } & Laurel Sumac & $7.34 \mathrm{mg} / \mathrm{kg}$ & - \\
\cline { 2 - 4 } & Summer Mustard & $1.43 \mathrm{mg} / \mathrm{kg}$ & $0.405 \mathrm{mg} / \mathrm{kg}$ \\
\hline \multirow{3}{*}{ Cadmium } & Mule Fat & $1.84 \mathrm{mg} / \mathrm{kg}$ & $3.64 \mathrm{mg} / \mathrm{kg}$ \\
\cline { 2 - 4 } & Coyote Brush & $1.52 \mathrm{mg} / \mathrm{kg}$ & $2.12 \mathrm{mg} / \mathrm{kg}$ \\
\hline Lead & Purple Needlegrass & $8.92 \mathrm{mg} / \mathrm{kg}$ & $1.17 \mathrm{mg} / \mathrm{kg}$ \\
\hline
\end{tabular}

Phytogenic compounds were a complicating factor when analyzing plant tissue for uptake of hydrocarbons and PAHs. The phytogenic compounds overshadowed any indication of hydrocarbon phytoextraction by any of the plant specimens. Phytogenic compounds were also observed in the PAH analyses of Mule Fat and Laurel Sumac. However, the microcosm Mule Fat microcosms resulted in much lower concentrations of PAHs in their foliage than the field specimens. It may be that the field specimens are more mature and produced these phytogenic compounds or that the field conditions cause the plants to produce them.

The microcosm results showed some indications that plants might be enhancing the reduction of PCBs in soil. The average Aroclor 1260 concentration reductions in soils for 
Purple Needlegrass and chelated Coyote Brush were $49.4 \%$ and $51.4 \%$ respectively. However, the sterilized unplanted control also had a decrease of Aroclor 1260 concentrations in the soil of $36.6 \%$. None of the species phytoextracted PCBs into roots or foliage and so the mechanism of remediation seems to be phytostimulation of the rhizosphere. The TRF results show about $60 \%$ similarity between Purple Needlegrass and the unplanted control which supports the reasoning that phytostimulation may be altering the microbial community although there was no statistical difference ( $90 \%$ confidence).

Plants may also have enhanced the reduction of chlorinated dioxins/furans in soil. Only the Coyote Brush and fertilized Coyote Brush significantly enhanced the reduction of the total dioxin/furan concentration in the soil and this decrease cannot be attributed to uptake alone. Phytodegradation may be occurring within the plant but this is unlikely according to the literature (Campanella, Bock, and Schröder 2002). It is more likely that the Coyote Brush is stimulating the rhizosphere to better degrade the dioxins/furans. Purple Needlegrass showed the greatest uptake of dioxins/furans into the foliage but did not reduce the dioxin/furan concentrations noticeably in the soil. Coyote Brush, fertilized Coyote Brush, and Mule Fat also showed uptake of dioxins/furans into the roots and foliage.

Although there was uptake of most of the contaminants in roots and foliage for one or more plant species, the plants did not significantly enhance the reduction of other COI concentrations in SSFL soil. For petroleum hydrocarbons, laboratory discrepancies in the EFH analyses precluded the ability to discern if plants enhanced biodegradation of 
petroleum hydrocarbons. For PAHs, mercury, silver, cadmium, and lead soil concentrations, the sterilized controls had the lowest average soil contaminant concentration compared to any of the treatments at the end of the experiment indicating the that plants had no significant effect on these COIs.

PAHs, PCBs, and chlorinated dioxins/furans can be degradation by gamma irradiation. $\mathrm{PAH}$ concentrations in sludge were reportedly reduced by gamma irradiation at $2 \mathrm{kGy}$ (Abo-El-Seoud et al. 2014). PCBs and chlorinated dioxins were also reportedly degraded by gamma irradiation at higher amounts of 75 to $800 \mathrm{kGy}$ (Hilarides et al. 1994; Hilarides et al. 1996; Singh, Khandal, and Singh 2007; Lépine and Massé 1990). Thus the gamma irradiation administered to the microcosms ( $25 \mathrm{kGy}$ to $62 \mathrm{kGy}$ ) could have caused the contaminant concentration decreases observed in the sterilized unplanted control.

None of the plants were identified as hyper-accumulators of metals and none of the soil metal concentrations significantly decreased during the 211-day microcosms experiment. All of the metals were taken into the plants to some degree, with Purple Needlegrass showing the most promise for metal extraction as it showed some of the highest concentrations of all metals tested in roots and was the only species that contained mercury and silver in the foliage. It is also possible that the contaminants found in the roots were actually adsorbed onto the surface and not actually phytoextracted into the root tissue. The chelated Coyote Brush had significantly higher concentrations of lead in the roots and foliage than normal Coyote Brush, which may account for the poor plant health of the plants grown in chelated soil. Even though the metal concentrations in the 
soil were not reduced by the plants during this experiment, they could still potentially assist in remediation given longer time with more biomass.

There was a significant amount of variability in contaminant concentrations even after the homogenization of soil. This was particularly observed for PAHs, PCBs, and dioxins/furans where one of the samples sometimes contained concentrations that were more than $50 \%$ greater than the other samples. The heterogeneity was also likely responsible for the apparent "increase" in concentrations observed for many of the COIs from Day 85 to Day 211 of the experiment.

The method of measuring volatilization did not detect any of the COIs coming off the microcosms. Volatile phytogenic compounds (d-limonene, stearic and oleic acids, and stigmastan-3, 5-diene) were detected which were likely produced by the plants. However, the method used may not be adequate for capturing mercury, which was not tested.

When conducting future research, each individual microcosm should be sampled initially immediately after planting to determine a starting concentration for each replicate instead of estimating the starting concentration of all the bulk soil before placement into the jars. The soil should also be analyzed after sterilization to obtain a true starting concentration after any changes caused by the sterilization process. Further study is needed to determine if the organic contaminants taken up by the plants were phytodegraded inside the plant tissue and also if/how rhizostimulation reduced the concentration of chlorinated compounds. It would also be beneficial to characterize the distribution of contaminants 
within the soil matrix to determine if there are pockets or "chunks" of certain contaminants that could have greatly increased individual sampling concentration values.

Is phytoremediation a viable remediation method for the COIs in soil? It is undetermined if phytoremediation with Coyote Brush, Mule Fat, or Purple Needlegrass would be viable for the remediation of petroleum hydrocarbons or PAHs based on the soil microcosm experiments. These plant species would not be good candidates for phytoextraction of metals at the site. Even if increased biomass would increase the uptake of metals into the roots of the plant, very little if any metals were located in the foliage of the plants. This creates a logistical problem of having to dig the plant roots up to remove the metals from the soil. Phytoremediation of PCBs and chlorinated dioxins/furans may be successful based on microcosm results. However, the high variability of measured soil concentrations makes it difficult to confirm this or to estimate the time required for remediation by this approach. A follow up study could be performed to identify the microorganisms that were potentially stimulated by Coyote Brush, Mule Fat, or Purple Needlegrass, and elucidate the mechanism for dioxin/furan reductions in Coyote Brush treatments. Another study could also be performed to see if Blue Elderberry or Yerba Santa would significantly reduce soil concentrations of the COIs. Overall this study suggests that more aggressive forms of remediation may be required to reduce the concentrations of COIs quickly. 


\section{References}

Abo-El-Seoud, M, RA El-Motaium, MI Batarseh, and R Kreuzig. 2014. "Impact of Gamma Radiation on the Degradability of Polynuclear Aromatic Hydrocarbons in Egyptian Sewage Sludge.” FRESENIUS ENVIRONMENTAL BULLETIN 13 (1): 5255. Accessed December 19.

http://apps.webofknowledge.com/full_record.do?product=WOS\&search_mode=Gen eralSearch\&qid=3\&SID=1CFOIdqRgGpIGiCZPCY \&page $=1 \&$ doc $=1$.

Aken, Benoit Van, Paola A. Correa, and Jerald L. Schnoor. 2010. "Phytoremediation of Polychlorinated Biphenyls: New Trends and Promises.” Environmental Science \& Technology 44 (8) (April): 2767-2776. doi:10.1021/es902514d. http://dx.doi.org/10.1021/es902514d.

Ali, Hazrat, Ezzat Khan, and Muhammad Anwar Sajad. 2013. "Phytoremediation of Heavy metals - Concepts and Applications.” Chemosphere 91 (7) (May): 869-881. doi:10.1016/j.chemosphere.2013.01.075. http://www.sciencedirect.com/science/article/pii/S0045653513001914.

Anderson, Todd A., Elizabeth A. Guthrie, and Barbara T. Walton. 1993. "Bioremediation in the Rhizosphere.” Environmental Science \& Technology 27 (13) (December): 2630-2636. doi:10.1021/es00049a001. http://dx.doi.org/10.1021/es00049a001.

ATSDR. 2014. "Toxic Substance Portal.” USA.gov. http://www.atsdr.cdc.gov/. 
Baker, A. J. M., and R. Brooks. 1989. “Terrestrial Higher Plants Which Hyperaccumulate Metallic Elements a Review of Their Distribution Ecology and Phytochemistry." Biorecovery 1 (2): 81-126.

Banks, M. K., P. Schwab, B. Liu, P. A. Kulakow, J. S. Smith, and R. Kim. 2003. "The Effect of Plants on the Degradation and Toxicity of Petroleum Contaminants in Soil: a Field Assessment.” Advances in Biochemical Engineering/biotechnology 78.

Blaylock, Michael J., David E. Salt, Slavik Dushenkov, Olga Zakharova, Christopher Gussman, Yoram Kapulnik, Burt D. Ensley, and Ilya Raskin. 1997. "Enhanced Accumulation of $\mathrm{Pb}$ in Indian Mustard by Soil-Applied Chelating Agents.” Environmental Science \& Technology 31 (3) (March): 860-865. doi:10.1021/es960552a. http://dx.doi.org/10.1021/es960552a.

Boeing. 2005. "The September 2005 Topanga Fire.” http://www.etec.energy.gov/Library/Main/BoeingSSFLTopangaFireFactSheet.pdf.

Briggs, Geoffrey G., Richard H. Bromilow, and Avis A. Evans. 1982. "Relationships Between Lipophilicity and Root Uptake and Translocation of Non-Ionised Chemicals by Barley." Pesticide Science 13 (5): 495-504. doi:10.1002/ps.2780130506. http://onlinelibrary.wiley.com/doi/10.1002/ps.2780130506/abstract.

Brooks, Robert R, Michael F Chambers, Larry J Nicks, and Brett H Robinson. 1998. “Phytomining." Trends in Plant Science 3 (9) (September): 359-362. 
doi:10.1016/S1360-1385(98)01283-7.

http://www.sciencedirect.com/science/article/pii/S1360138598012837.

Campanella, Claudia Bock, and Peter Schröder. 2002. "Phytoremediation to Increase the Degradation of PCBs and PCDD/Fs." Environmental Science and Pollution Research 9 (1) (January): 73-85. doi:10.1007/BF02987318. http://link.springer.com.ezproxy.lib.calpoly.edu/article/10.1007/BF02987318.

Campanella, and R. Paul. 2000. "Presence, in the Rhizosphere and Leaf Extracts of Zucchini ( Cucurbita Pepo L.) and Melon ( Cucumis Melo L.), of Molecules Capable of Increasing the Apparent Aqueous Solubility of Hydrophobic Pollutants." International Journal of Phytoremediation 2 (2). doi:10.1080/15226510008500036.

Centers for Disease Control and Prevention. 2014. “CDC - NIOSH Manual of Analytical Methods." NIOSH. http://www.cdc.gov/niosh/docs/2003-154/.

Chang, Roberto, Dorila Pilo-Veloso, Sergio A. L. Morais, and Evandro A. Nascimento. 2008. “Analysis of a Brazilian Green Propolis from Baccharis Dracunculifolia by HPLC-APCI-MS and GC-MS.” REVISTA BRASILEIRA DE FARMACOGNOSIABRAZILIAN JOURNAL OF PHARMACOGNOSY 18 (4): 549-556.

http://apps.webofknowledge.com/full_record.do?product=WOS\&search_mode=Gen eralSearch\&qid=3\&SID=2E4pioQpwAdYwMXpkpY\&page=1\&doc=1.

Chekol, Tesema, Lester R. Vough, and Rufus L. Chaney. 2004. "Phytoremediation of Polychlorinated Biphenyl-Contaminated Soils: The Rhizosphere Effect.” 
Environment International 30 (6) (August): 799-804.

doi:10.1016/j.envint.2004.01.008.

http://www.sciencedirect.com/science/article/pii/S0160412004000339.

Coleman, Julian, Mechteld Blake-Kalff, and Emyr Davies. 1997. "Detoxification of Xenobiotics by Plants: Chemical Modification and Vacuolar Compartmentation." Trends in Plant Science 2 (4) (April): 144-151. doi:10.1016/S1360-1385(97)010194. http://www.sciencedirect.com/science/article/pii/S1360138597010194.

Concha, Juan, Cavieres Lohengrin, Gaston Sotes, and Victor Hernandez. 2014. "Essential Oil Composition of Baccharis Linearis (Ruiz \& Pav.) Pers. and Baccharis Paniculata DC. Leaves from Chile.” American Journal of Essential Oil and Natural Products 1 (4): 6-8. http://www.essencejournal.com/vol1/issue4/10.1.html.

Cook, Rachel L., and Dean Hesterberg. 2013. "Comparison of Trees and Grasses for Rhizoremediation of Petroleum Hydrocarbons." International Journal of Phytoremediation 15 (9): 844-860. doi:10.1080/15226514.2012.760518. http://www.tandfonline.com/doi/abs/10.1080/15226514.2012.760518.

Cordale Johnson, John Thomlinson, Connie Vadheim Roth. 2009. “The Phytoremediation Capacity of Baccharis Salicifolia with Respect to Copper Sequestration." Bulletin of the Southern California Academy of Sciences 108 (2): 13. http://scholar.oxy.edu/cgi/viewcontent.cgi?article=1081\&context=scas. 
Cunningham, Scott D., and William R. Berti. 1993. "Remediation of Contaminated Soils with Green Plants: An Overview.” In Vitro Cellular \& Developmental Biology. Plant 29P (4) (October): 207-212. doi:10.2307/4293003. http://www.jstor.org/stable/4293003.

D’Orazio, Valeria, Alaà Ghanem, and Nicola Senesi. 2013. "Phytoremediation of Pyrene Contaminated Soils by Different Plant Species.” CLEAN - Soil, Air, Water 41 (4): 377-382. doi:10.1002/clen.201100653. http://onlinelibrary.wiley.com/doi/10.1002/clen.201100653/abstract.

Department of Energy. 2003. "Environmental Assessment for Cleanup and Closure of the Energy Technology Engineering Center”. NNSA Service Center Oakland, CA. http://energy.gov/nepa/downloads/ea-1345-final-environmental-assessment.

Duckart, Ec, Lj Waldron, and He Donner. 1992. “Selenium Uptake and Volatilization from Plants Growing in Soil.” Soil Science 153 (2) (February): 94-99. doi:10.1097/00010694-199202000-00002.

Dushenkov, Viatcheslav., P. B. A. Nanda. Kumar, Harry. Motto, and Ilya. Raskin. 1995. "Rhizofiltration: The Use of Plants to Remove Heavy Metals from Aqueous Streams.” Environmental Science \& Technology 29 (5) (May): 1239-1245. doi:10.1021/es00005a015. http://dx.doi.org/10.1021/es00005a015.

Ent, Antony van der, Alan J. M. Baker, Roger D. Reeves, A. Joseph Pollard, and Henk Schat. 2013. "Hyperaccumulators of Metal and Metalloid Trace Elements: Facts and 
Fiction.” Plant and Soil 362 (1-2) (January): 319-334. doi:10.1007/s11104-012-

1287-3. http://link.springer.com/article/10.1007/s11104-012-1287-3.

EPA. 1995. "National Primary Drinking Water Regulations."

—. 1999. "Phytoremediation Resource Guide."

Fava, Fabio, Diana Di Gioia, and Leonardo Marchetti. 1998. "Cyclodextrin Effects on the Ex-Situ Bioremediation of a Chronically Polychlorobiphenyl-Contaminated Soil.” Biotechnology and Bioengineering 58 (4): 345-355. doi:10.1002/(SICI)10970290(19980520)58:4<345::AID-BIT1>3.0.CO;2-J. http://onlinelibrary.wiley.com.ezproxy.lib.calpoly.edu/doi/10.1002/(SICI)10970290(19980520)58:4<345::AID-BIT1>3.0.CO;2-J/abstract.

Ficko, Sarah A., Allison Rutter, and Barbara A. Zeeb. 2010. "Potential for Phytoextraction of PCBs from Contaminated Soils Using Weeds." Science of The Total Environment 408 (16) (July): 3469-3476. doi:10.1016/j.scitotenv.2010.04.036. http://www.sciencedirect.com/science/article/pii/S0048969710004146.

Flora, Swaran J S, and Vidhu Pachauri. 2010. "Chelation in Metal Intoxication." International Journal of Environmental Research and Public Health 7 (7) (July 28): 2745-88. doi:10.3390/ijerph7072745. http://www.mdpi.com/16604601/7/7/2745/htm. 
Freitas, H., M.N.V. Prasad, and J. Pratas. 2004. “Analysis of Serpentinophytes from North-east of Portugal for Trace Metal Accumulation-relevance to the Management of Mine Environment.” Chemosphere 54 (11) (March): 1625-1642. doi:10.1016/j.chemosphere.2003.09.045. http://www.sciencedirect.com/science/article/pii/S0045653503009573.

Gao, Yanzheng, and Lizhong Zhu. 2004. "Plant Uptake, Accumulation and Translocation of Phenanthrene and Pyrene in Soils." Chemosphere 55 (9) (June): 1169-1178. doi:10.1016/j.chemosphere.2004.01.037. http://www.sciencedirect.com/science/article/pii/S0045653504000748.

Gerhardt, Karen E., Xiao-Dong Huang, Bernard R. Glick, and Bruce M. Greenberg. 2009. "Phytoremediation and Rhizoremediation of Organic Soil Contaminants: Potential and Challenges." Plant Science 176 (1) (January): 20-30. doi:10.1016/j.plantsci.2008.09.014. http://www.sciencedirect.com/science/article/pii/S0168945208002720.

Giller, Ken E, Ernst Witter, and Steve P Mcgrath. 1998. “Toxicity of Heavy Metals to Microorganisms and Microbial Processes in Agricultural Soils: a Review." Soil Biology and Biochemistry 30 (10-11) (September): 1389-1414. doi:10.1016/S00380717(97)00270-8. http://www.sciencedirect.com/science/article/pii/S0038071797002708.

Gisbert, Carmina, Concepción Almela, Dinoraz Vélez, J. Rafael López-Moya, Antonio De Haro, Ramón Serrano, Rosa Montoro, and Juan Navarro-Aviñó. 2008. 
"Identification of as Accumulation Plant Species Growing on Highly Contaminated Soils.” International Journal of Phytoremediation 10 (3) (May): 185-196.

doi:10.1080/15226510801997457.

http://search.ebscohost.com/login.aspx?direct=true \&db=aph\&AN=32746677\&site= ehost-live.

Gisbert, Carmina, Rafael Clemente, Juan Navarro-Aviñó, Carlos Baixauli, Alfonso Ginér, Ramón Serrano, David J. Walker, and M. Pilar Bernal. 2006. “Tolerance and Accumulation of Heavy Metals by Brassicaceae Species Grown in Contaminated Soils from Mediterranean Regions of Spain.” Environmental and Experimental Botany 56 (1) (May): 19-27. doi:10.1016/j.envexpbot.2004.12.002. http://www.sciencedirect.com/science/article/pii/S0098847204001777.

Greenwood, Scott J., Allison Rutter, and Barbara A. Zeeb. 2011. “The Absorption and Translocation of Polychlorinated Biphenyl Congeners by Cucurbita Pepo Ssp Pepo.” Environmental Science \& Technology 45 (15) (August): 6511-6516. doi:10.1021/es200598u. http://dx.doi.org/10.1021/es200598u.

Hall, Jessica, Kathleen Soole, and Richard Bentham. 2011. "Hydrocarbon Phytoremediation in the Family Fabacea-A Review." International Journal of Phytoremediation 13 (4) (April): 317-332. doi:10.1080/15226514.2010.495143. http://search.ebscohost.com/login.aspx?direct=true \&db=aph\&AN=58528644\&site= ehost-live. 
Heath, J. S., K. Koblis, and S. L. Sager. 1993. "Review of Chemical, Physical, and Toxicologic Properties of Components of Total Petroleum Hydrocarbons.” Journal of Soil Contamination 2 (1).

Heaton, A. C. P., C. L. Rugh, N. J. Wang, and R. B. Meagher. 1998. "Phytoremediation of Mercury- and Methylmercury-Polluted Soils Using Genetically Engineered Plants." Journal of Soil Contamination 7 (4): 497-509.

Hilarides, Roger, K A Gray, J Guzzetta, N Cortellucci, and C Sommer. 1994. "Radiolytic Degradation of 2,3,7,8-TCDD in Artificially Contaminated Soils.” Environmental Science \& Technology 28 (13) (December 1): 2249-58. doi:10.1021/es00062a008. http://dx.doi.org/10.1021/es00062a008.

Hilarides, Roger, Kimberly A. Gray, Joseph Guzzetta, Norma Cortellucci, and Christopher Sommer. 1996. "Feasibility, System Design, and Economic Evaluation of Radiolytic Degradation of 2,3,7,8-Tetrachlorodibenzo-p-Dioxin on Soil.” Water Environment Research 68 (2) (March 1): 178-187. doi:10.2175/106143096X127361. http://www.ingentaconnect.com/content/wef/wer/1996/00000068/00000002/art0000 7?token $=00591$ dea94501712bd49c5a666f3a7b6c2a317b6f5b6b65527a6b6749264f6 $52330434 \mathrm{f} 58762 \mathrm{f} 46 \mathrm{ac} 4510 \mathrm{~b} 0 \mathrm{a} 6$.

Huang, J. W., and S. D. Cunningham. 1996. "Lead Phytoextraction: Species Variation in Lead Uptake and Translocation.” New Phytologist 134 (1) (September): 75-84. doi:10.2307/2558516. http://www.jstor.org/stable/2558516. 
Huang, Jianwei W., Jianjun Chen, William R. Berti, and Scott D. Cunningham. 1997. "Phytoremediation of Lead-Contaminated Soils: Role of Synthetic Chelates in Lead Phytoextraction.” Environmental Science \& Technology 31 (3) (March): 800-805. doi:10.1021/es9604828. http://dx.doi.org/10.1021/es9604828.

Huelster, Anke., Jochen F. Mueller, and Horst. Marschner. 1994. "Soil-Plant Transfer of Polychlorinated Dibenzo-p-Dioxins and Dibenzofurans to Vegetables of the Cucumber Family (Cucurbitaceae).” Environmental Science \& Technology 28 (6) (June): 1110-1115. doi:10.1021/es00055a021. http://dx.doi.org/10.1021/es00055a021.

HydroGeoLogic. 2010. "Final Gamma Radiation Scanning Sampling and Analysis Plan Area IV Radiological Study Santa Susana Field Laboratory Ventura County, California.” http://www.dtscssfl.com/files/lib_doe_area_iv/bgstudy/64718_Final_Gamma_Scanning_SAP_2-2210.pdf.

HydroGeoLogic Inc. 2012. "Final Radiological Characterization of Soils Area IV and the Northern Buffer Zone”. Calabasas, California. http://www.dtscssfl.com/files/lib_doe_area_iv/epaareaivsurvey/techdocs/65789_Final_Radiological _Characterization_of_Soils_122112.pdf.

Institute, Sierra Streams. 2013. "Sierra Streams Institute: Brownfields Assessment and Clean-Up.” http://www.friendsofdeercreek.org/brownfields.html. 
Kaplan, C. W., and C. L. Kitts. 2004. "Bacterial Succession in a Petroleum Land Treatment Unit." Applied and Environmental Microbiology 70 (3) (March 8): 17771786. doi:10.1128/AEM.70.3.1777-1786.2004. http://aem.asm.org/content/70/3/1777.

Kuiper, I., E. L. Lagendijk, G. V. Bloemberg, and B. J. J. Lugtenberg. 2004. "Rhizoremediation: A Beneficial Plant-Microbe Interaction." Molecular PlantMicrobe Interactions 17 (1) (January): 6-15. doi:10.1094/MPMI.2004.17.1.6.

Lee, Jae Heung. 2013. “An Overview of Phytoremediation as a Potentially Promising Technology for Environmental Pollution Control." Biotechnology and Bioprocess Engineering 18 (3) (June): 431-439. doi:10.1007/s12257-013-0193-8. http://ink.springer.com/article/10.1007/s12257-013-0193-8.

Lee, Sang-Hwan, Won-Seok Lee, Chang-Ho Lee, and Jeong-Gyu Kim. 2008. "Degradation of Phenanthrene and Pyrene in Rhizosphere of Grasses and Legumes." Journal of Hazardous Materials 153 (1-2) (May): 892-898. doi:10.1016/j.jhazmat.2007.09.041. http://www.sciencedirect.com/science/article/pii/S0304389407013313.

Lemieux, Paul M, Christopher C Lutes, and Dawn A Santoianni. 2004. "Emissions of Organic Air Toxics from Open Burning: a Comprehensive Review." Progress in Energy and Combustion Science 30 (1): 1-32. doi:10.1016/j.pecs.2003.08.001. http://www.sciencedirect.com/science/article/pii/S0360128503000613. 
Lépine, François, and Robert Massé. 1990. "Effect of Gamma Irradiation on a PCB Mixture in Organic Solvent." Bulletin of Environmental Contamination and Toxicology 44 (4) (April): 549-554. doi:10.1007/BF01700874. http://link.springer.com/10.1007/BF01700874.

Lewis, B. G., C. M. Johnson, and C. C. Delwiche. 1966. "Release of Volatile Selenium Compounds by Plants. Collection Procedures and Preliminary Observations." Journal of Agricultural and Food Chemistry 14 (6) (November): 638-640. doi:10.1021/jf60148a027. http://dx.doi.org/10.1021/jf60148a027.

Li, Ying, Fang Liang, Youfeng Zhu, and Fengping Wang. 2013. "Phytoremediation of a PCB-Contaminated Soil by Alfalfa and Tall Fescue Single and Mixed Plants Cultivation." Journal of Soils and Sediments 13 (5) (February): 925-931. doi:10.1007/s11368-012-0618-6. http://link.springer.com/content/pdf/10.1007/s11368-012-0618-6.pdf.

Lin, Zhi-Qing, and Norman Terry. 2003. "Selenium Removal by Constructed Wetlands: Quantitative Importance of Biological Volatilization in the Treatment of SeleniumLaden Agricultural Drainage Water.” Environmental Science \& Technology 37 (3) (February): 606-615. doi:10.1021/es0260216. http://dx.doi.org/10.1021/es0260216.

Liste, Hans-Holger, and Martin Alexander. 2000. "Plant-Promoted Pyrene Degradation in Soil." Chemosphere 40 (1) (January): 7-10. doi:10.1016/S0045-6535(99)00216-7. http://www.sciencedirect.com/science/article/pii/S0045653599002167. 
Liu, Jiyan, and Jerald L. Schnoor. 2008. "Uptake and Translocation of LesserChlorinated Polychlorinated Biphenyls (PCBs) in Whole Hybrid Poplar Plants after Hydroponic Exposure.” Chemosphere 73 (10) (November): 1608-1616. doi:10.1016/j.chemosphere.2008.08.009. http://www.sciencedirect.com/science/article/pii/S0045653508010370.

Marchiol, Luca, Guido Fellet, Francesco Boscutti, Carlo Montella, Riccardo Mozzi, and Carmine Guarino. 2013. "Gentle Remediation at the Former 'Pertusola Sud' Zinc Smelter: Evaluation of Native Species for Phytoremediation Purposes.” Ecological Engineering 53 (April): 343-353. doi:10.1016/j.ecoleng.2012.12.072. http://www.sciencedirect.com/science/article/pii/S0925857412004272.

Marr, Linsey C., Elizabeth C. Booth, Rikke G. Andersen, Mark A. Widdowson, and John T. Novak. 2006. "Direct Volatilization of Naphthalene to the Atmosphere at a Phytoremediation Site.” Environmental Science \& Technology 40 (17Marr, L. C., Booth, E. C., Andersen, R. G., Widdowson, M. A., \& Novak, J. T. (2006). Direct Volatilization of Naphthalene to the Atmosphere at a Phytoremediation Site. Environmental Science \& Technology, 40(17), 5560-5566. doi:10.1021/es060087+) (September): 5560-5566. doi:10.1021/es060087+. http://dx.doi.org/10.1021/es060087+.

McGrath, Steve P, and Fang-Jie Zhao. 2003. "Phytoextraction of Metals and Metalloids from Contaminated Soils." Current Opinion in Biotechnology 14 (3) (June): $277-$ 
282. doi:10.1016/S0958-1669(03)00060-0.

http://www.sciencedirect.com/science/article/pii/S0958166903000600.

Mejáre, Malin, and Leif Bülow. 2001. "Metal-Binding Proteins and Peptides in Bioremediation and Phytoremediation of Heavy Metals." Trends in Biotechnology 19 (2) (February): 67-73. doi:10.1016/S0167-7799(00)01534-1. http://www.sciencedirect.com/science/article/pii/S0167779900015341.

Memon, Abdul R., and Peter Schröder. 2009. "Implications of Metal Accumulation Mechanisms to Phytoremediation." Environmental Science and Pollution Research 16 (2) (March): 162-175. doi:10.1007/s11356-008-0079-z. http://link.springer.com/article/10.1007/s11356-008-0079-z.

Miya, Ryan K., and Mary K. Firestone. 2000. "Phenanthrene-Degrader Community Dynamics in Rhizosphere Soil from a Common Annual Grass." Journal of Environmental Quality 29 (2): 584-592. doi:10.2134/jeq2000.00472425002900020029x. https://www.agronomy.org/publications/jeq/abstracts/29/2/JEQ0290020584. . 2001. "Enhanced Phenanthrene Biodegradation in Soil by Slender Oat Root Exudates and Root Debris." Journal of Environment Quality 30 (6): 1911. doi:10.2134/jeq2001.1911. https://www.agronomy.org/publications/jeq/abstracts/30/6/1911. 
Morikawa, Hiromichi, and Özgür Cem Erkin. 2003. "Basic Processes in Phytoremediation and Some Applications to Air Pollution Control." Chemosphere 52 (9) (September): 1553-1558. doi:10.1016/S0045-6535(03)00495-8. http://www.sciencedirect.com/science/article/pii/S0045653503004958.

Newman, Lee A, and Charles M Reynolds. 2004. "Phytodegradation of Organic Compounds." Current Opinion in Biotechnology 15 (3) (June): 225-230. doi:10.1016/j.copbio.2004.04.006. http://www.sciencedirect.com/science/article/pii/S0958166904000588.

Newman, Lee A., Stuart E. Strand, Nami Choe, James Duffy, Gordon Ekuan, Martin Ruszaj, B. Brook Shurtleff, Jodi Wilmoth, Paul Heilman, and Milton P. Gordon. 1997. "Uptake and Biotransformation of Trichloroethylene by Hybrid Poplars." Environmental Science \& Technology 31 (4) (April): 1062-1067. doi:10.1021/es960564w. http://dx.doi.org/10.1021/es960564w.

Nietch, Christopher T., James T. Morris, and Don A. Vroblesky. 1999. "Biophysical Mechanisms of Trichloroethene Uptake and Loss in Baldcypress Growing in Shallow Contaminated Groundwater." Environmental Science \& Technology 33 (17) (September): 2899-2904. doi:10.1021/es981183g. http://dx.doi.org/10.1021/es981183g.

Orchard, Brady J., William J. Doucette, Julie K. Chard, and Bruce Bugbee. 2000. “A Novel Laboratory System for Determining Fate of Volatile Organic Compounds in 
Planted Systems.” Environmental Toxicology and Chemistry 19 (4) (April): 888894. doi:10.1002/etc.5620190415. http://doi.wiley.com/10.1002/etc.5620190415.

Parrish, Zakia D., M. Katherine Banks, and A. Paul Schwab. 2004. "Effectiveness of Phytoremediation as a Secondary Treatment for Polycyclic Aromatic Hydrocarbons (PAHs) in Composted Soil." International Journal of Phytoremediation 6 (2) (June): 119-137. doi:10.1080/16226510490454803. http://search.ebscohost.com/login.aspx?direct=true\&db=aph\&AN=13705452\&site= ehost-live.

Patra, Manomita, Niladri Bhowmik, Bulbul Bandopadhyay, and Archana Sharma. 2004. "Comparison of Mercury, Lead and Arsenic with Respect to Genotoxic Effects on Plant Systems and the Development of Genetic Tolerance." Environmental and Experimental Botany 52 (3) (December): 199-223. doi:10.1016/j.envexpbot.2004.02.009. http://www.sciencedirect.com/science/article/pii/S0098847204000346.

Peng, Shengwei, Qixing Zhou, Zhang Cai, and Zhineng Zhang. 2009. "Phytoremediation of Petroleum Contaminated Soils by Mirabilis Jalapa L. in a Greenhouse Plot Experiment." Journal of Hazardous Materials 168 (2-3) (September): 1490-1496. doi:10.1016/j.jhazmat.2009.03.036. http://www.sciencedirect.com/science/article/pii/S0304389409004348.

Phillips, Lori A., Charles W. Greer, R.E. Farrell, and James J. Germida. 2009. "FieldScale Assessment of Weathered Hydrocarbon Degradation by Mixed and Single 142 
Plant Treatments." Applied Soil Ecology 42 (1) (May): 9-17.

doi:10.1016/j.apsoil.2009.01.002.

http://www.sciencedirect.com/science/article/pii/S0929139309000067.

Pilon-Smits, Elizabeth. 2005. "Phytoremediation.” Annual Review of Plant Biology 56 (1): 15-39. doi:10.1146/annurev.arplant.56.032604.144214. http://www.annualreviews.org/doi/abs/10.1146/annurev.arplant.56.032604.144214.

Poschenrieder, Charlotte, Jaume Bech, Mercè Llugany, Alina Pace, Eva Fenés, and Juan Barceló. 2001. "Copper in Plant Species in a Copper Gradient in Catalonia (North East Spain) and Their Potential for Phytoremediation." Plant and Soil 230 (2) (March): 247-256. doi:10.1023/A:1010374732486. http://ink.springer.com/article/10.1023/A:1010374732486.

Pourrut, Bertrand, Muhammad Shahid, Camille Dumat, Peter Winterton, and Eric Pinelli. 2011. "Lead Uptake, Toxicity, and Detoxification in Plants." Reviews of Environmental Contamination and Toxicology 213 (January): 113-36. doi:10.1007/978-1-4419-9860-6_4. http://apps.webofknowledge.com/full_record.do?product=WOS\&search_mode=Gen eralSearch\&qid=1\&SID=2FcaxJYIc2HJfLQH5y9\&page $=2 \&$ doc $=15$.

Providenti, Miguel A., Hung Lee, and Jack T. Trevors. 1993. "Selected Factors Limiting the Microbial Degradation of Recalcitrant Compounds." Journal of Industrial Microbiology 12 (6) (December): 379-395. doi:10.1007/BF01569669. http://link.springer.com.ezproxy.lib.calpoly.edu/article/10.1007/BF01569669. 
Raphael, Deborah. 2013. "Chemical Look-Up Table Technical Memorandum Santa Susana Field Laboratory, Ventura County, California.” www.dtscssfl.com/files/lib_look-uptables\chemical/66073_06112013LUTand_cover.pdf.

Raskin, Ilya, Robert D Smith, and David E Salt. 1997. "Phytoremediation of Metals: Using Plants to Remove Pollutants from the Environment." Current Opinion in Biotechnology 8 (2) (April): 221-226. doi:10.1016/S0958-1669(97)80106-1. http://www.sciencedirect.com/science/article/pii/S0958166997801061.

Robinson, S., J. Novak, M. Widdowson, S. Crosswell, and G. Fetterolf. 2003. "Field and Laboratory Evaluation of the Impact of Tall Fescue on Polyaromatic Hydrocarbon Degradation in an Aged Creosote-Contaminated Surface Soil.” Journal of Environmental Engineering 129 (3): 232-240. doi:10.1061/(ASCE)07339372(2003)129:3(232). http://ascelibrary.org/doi/abs/10.1061/(ASCE)07339372(2003)129:3(232).

Rugh, C. L., J. F. Senecoff, R. B. Meagher, and S. A. Merkle. 1998. "Development of Transgenic Yellow Poplar for Mercury Phytoremediation.” Nature Biotechnology 16 (10) (October): 925-928. doi:10.1038/nbt1098-925.

Rugh, C. L., H. D. Wilde, N. M. Stack, D. M. Thompson, A. O. Summers, and R. B. Meagher. 1996. "Mercuric Ion Reduction and Resistance in Transgenic Arabidopsis Thaliana Plants Expressing a Modified Bacterial merA Gene." Proceedings of the National Academy of Sciences 93 (8) (April): 3182-3187. http://www.pnas.org/content/93/8/3182. 
Sakakibara, Masayuki, Aya Watanabe, Masahiro Inoue, Sakae Sano, and Toshikazu Kaise. 2010. Phytoextraction And Phytovolatilization Of Arsenic From AsContaminated Soils By Pteris Vittata. Proceedings of the Annual International Conference on Soils, Sediments, Water and Energy. Vol. 12. http://scholarworks.umass.edu/soilsproceedings/vol12/iss1/26.

Salt, D. E., R. D. Smith, and I. Raskin. 1998. "Phytoremediation.” Annual Review of Plant Physiology \& Plant Molecular Biology 49 (1) (June): 643. http://search.ebscohost.com/login.aspx?direct=true $\& d b=a p h \& A N=5371780 \&$ site $=e$ host-live.

San Miguel, Angélique, Patrick Ravanel, and Muriel Raveton. 2013. “A Comparative Study on the Uptake and Translocation of Organochlorines by Phragmites Australis.” Journal of Hazardous Materials 244-245 (January 15): 60-9. doi:10.1016/j.jhazmat.2012.11.025. http://apps.webofknowledge.com/full_record.do?product=UA\&search_mode=Gener alSearch\&qid=10\&SID=2DyEfGLr12up9XphqGB\&page=1\&doc $=1$.

Sánchez-Pérez, José D. L., Ma. Guadalupe Jaimes-Lara, Rafael Salgado-Garciglia, and Joel E. López-Meza. 2009. "Root Extracts from Mexican Avocado (Persea Americana Var. Drymifolia) Inhibit the Mycelial Growth of the Oomycete Phytophthora Cinnamomi.” European Journal of Plant Pathology 124 (4) (March 6): 595-601. doi:10.1007/s10658-009-9446-y. 
http://apps.webofknowledge.com/full_record.do?product=WOS\&search_mode=Gen eralSearch\&qid=5\&SID=2E4pioQpwAdYwMXpkpY\&page=1\&doc=1.

Sandia National Laboratories. 2012. "Investigations Recommended for Resolving Uncertainty About Soil Remediation at ETEC."

Schnoor, Jerald L., Louis A. Light, Steven C. McCutcheon, N. Lee Wolfe, and Laura H. Carreia. 1995. "Phytoremediation of Organic and Nutrient Contaminants." Environmental Science \& Technology 29 (7) (July): 318A-323A. doi:10.1021/es00007a002. http://dx.doi.org/10.1021/es00007a002.

Secher, C., M. Lollier, K. Jézéquel, J. Y. Cornu, L. Amalric, and T. Lebeau. 2013. "Decontamination of a Polychlorinated Biphenyls-Contaminated Soil by Phytoremediation-Assisted Bioaugmentation.” Biodegradation 24 (4) (July): 549 562. doi:10.1007/s10532-013-9625-6. http://link.springer.com.ezproxy.lib.calpoly.edu/article/10.1007/s10532-013-9625-6.

Seo, Jong-Su, Young-Soo Keum, and Qing X. Li. 2009. "Bacterial Degradation of Aromatic Compounds." International Journal of Environmental Research and Public Health 6 (1) (January): 278-309. doi:10.3390/ijerph6010278. http://www.ncbi.nlm.nih.gov/pmc/articles/PMC2672333/.

Shang, T. Q., L. A. Newman, and M. P. Gordon. 2003. Fate of Trichloroethylene in Terrestrial Plants. Edited by S. McCutcheon and J. L. Schnoor. Hoboken, USA: Wiley-Interscience. 
Shen, Chaofeng, Xianjin Tang, Sardar Alam Cheema, Congkai Zhang, Muhammad Imran Khan, Fang Liang, Xincai Chen, Youfeng Zhu, Qi Lin, and Yingxu Chen. 2009. "Enhanced Phytoremediation Potential of Polychlorinated Biphenyl Contaminated Soil from e-Waste Recycling Area in the Presence of Randomly Methylated- $\beta$ Cyclodextrins." Journal of Hazardous Materials 172 (2-3) (December): 1671-1676. doi:10.1016/j.jhazmat.2009.08.064. http://www.sciencedirect.com/science/article/pii/S0304389409013399.

Siciliano, Steven D, James J Germida, Kathy Banks, and Charles W Greer. 2003. "Changes in Microbial Community Composition and Function During a Polyaromatic Hydrocarbon Phytoremediation Field Trial." Applied and Environmental Microbiology 69 (1) (January): 483-9. http://www.pubmedcentral.nih.gov/articlerender.fcgi?artid=152433\&tool=pmcentre $z \&$ rendertype $=$ abstract.

Singh, R.K., R.K. Khandal, and Gurdeep Singh. 2007. "Effect Of Gamma Radiation On Destruction Of Toxic Polychlorinated Biphenyls (pcbs) In Hydraulic Oils." Journal of Applied Sciences and Environmental Management 11 (4): 143-146. http://www.bioline.org.br/request?ja07111.

Slater, Heather, Todd Gouin, and Mary Beth Leigh. 2011. "Assessing the Potential for Rhizoremediation of PCB Contaminated Soils in Northern Regions Using Native Tree Species.” Chemosphere 84 (2) (June): 199-206. 
doi:10.1016/j.chemosphere.2011.04.058.

http://www.sciencedirect.com/science/article/pii/S0045653511004759.

Terry, N., A. M. Zayed, M. P. de Souza, and A. S. Tarun. 2000. "Selenium in Higher Plants." Annual Review of Plant Physiology \& Plant Molecular Biology 51 (1) (June): 401. http://search.ebscohost.com/login.aspx?direct=true $\& \mathrm{db}=\mathrm{aph} \& \mathrm{AN}=5366615 \&$ site $=\mathrm{e}$ host-live.

US EPA. 2011. "Dioxins and Furans | Persistent Bioaccumulative and Toxic (PBT) Chemical Program | US EPA.” April. http://www.epa.gov/pbt/pubs/dioxins.htm.

—. 2013a. "Basic Information | Mercury | US EPA.” July. http://www.epa.gov/mercury/about.htm.

US EPA, OSWER. 2013b. "Basic Information| Polychlorinated Biphenyls (PCBs)| US EPA.” April. http://www.epa.gov/epawaste/hazard/tsd/pcbs/about.htm.

Vangronsveld, Jaco, Rolf Herzig, Nele Weyens, Jana Boulet, Kristin Adriaensen, Ann Ruttens, Theo Thewys, et al. 2009. "Phytoremediation of Contaminated Soils and Groundwater: Lessons from the Field." Environmental Science and Pollution Research 16 (7) (November): 765-794. doi:10.1007/s11356-009-0213-6. http://link.springer.com.ezproxy.lib.calpoly.edu/article/10.1007/s11356-009-0213-6.

Wang, Jianxu, Xinbin Feng, Christopher W.N. Anderson, Ying Xing, and Lihai Shang. 2012. "Remediation of Mercury Contaminated Sites - A Review." Journal of 
Hazardous Materials 221-222 (June): 1-18. doi:10.1016/j.jhazmat.2012.04.035. http://www.sciencedirect.com/science/article/pii/S0304389412004268.

Wei, Shuhe, Qixing Zhou, Uttam Kumar Saha, Hong Xiao, Yahu Hu, Liping Ren, and Gu Ping. 2009. "Identification of a Cd Accumulator Conyza Canadensis." Journal of Hazardous Materials 163 (1) (April): 32-35. doi:10.1016/j.jhazmat.2008.06.062. http://www.sciencedirect.com/science/article/pii/S0304389408009369.

Wu, Chunhua, Xin Chen, and Jianjun Tang. 2005. "Lead Accumulation in Weed Communities with Various Species." Communications in Soil Science and Plant Analysis 36 (13-14): 1891-1902. doi:10.1081/CSS-200062486. http://www.tandfonline.com/doi/abs/10.1081/CSS-200062486.

Xu, Li, Ying Teng, Zhen-Gao Li, Jeanette M. Norton, and Yong-Ming Luo. 2010. "Enhanced Removal of Polychlorinated Biphenyls from Alfalfa Rhizosphere Soil in a Field Study: The Impact of a Rhizobial Inoculum." Science of The Total Environment 408 (5) (February): 1007-1013. doi:10.1016/j.scitotenv.2009.11.031. http://www.sciencedirect.com/science/article/pii/S0048969709011462.

Ying Teng, Yongming Luo, Xianghui Sun, Chen Tu, Li Xu, Wuxing Liu, Zhengao Li, and Peter Christie. 2010. "Influence of Arbuscular Mycorrhiza and Rhizobium on Phytoremediation by Alfalfa of an Agricultural Soil Contaminated with Weathered PCBs: A Field Study.” International Journal of Phytoremediation 12 (5) (July): 516-533. doi:10.1080/15226510903353120. 
http://search.ebscohost.com/login.aspx?direct=true\&db=aph\&AN=51981977\&site= ehost-live.

Yu, Xiao-Zhang, and Ji-Dong Gu. 2006. "Uptake, Metabolism, and Toxicity of Methyl Tert-Butyl Ether (MTBE) in Weeping Willows.” Journal of Hazardous Materials 137 (3) (October): 1417-1423. doi:10.1016/j.jhazmat.2006.04.024. http://www.sciencedirect.com/science/article/pii/S0304389406003955.

Zeeb, Barbara A., Jane S. Amphlett, Allison Rutter, and Kenneth J. Reimer. 2006. "Potential for Phytoremediation of Polychlorinated Biphenyl-(PCB)-Contaminated Soil.” International Journal of Phytoremediation 8 (3) (July): 199-221. doi:10.1080/15226510600846749. http://search.ebscohost.com/login.aspx?direct=true\&db=aph\&AN=22018541\&site= ehost-live. 
APPENDICES 
A. Graphs of Soil Microcosm Concentrations after 0, 85, and 211 Days

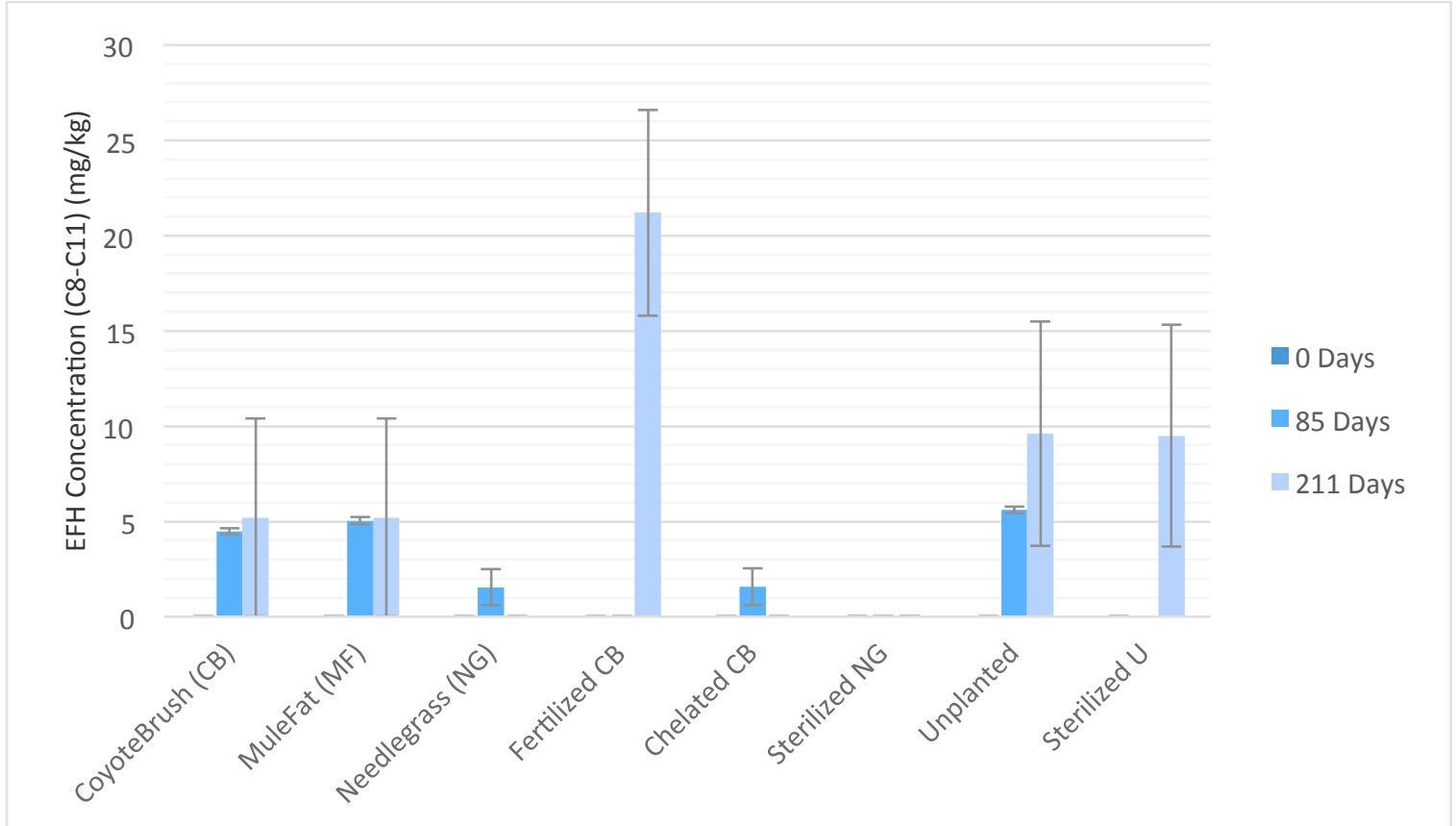

Figure A1: EFH (C8-C11) concentrations in microcosm soil after 0,85 , and 211 days

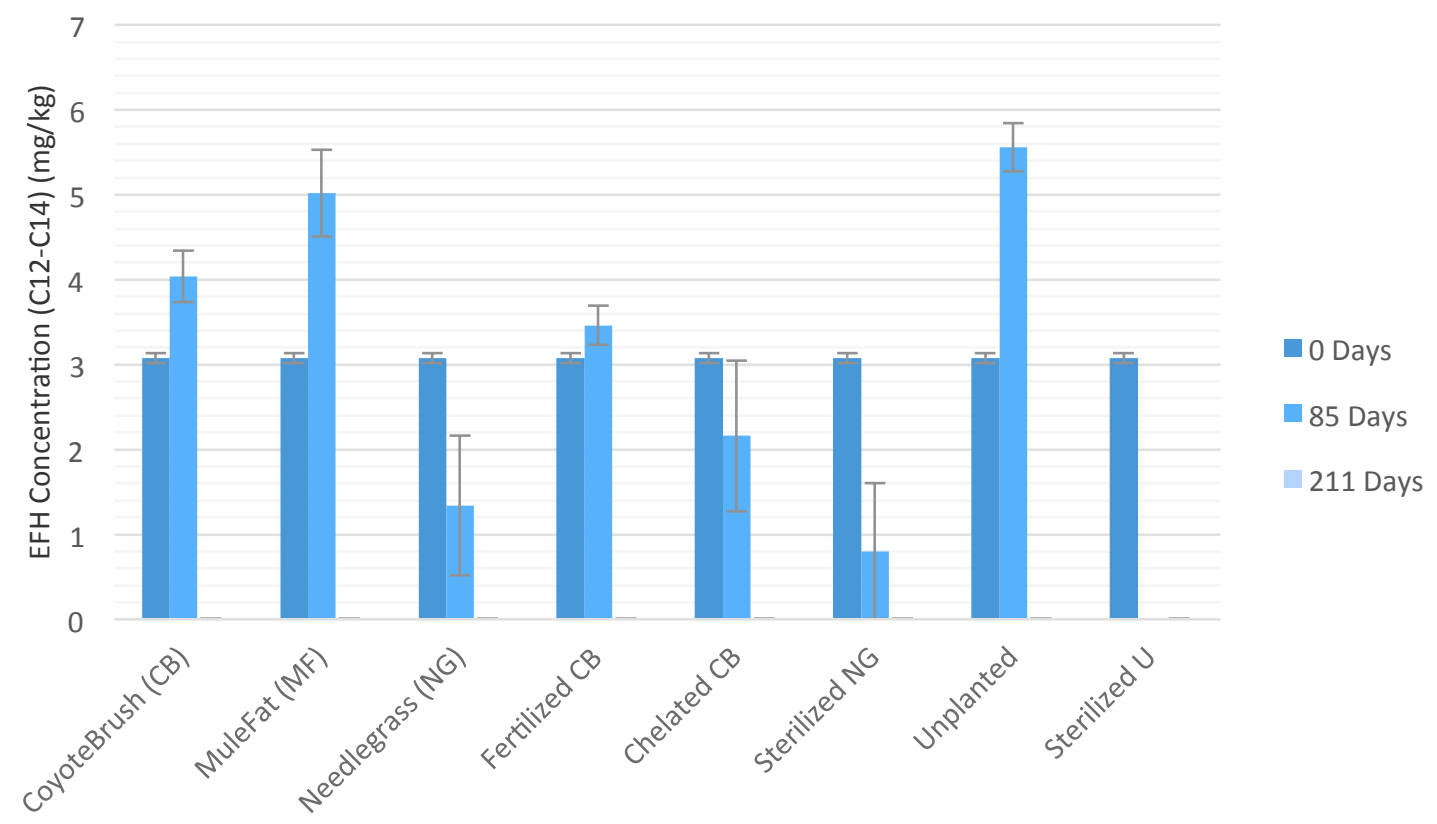

Figure A2: EFH (C12-C14) concentrations in microcosm soil after 0, 85, and 211 days 


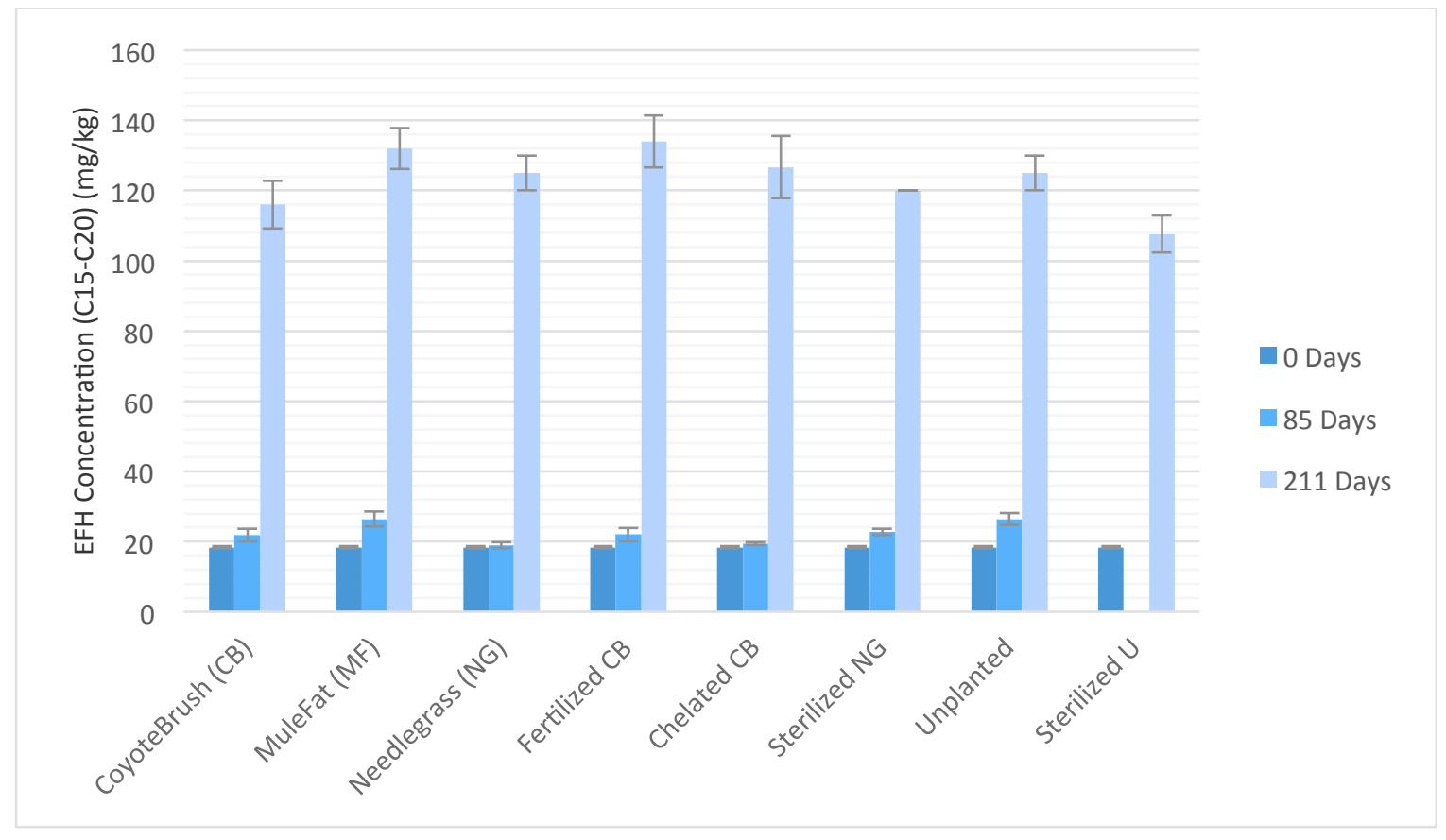

Figure A3: EFH (C15-C20) concentrations in microcosm soil after 0, 85, and 211 days

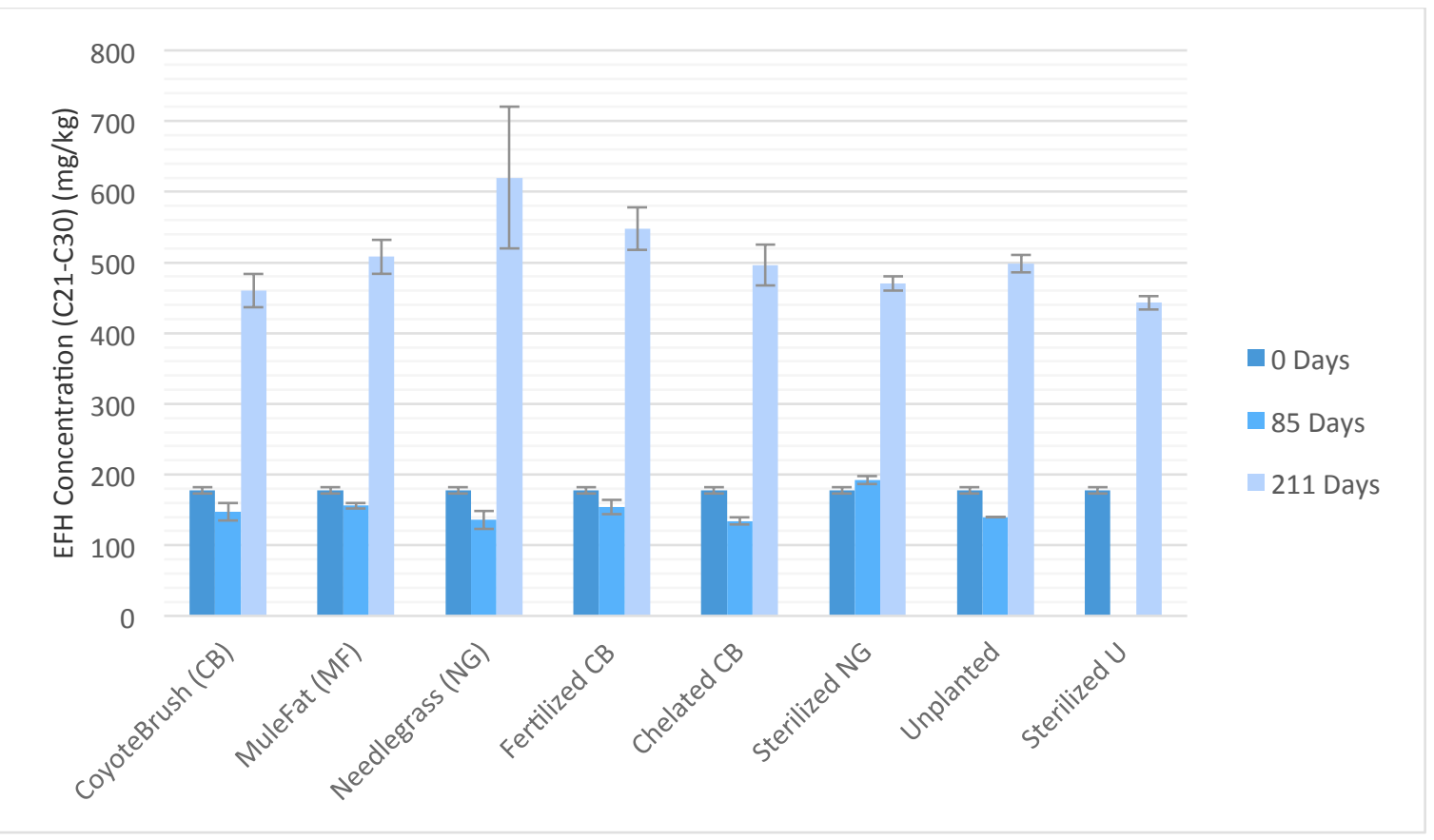

Figure A4: EFH (C21-C30) concentrations in microcosm soil after 0, 85, and 211 days 


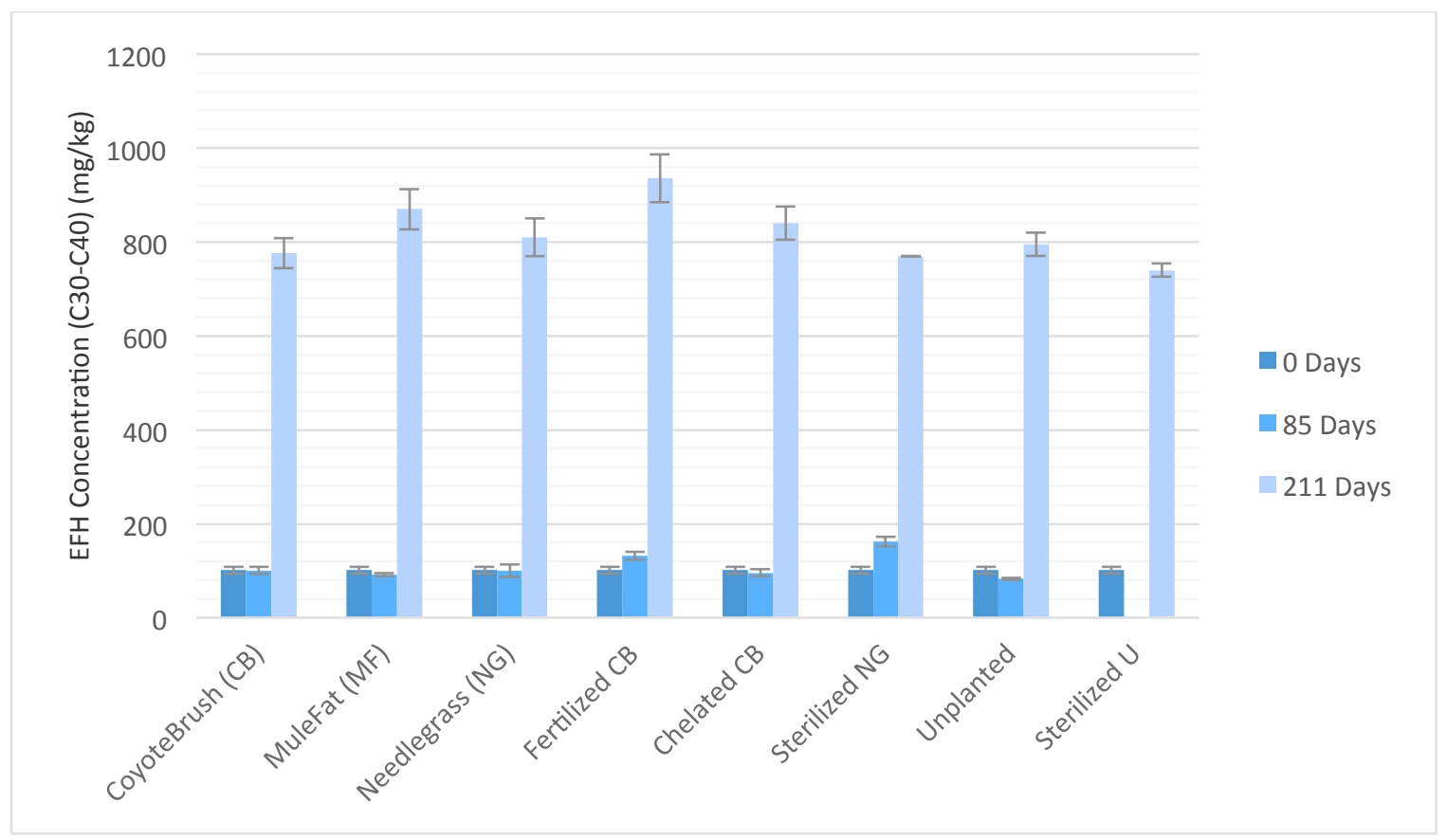

Figure A5: EFH (C30-C40) concentrations in microcosm soil after 0, 85, and 211 days 


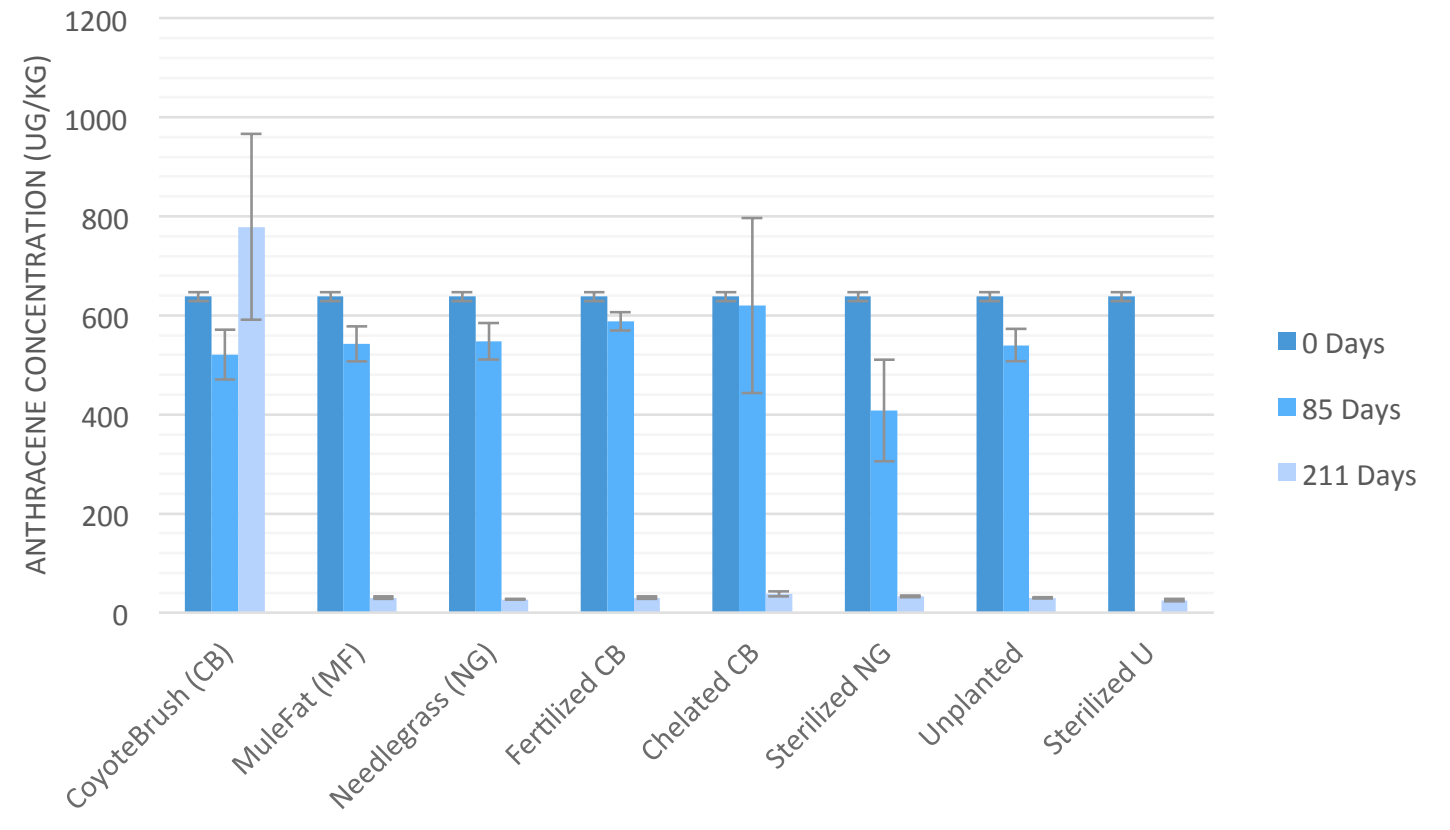

Figure A6: Anthracene concentrations in microcosm soil after 0, 85, and 211 days

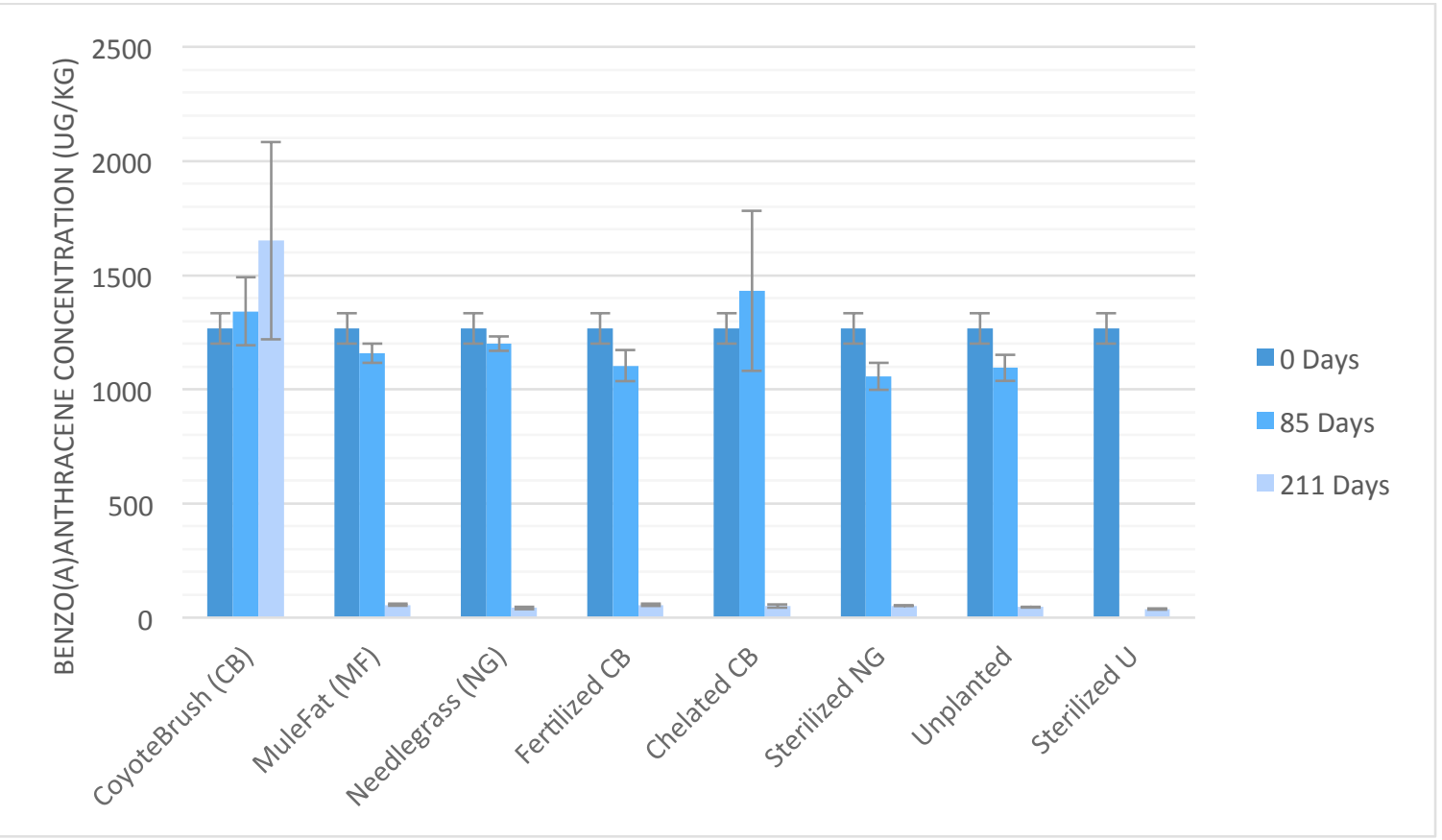

Figure A7: Benzo(a)anthracene concentrations in microcosm soil after 0, 85, and 211 days 


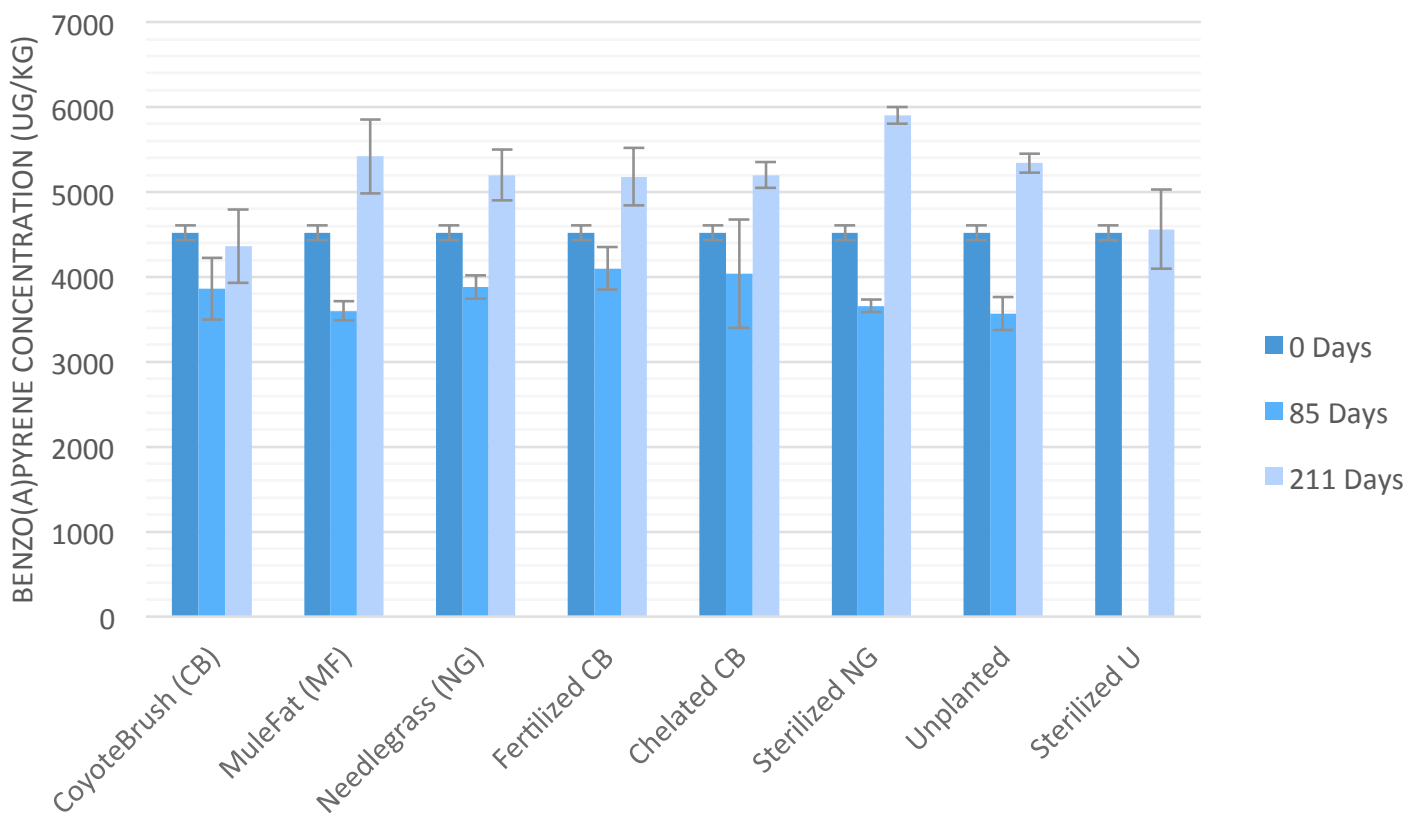

Figure A8: Benzo(a)pyrene concentrations in microcosm soil after 0, 85, and 211 days

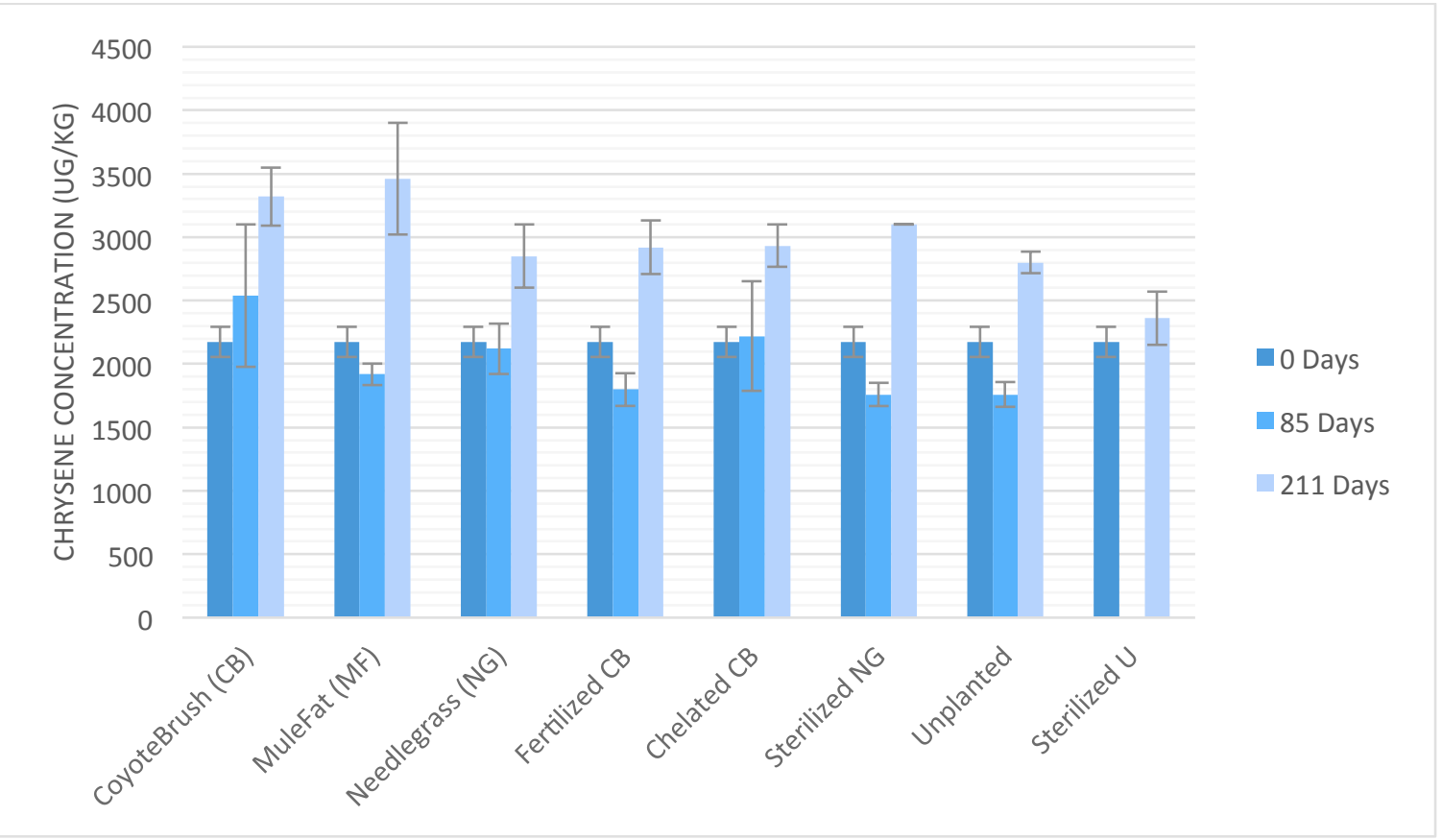

Figure A9: Chrysene concentrations in microcosm soil after 0,85 , and 211 days 


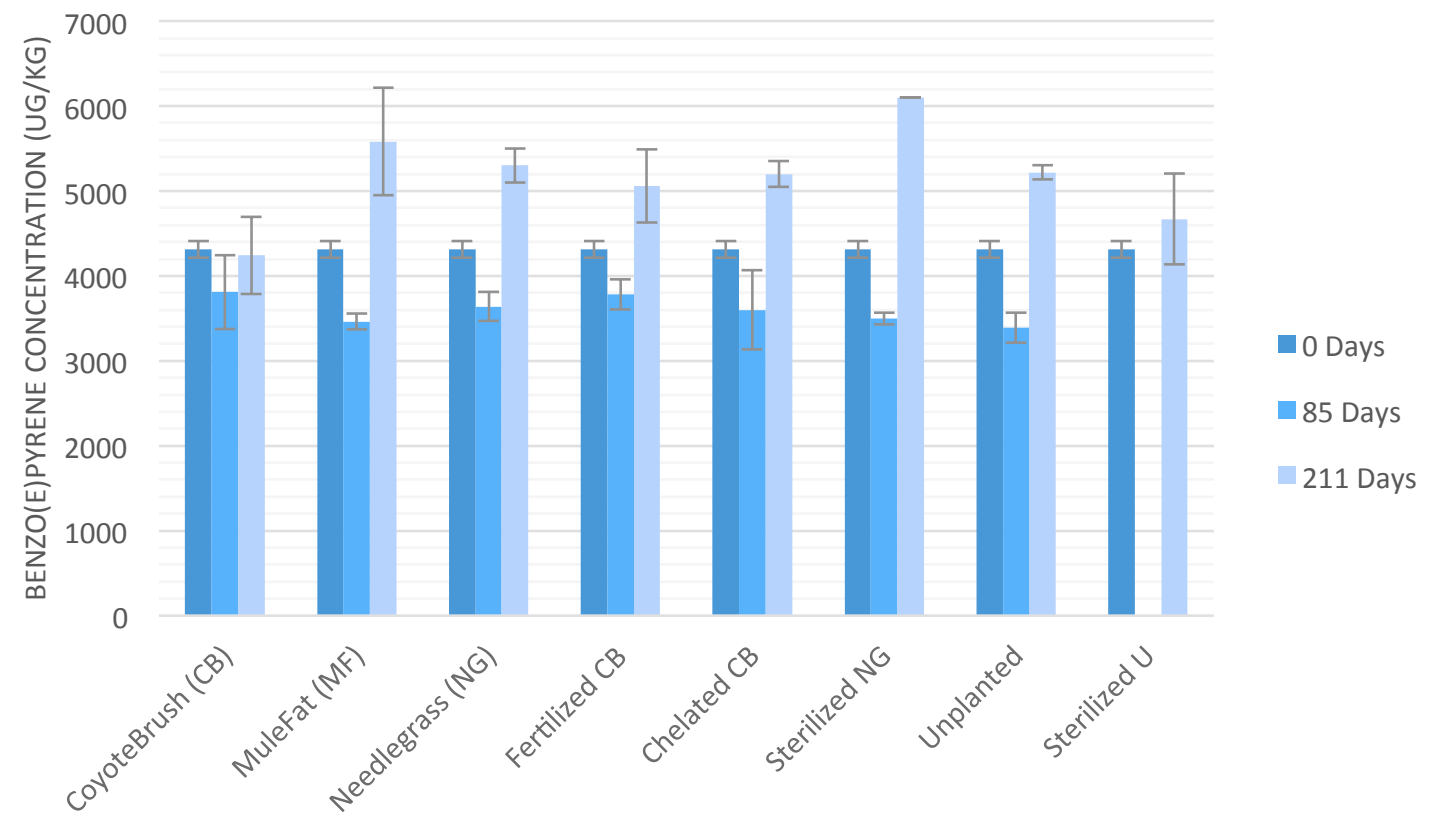

Figure A10: Benzo(e)pyrene concentrations in microcosm soil after 0, 85, and 211 days

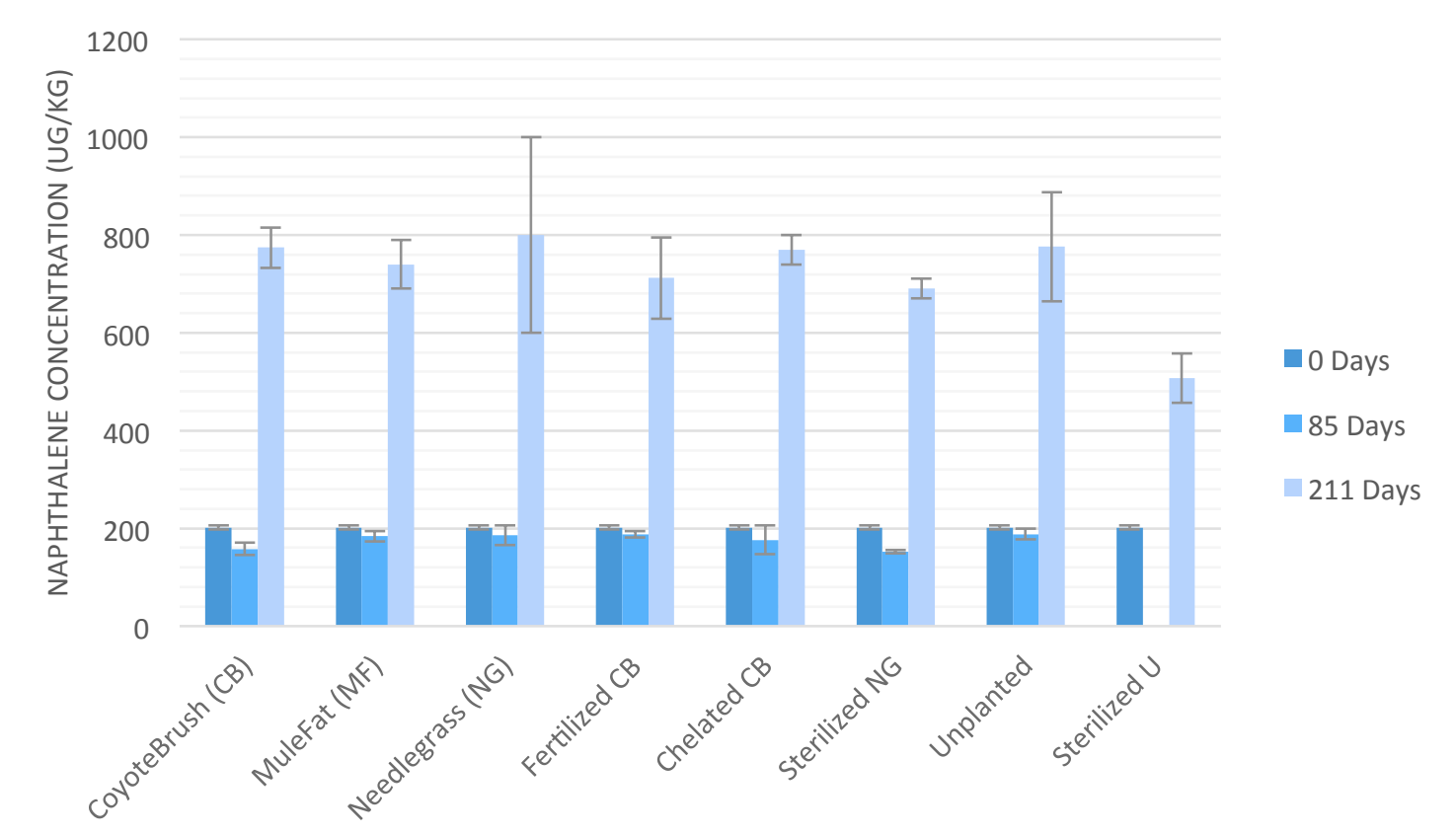

Figure A11: Naphthalene concentrations in microcosm soil after 0, 85, and 211 days 


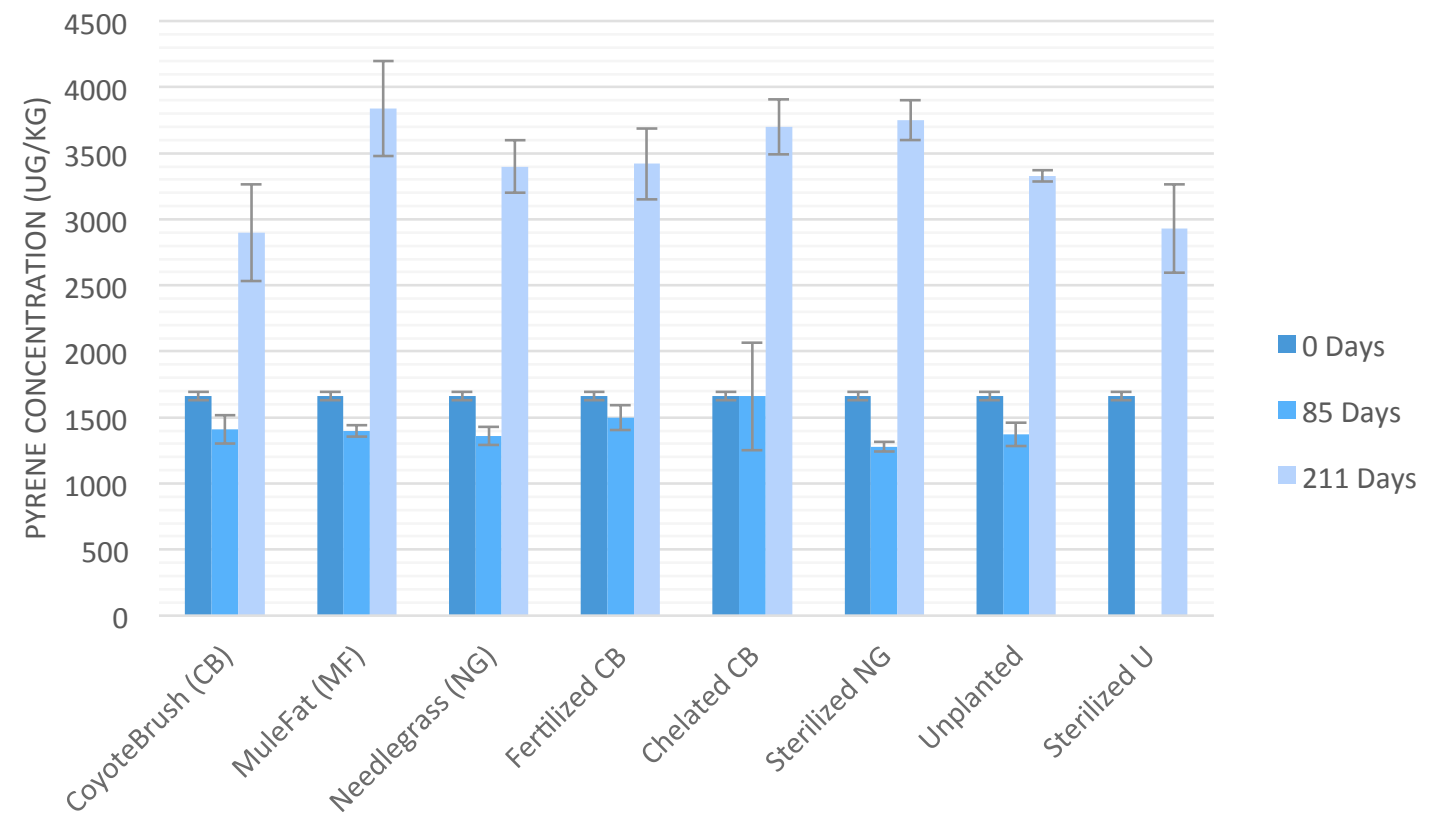

Figure A12: Pyrene concentrations in microcosm soil after 0, 85, and 211 days

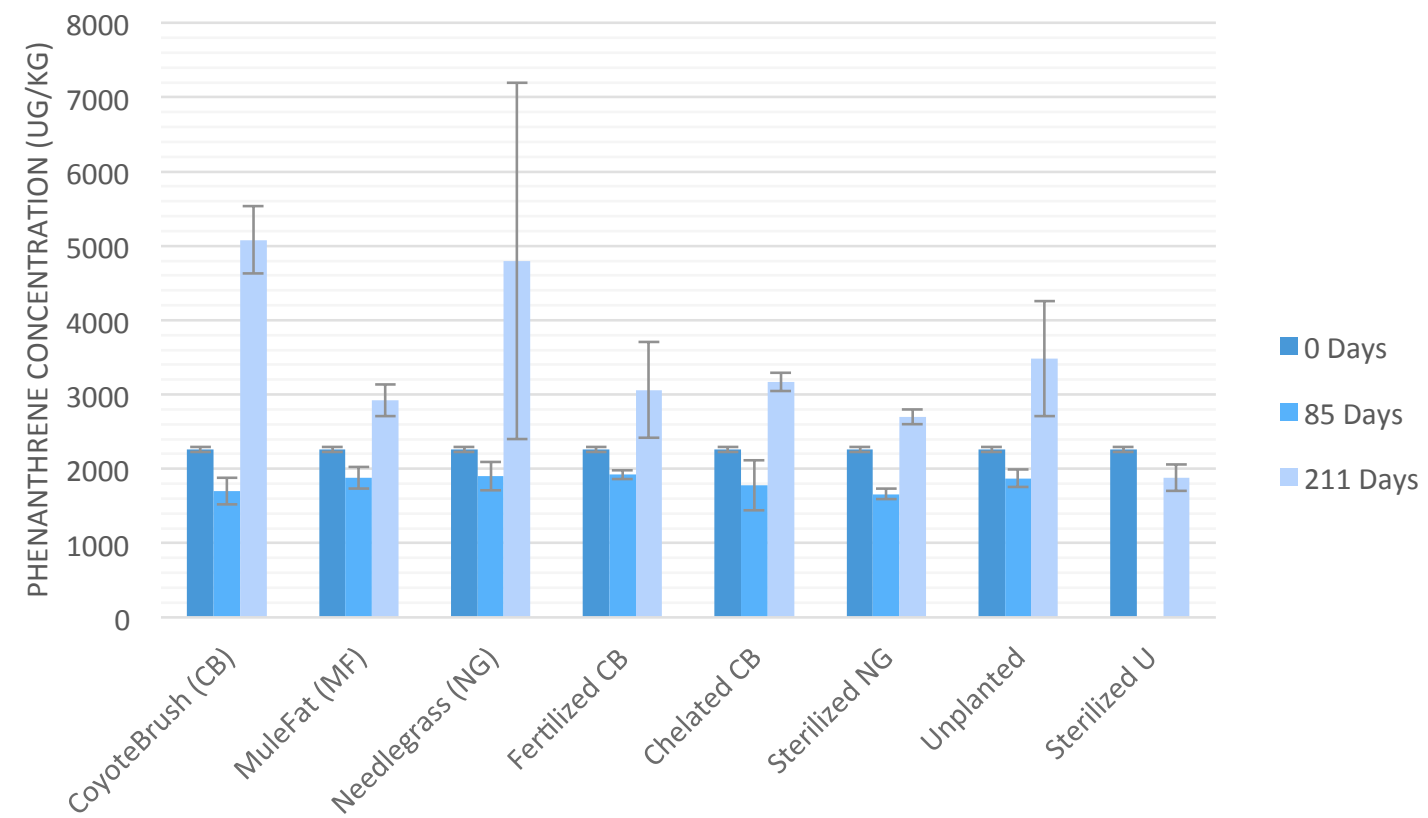

Figure A13: Phenanthrene concentrations in microcosm soil after 0,85 , and 211 days 


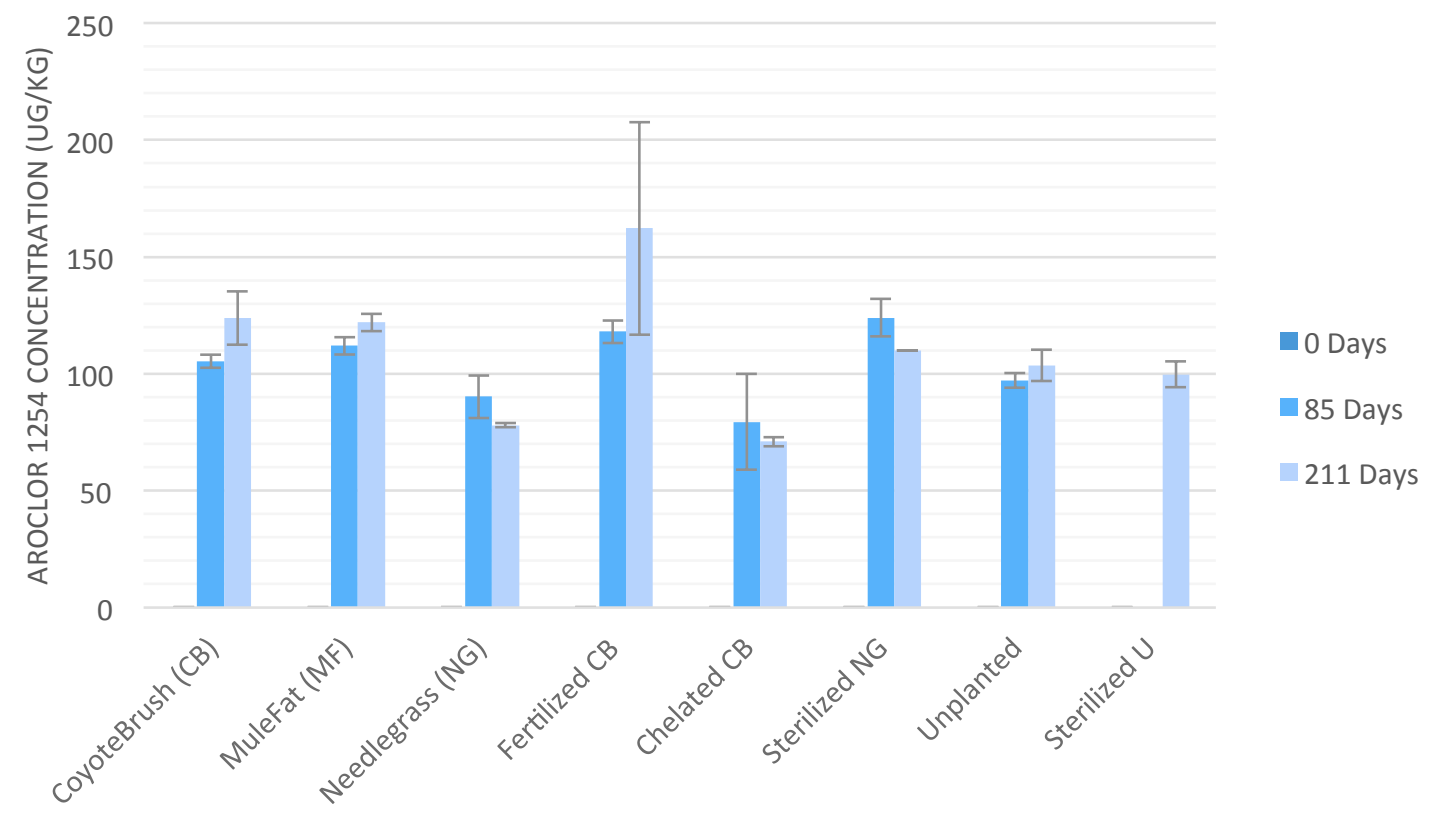

Figure A14: Aroclor 1254 concentrations in microcosm soil after 0, 85, and 211 days

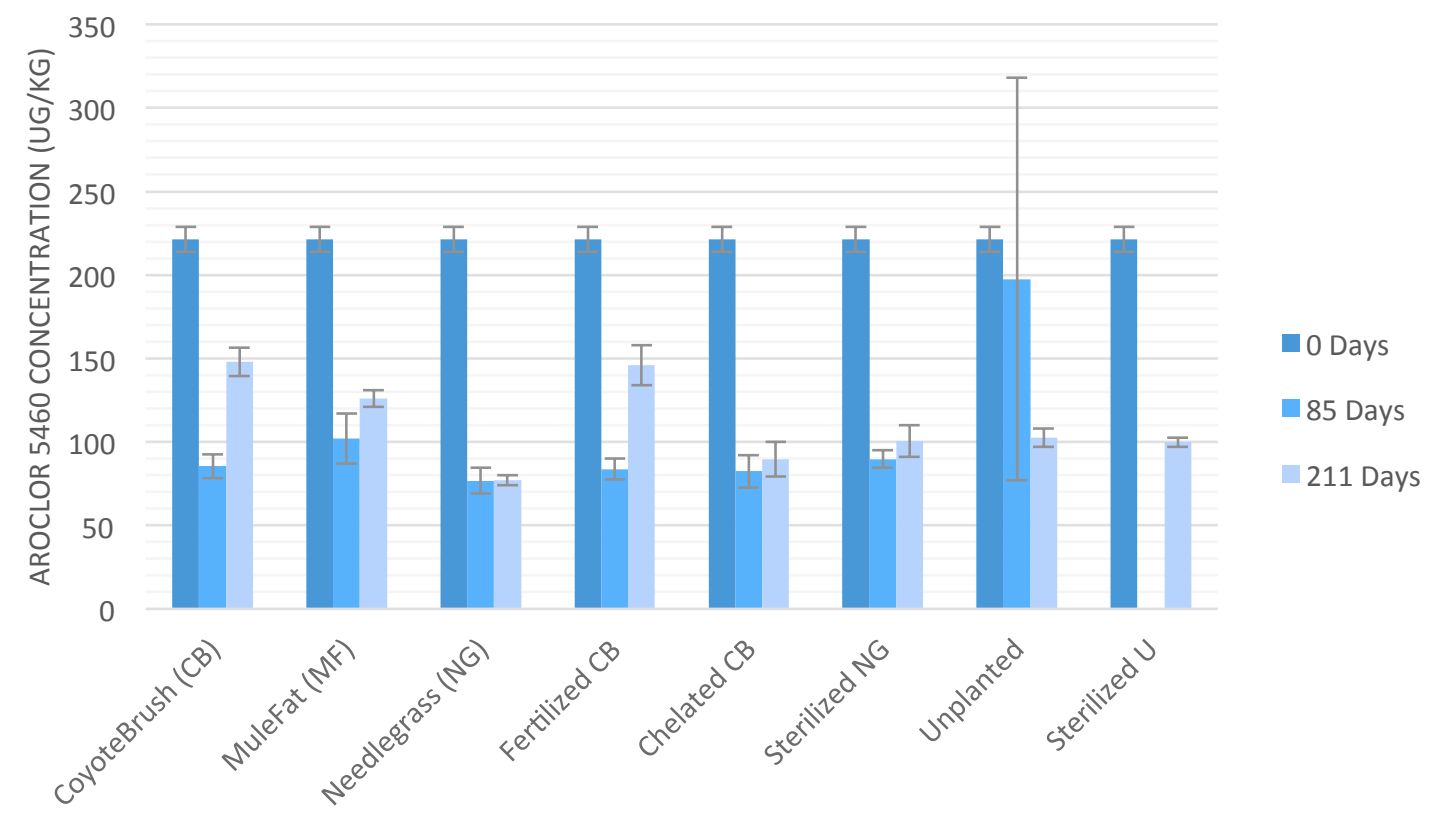

Figure A15: Aroclor 5460 concentrations in microcosm soil after 0, 85, and 211 days 


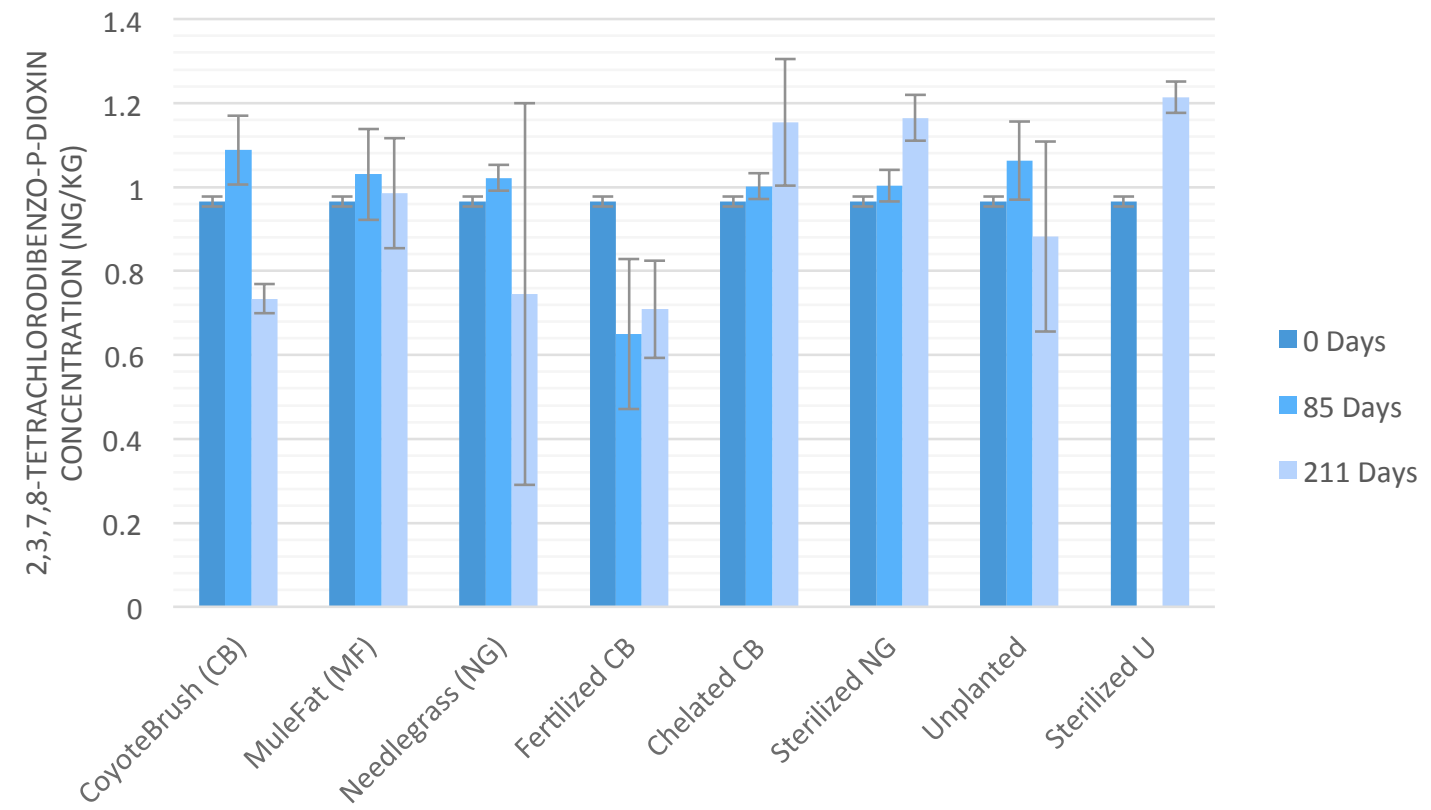

Figure A16: 2,3,7,8-Tetrachlorodibenzo-p-dioxin concentrations in microcosm soil after 0, 85, and 211 days

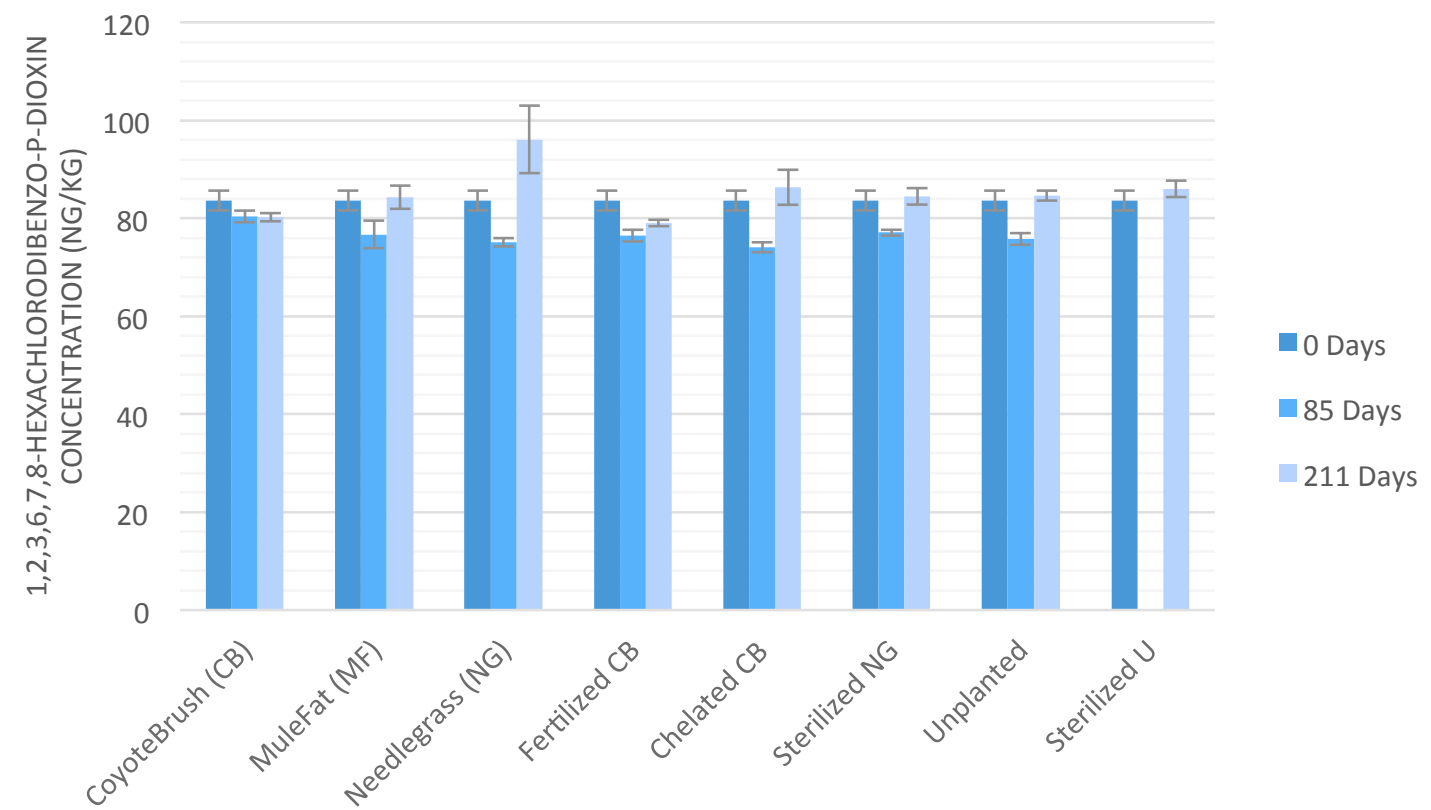

Figure A17: 1,2,3,6,7,8-Hexachlorodibenzo-p-dioxin concentrations in microcosm soil after 0,85 , and 211 days 


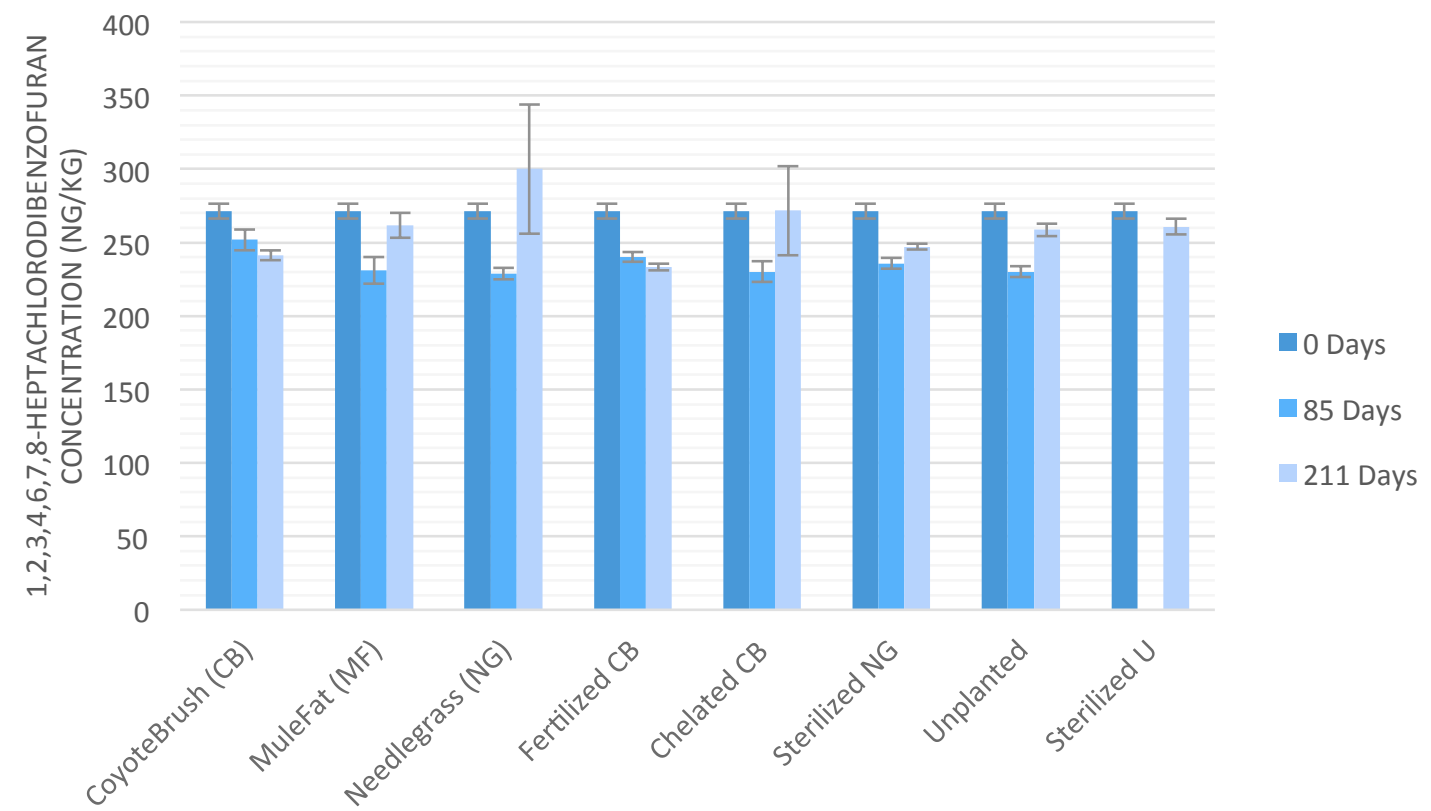

Figure A18: 1,2,3,4,6,7,8-Heptachlorodibenzofuran concentrations in microcosm soil after 0,85 , and 211 days

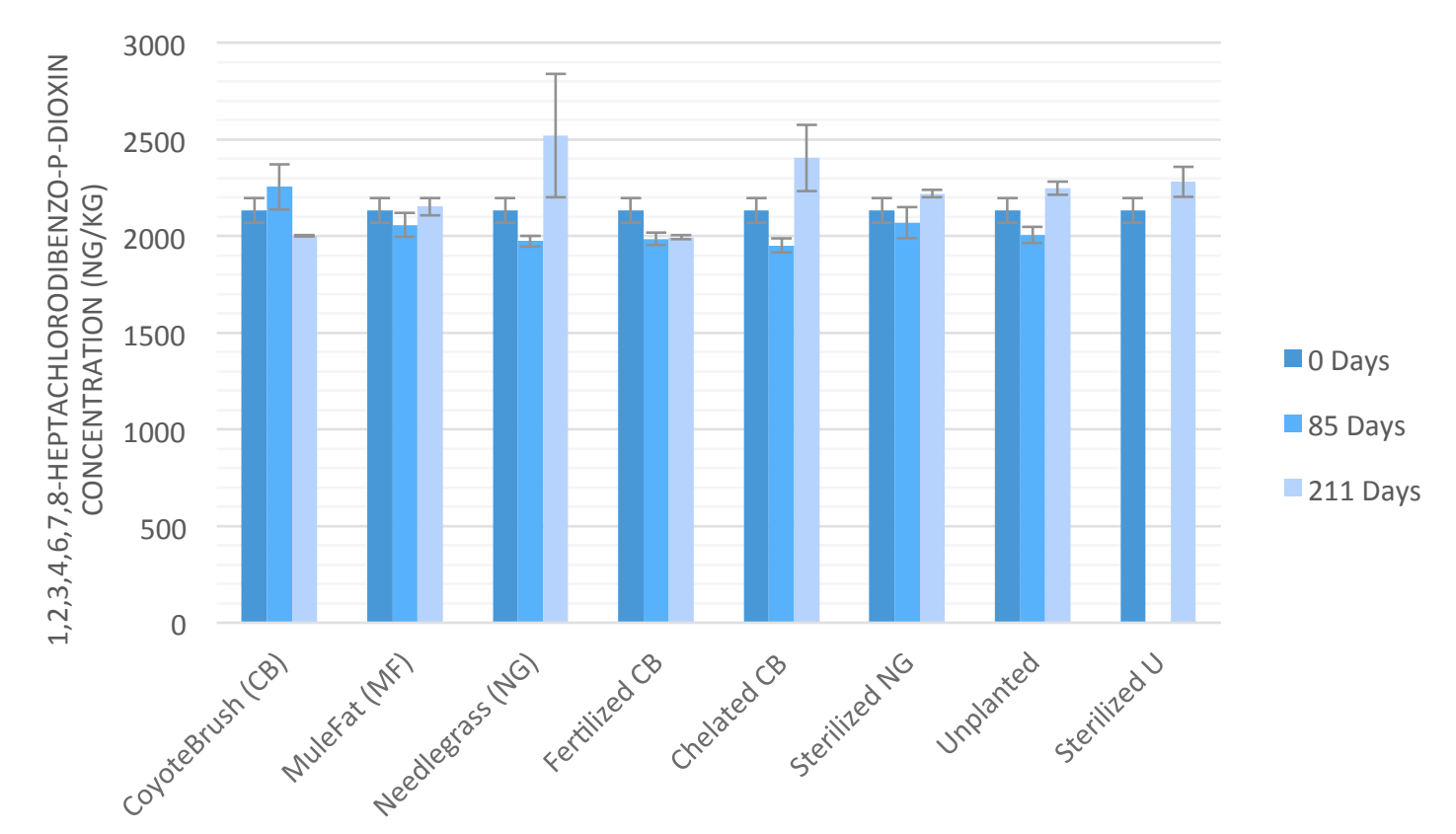

Figure A19: 1,2,3,4,6,7,8-Heptachlorodibenzo-p-dioxin concentrations in microcosm soil after 0,85 , and 211 days 


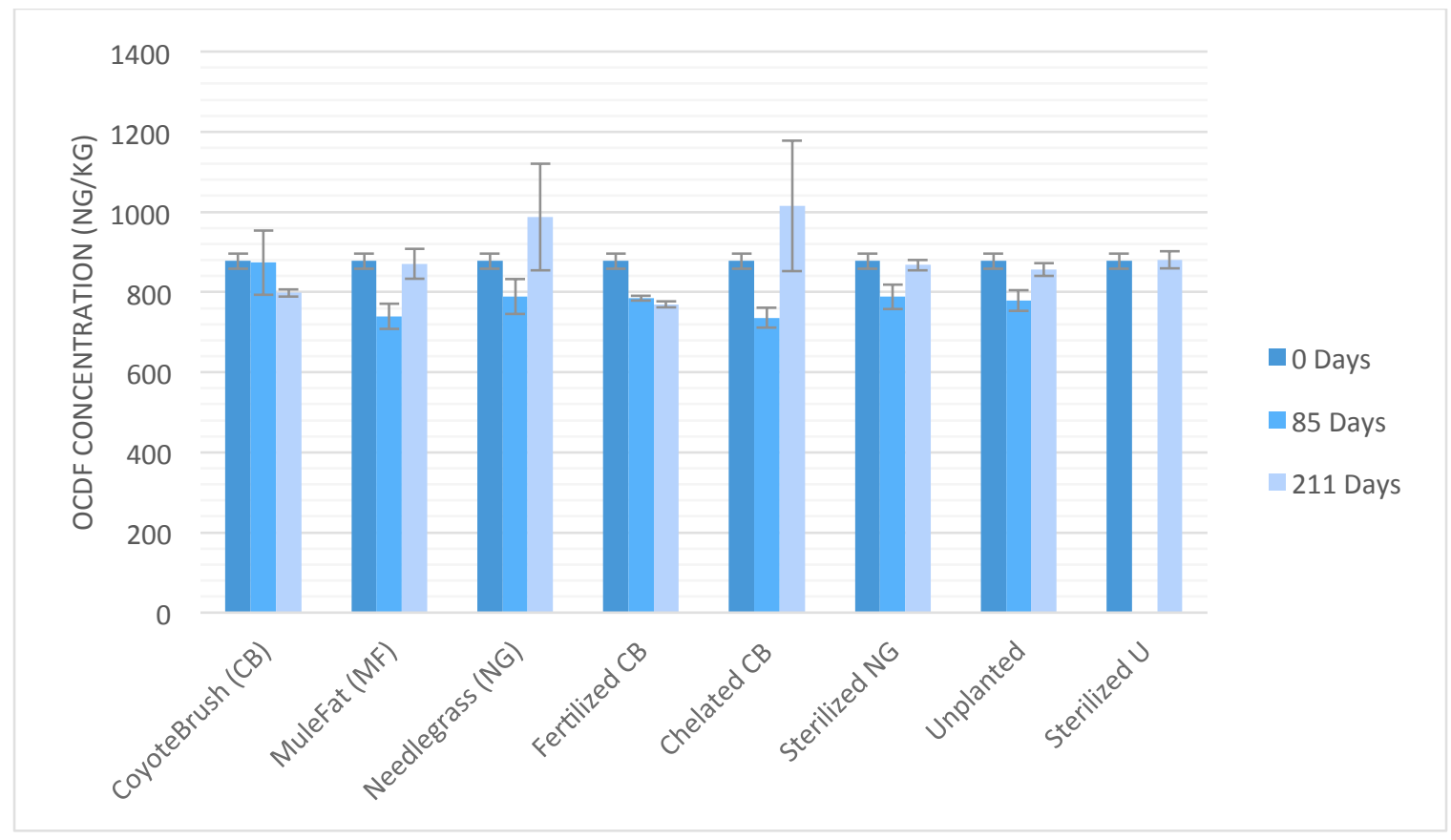

Figure A20: OCDF concentrations in microcosm soil after 0, 85, and 211 days

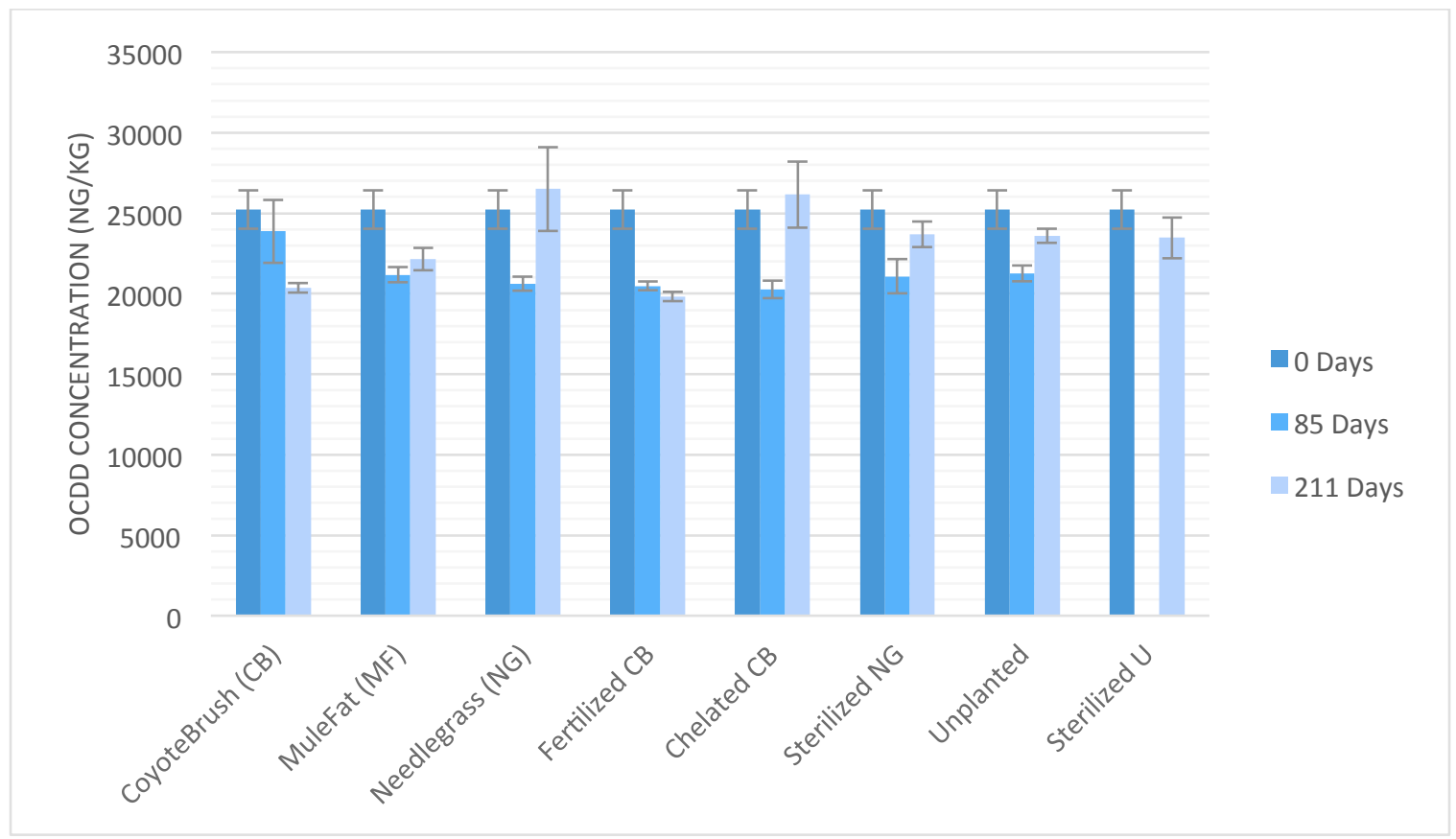

Figure A21: OCDD concentrations in microcosm soil after 0, 85, and 211 days 
B. Statistical Analysis on Microcosm Experiment Results

\section{One-way ANOVA: Total EFH versus Treatment}

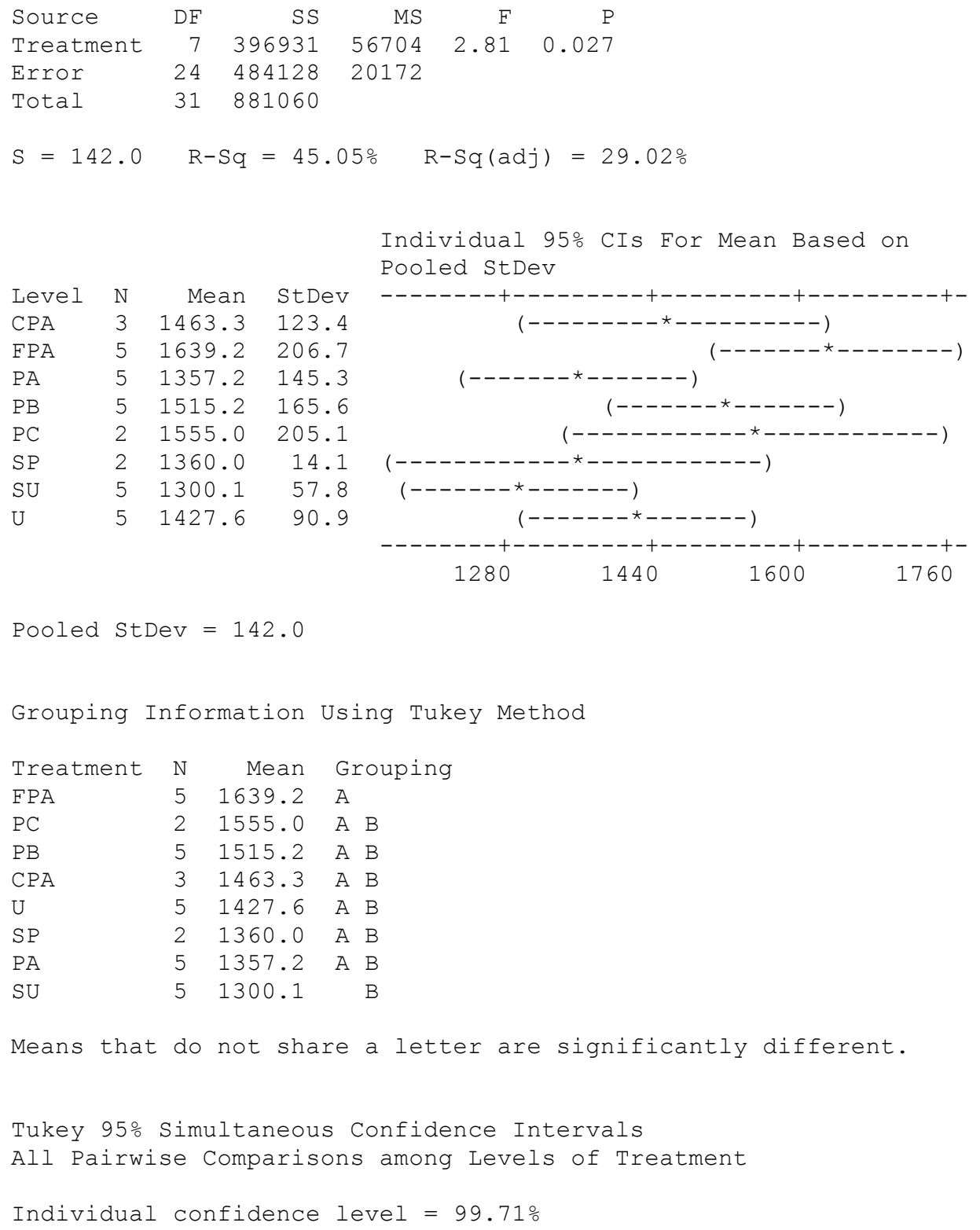




\section{One-way ANOVA: Sum of PAHs versus Treatment}

$\begin{array}{lrrrrr}\text { Source } & \text { DF } & \text { SS } & \text { MS } & F & P \\ \text { Treatment } & 7 & 784715889 & 112102270 & 2.02 & 0.094 \\ \text { Error } & 24 & 1331621322 & 55484222 & & \\ \text { Total } & 31 & 2116337212 & & & \\ \text { S }=7449 & \text { R-Sq }=37.08 \% & \text { R-Sq }(\text { adj })=18.73 \%\end{array}$

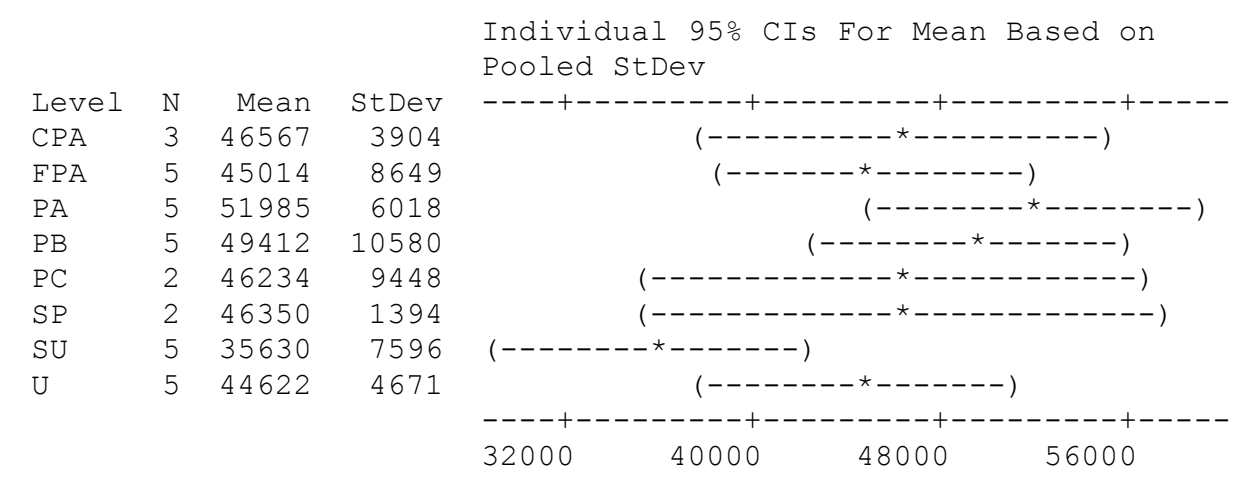

Pooled StDev $=7449$

\section{Results for: Soil Day 85 no SU.MTW}

\section{One-way ANOVA: Sum of PAHs versus Treatment}

$\begin{array}{lrrrrr}\text { Source } & \text { DF } & \text { SS } & \text { MS } & \text { F } & P \\ \text { Treatment } & 6 & 117344978 & 19557496 & 0.41 & 0.868 \\ \text { Error } & 28 & 1347692627 & 48131880 & & \\ \text { Total } & 34 & 1465037605 & & & \\ \text { S }=6938 & \text { R-Sq }=8.01 \% & R-S q(\text { adj })=0.00 \%\end{array}$

\begin{tabular}{|c|c|c|c|c|}
\hline & & & & $\begin{array}{l}\text { Individual 95\% CIs For Mean Based on } \\
\text { Pooled StDev }\end{array}$ \\
\hline Level & $\mathrm{N}$ & Mean & StDev & ---------+---------+--------- \\
\hline $\mathrm{CPA}$ & 5 & 38232 & 14360 & $(------------\star-------------)$ \\
\hline FPA & 5 & 42952 & 4013 & $(------------\star---1$ \\
\hline $\mathrm{PA}$ & 5 & 36956 & 8057 & $(------------\star------------)$ \\
\hline $\mathrm{PB}$ & 5 & 37609 & 3564 & $(------------\star-------------)$ \\
\hline PC & 5 & 38132 & 1945 & $(-----------\star *------------)$ \\
\hline SP & 5 & 38185 & 1691 & $(-----------\star------------)$ \\
\hline $\mathrm{U}$ & 5 & 38037 & 5509 & $(------------\star------------)$ \\
\hline & & & & 40000 \\
\hline
\end{tabular}

Pooled StDev $=6938$ 


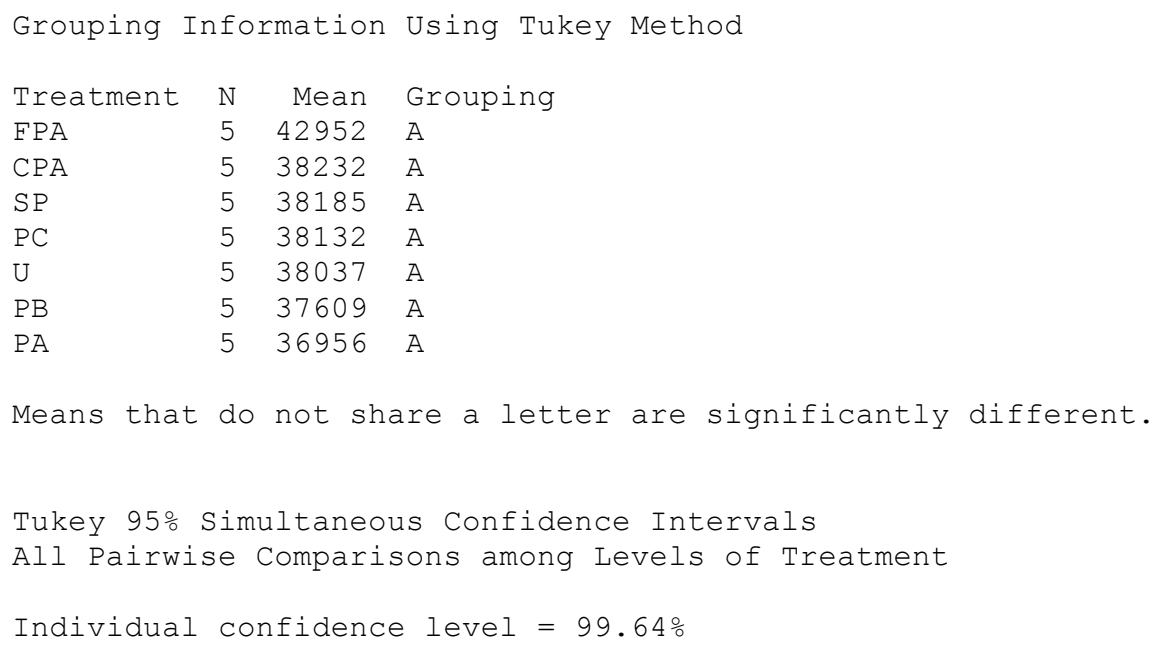

Two-Sample T-Test and Cl: Total PAH Conc. (roots), Treatment

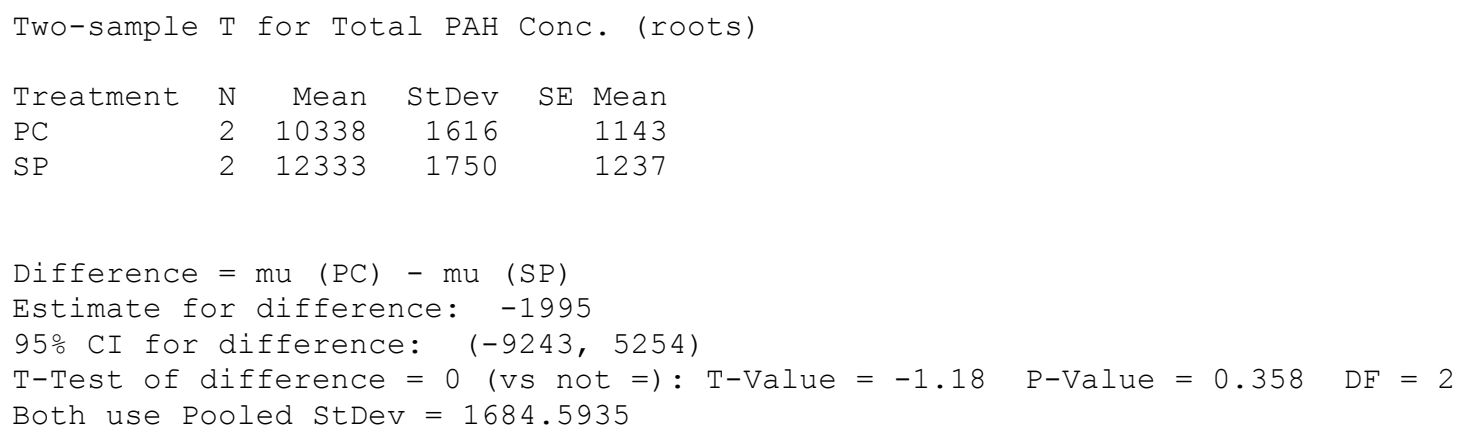

One-way ANOVA: Aroclor 1260 versus Treatment
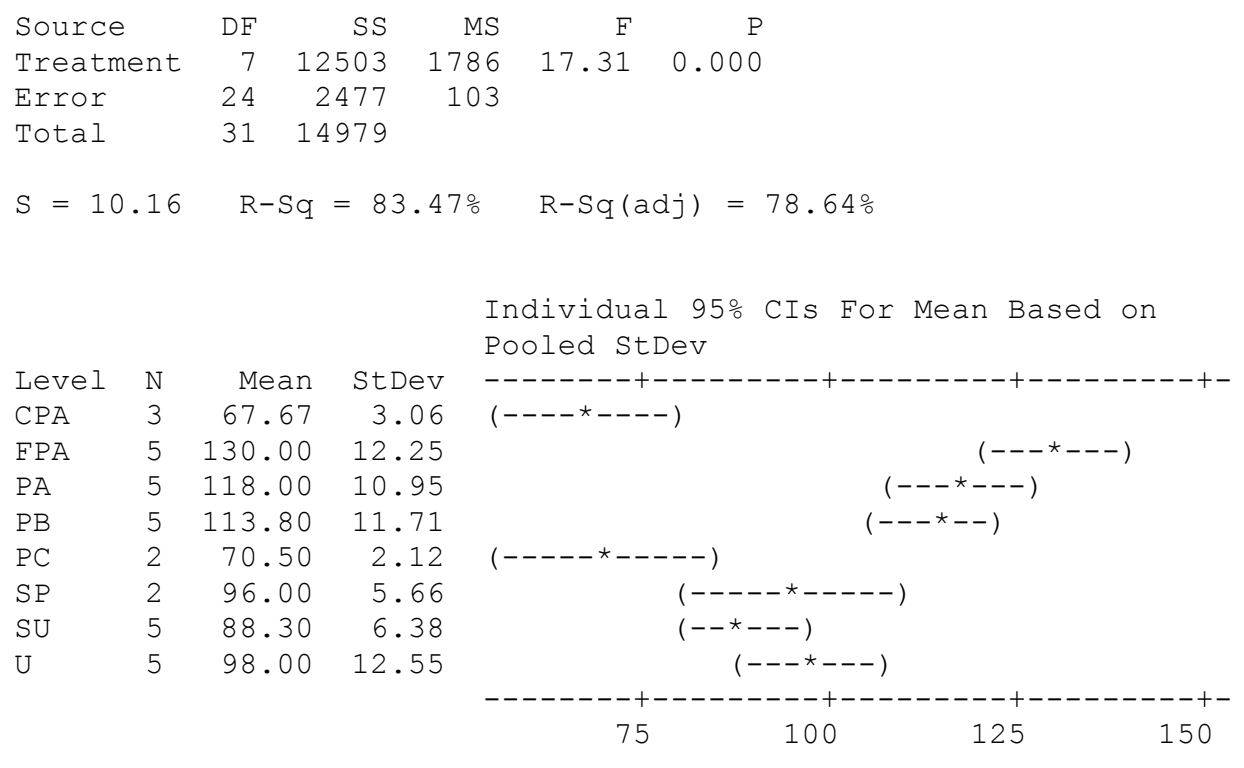


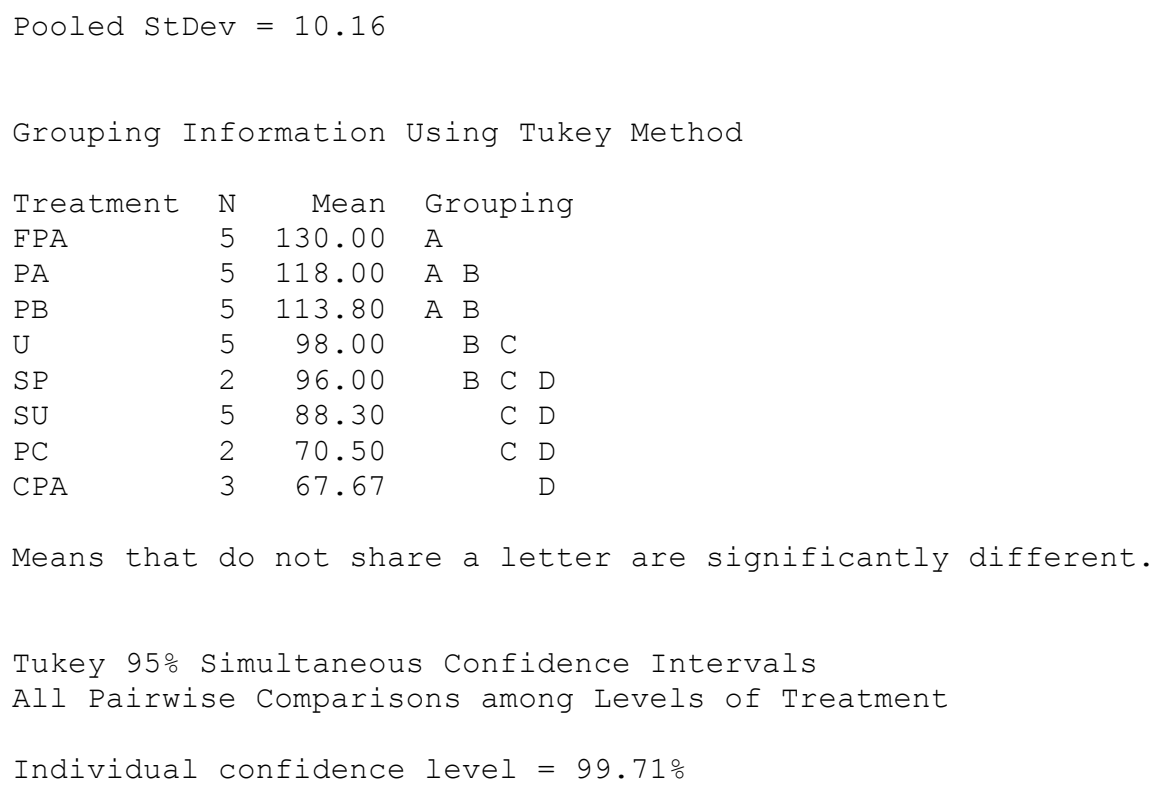

Results for: Initial vs Final U.MTW

Two-Sample T-Test and Cl: Aroclor 1260, Time (days)

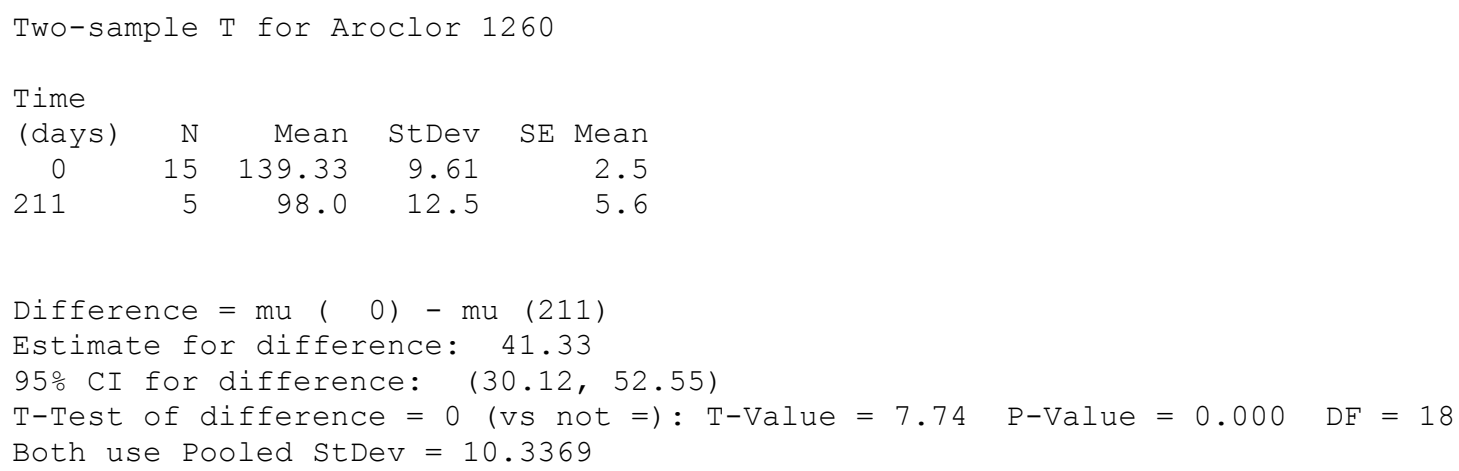

\section{Results for: Initial vs Final SU.MTW}

Two-Sample T-Test and $\mathrm{Cl}$ : Aroclor 1260, Time (days)

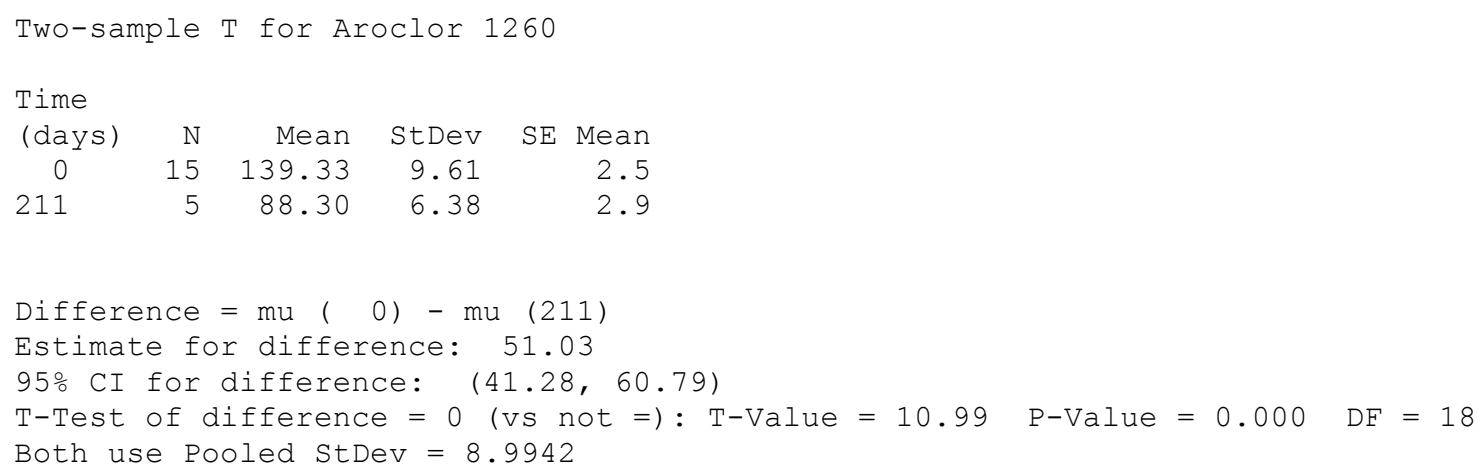




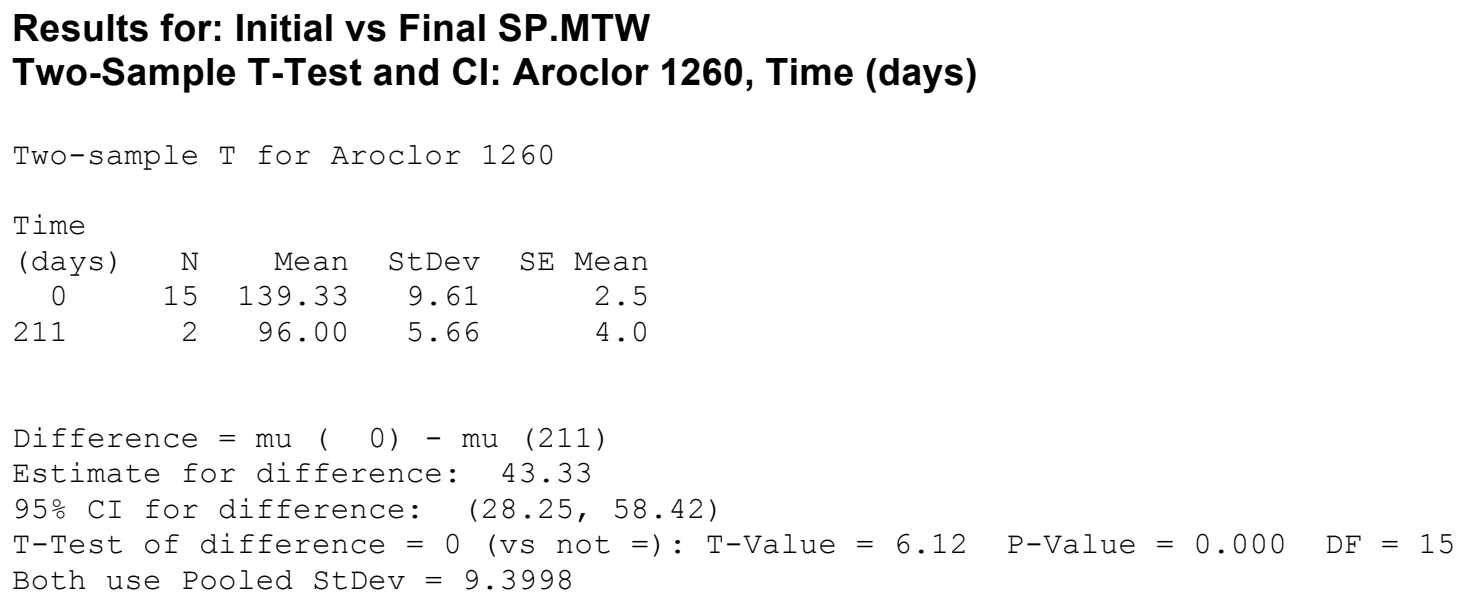

Results for: Initial vs Final PC.MTW

Two-Sample T-Test and Cl: Aroclor 1260, Time (days)

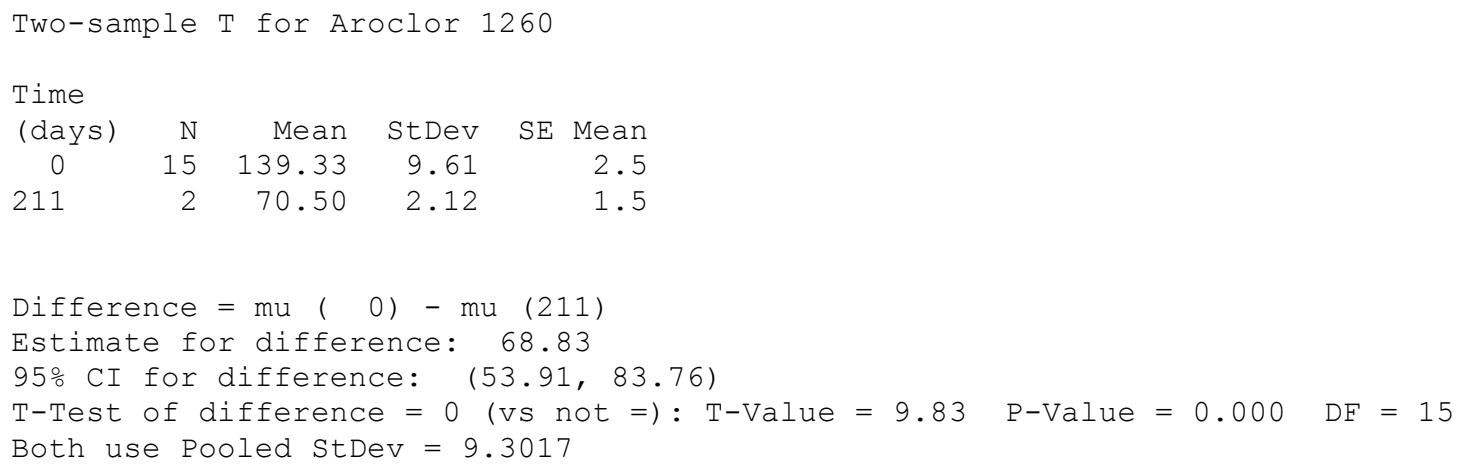

Results for: Initial vs Final CPA.MTW

Two-Sample T-Test and $\mathrm{Cl}$ : Aroclor 1260, Time (days)

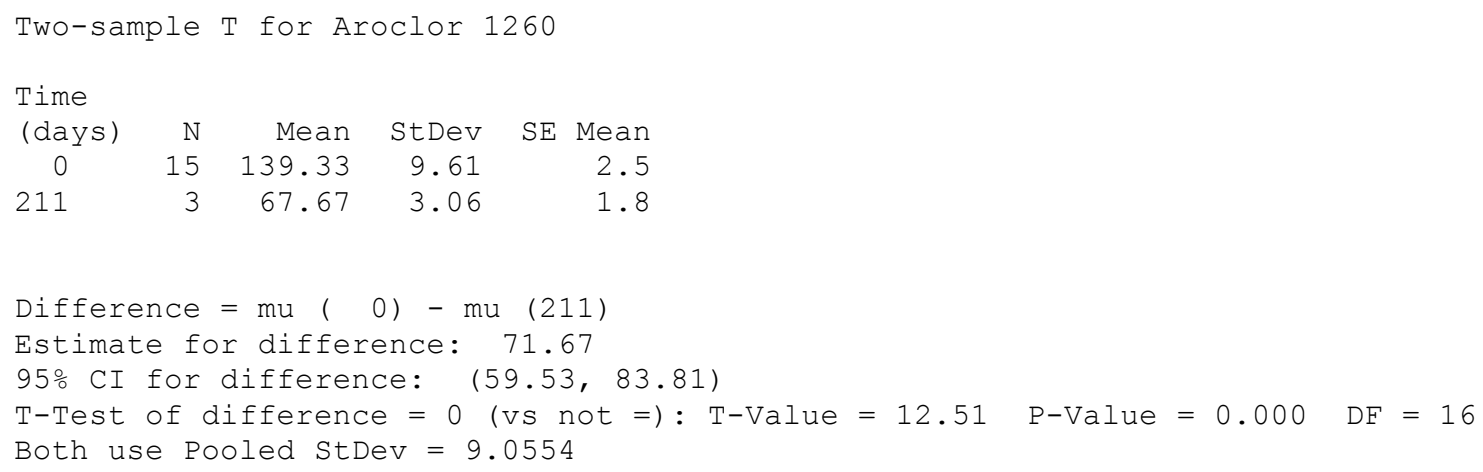




\section{One-way ANOVA: Total Dioxins/Furans versus Treatment}

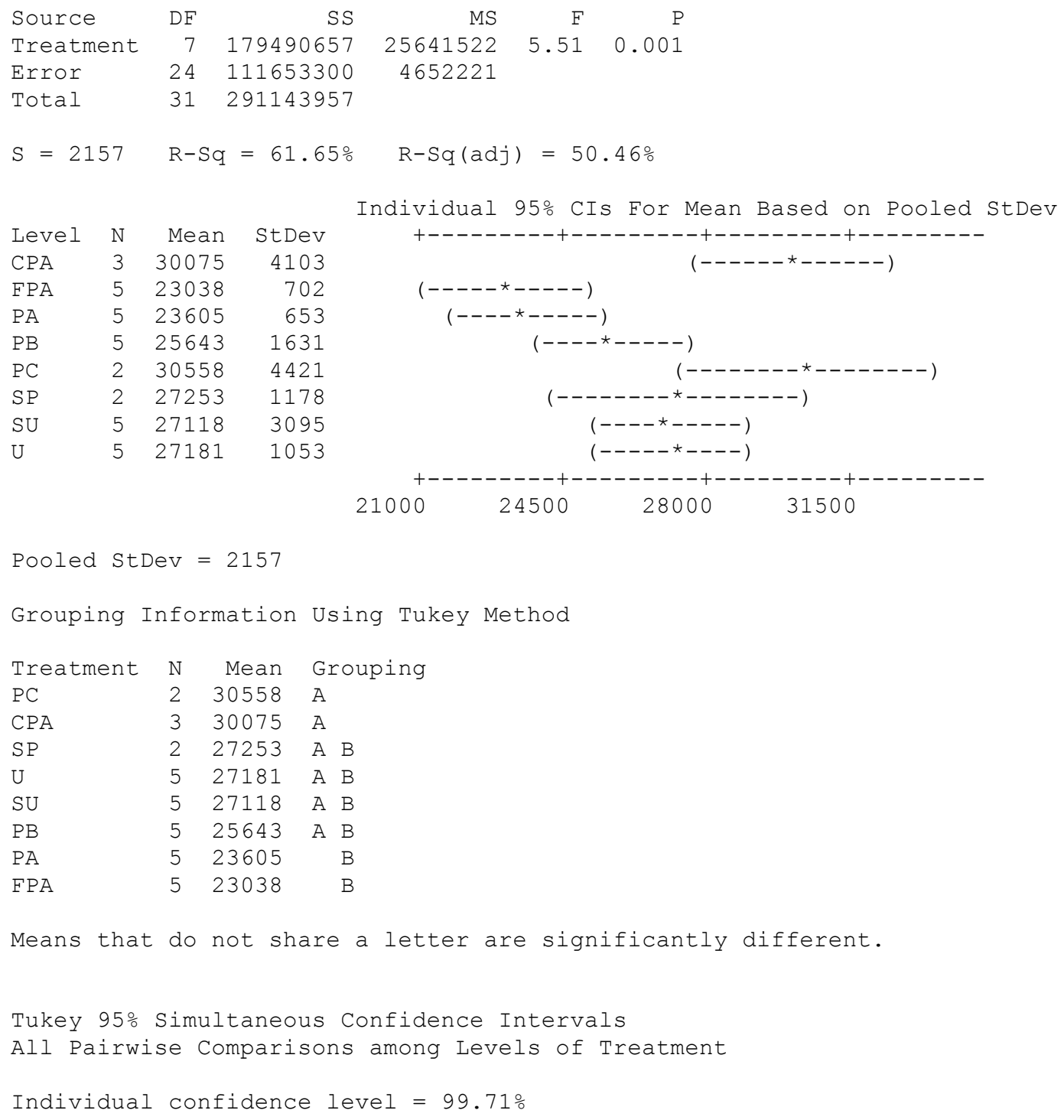

\section{Two-Sample T-Test and Cl: Total Dioxins/Furans, Treatment}

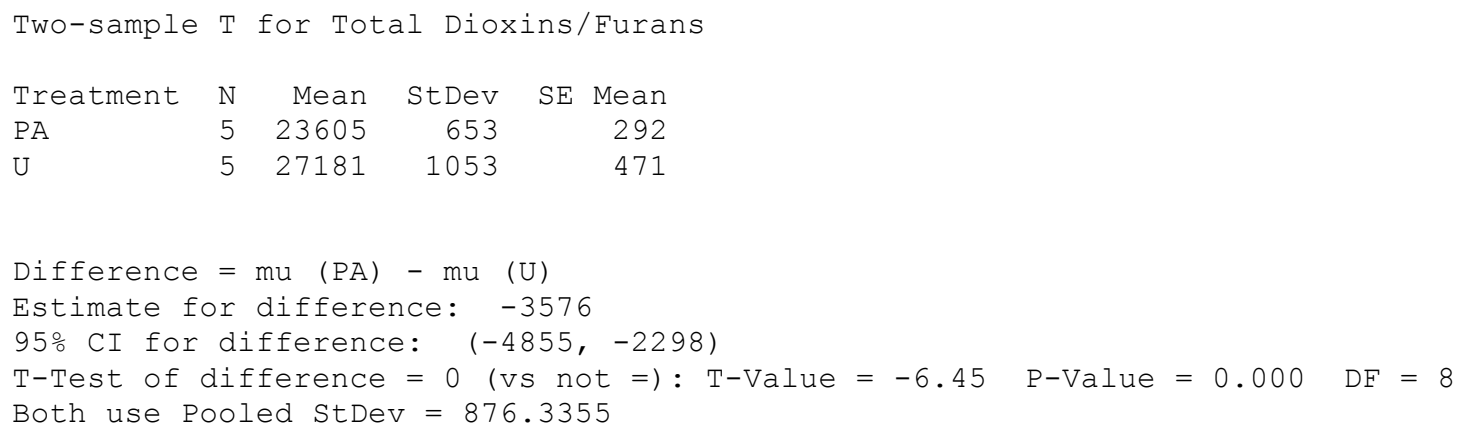




\section{Two-Sample T-Test and Cl: Total Dioxins/Furans, Treatment}

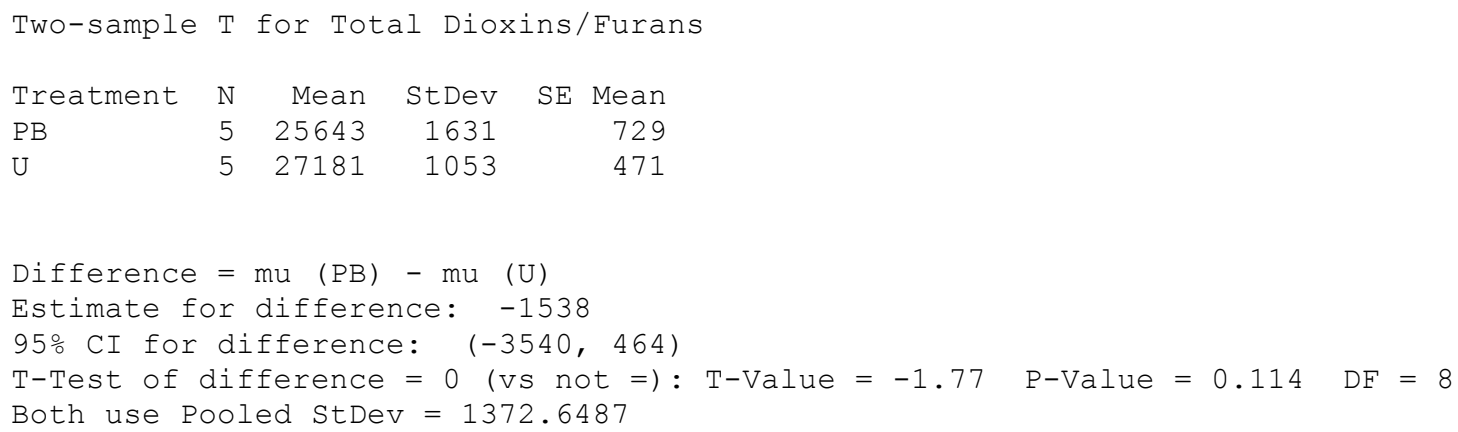

Two-Sample T-Test and Cl: Total Dioxin/Furan Conc. (roots, Treatment

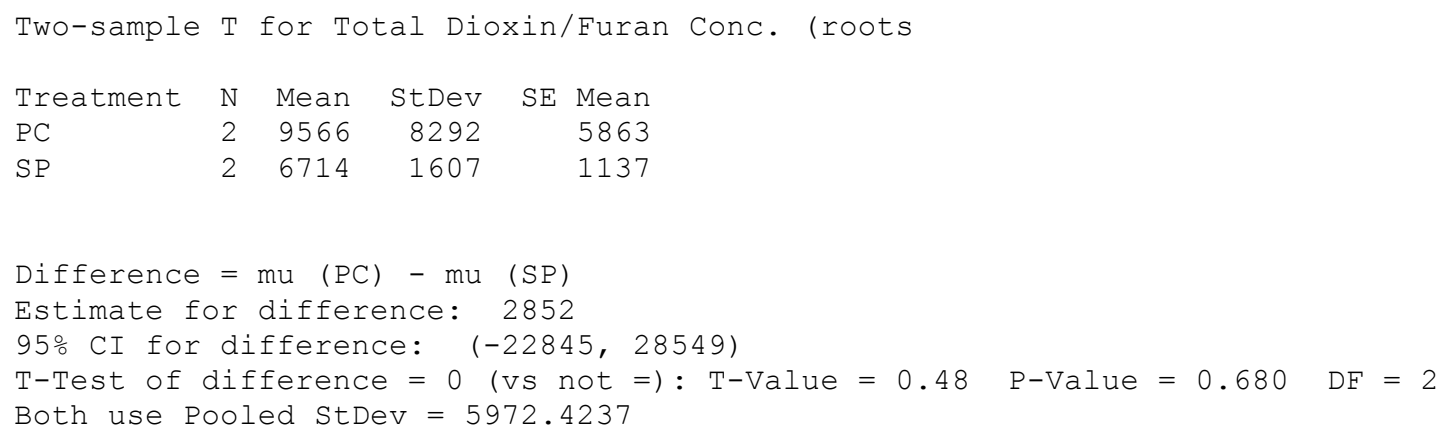

\section{Results for: Initial vs Final PA.MTW}

One-way ANOVA: Total Dioxins/Furans versus Time (days)
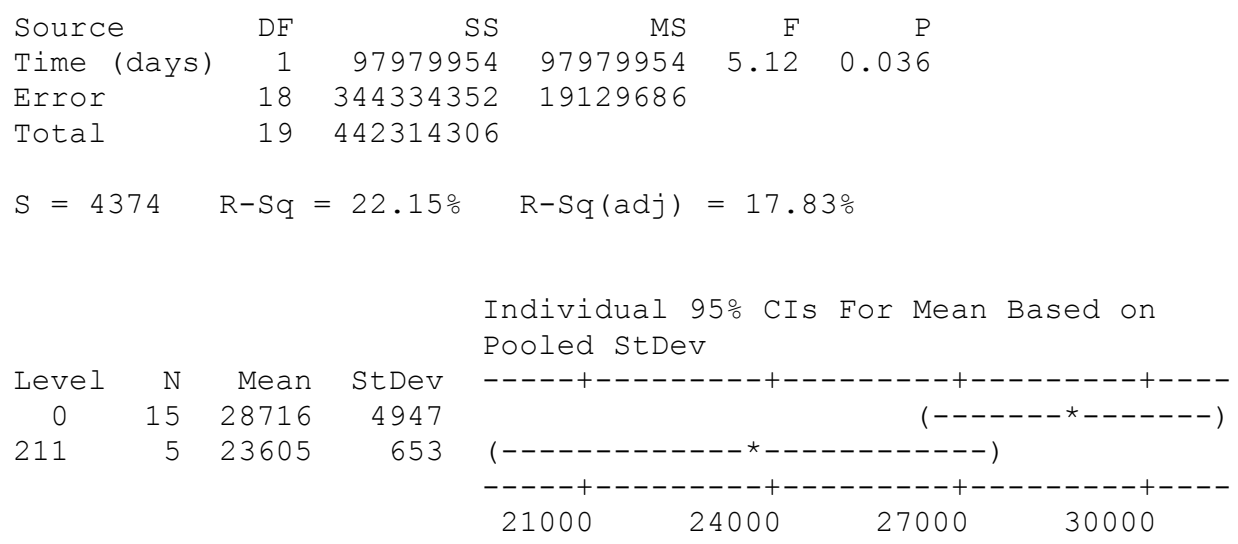

Pooled StDev $=4374$

*Normality not met because of high dioxin concentration for one bulk soil replicate. However subsequent test omitting this replicate meets normality and is significant. 


\section{Results for: Initial vs Final FPA.MTW \\ Two-Sample T-Test and Cl: Total Dioxins/Furans, Time (days)}

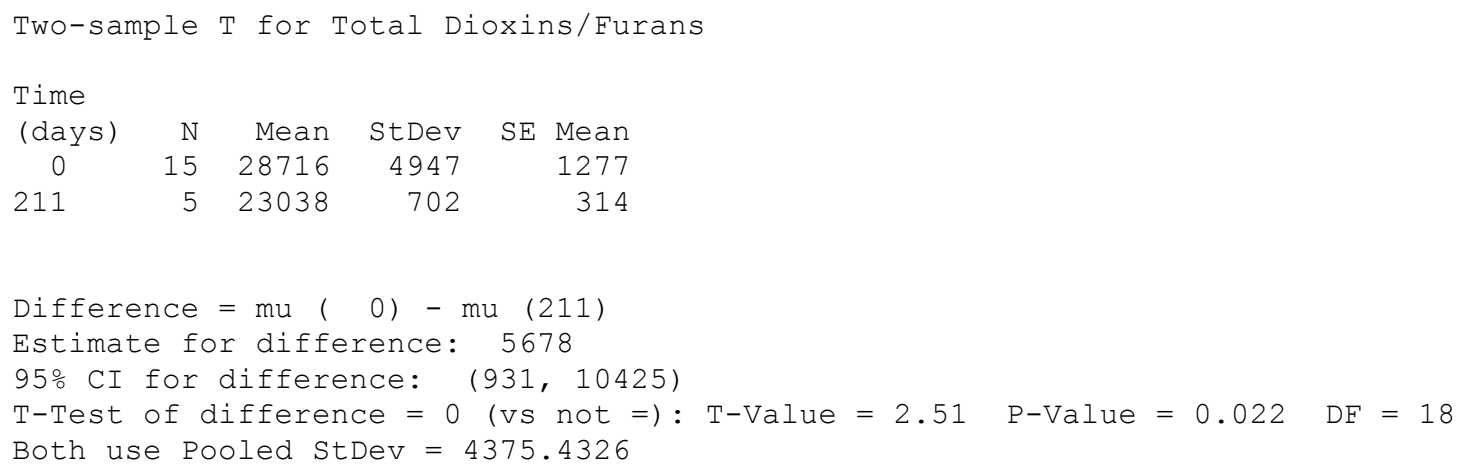

\section{Two-Sample T-Test and Cl: Mercury, Time (days) (Sterilized Unplanted)}

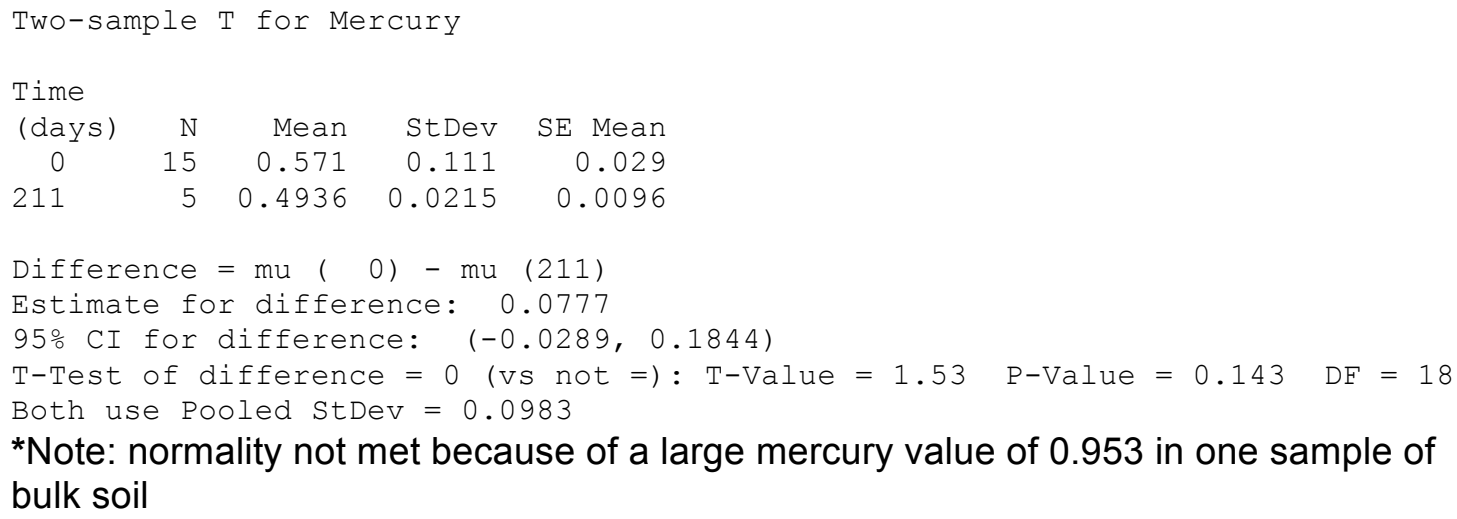

*Note: normality not met because of a large mercury value of 0.953 in one sample of bulk soil

\section{One-way ANOVA: Mercury versus Treatment}
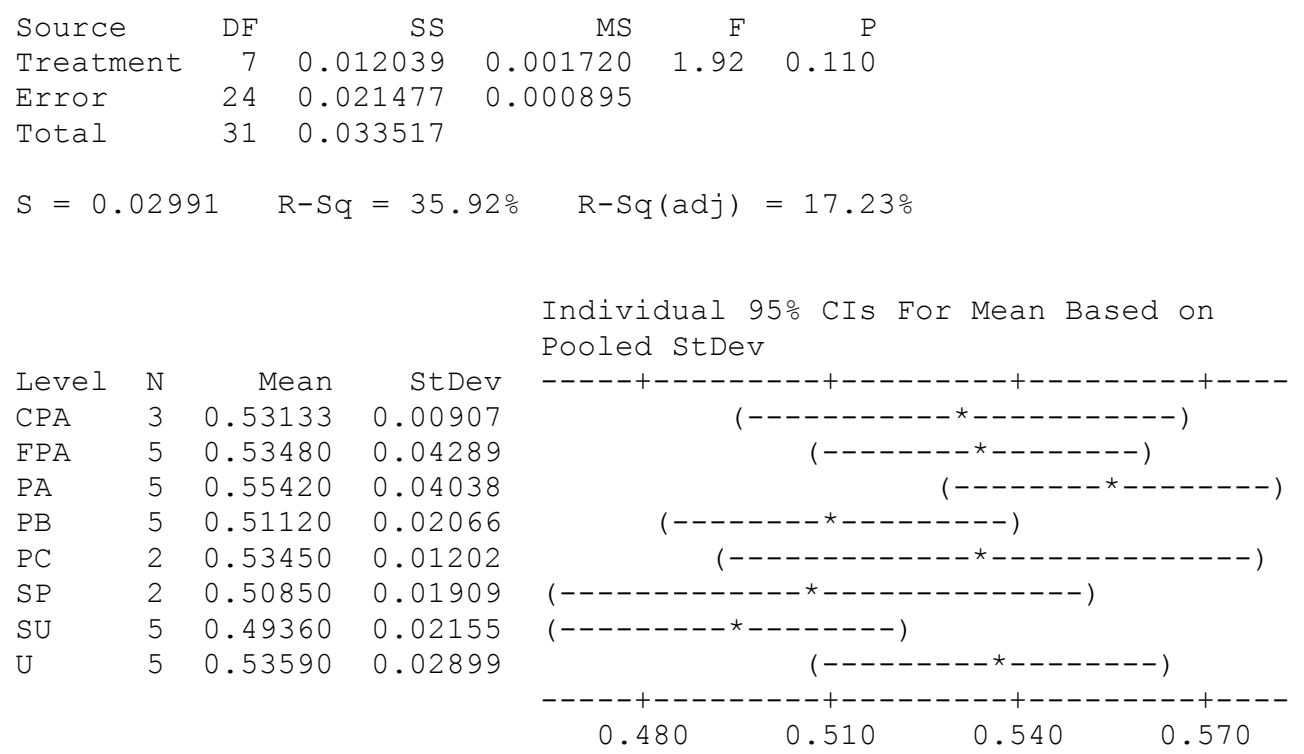


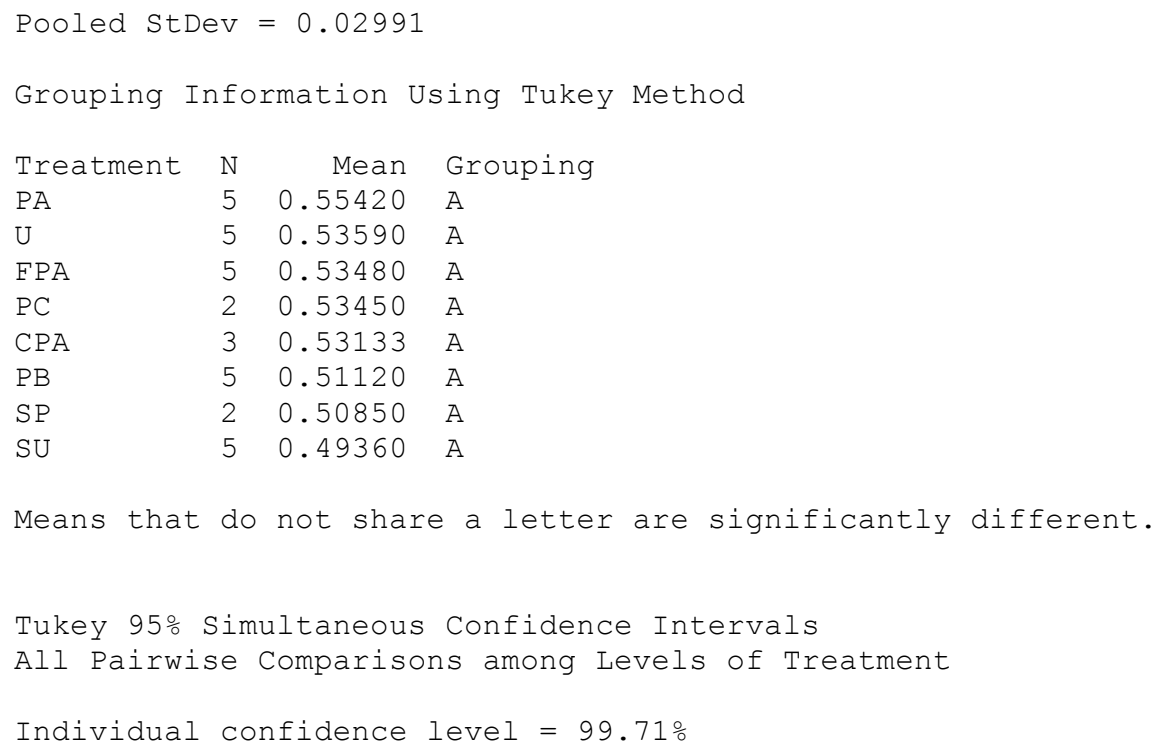

One-way ANOVA: Silver Conc. (roots) versus Treatment

$\begin{array}{lrrrrr}\text { Source } & \text { DF } & \text { SS } & \text { MS } & \text { F } & \text { P } \\ \text { Treatment } & 5 & 19.664 & 3.933 & 12.78 & 0.000 \\ \text { Error } & 16 & 4.924 & 0.308 & & \\ \text { Total } & 21 & 24.588 & & & \\ \text { S }=0.5548 & \text { R-Sq }=79.97 \% & \text { R-Sq }(\text { adj })=73.72 \%\end{array}$

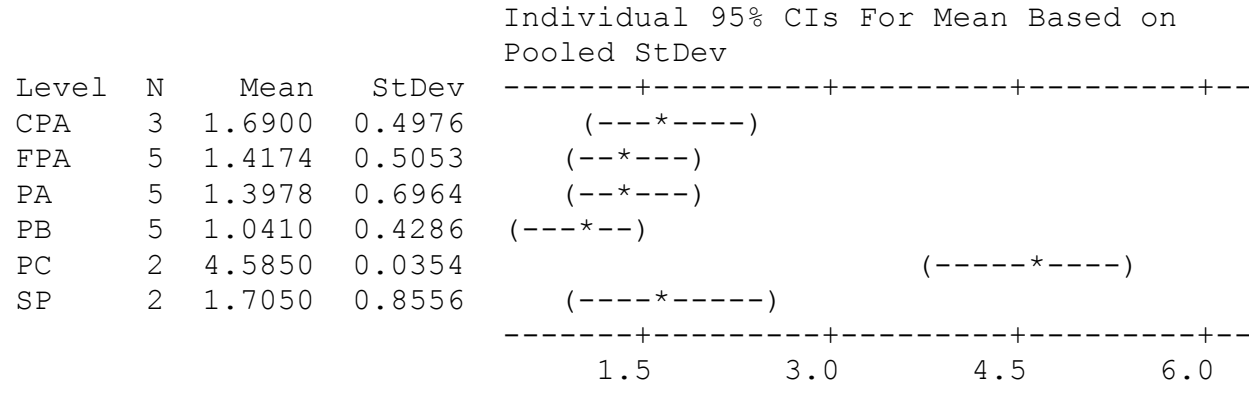

Pooled StDev $=0.5548$

Grouping Information Using Tukey Method

Treatment $N$ Mean Grouping

PC 24.5850 A

$\begin{array}{llll}\mathrm{SP} & 2 & 1.7050 & \mathrm{~B}\end{array}$

$\begin{array}{llll}\mathrm{CPA} & 3 & 1.6900 \quad \mathrm{~B}\end{array}$

$\begin{array}{llll}\mathrm{FPA} & 5 & 1.4174 \quad \mathrm{~B}\end{array}$

$\begin{array}{llll}\mathrm{PA} & 5 & 1.3978 & \mathrm{~B}\end{array}$

$\mathrm{PB} \quad 5 \quad 1.0410 \quad \mathrm{~B}$

Means that do not share a letter are significantly different. 
Tukey 95\% Simultaneous Confidence Intervals

All Pairwise Comparisons among Levels of Treatment

Individual confidence level $=99.47 \%$

\section{Two-Sample T-Test and CI: Silver Conc. (roots), Treatment}

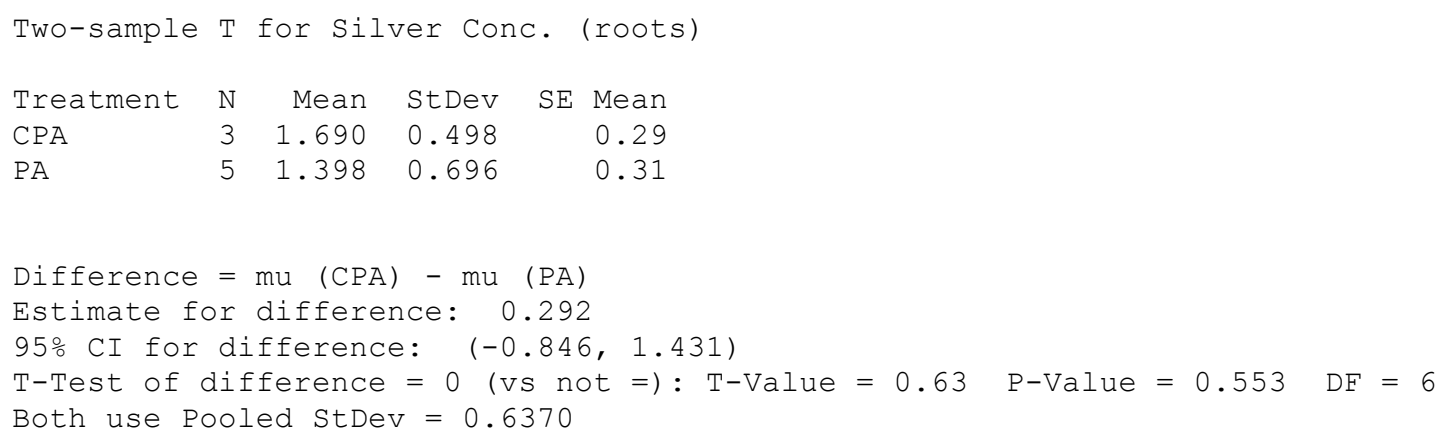

\section{One-way ANOVA: Cadmium versus Treatment}

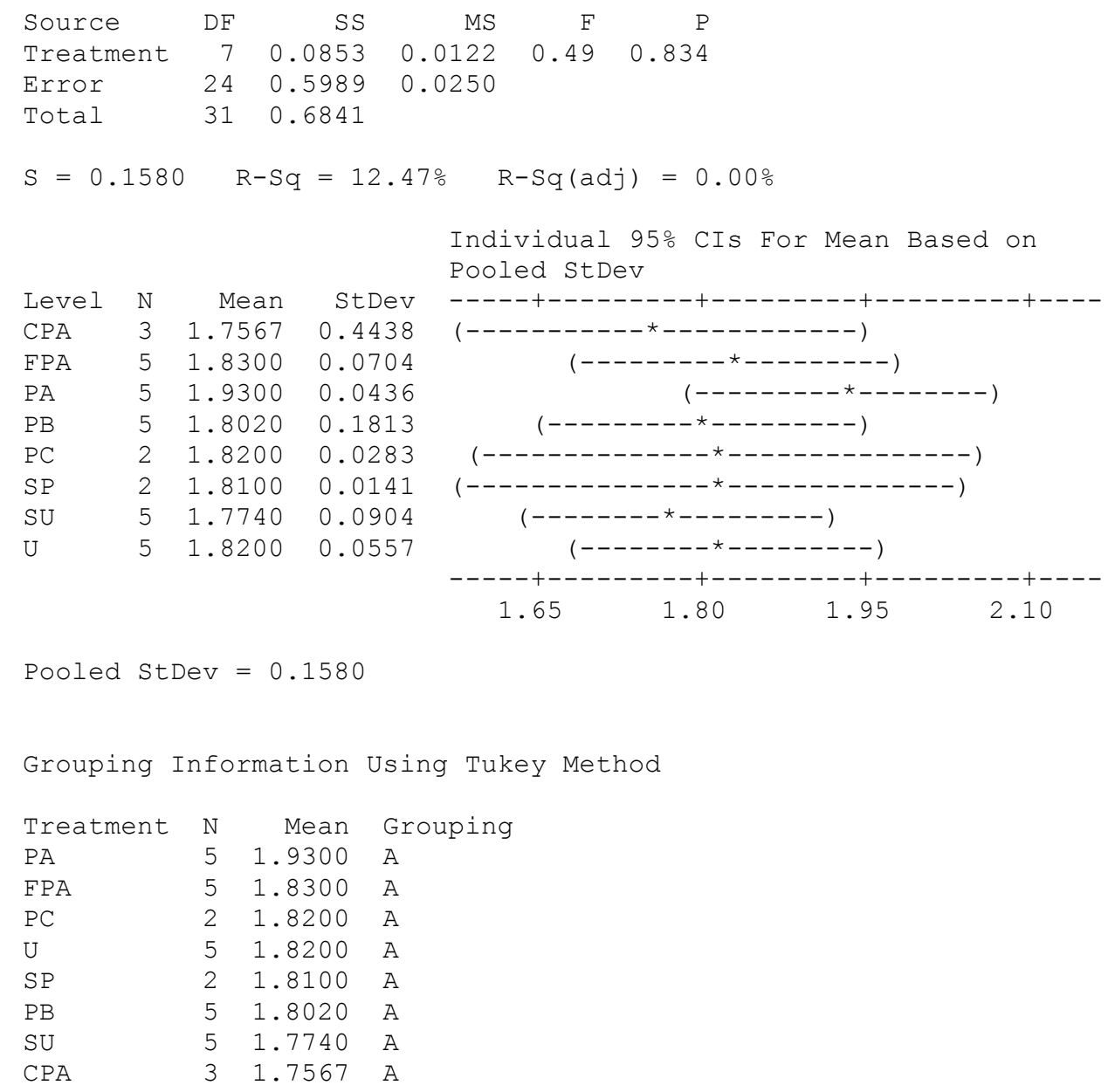


Means that do not share a letter are significantly different.

Tukey 95\% Simultaneous Confidence Intervals

All Pairwise Comparisons among Levels of Treatment

Individual confidence level $=99.71 \%$

Two-Sample T-Test and Cl: Cadmium Conc. (roots), Treatment

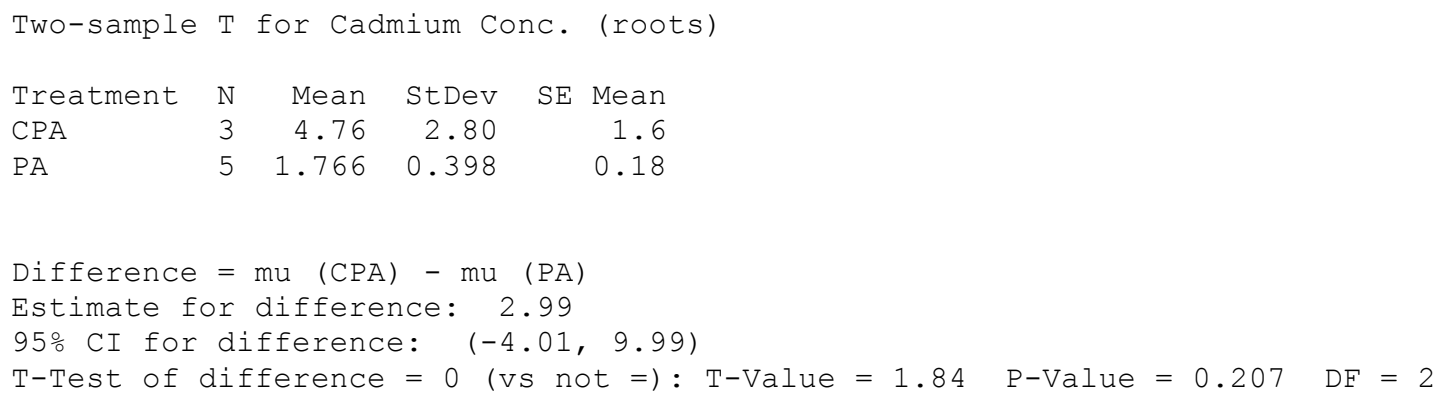

\section{Two-Sample T-Test and Cl: Cadmium Conc. (Foliage), Treatment}

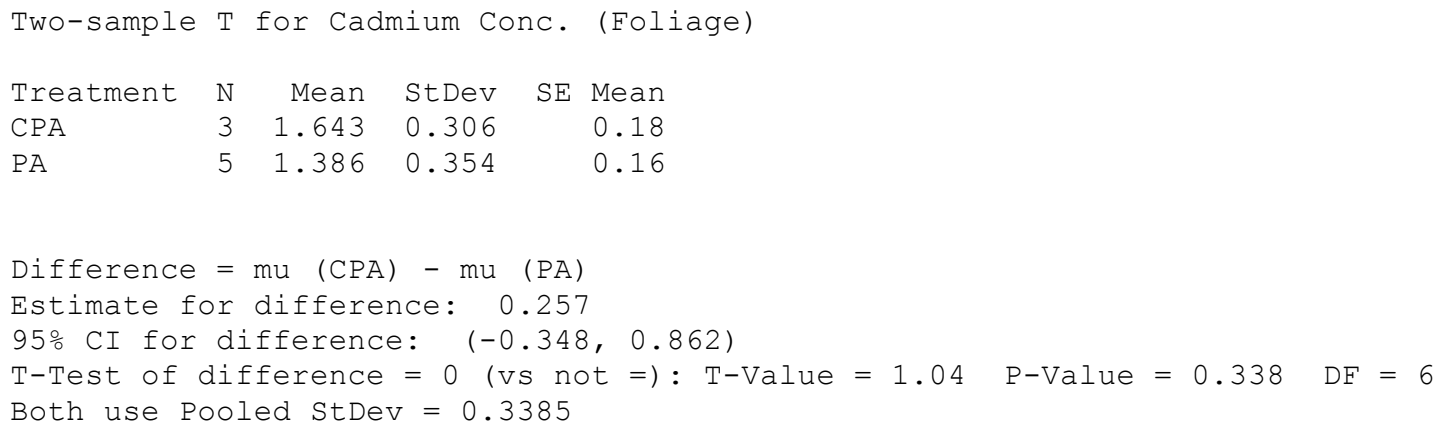

One-way ANOVA: Lead versus Treatment

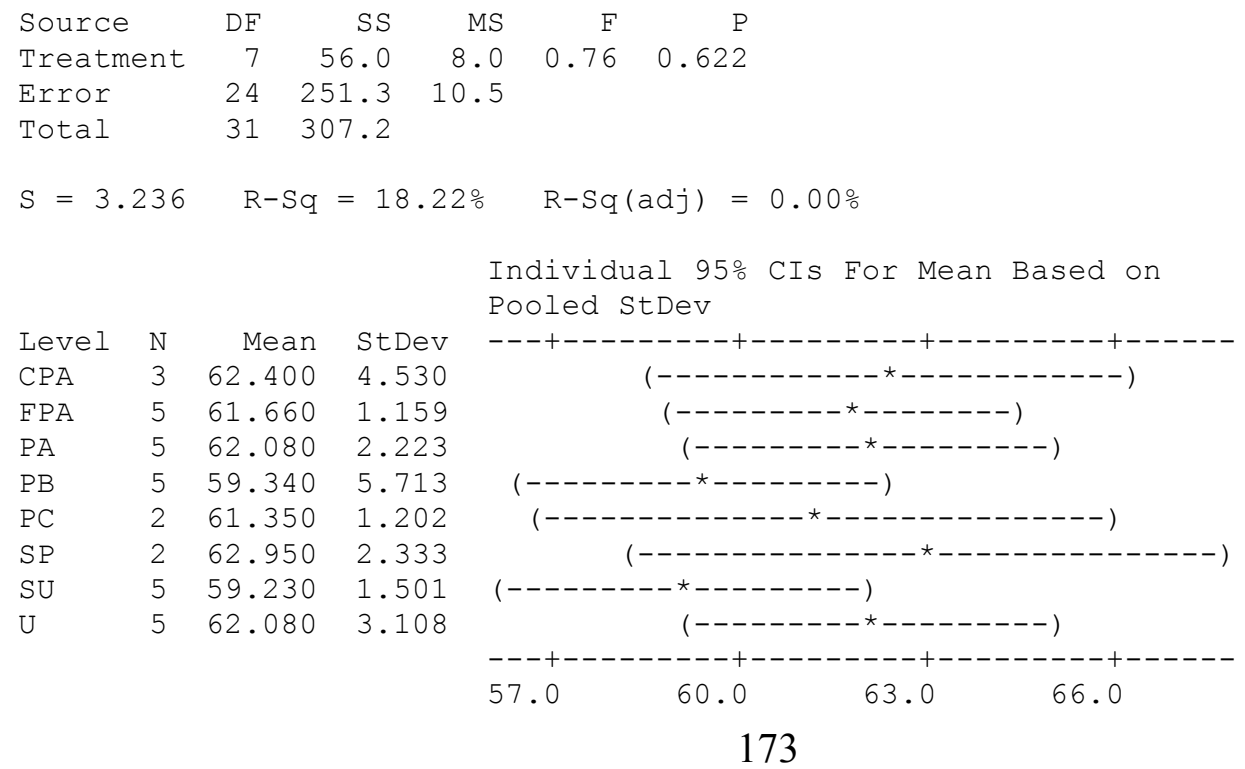




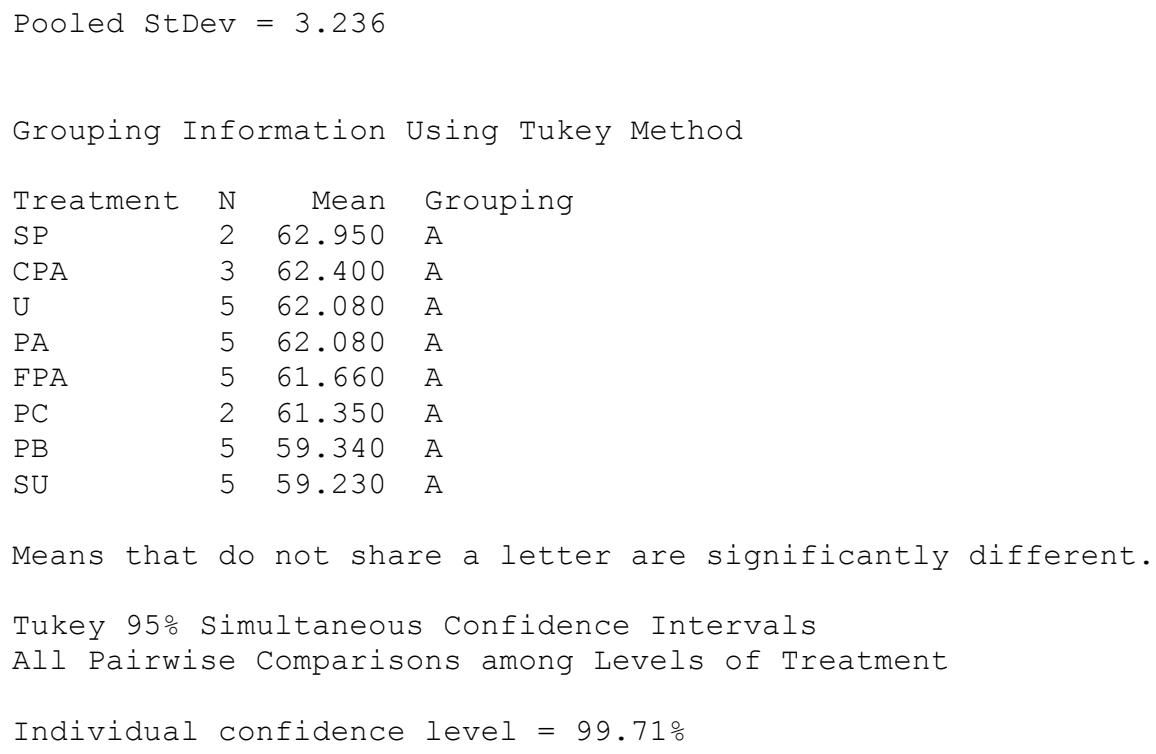

One-way ANOVA: Lead versus Time (days)

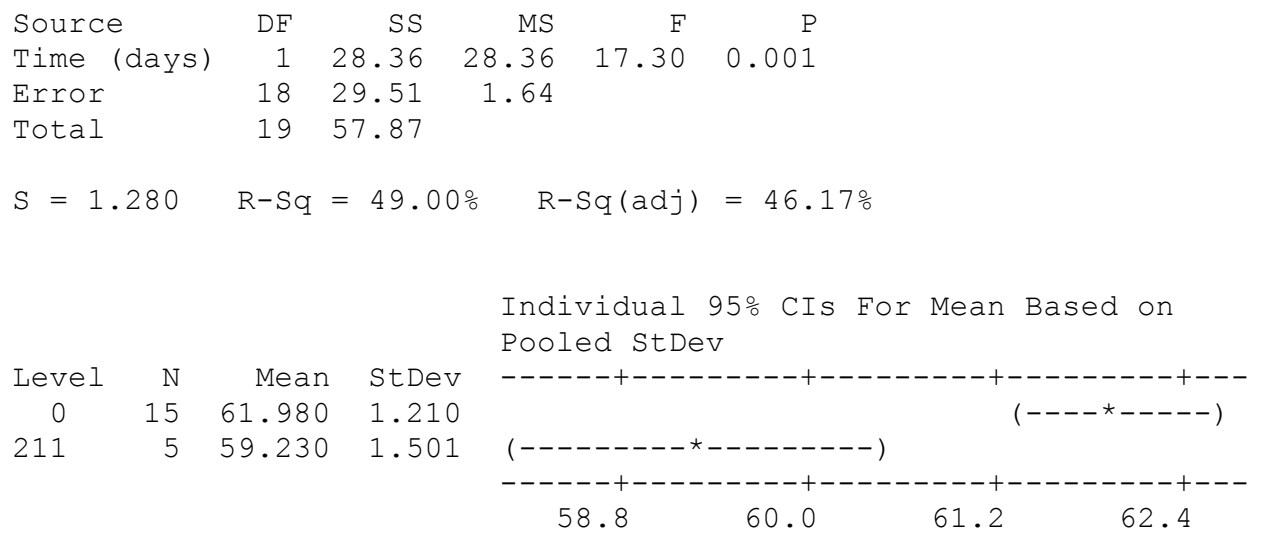

Two-Sample T-Test and Cl: Lead Conc. (roots), Treatment

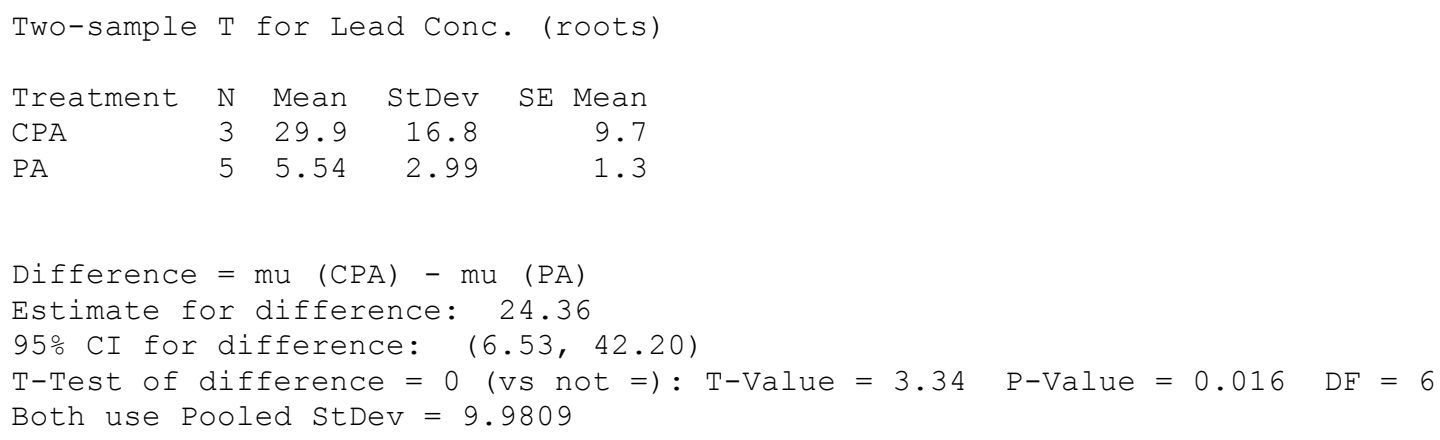


Two-Sample T-Test and CI: Lead Conc. (Foliage), Treatment

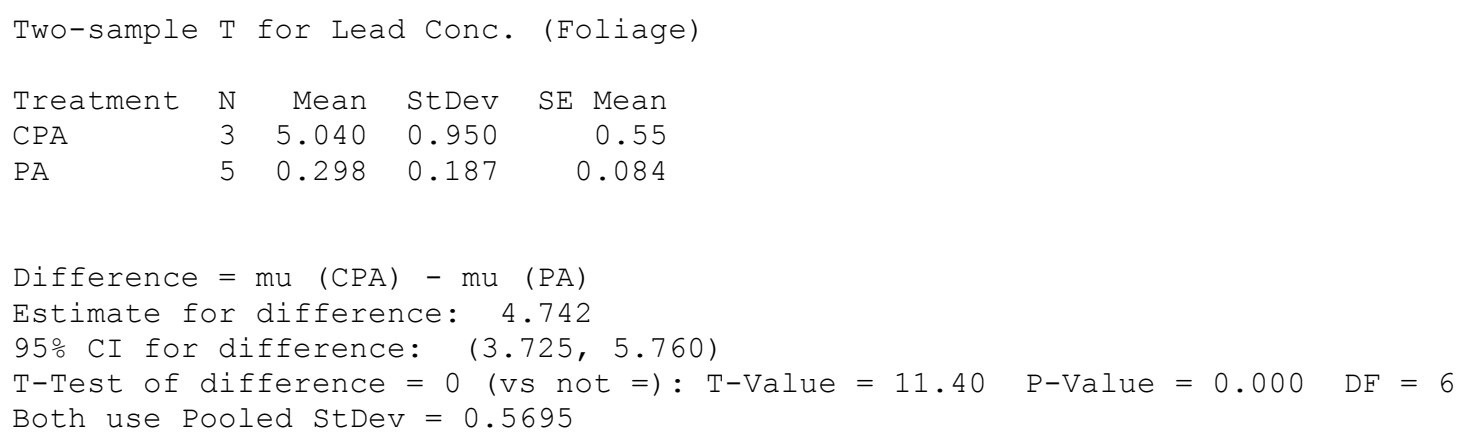

\section{ANOSIM Analysis}

PRIMER 12/19/2014

Similarity

Create triangular similarity/distance matrix

Worksheet

File: C: $\backslash$ Documents and Settingslebi|Desktop $\backslash$ santa susanalSanta Susanna 11-21-14.xls

Sample selection: $2-10$

Variable selection: All

Parameters

Analyse between: Samples

Similarity measure: Bray Curtis

Standardise: No

Transform: Square root

Outputs

Worksheet: Sheet1

\section{ANOSIM}

Analysis of Similarities

Similarity Matrix

File: Sheet1

Data type: Similarities

Sample selection: All

One-way Analysis

Factor Values

Factor: treatment

SP

$\mathrm{PC}$

$\mathrm{U}$ 
Factor Groups

Sample treatment

$\mathrm{SPc}$ SP

$\mathrm{SPb} \quad \mathrm{SP}$

$\mathrm{SPa} \quad \mathrm{SP}$

$\mathrm{PCc} \quad \mathrm{PC}$

$\mathrm{PCb} \quad \mathrm{PC}$

$\mathrm{PCa} \mathrm{PC}$

Uc U

$\mathrm{Ub} \quad \mathrm{U}$

Ua U

Global Test

Sample statistic (Global R): 0.613

Significance level of sample statistic: $1.4 \%$

Number of permutations: 280 (All possible permutations)

Number of permuted statistics greater than or equal to Global R: 4

Pairwise Tests

R Significance Possible Actual Number $>=$

Groups Statistic Level \% Permutations Permutations Observed

$\begin{array}{llllll}\text { SP, PC } & 0.889 & 10 . & 10 & 10 & 1\end{array}$

$\begin{array}{llllll}\mathrm{SP}, \mathrm{U} & 0.963 & 10 . & 10 & 10 & 1\end{array}$

$\begin{array}{llllll}\mathrm{PC}, \mathrm{U} & 0.074 & 40 . & 10 & 10 & 4\end{array}$

